НАУЧНОЕ ИЗДАНИЕ

ИЗВЕСТИЯ ПЕТЕРБУРГСКОГО УНИВЕРСИТЕТА ПУТЕЙ СООБЩЕНИЯ, ТОМ 18, ВЫПУСК 2, 2021

ISSN (Print) 1815-588X

ISSN (Online) 2658-6851

\section{Учредитель}

Федеральное государственное бюджетное образовательное учреждение высшего образования «Петербургский государственный университет путей сообщения Императора Александра |»

\section{Издатель}

Общество с ограниченной ответственностью «Издательский дом Т-ПРЕССА» по договору № ЭОА21990 от 01.03.2021 г.

\section{Адрес учредителя}

190031, СПб., Московский пр., 9, тел. (812) 314-92-32

\section{Адрес издателя}

190031, СПб., наб. реки Фонтанки, 117-А, пом. $1 \mathrm{H}$, офис 350

e-mail: izvestia@izvestiapgups.org

\section{Свидетельство о регистрации средства массовой информации}

ПИ № ФС2-7499 от 06.04.2005 г., выдано Федеральной службой по надзору за соблюдением законодательства в сфере массовых коммуникаций и охране культурного наследия, Управление по Северо-Западному федеральному округу

\section{Журнал зарегистрирован}

в Российском индексе научного цитирования (РИНЦ)

Журнал включен в перечень ведущих рецензируемых научных журналов и изданий (решение Президиума Высшей аттестационной комиссии Минобрнауки России от 29.12.2015 г., № $6 / 6$ )

Журнал публикует научные статьи в областях технические науки (05.00.00), транспорт (05.22.00)

Журнал имеет институт рецензирования

Журнал распространяется

по адресно-целевой подписке через редакцию и каталог ОАО «Роспечать» (индекс 18509)

\section{РЕДАКЦИЯ ЖУРНАЛА}

Главный редактор

А. Ю. Панычев, канд. экон. наук, доцент

Заместитель главного редактора

А. К. Канаев, д-р техн. наук, профессор

Научный редактор

А. М. Евстафьев, д-р техн. наук, профессор

Выпускающий редактор

Э. А. Горелик

Перевод на английский язык

А. Н. Крышня, У. Л. Романова

Верстка

А. А. Стуканова
МЕЖДУНАРОДНЫЙ РЕДАКЦИОННЫЙ СОВЕТ

Панычев Александр Юрьевич, канд. экон. наук, доцент, ПГУПС, Санкт-Петербург, Россия, председатель Совета

Шнайдер Экхард, профессор, Фраунгоферовский институт неразрушающего контроля, Саарбрюкен, Германия

Ситаж Марек, профессор, Силезский технический университет, Польша

Христов Христо, профессор, Технический университет, София, Болгария

\section{РЕДКОЛЛЕГИЯ}

Сапожников Валерий Владимирович, д-р техн. наук, профессор, ПГУПС, Санкт-Петербург, Россия, председатель редколлегии Бадёр Михаил Петрович, д-р техн. наук, профессор, МГУПС (МИИТ), Москва, Россия

Белаш Татьяна Александровна, д-р техн. наук, профессор, ПГУПС, Санкт-Петербург, Россия

Беленцов Юрий Алексеевич, д-р техн. наук, профессор, ПГУПС, Санкт-Петербург, Россия

Блажко Людмила Сергеевна, д-р техн. наук, профессор, ПГУПС, Санкт-Петербург, Россия

Бороненко Юрий Павлович, д-р техн. наук, профессор, ПГУПС, Санкт-Петербург, Россия

Брынь Михаил Ярославович, д-р техн. наук, профессор, ПГУПС Санкт-Петербург, Россия

Губачева Лариса Александровна, д-р техн. наук, профессор, Восточно-Украинский национальный университет им. В. Даля, Луганск, Украина

Егоров Владимир Викторович, д-р техн. наук, доцент, ПГУПС, Санкт-Петербург, Россия

Канаев Андрей Константинович, д-р техн. наук, профессор, ПГУПС, Санкт-Петербург, Россия

Ледяев Александр Петрович, д-р техн. наук, профессор, ПГУПС Санкт-Петербург, Россия

Петрова Татьяна Михайловна, д-р техн. наук, профессор, ПГУПС Санкт-Петербург, Россия

Покровская Оксана Дмитриевна, д-р техн. наук, доцент, ПГУПС, Санкт-Петербург, Россия

Смирнов Владимир Николаевич, д-р техн. наук, профессор, ПГУПС, Санкт-Петербург, Россия

Соловьева Валентина Яковлевна, д-р техн. наук, профессор,

ПГУПС, Санкт-Петербург, Россия

Талантова Клара Васильевна, д-р техн. наук, доцент, ПГУПС, Санкт-Петербург, Россия

Титова Тамила Семеновна, д-р техн. наук, профессор, ПГУПС, Санкт-Петербург, Россия

Фролов Юрий Степанович, д-р техн. наук, профессор, ПГУПС, Санкт-Петербург, Россия

Шангина Нина Николаевна, д-р техн. наук, профессор, ПГУПС Санкт-Петербург, Россия

Штыков Валерий Иванович, д-р техн. наук, профессор, ПГУПС, Санкт-Петербург, Россия

Фото на обложке из архивов библиотеки ФГБОУ ВО ПГУПС. 1910 г.

Подписано в печать с оригинал-макета 25.06.2021. Формат 60×84 1/8. Бумага офсетная. Печать МФУ Усл. печ. л. 20. Уч. изд. л. 10. Установочный тираж 300 экз.

Заказ . Цена свободная.

Отпечатано в типографии ООО «Издательство ОМ-Пресс»

190031, СПб., наб. р. Фонтанки, 117 
SCIENTIFIC PUBLICATION

PROCEEDINGS OF PETERSBURG TRANSPORT

UNIVERSITY, volume 18, issue 2, 2021

ISSN (Print) 1815-588X

ISSN (Online) 2658-6851

\section{Founder}

Federal State Budgetary Educational Institution of Higher Education "Emperor Alexander I Petersburg State Transport University"

\section{Publisher}

Limited Liability Company "T-PRESSA Publishing House", under contract N $\ni$ OA21990 dated

March 01, 2021

Founder's address

190031, St. Petersburg, Moskovskiy pr., 9, (812) 314-92-32

\section{Publisher's address}

190031, St. Petersburg, room 1H, office 350, 117-A, Fontanka River emb., e-mail: izvestia@izvestiapgups.org

\section{Mass media registration certificate number} ПИ N ФС2-7499 dd. 06.04.2005 issued by the Federal service for the monitoring of legislation compliance in the sphere of mass communications and the preservation of cultural heritage, North West Federal district division

The journal is registered in the Russian Science Citation Index (RSCI)

The journal is included in the List of leading peer-reviewed scientific journals and publications

The journal publishes scientific articles in the fields of Technics (05.00.00), Transport (05.22.00)

The journal has the Peer-review division

The journal is destributed by direct subscription via Editorial office and Rospechat catalogue (item 18509)

\section{JOURNAL STAFF}

Editor-in-chief

A. Yu. Panychev, PhD of Economics,

Associate Professor

\section{Deputy chief editor}

A. Kanayev, D. Eng. Sci., Professor

\section{Science editor}

A. Evstafev, D. Eng. Sci., Professor

\section{Executive editor}

E. Gorelik

\section{English translation}

A. Kryshnia, U. Romanova

Layout

A. Stukanova

\section{INTERNATIONAL EDITORIAL BOARD}

Aleksander Panychev, PhD in Economics, Professor, Petersburg State Transport University, St. Petersburg, Russia, Chairman of Editorial board

Ekhard Shneider, Professor, Fraunhofer Institute for Non-Destructive Testing, Saarbrucken, Germany

Marek Sitazh, Professor, Silesian University of Technology, Poland

Khristo Khristov, Professor, Technical University of Sofia, Bulgaria

\section{EDITORIAL TEAM}

Valeriy Sapozhnikov, D. Eng. Sci., Professor, Petersburg State Transport University, St. Petersburg, Russia, Chairman of Editorial team Mikhail Badyer, D. Eng. Sci., Professor, Moscow State University of Railway Engineering, Moscow, Russia

Tatiana Belash, D. Eng. Sci., Professor, Petersburg State Transport University, St. Petersburg, Russia

Yury Belentsov, D. Eng. Sci., Professor, Petersburg State Transport University, St. Petersburg, Russia Liudmila Blazhko, D. Eng. Sci., Professor, Petersburg State Transport University, St. Petersburg, Russia Yuriy Boronenko, D. Eng. Sci., Professor, Petersburg State Transport University, St. Petersburg, Russia Mikhail Bryn', D. Eng. Sci., Professor, Petersburg State Transport University, St. Petersburg, Russia

Larisa Gubachyeva, D. Eng. Sci., Professor, Volodymyr Dahl East Ukrainian National University, Luhansk, Ukraine

Vladimir Egorov, D. Eng. Sci., Associate Professor, Petersburg State Transport University, St. Petersburg, Russia

Andrey Kanayev, D. Eng. Sci., Professor, Petersburg State Transport University, St. Petersburg, Russia

Aleksander Ledyayev, D. Eng. Sci., Professor, Petersburg State Transport University, St. Petersburg, Russia

Tatiana Petrova, D. Eng. Sci., Professor, Petersburg State Transport University, St. Petersburg, Russia

Oksana Pokrovskaya, D. Eng. Sci., Associate Professor, Petersburg State Transport University, St. Petersburg, Russia

Vladimir Smirnov, D. Eng. Sci., Professor, Petersburg State Transport University, St. Petersburg, Russia

Valentina Solovyova, D. Eng. Sci., Professor, Petersburg State Transport University, St. Petersburg, Russia

Klara Talantova, D. Eng. Sci., Associate Professor, Petersburg State Transport University, St. Petersburg, Russia

Tamila Titova, D. Eng. Sci., Professor, Petersburg State Transport University, St. Petersburg, Russia

Yury Frolov, D. Eng. Sci., Professor, Petersburg State Transport University, St. Petersburg, Russia

Nina Shangina, D. Eng. Sci., Professor, Petersburg State Transport University, St. Petersburg, Russia

Valeriy Shtikov, D. Eng. Sci., Professor, Petersburg State Transport University, St. Petersburg, Russia

Published by Limited Liability Company "OM-Press Publishing House" 190031, St. Petersburg, Fontanka River emb., 117 Open price 


\section{СОДЕРЖАНИЕ}

\section{ПРОБЛЕМАТИКА ТРАНСПОРТНЫХ СИСТЕМ}

\section{В. В. Галов, В. А. Башмаков, А. В. Григорьев}

Оценка ресурса при соударении вагонов-цистерн современных конструкций

производства АО «Рузхиммаш»

\section{К. Е. Ковалев, А. В. Новичихин}

Развитие научно-технических основ повышения эффективности функционирования транспортной системы при взаимодействии интенсивных и малодеятельных линий

\section{С. В. Кротов, Д. П. Кононов, Е. В. Пакулина}

Напряженное состояние в контакте колеса и рельса при наличии скольжения и сцепления

\section{Т. М. Шманёв, В. И. Ульяницкая, М. С. Пухова}

Повышение эффективности работы в пассажирском комплексе Октябрьской железной дороги за счет использования алгоритма принятия решений с помощью аналитических инструментов качества

\section{СОВРЕМЕННЫЕ ТЕХНОЛОГИИ - ТРАНСПОРТУ}

\section{А. Г. Андриевский, Е. А. Чабан, В. В. Москвичев}

Анализ нагруженности кожуха зубчатой передачи электровоза при условии ослабления затяжки болтов его крепления к тяговому двигателю

\section{М. Я. Брынь, Д. Р. Баширова, А. Г. Багишян}

Сравнительная оценка мобильного лазерного сканирования, аэрофотосъемки с беспилотной авиационной системы и съемки с комплексной дорожной лаборатории при выполнении диагностики автомобильных дорог

\section{А. М. Костроминов, Р. О. Ложкин}

Влияние геоиндуцированных токов на дроссель-трансформаторы рельсовых цепей железнодорожной автоматики

\section{В. Л. Лукичева, А. А. Привалов, Д. Д. Титов}

Модель процесса доставки пакетов по каналу передачи данных в условиях компьютерных атак нарушителя

\section{В. Н. Смирнов, Л. К. Дьяченко}

Предложения по проектированию пролётных строений мостовых сооружений эстакадного типа с учетом резонансных явлений на высокоскоростной магистрали Москва-Петербург

\section{А. Е. Цаплин, Ж. О. Кувондиков}

Анализ надежности узлов подвижного состава на основе эксплуатационных данных 


\section{Л. С. Блажко, А. А. Киселев, И. П. Киселев, А. В. Романов}

О влиянии эквивалентной конусности колесной пары на напряженно-деформированное состояние рельса

\section{Ю. П. Бороненко, О. И. Зайнитдинов}

Выбор и анализ конструктивных решений основания съемного кузова

\section{Е. А. Буквина, Е. В. Зверева, Е. В. Фалеева, Р. А. Ешенко}

Разработка методов обеспечения информационной безопасности децентрализованных баз данных

\section{М. С. Коровина, С. К. Коровин}

Распределенная система многопараметрического ежедневного контроля технического состояния рабочего оборудования мобильных подъемников с рабочими платформами мачтового типа

\section{В. И. Штыков, А. Б. Пономарев, Ю. Г. Янко}

О расчете размывающих скоростей при проектировании фильтрующих сооружений в связных грунтах 


\section{CONTENTS}

\section{PROBLEMATIC OF TRANSPORT SYSTEM}

\section{V. Galov, V. A. Bashmakov, A. V. Grigoriev}

Resource assessment in the collision of modern designed tank cars manufactured by JSC "Ruzkhimmash"

\section{K. E. Kovalev, A. V. Novichikhin}

Evolution of scientific and technical foundations for the transport system efficiency improvement with the interaction of heavy- and low-traffic lines

\section{S. V. Krotov, D. P. Kononov, E. V. Pakulina}

Stress state in contact between wheel and rail in the presence of slip and adhesion

\section{T. M. Shmanyov, V.I. Ulyanitskaya, M. S. Pukhova}

Improving the Oktyabrskaya Railway passenger complex performance with a decision-making algorithm using analytical quality tools

\section{HIGH TECHNOLOGIES FOR TRANSPORT}

\section{A. G. Andrievsky, E. A. Chaban, V. V. Moskvichev}

Analysis of the loading of the gear casing of an electric locomotive provided

that the bolts fastening it to traction motor are loosened

\section{Ya. Bryn, D. R. Bashirova, A. G. Bagishyan}

Comparative evaluation of mobile laser scanning, aerial photography

from an unmanned aircraft system and surveying from an integrated road laboratory when performing diagnostics of highways

\section{A. M. Kostrominov, R. O. Lozhkin}

Influence of geoinduced currents on impedance bonds with secondary windings

used in railway automation circuits

\section{L. Lukicheva, A. A. Privalov, D.D. Titov}

A model of the process of package delivering over a data transmission channel

\section{N. Smirnov, L. K. D'yachenko}

Proposals for the design of overhead bridge span superstructures in view of the resonance phenomena on the Moscow - Petersburg High-Speed Railway

\section{A. E. Tsaplin, Zh. O. Kuvondikov}

Analyzing the reliability of rolling stock units based on operational data 


\section{S. Blazhko, A. A. Kiselev, I. P. Kiselev, A. V. Romanov}

Discussing the effect of the wheelset equivalent conicity on the stress-strain state

of the rails

\section{Y. P. Boronenko, O. I. Zaynitdinov}

Selection and analysis of design solutions for the base of the swap body

\section{E. A. Bukvina, E. V. Zvereva, E. V. Faleeva, R. A. Yeshenko}

Development of methods for ensuring information security of decentralized databases

\section{S. Korovina, S. K. Korovin}

The distributed system of multipoint daily monitoring of the technical condition of the working equipment of mobile lifts with mast-type work platforms

\section{I. Shtykov, A. B. Ponomarev, Yu. G. Yanko}

Discussing the calculation of erosion rates in the design of filtering structures in cohesive soils 


\section{Оценка ресурса при соударении вагонов-цистерн современных конструкций производства АО «Рузхиммаш»}

\section{В. В. Галов ${ }^{1}$, В. А. Башмаков ${ }^{2}$, А. В. Григорьев ${ }^{3}$}

${ }^{1}$ Петербургский государственный университет путей сообщения Императора Александра I, Российская Федерация, 190031, Санкт-Петербург, Московский пр., 9

${ }^{2} \mathrm{OOO}$ «Инженерный Центр подвижного состава» (ООО «ИЦПС»), Российская Федерация, 190013, Санкт-Петербург, наб. реки Фонтанки, 108

${ }^{3}$ АО «РМ Рейл Инжиниринг», Российская Федерация, 431446, Республика Мордовия, г. Саранск, ул. Лодыгина, 3

Для цитирования: Галов В.В., Башмаков В.А., Григорьев А. В. Оценка ресурса при соударении вагонов-цистерн современных конструкций производства АО «Рузхиммаш» // Известия Петербургского университета путей сообщения.- СПб.: ПГУПС, 2021.- Т. 18.- Вып. 2.- С. 159-168.

DOI: $10.20295 / 1815-588 X-2021-2-159-168$

\section{Аннотация}

Цель: Изучить характер усталостных повреждений вагонов-цистерн современных конструкций по результатам ресурсных испытаний при многократных соударениях. Показать необходимость проведения ресурсных испытаний по причине увеличения срока службы вагонов, внесением соответствующих изменений в конструкторскую документацию и повышением конкурентоспособности продукции. Подтвердить возможность большего срока службы вагонов. Определить потенциально опасные зоны в конструкциях вагонов, наиболее подверженные повреждениям в эксплуатации. Методы: Применен экспериментальный метод оценки показателей циклической долговечности элементов конструкции вагонов путем испытаний на ресурс при многократных соударениях. Использованы методы математической статистики для оценки результатов испытаний и выявленных усталостных повреждений. Результаты: Выполнен сравнительный анализ конструктивных особенностей испытуемых вагонов. Описан порядок проведения испытаний на ресурс при соударениях. Представлена статистическая оценка режимов нагружения и накопленных усталостных повреждений. Получены разрушения, препятствующие дальнейшему проведению испытаний. По результатам проведенных испытаний подтверждено увеличение срока службы вагонов до 32 лет. На основании обнаруженных разрушений статистически определены зоны конструкций вагонов, наиболее подверженные повреждениям в эксплуатации. Практическая значимость: Подтверждена необходимость в увеличении срока службы вагонов до 32 лет. Результаты проведенных испытаний позволили внести соответствующие изменения в конструкторскую документацию и повысить конкурентоспособность вагонов производства АО «Рузхиммаш» в условиях современного рынка. Накопленные экспериментальные данные могут быть использованы в дальнейшем при проектировании вагонов-цистерн с улучшенными по сравнению с существующим подвижным составом эксплуатационными характеристиками, включая узлы конструкции, подверженные усталостным повреждениям в эксплуатации.

Ключевые слова: Вагон-цистерна, ресурсные испытания, многократные соударения, увеличение срока службы, статистика повреждений. 


\section{Введение}

Компания АО «РМ Рейл Инжиниринг» (Республика Мордовия, г. Саранск) занимает лидирующие позиции в отрасли по номенклатуре разработанных и поставленных на серийное производство моделей железнодорожного подвижного состава.

Одной из преимущественных специализаций компании является разработка перспективных конструкций специализированных вагонов-цистерн для перевозки опасных химических грузов. Срок службы указанных вагонов составляет 24 года. Среди последних разработок $\mathrm{AO}$ «РМ Рейл Инжиниринг» отмечены вагоныцистерны моделей 15-1264 для метанола и 151269 для серы расплавленной, которые поставлены на производство в 2017 и 2018 гг. соответственно.

В современных рыночных условиях с целью повышения конкурентоспособности вагонов возникла необходимость подтверждения назначенного их срока службы до 32 лет. Для этого требуется проведение ресурсных испытаний на циклическую долговечность при многократных соударениях вагонов с внесением соответствующих изменений в конструкторскую документацию.

Первоначально компанией АО «РМ Рейл Инжиниринг» в 2018 г. был успешно реализован комплекс работ по увеличению срока службы до 32 лет вагона-цистерны для метанола модели 151264 (рис. 1, a). Испытания были проведены испытательным центром ООО «ИЦПС» (г. СанктПетербург) в условиях завода-изготовителя вагона АО «Рузхиммаш» [1].

В 2019 г. АО «РМРейл Инжиниринг» совместно с испытательным центром ООО «ИЦПС» выполнен аналогичный комплекс работ на образце вагона-цистерны для перевозки серы расплавленной модели 15-1269 производства АО «Рузхиммаш» с подтверждением увеличенного срока службы 32 года (рис. 1, б).

Основными задачами испытаний для реализации поставленной цели являлись оценка накопленного усталостного повреждения при действии нормативных ударных нагрузок, согласно ГОСТ 33788-2016 [2], РД 24.050.37.95 [3], подтверждение назначенного срока службы вагонов и определение потенциально опасных мест в конструкции, наиболее подверженных повреждениям.

\section{Анализ особенностей конструкции вагонов-цистерн}

На первоначальном этапе до начала испытаний был проведен анализ особенностей конструкции указанных моделей вагонов.

Вагон-цистерна для перевозки метанола модели 15-1264 имеет максимальный объем котла $87,1 \mathrm{M}^{3}$ и грузоподъемность 66,5 т, среди аналогов с осевой нагрузкой 23,5 т на ось [4-6].

Вагон-цистерна для перевозки серы расплавленной модели 15-1269 в отличие от вагона модели 15-1264 оборудован теплоизоляцией котла, позволяющей сохранять груз в жидком состоянии до 10 суток при температуре окружающего воздуха до $-40{ }^{\circ} \mathrm{C}$, системой разогрева груза в случае его остывания с помощью электрических нагревателей (ТЭНов) общей мощностью 90 кВт. На котле вагона смонтирован специальный кожух, обеспечивающий защиту теплоизоляции и электрооборудования вагона от механических воздействий, дополнительно имеется защитный воротник из нержавеющей стали (под загрузочным люком), исключающий попадание груза (серы) под кожух теплоизоляции с целью предотвращения его коррозии и улучшения пожарной безопасности. Конструкция вагона адаптирована под тележку с нагрузкой 25 т на ось и межремонтным пробегом 500 тыс. км $[4,5,7]$.

Основные технические характеристики испытуемых вагонов представлены в табл. 1 [4-7].

\section{Проведение испытаний}

Основной этап работ заключался в выполнении объема испытаний, позволяющим подтвердить назначенный срок службы вагонов 32 года. 
$a$

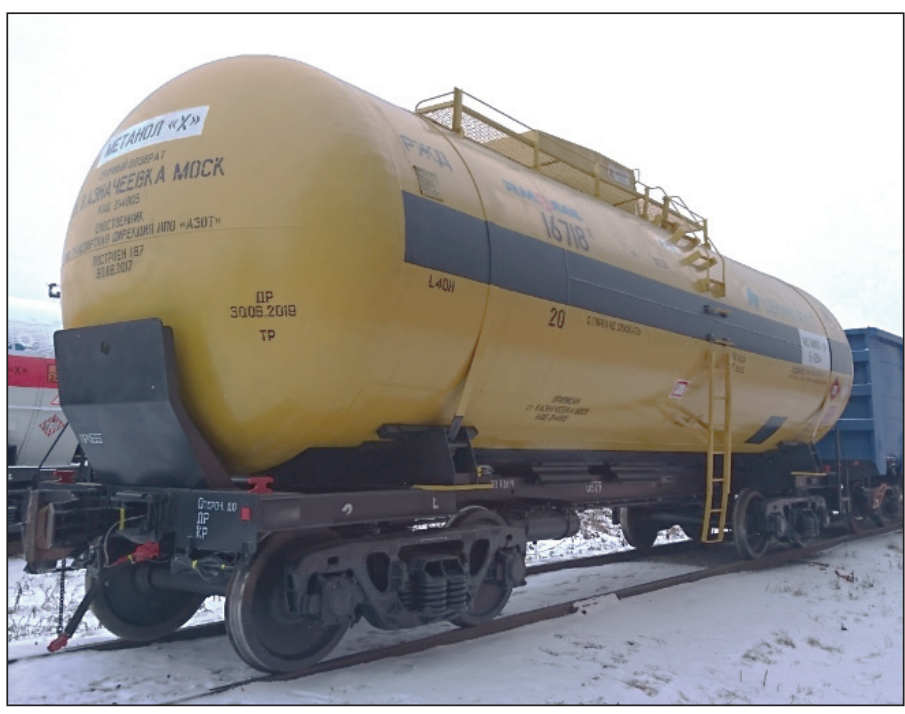

$\sigma$



Рис. 1. Испытуемые образцы вагонов-цистерн: $a$ - модель 15-1264; $\sigma$ - модель 15-1269
До начала ресурсных испытаний с целью сокращения времени их проведения поглощающие аппараты автосцепных устройств вагонов были исключены из работы путем установки жестких вставок.

Схема расположения вагонов на стенде-горке при испытаниях приведена на рис. 2.

Ресурсные испытания осуществлялись путем многократных соударений вагона-бойка в испытуемый вагон, стоящий в подпоре (рис. 2). Подпор был сформирован из вагонов различных моделей общей массой более 300 т. Образцы вагонов при испытаниях были загружены до пол- ной грузоподъемности (модель 15-1264 - водой, модель 15-1269 - водой с песком). Испытания вагонов проводили до момента, пока накопленное в процессе испытаний усталостное повреждение $D_{\text {исп }}$ не превысит расчетного значения $D_{\text {расч }}$ за установленный период эксплуатации вагонов (32 года):

$$
D_{\text {исп }} \geq D_{\text {расч}} \text {. }
$$

Далее испытания продолжались до получения повреждений вагонов, препятствующих дальнейшим испытаниям с учетом «Инструкции...» [8]. 
ТАБЛИЦА 1. Основные технические характеристики вагонов

\begin{tabular}{|c|c|c|}
\hline Наименование характеристики & $\begin{array}{l}\text { Модель } \\
15-1264\end{array}$ & $\begin{array}{l}\text { Модель } \\
15-1269\end{array}$ \\
\hline Грузоподъемность, т & 66,5 & 72,5 \\
\hline Масса тары, т & $\begin{array}{c}\text { Макс. 27,5, } \\
\text { мин. 26,5 }\end{array}$ & $\begin{array}{c}\text { Макс. 27,5, } \\
\text { мин. 27,0 }\end{array}$ \\
\hline $\begin{array}{l}\text { Максимальная расчетная статическая нагрузка от колесной пары } \\
\text { на рельсы, кН (тс) }\end{array}$ & $230,5(23,5)$ & $245,0(25,0)$ \\
\hline Габарит по ГОСТ 9238 & $1-\mathrm{T}$ & $1-\mathrm{T}$ \\
\hline Конструкционная скорость, км/ч & 120 & 120 \\
\hline $\begin{array}{l}\text { Объем котла, м³ } \\
\text { - полный } \\
\text { - полезный } \\
\end{array}$ & $\begin{array}{l}87,1 \\
82,7 \\
\end{array}$ & $\begin{array}{c}44,0 \\
40,7^{*} \\
\end{array}$ \\
\hline Диаметр котла внутренний, мм & $3200^{* * *}$ & $2400 \pm 6$ \\
\hline $\begin{array}{l}\text { Толщина стенки котла, мм } \\
\text { - верхних листов } \\
\text { - броневых листов } \\
\text { - днищ } \\
\end{array}$ & $\begin{array}{l}10 \\
12 \\
12\end{array}$ & $\begin{array}{c}8 \\
11 \\
10\end{array}$ \\
\hline Плотность (при температуре $\left.0^{\circ} \mathrm{C}\right), \mathrm{T} / \mathrm{M}^{3}$ & 0,81 & 1,78 \\
\hline Длина по осям сцепления автосцепок, мм & $12020_{-45}^{+67}$ & $12020^{+67}$ \\
\hline Длина вагона по концевым балкам рамы, мм & $11000^{+10}$ & $10800^{+11}$ \\
\hline Длина котла, мм & $11400 \pm 10$ & $10150 \pm 10$ \\
\hline Длина котла с теплоизоляцией, мм & - & $10750 \pm 20$ \\
\hline База цистерны, мм & $7800 \pm 5$ & $7800 \pm 5$ \\
\hline Ширина максимальная, мм & 3276 & 3135 \\
\hline $\begin{array}{l}\text { Высота от уровня верха головок рельсов, мм: } \\
\text { - максимальная } \\
\text { - до оси автосцепок }\end{array}$ & $\begin{array}{c}5210 \\
1060 \pm 20\end{array}$ & $\begin{array}{c}4570 \\
1060 \pm 20\end{array}$ \\
\hline
\end{tabular}

* При плотности продукта 1780 кг/м³ при температуре от 130 до $140{ }^{\circ} \mathrm{C}$.

** Диаметр котла внутренний номинальный.



Рис. 2. Схема расположения вагонов на стенде-горке при ресурсных испытаниях 


\section{Оценка результатов испытаний}

Выявленные на основании результатов ресурсных испытаний вагонов распределения сил соударений в процессе испытаний (рис. 3,4$)$ и их вероятностная оценка (табл. 2) показывают, что накопление усталостных повреждений в конструкциях вагонов за период испытаний произошло при средних значениях сил соударений в диапазоне от 3,0 до 3,5 MH (3,102 и 3,252 MH для вагонов моделей 15-1264 и 15-1269 соответственно) при нормативном значении максимальной силы соударения $3,5^{+0,35} \mathrm{MH}$.

Накопленные в испытательных процессах усталостные повреждения определялись по формуле

$$
D_{\text {исп }}=\sum F_{\text {исп } i}^{m} \text {. }
$$

В (2) $F_{\text {исп } i}$ - максимальная сила, действующая в автосцепке между вагоном-бойком и испытуемым вагоном, МH; $i$ - порядковый номер соударения; $n$ - число соударений; $m$ - показатель степени, принято $m=4$ в соответствии с п. 9.8.1 [2].

Накопленные усталостные повреждения $D_{\text {исп }}$ для испытуемых вагонов моделей 15-1264 и 151269 составили $6,76 \cdot 10^{5}$ и $6,79 \cdot 10^{5} \mathrm{MH}^{4}$ соответственно и превышают расчетное значение $D_{\text {расч }}=6,58 \cdot 10^{5} \mathrm{MH}^{4}$, определенное согласно п. 9.8.2 [2], что удовлетворяет неравенству (1). Полученные по результатам испытаний сроки службы вагонов в таком случае - 32,87 года для

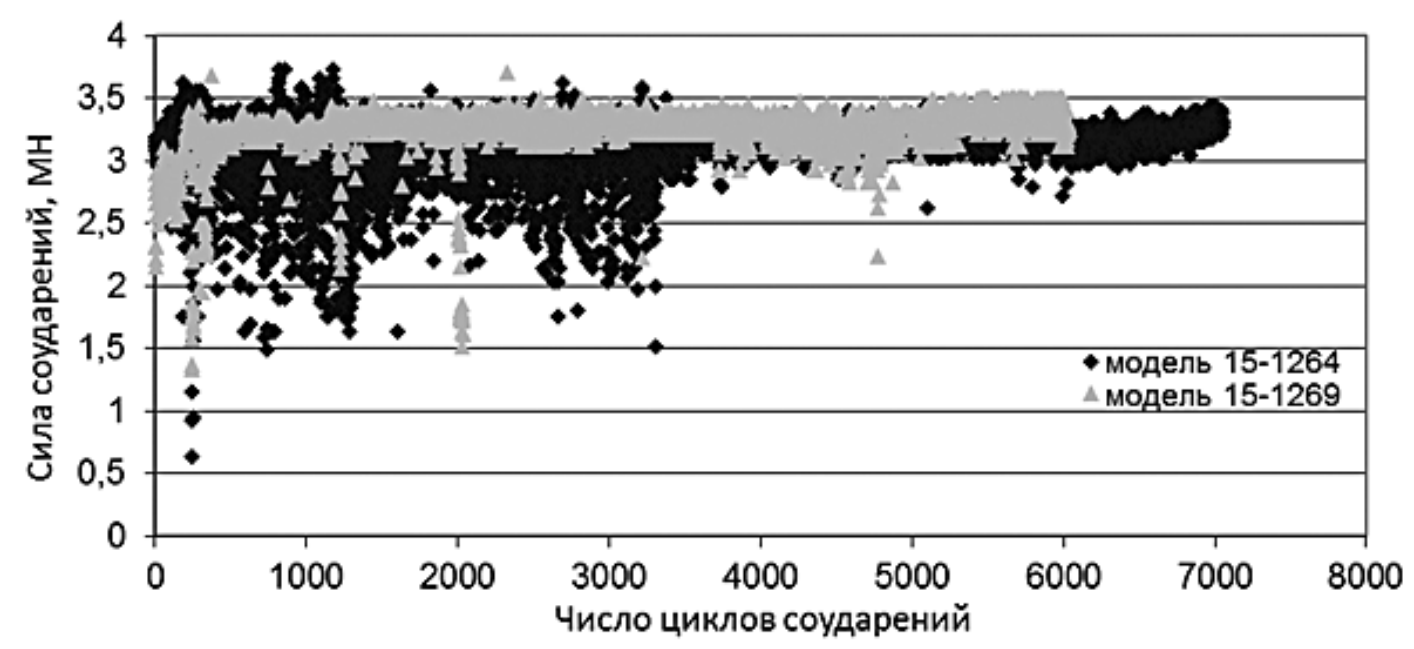

Рис. 3. Распределение сил соударений в процессе испытаний вагонов

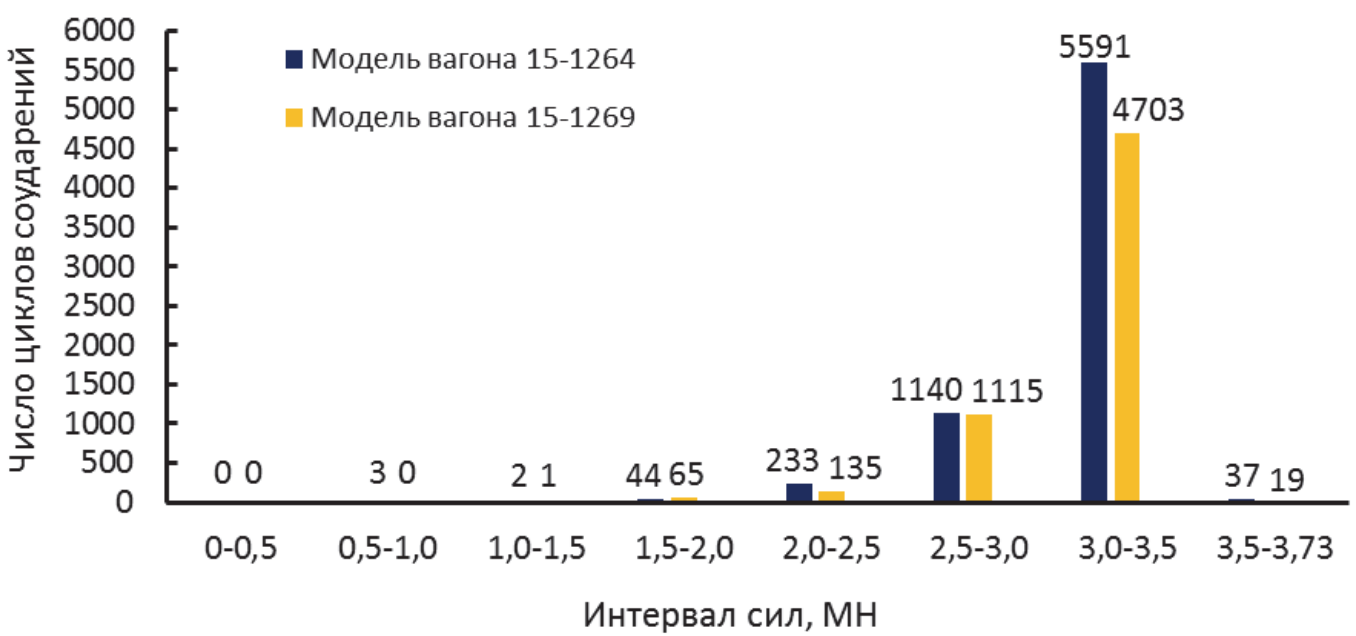

Рис. 4. Распределение числа циклов соударений по интервалам сил 
ТАБЛИЦА 2. Вероятностная оценка сил соударений $[9,10]$

\begin{tabular}{|c|c|c|c|c|c|}
\hline $\begin{array}{c}\text { Модель } \\
\text { вагытомого }\end{array}$ & $\begin{array}{c}\text { Количество } \\
\text { соударений } \\
\text { (число } \\
\text { циклов) }\end{array}$ & $\begin{array}{c}\text { Диапазон сил } \\
\text { соударений, } \\
\text { МН }\end{array}$ & $\begin{array}{c}\text { Доверитель- } \\
\text { ная вероят- } \\
\text { ность, } p\end{array}$ & $\begin{array}{c}\text { Среднее } \\
\text { значение } \\
\text { силы, МН }\end{array}$ & $\begin{array}{c}\text { Относитель- } \\
\text { ная погреш- } \\
\text { ность силы, } \\
\varepsilon, \%\end{array}$ \\
\hline $15-1264$ & 7050 & $\begin{array}{c}\text { От 0,64 } \\
\text { до 3,73 }\end{array}$ & 0,9 & $3,102 \pm 0,005$ & 0,002 \\
\hline $15-1269$ & 6038 & $\begin{array}{c}\text { От } 1,33 \\
\text { до 3,71 }\end{array}$ & 0,9 & $3,252 \pm 0,005$ & 0,002 \\
\hline
\end{tabular}

модели 15-1264 и 33,06 лет для модели 15-1269, что подтверждает назначенный срок их службы 32 года.

\section{Систематика повреждений конструкций вагонов-цистерн}

На заключительном этапе были систематизированы повреждения на вагонах, выявленные в процессе ресурсных испытаний (табл. 3). Стабильная повторяемость отмечена в элементах крепления тормозного оборудования, которые относятся к наиболее ответственным узлам конструкций вагонов.

Одним из критериев прекращения ресурсных испытаний является наличие повреждений, препятствующих дальнейшему их проведению. Ре- сурсные испытания вагонов были остановлены из-за развития трещин в кронштейнах крепления воздухораспределителей (рис. 5, 6). В связи с одинаковой конструкцией кронштейнов, применяемых на рамах вагонов, полученные повреждения по характеру мест расположения и размеров трещин идентичны, что позволило определить узлы конструкции, наиболее восприимчивые к повреждениям при многократных соударениях.

После завершения ресурсных испытаний были осуществлены тщательные осмотры испытуемых вагонов. На вагоне-цистерне для перевозки метанола модели 15-1264 в корпусе котла, элементах крепления котла к раме, в том числе опор с лежневыми брусьями, фасонных лап повреждений (изломов, трещин сварных швов) и видимых деформаций в конструкции вагона не обнаружено.

ТАБЛИЦА 3. Повреждения в конструкциях вагонов-цистерн по результатам испытаний

\begin{tabular}{|c|c|c|c|}
\hline \multirow{2}{*}{ Вид повреждений } & \multirow{2}{*}{$\begin{array}{l}\text { Количество } \\
\text { циклов } \\
\text { соударений }\end{array}$} & \multicolumn{2}{|c|}{ Модель испытуемого вагона } \\
\hline & & $15-1264$ & $15-1269$ \\
\hline Отрыв поручня составителя & После 740 & + & - \\
\hline Разрыв скобы на шкворневой балке & После 1230 & + & $\begin{array}{c}\text { Скоба } \\
\text { отсутствует }\end{array}$ \\
\hline Трещина в кронштейне воздухораспределителя & $\begin{array}{c}\text { После } \\
\text { 2500/3000 }\end{array}$ & \multicolumn{2}{|c|}{$+/+$} \\
\hline Отрыв заклепок кожуха & После 1750 & $\begin{array}{c}\text { Кожух } \\
\text { отсутствует }\end{array}$ & + \\
\hline Излом фиксатора колпака крышки люка-лаза & После 2250 & $\begin{array}{c}\text { Колпак } \\
\text { отсутствует }\end{array}$ & + \\
\hline
\end{tabular}




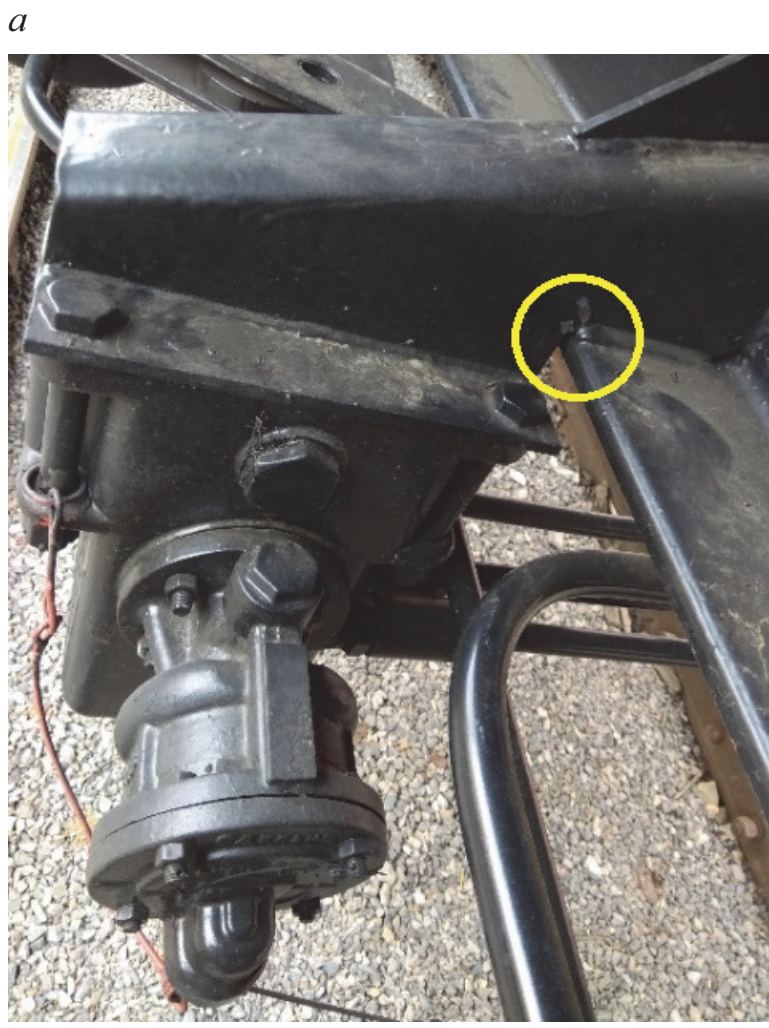

$\sigma$

Рис. 5. Повреждения конструкции кронштейна воздухораспределителя на вагоне-цистерне модели 15-1264: $a$ - общий вид; $\sigma$ - зона разрушения

$a$



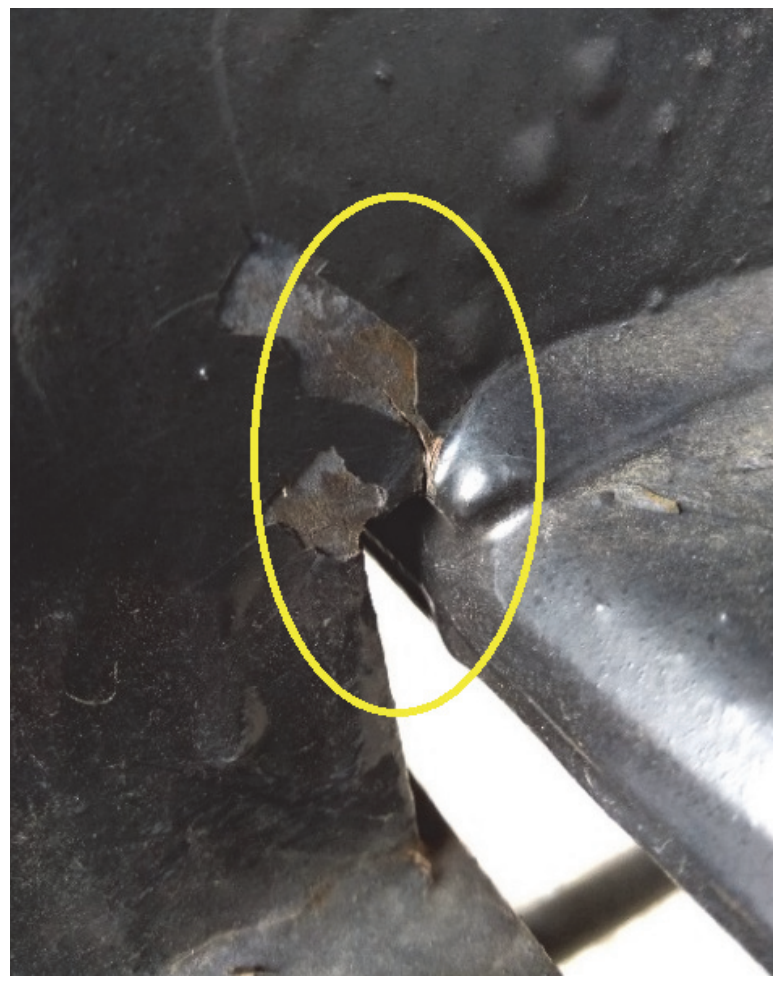

6

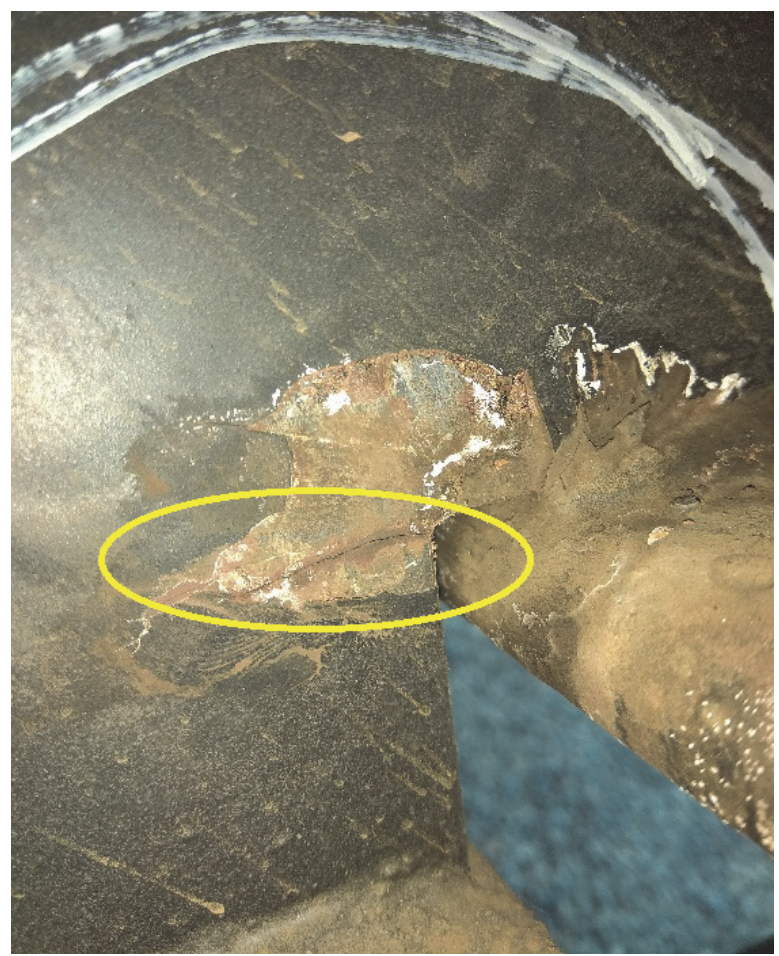

Рис. 6. Повреждения конструкции кронштейна воздухораспределителя на вагоне-цистерне модели 15-1269: $a$ - общий вид; $\sigma$ - зона разрушения 
На вагоне-цистерне для перевозки серы расплавленной модели 15-1269 для проведения осмотра был произведен демонтаж кожуха, теплоизоляции и электрооборудования котла вагона. В оболочке котла и элементах крепления котла к раме, в том числе опорах котла, в фасонных лапах, подкрепляющих элементах (кронштейны крепления кожуха теплоизоляции, электрооборудования) повреждения (изломы, трещины сварных швов) и видимые деформации отсутствовали.

\section{Заключение}

На основании анализа результатов ресурсных испытаний на циклическую долговечность при многократных соударениях вагонов-цистерн моделей 15-1264 и 15-1269 установлено, что накопленные усталостные повреждения в конструкции вагонов превышают расчетные значения за срок службы 32 года, что подтверждает возможность увеличения назначенного срока службы и целесообразность внесения соответствующих изменений в конструкторскую документацию на указанные модели вагонов.

Ресурсные испытания позволили выявить узлы конструкции, наиболее подверженные повреждениям от воздействия многократных продольных нагрузок при соударениях. По результатам полученных повреждений кронштейнов крепления тормозного оборудования следует обратить внимание на подобные узлы конструкции в процессе эксплуатации вагонов-цистерн как моделей, подвергнутых испытаниям, так и вагонов с аналогичной конструкцией.

\section{Библиографический список}

1. Клемин В. В. Испытания на ресурс при соударении вагона-цистерны для метанола модели 15-1264 / В.В. Клемин, А. В. Григорьев, В. В. Галов, В.А. Башмаков // Подвижной состав XXI века : идеи, требования, проекты : Материалы XIV Междунар. науч.-технич. конференции, 210-летию создания первого транспортного вуза России посвящается.- СПб. : ПГУПС, 2019. - C. 142-146.

2. ГОСТ 33788-2016. Вагоны грузовые и пассажирские. Методы испытаний на прочность и динамические качества. - М. : Стандартинформ, 2016.$41 \mathrm{c}$.

3. РД 24.050.37.95. Вагоны грузовые и пассажирские. Методы испытаний на прочность и ходовые качества. - М. : ГосНИИВ, 1995.- 102 с.

4. Сайт о вагонном парке и вагонном хозяйстве.Vagon.by, 2013-2019.- URL : http://vagon.by/railcars (даты обращения : 05.05.2019 г., 27.03.2020 г.).

5. Сайт изготовителя $\mathrm{AO}$ «РМ Рейл Рузхиммаш».URL: https://rmrail.ru/catalogue/gruzovye-vagony/(даты обращения : 05.05.2019 г., 27.03.2020 г.).

6. ТУ 3182-046-77518316-2017. Вагон-цистерны для перевозки метанола. Модель 15-1264. Технические условия. - Саранск : АО «РМ Рейл Инжиниринг», 2017. $-62 \mathrm{c}$.

7. ТУ 3182-048-77518316-2017. Вагон-цистерны для перевозки серы расплавленной. Модель 15-1269. Технические условия.-Саранск : АО «РМ Рейл Инжиниринг», 2018.- 63 с.

8. Инструкция по исключению из инвентаря вагонов МПС СССР.- М. : Транспорт, 1987.- 29 с.

9. Монсик В.Б. Вероятность и статистика : учеб. пособие / В. Б. Монсик, А. А. Скрынников. - М. : Бином, 2013. $-381 \mathrm{c}$.

10. Ивченко Г. И. Математическая статистика : учебник / Г.И. Ивченко, Ю.И. Медведев.- М. : Книжный дом «ЛИБРОКОМ», 2014.- 352 с.

Дата поступления: 04.04.2021

Решение о публикации: 15.04.2021

\section{Контактная информация:}

ГАЛОВ Владимир Викторович - канд. техн. наук, доц.; v_galov@hotmail.com

БАШМАКОВ Василий Андреевич - инженер; bva@engcenter.ru

ГРИГОРЬЕВ Алексей Владимирович - ведущий инженер; alexey.grigoriev@engine.rmrail.ru 


\title{
Resource assessment in the collision of modern designed tank cars manufactured by JSC "Ruzkhimmash"
}

\author{
V. V. Galov' ${ }^{1}$, V. A. Bashmakov², A. V. Grigoriev ${ }^{3}$ \\ ${ }^{1}$ Emperor Alexander I Petersburg State Transport University, 9, Moskovsky pr., Saint Petersburg, \\ 190031, Russian Federation \\ ${ }^{2}$ LLC “Engineering Center of Rolling Stock" (LLC “ITsPS”), 108, nab. Fontanka river, \\ Saint Petersburg, 190013, Russian Federation \\ 3 JSC "RM Rail Engineering”, Russian Federation, 431446, 3, ul. Lodygina, Saransk, \\ Republic of Mordovia, Russian Federation
}

For citation: Galov V.V., Bashmakov V.A., Grigoriev A. V. Assessment of the resource in the collision of tank cars of modern designs manufactured by JSC "Ruzkhimmash". Proceedings of Petersburg Transport University. Saint Petersburg, Petersburg State Transport University, 2021, vol. 18, iss. 2, pp. 159-168. (In Russian) DOI: 10.20295/1815-588X-2021-2-159-168

\section{Summary}

Objective: To study the nature of fatigue damage in modern tank cars using the results of multiple collision life tests. To show the need for life tests by making appropriate changes to design documentation and increasing the competitiveness of products due to the increase in service life. To confirm the possibility of a longer service life of the wagons. To identify potentially hazardous areas in car's structure, most susceptible to damage during operation. Methods: An experimental method was applied to assess the indicators of the cyclic durability on elements of the car's structure by testing the resource in multiple collisions. Mathematical statistics were used to assess the test results and identify fatigue damage. Results: A comparative analysis was conducted on the design features of tested cars. The procedure for testing in impacts is also described. A statistical assessment of loading modes and accumulated fatigue damage is presented. Failures were experienced that impeded further testing. The results of the tests confirmed an increase in the service life of the cars of up to 32 years. On the basis of the detected damage, the car structure zones most susceptible to damage in operation were statistically determined. Practical importance: The need to increase the service life of cars up to 32 years was confirmed. The results of the tests carried out made it possible to make appropriate changes in the design documentation and to increase the competitiveness of cars produced by JSC Ruzkhimmash in the modern market. The accumulated experimental data can be used in the future design of tank cars giving improved operational characteristics compared to the existing rolling stock, including structural units subject to fatigue damage during operation.

Keywords: Tank car, life tests, multiple collisions, increased service life, damage statistics.

\section{References}

1. Klemin V.V., Grigoriev A. V., Galov V.V. \& Bashmakov V.A. Ispytaniya na resurs pri soudarenii vagonatsisterny dlya metanola modeli 15-1264 [Tests for resource at collision of a tank car for methanol model 15 1264]. Podvizhnoy sostav XXI veka: idei, trebovaniya, proyekty. Materialy XIV Mezhdunarodnoy nauchno- tekhnicheskoy konferentsii, 210-letiyu sozdaniya pervogo transportnogo vuza Rossii posvyashchayetsya [Rolling stock of the XXI century: ideas, requirements, projects. Materials of the XIV International Scientific and Technical Conference, dedicated to the 210th anniversary of the creation of the first transport university in Russia]. Saint 
Petersburg, Petersburg State Transport University Publ., 2021, pp. 142-146. (In Russian)

2. GOST 33788-2016. Vagony gruzovyye i passazhirskiye. Metody ispytaniy na prochnost'i dinamicheskiye kachestva [GOST 33788-2016. Freight and passenger cars. Test methods for strength and dynamic properties]. Moscow, Standartinform Publ., 2016, 41 p. (In Russian)

3. RD 24.050.37.95. Vagony gruzovyye i passazhirskiye. Metody ispytaniy na prochnost' $i$ khodovyye kachestva $[R D$ 24.050.37.95. Freight and passenger cars. Test methods for strength and driving performance]. Moscow, State Research Institute of Carriage Building Publ., 1995, 102 p. (In Russian)

4. Site about the carriage park and carriage facilities. Vagon.by, 2013-2019. Available at: http://vagon.by/railcars (accessed: May 05, 2019, March 27, 2020). (In Russian)

5. Site of the manufacturer JSC "RM Rail Ruzkhimmash”. Available at: https://rmrail.ru/catalogue/gruzovye-vagony/(accessed: May 05, 2019, March 27, 2020). (In Russian)

6. TU3182-046-77518316-2017. Vagon-tsisterny dlya perevozki metanola. Model'15-1264. Tekhnicheskiye usloviya [TU 3182-046-77518316-2017. Tank car for transportation of methanol. Model 15-1264. Technical conditions]. Saransk, JSC “RM Rail Engineering” Publ., 2017, 62 p. (In Russian)
7. TU 3182-048-77518316-2017. Vagon-tsisterny dlya perevozki sery rasplavlennoy. Model'15-1269. Tekhnicheskiye usloviya [TU 3182-048-77518316-2017. Tank car for transportation of molten sulfur. Model 15-1269. Technical conditions]. Saransk, JSC "RM Rail Engineering” Publ., 2018, 63 p. (In Russian)

8. Instruktsiya po isklyucheniyu iz inventarya vagonov MPS SSSR [Instructions for the removal from inventory of railroad cars of the USSR Ministry of Railways]. Moscow, Transport Publ., 1987, 29 p. (In Russian)

9. Monsik V.B. \& Skrynnikov A.A. Veroyatnost' $i$ statistika. Uchebnoye posobiye [Probability and Statistics. A Study Guide]. Moscow, Binom Publ., 2013, 381 p.

10. Ivchenko G. I. \& Medvedev Y. I. Matematicheskaya statistika. Uchebnik [Mathematical Statistics. A Textbook]. Moscow, Book House "LIBROKOM" Publ., 2014, 352 p. (In Russian)

Received: April 04, 2021

Accepted: April 15, 2021

\section{Authors' information:}

Vladimir V. GALOV - PhD in Engineering, Associate Professor; v_galov@hotmail.com Vasily A. BASHMAKOV - Engineer; bva@engcenter.ru Alexey V. GRIGORIEV - Leading Engineer; alexey.grigoriev@engine.rmrail.ru 
УДК 656.02

\title{
Развитие научно-технических основ повышения эффективности функционирования транспортной системы при взаимодействии интенсивных и малодеятельных линий
}

\author{
К.Е. Ковалев, А. В. Новичихин
}

Петербургский государственный университет путей сообщения Императора Александра I, Российская Федерация, 190031, Санкт-Петербург, Московский пр., 9

Для цитирования: Ковалев К.. ., Новичихин А. B. Развитие научно-технических основ повышения эффективности функционирования транспортной системы при взаимодействии интенсивных и малодеятельных линий // Известия Петербургского университета путей сообщения.- СПб.: ПГУПС, 2021.- T. 18. - Вып. 2. - С. 169-176. DOI: 10.20295/1815-588X-2021-2-169-176

\begin{abstract}
Аннотация
Цель: Рассматриваются решения проблемы функционирования малодеятельных железнодорожных линий, характеристика подхода к повышению эффективности функционирования транспортной системы при взаимодействии интенсивных и малодеятельных линий. Методы: Применяются методы анализа и синтеза, теория систем, математического моделирования. Результаты: Разработаны принципы управления транспортной сетью и выполнена математическая постановка задачи повышения эффективности функционирования малодеятельных линий. Дополнена классификация существующих малодеятельных линий с целью разработки для них более точных сценариев повышения доходности и развития. Графически описана модель управления интенсивных и малодеятельных линий, управляющей системы, состоящей из структурных подразделений ОАО «РЖД» и органов региональной власти региона, с учетом внешних воздействующих факторов, потребностей населения и предприятий в перевозках и их удовлетворенность, а также технических, технологических и информационных ресурсов. Предложена концептуальная структура модели управления интенсивными и малодеятельными линиями. Практическая значимость: Представлен комплекс показателей для оценки работы малодеятельных линий, включающий количественные технические, технологические и экономические параметры, а также показатели оценки качества транспортного обслуживания. Определены этапы жизненного цикла железнодорожных линий и даны сценарии развития и эксплуатации малодеятельных линий.
\end{abstract}

Ключевые слова: Железнодорожный транспорт, подход к управлению, малодеятельные линии, интенсивные линии, управление перевозками.

\section{Введение}

В современных технико-технологических и экономических условиях на железнодорожном транспорте в Российской Федерации сложилась тенденция к разделению линий по массовости эксплуатации и приоритетному использованию интенсивных линий, которые обеспечивают дви- жение магистральных вагонопотоков и входят в международные транспортные коридоры, примыкают к портам и другим крупным передаточным транспортным узлам. В настоящее время большинство актуальных научных исследований направлено на повышение пропускной способности инфраструктуры железнодорожного транспорта именно на интенсивных линиях, что, 
в свою очередь, негативно отражается на развитии подходов к управлению перевозками на малодеятельных линиях [1-3].

Современные тенденции развития малодеятельных линий (например, $[4,5])$ направлены на: 1) повышение эффективности использования подвижного состава за счет рельсовых автобусов и частичного применения локомотивов малой мощности; 2) совершенствование организации движения посредством внедрения современных цифровых сервисов автоматизированных систем управления и выполнения обеспечивающих перевозочный процесс операций; 3) снижение затрат на использование инфраструктуры за счет совмещения профессий и должностей оперативного персонала участков, сокращение видов и периодичности осмотров состояния технических устройств.

Существующие нерентабельные малодеятельные железнодорожные линии, размеры движения на которых низкие, с экономической точки зрения целесообразно консервировать или полностью демонтировать. Но такие линии выполняют важную социальную роль - создание резерва пропускной и провозной способностей линий на перспективных территориях при миграции полюсов роста экономики нашей страны.

Одними из наиболее значимых исходных данных для проектирования железнодорожных линий являются прогнозируемые размеры грузопотоков и пассажиропотоков на линии на определенном перспективном периоде. Но в процессе эксплуатации железнодорожной линии грузопотоки могут существенно меняться, что связано с миграцией населения, ростом или спадом производства, различными политическими и социальными изменениями и обстоятельствами, которые невозможно учесть при проектировании и строительстве железнодорожных линий. Следует отметить, что большинство мероприятий по реконструкции и ремонту железнодорожных линий разрабатывается и применяется на интенсивных линиях.

К настоящему времени нет инструментария планирования структурных изменений условий эксплуатации железных дорог, учитывающего условия снижения размеров движения на малодеятельных линиях [6-8]. При размерах движения ниже шести пар поездов в сутки переводит железнодорожную линию в разряд малодеятельных и нерентабельных. Отсутствует методологический подход по выходу из убыточного положения малодеятельных линий, стимулирования новых или перераспределения действующих перевозок. Перманентные изменения внешних условий функционирования предъявляют новые требования к разработке, адаптивности и конкретизации в практических условиях эффективных методов и соответствующего инструментария повышения доходности линий, связанных с привлечением грузопотоков и пассажиропотоков на малодеятельные участки. Закрытие малодеятельных линий является малопривлекательным сценарием для государства и участников перевозочного процесса ввиду их важного социально-экономического значения [9].

Таким образом, развитие научно-технических основ повышения эффективности транспортной системы при взаимодействии интенсивных и малодеятельных линий, в том числе подхода и соответствующего инструментария для управления перевозками, актуально в теоретическом и практическом аспектах.

\section{Подход к управлению взаимодействием интенсивных и малодеятельных линий}

Для увеличения эффективности функционирования транспортной системы при взаимодействии интенсивных и малодеятельных линий предлагается подход, направленный на устранение неопределенностей и изменение структуры транспортных потоков. Он основывается на следующих принципах:

принцип 1 - согласованное индикаторное управление при взаимодействии интенсивных и малодеятельных линий;

принцип 2 - мониторинг функционирования и перехода в другую категорию интенсивных и малодеятельных направлений; 
принцип 3 - декомпозиция и комплексирование элементов системы управления и транспортной инфраструктуры для обеспечения синергетического эффекта развития;

принцип 4 - использование динамического скользящего горизонта при планировании процессов взаимодействия интенсивных и малодеятельных линий;

принцип 5 - обеспечение нормативного баланса провозной и пропускной способностей транспортной сети без существенного увеличения ее протяженности;

принцип 6 - устойчивость функционирования малодеятельных железнодорожных линий к внешним негативным воздействиям;

принцип 7 - привлечение государственных субсидий и инвестиций на развитие инфраструктуры и стимулирование клиентов к перевозкам по малодеятельным линиям.

Интенсивные направления часто испытывают затруднения в продвижении транспортных потоков, связанных с неравномерностью движения и техническими неисправностями. Частично снизить неравномерность движения можно за счет резервов пропускной способности малодеятельных линий.

Для эффективного использования малодеятельных линий необходима их четкая классификация. Существующие классификации выделяют транзитные, тупиковые и примыкающие к границе участков малодеятельные линии [10].

В настоящей работе будет дополнена существующая классификация другими видами малодеятельных линий, в частности перспективными и стагнирующими. Это обеспечит разработку сценариев развития и эксплуатации малодеятельных линий при различных проблемных ситуациях и скользящего горизонта планирования.

\section{Система управления взаимодействием малодеятельных и интенсивных железнодорожных линий}

При разработке структуры системы управления вычленены процессы взаимодействия объекта управления, состоящего из интенсивных, малодеятельных и проектируемых линий, и управляющей системы, включающей подразделения ОАО «РЖД» и органы исполнительной власти.

На входе концептуальной структуры системы управления интенсивными, малодеятельными и проектируемыми железнодорожными линиями учитывает потребности населения и предприятий в перевозках вектор $V(t)$ (рисунок). Под воздействиями внешней среды понимаются изменения спроса и предложения на перевозки, размеров погрузки и выгрузки, сезонность перевозок и политические решения в сфере транспорта.

Объект управления состоит из интенсивных, проектируемых, малодеятельных линий и взаимосвязей между ними. Характеристиками объекта управления являются вектора входных $W(t)$ и выходных величин $Y(t)$, а также состояния $S(t)$.

Управляющая система включает подразделения ОАО «РЖД» по планированию перевозок, структурных подразделений, осуществляющих перевозки, и подразделений по учету малодеятельных линий, а также органов местной исполнительной власти по планированию перевозок и компенсированию убытков за пассажирские железнодорожные перевозки.

Управляющие воздействия $U(t)$ в соответствии с целью управления $X(t)$ направлены на объект с учетом оценок векторов контролируемых внешних воздействий $W_{k}(t)$ и контролируемых переменных состояний $Y_{k}(t)$. На выходе $V_{i}(t)$ определяется удовлетворенность населения и предприятий в перевозках.

\section{Комплекс показателей взаимодействия интенсивных, малодеятельных и проектируемых железнодорожных линий}

В качестве характеристик взаимодействия интенсивных, проектируемых и малодеятельных линий определяются количественные и ка- 




Концептуальная структура системы управления интенсивными, малодеятельными и проектируемыми железнодорожными линиями

чественные показатели работы транспортной системы. Для комплексной оценки количественные показатели выделены в качестве технических, технологических и экономических:

1. Грузонапряженность на участке, млн т-км брутто/км в год:

$$
\Gamma(t)=365\left(Q_{\text {гр }} \cdot n_{\text {гр }}+Q_{\Pi} \cdot n_{\text {п }}\right) \cdot a,
$$

где $Q_{\text {гр }}, Q_{\text {п }}$ - масса соответственно грузовых и пассажирских поездов, т; $n_{\text {гр }}, n_{\text {п }}-$ количество грузовых и пассажирских поездов, шт.; $\alpha$ - коэффициент неравномерности движения.

2. Количество вагонов с местными операциями на рассматриваемом полигоне взаимодействия интенсивных и малодеятельных линий:

$$
\mathrm{n}(t)_{\mathrm{M}}=n_{\mathrm{u}}^{\Pi}+n_{\mathrm{u}}^{\mathrm{B}}+n_{\mathrm{M}}^{\Pi}+n_{\mathrm{M}}^{\mathrm{B}},
$$

здесь, $n_{\text {и }}^{\Pi}, n_{\text {и }}^{\text {в }}$ - количество погруженных и выгруженных вагонов на прилагаемой к малодеятельной интенсивной линии; $n_{\mathrm{M}}^{\text {П }}, n_{\mathrm{M}}^{\mathrm{B}}-$ количество погруженных и выгруженных вагонов на малодеятельной линии.

Выполнение плана по работе с местными вагонами является основным источником дохода для малодеятельных линий. За счет этой категории вагонов, осуществления подач и уборок вагонов, обслуживания путей необщего пользования получается доход от эксплуатации малодеятельной линии.

3. Резерв пропускной способности малодеятельных линий $N_{p}^{t}$ в парах поездов за сутки:

$$
N_{p}^{t}=\frac{N_{\text {реализ }}}{\frac{\left(1440-t_{\text {тех }}\right) \alpha_{\mathrm{H}}}{T_{\text {пер }}}},
$$


где $N_{\text {реализ }}-$ реализованная пропускная способность; $t_{\text {тех }}$ - продолжительность технологического окна; $\alpha_{\text {н }}-$ коэффициент надежности работы технических устройств; $T_{\text {пер}}-$ период графика на ограничивающем перегоне.

4. Ресурсоемкость малодеятельных линий:

$$
P_{\text {мдл }}(t)=\frac{3_{\text {млд }}}{m_{\text {млд }}},
$$

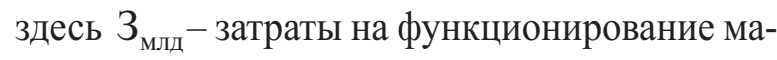
лодеятельных линий; $m_{\text {млд }}$ - масса перевозимых грузов на малодеятельных линиях.

Устойчивость транспортной системы $M F(x)$ к изменениям транспортных потоков предлагается установить с помощью нечетких множеств и записи треугольной формы задания функции принадлежности. При рассмотрении модели управления транспортная система является статичной, а входной и выходной поток динамичные.

Таким образом, функция принадлежности $M$ определяется численными значениями ранее рассчитанных показателей по формуле

$$
M F(x)=\left\{\begin{array}{l}
1-\frac{P_{\text {мдл }}(t)-x}{P_{\text {мдл }}(t)-\Gamma(t)}, \quad \Gamma(t) \leq x \leq P_{\text {мдл }}(t), \\
1-\frac{x-P_{\text {мдл }}(t)}{N_{p}^{t}-P_{\text {мдл }}(t)}, \quad P_{\text {мдл }}(t) \leq x \leq N_{p}^{t}, \\
0, \text { в остальных случаях } x,
\end{array}\right.
$$

в которой $\Gamma(t)$ - грузонапряженность на участке, $P_{\text {мдл }}(t)$ - ресурсоемкость малодеятельных линий, $N_{p}^{t}$ - резерв пропускной способности малодеятельных линий, $x$ - значение функции $M F(x)$ в точке.

Состояние системы $Z(t)$ есть функция $F c$ совокупности свойств ее элементов, которое можно представить выражением

$$
Z(t)=F c\left(\left(\Gamma(t), n(t)_{\mathrm{M}}, N_{p}^{t}, P_{\text {мдл }}(t), M F(x)\right) .\right.
$$

Интенсивные линии в качестве свойств элемента имеют приведенную грузонапряженность и техническую скорость, малодеятельные ли- нии - размеры движения и тонно-километры работы, новые линии - приведенную грузонапряженность, чистый дисконтированный доход и эксплуатационные расходы на обслуживание линии.

\section{Сценарии функционирования малодеятельных линий}

Содержание и диапазоны целевых значений количественных и качественных показателей для малодеятельных, интенсивных и проектируемых линий, определяемые на основе модели управления, в зависимости от этапа «жизненного цикла железнодорожной линии» различаются.

Под «жизненным циклом линии» понимается определение состояния железнодорожной линии по набору индикаторов для разработки сценариев ее развития, направленных на повышение доходности за счет использования существующей инфраструктуры.

Жизненный цикл железнодорожной линии можно разделить на следующие этапы:

1) оценка потребности в перевозках на данном направлении;

2) разработка и проектирование;

3) строительство;

4) выход на проектную мощность;

5) активная эксплуатация железнодорожной линии;

6) спад производительности, определение линии к категории малодеятельных (убыточность линии).

После отнесения линии к категории малодеятельных существуют несколько устоявшихся сценариев функционирования среди них:

1) повышение интенсивности движения на малодеятельных линиях;

2) консервирование линии;

3) передача линии сторонним организациям в пользование;

4) полный демонтаж линии.

Каждый из сценариев может быть реализован на малодеятельных линиях. Но необходим на- 
учно обоснованный подход, позволяющий дать количественную и качественную оценки того или иного сценария функционирования с учетом промышленной и экономической обстановок.

Помимо традиционных возможны также альтернативные сценарии функционирования малодеятельных линий, например:

1) туристический маршрут линии. Возможна организация круглогодичных туристических поездок по достопримечательностям, расположенным рядом с малодеятельной железнодорожной линией;

2) переход от железнодорожной линии к автомобильной. В таких случаях технологически возможна переквалификация железной дороги в автомобильную. Технологически это не требует больших затрат на земляные работы, так как линия с подходящими уклонами уже имеется. На автомобильном транспорте допускаются более крутые значения вертикальных и горизонтальных углов поворота трассы. Для этого необходимы снятие части верхнего строения пути, досыпка балластной призмы до необходимого количества полос автомобильного движения и обочины и асфальто-укладочные работы;

3) продление тупиковой железнодорожной линии до близлежащих узловых станций и переход из тупиковой в транзитную, что позволит перераспределить избыточный вагонопоток на интенсивных направлениях;

4) использование инфраструктуры малодеятельных линий для отстоя избыточного вагонного парка.

\section{Заключение}

Повышение эффективности эксплуатации малодеятельных линий в современных условиях является важной социально-экономической проблемой для нашей страны. В статье представлено решение проблемы эффективного функционирования и развития методологии управления перевозками на малодеятельных же- лезнодорожных линиях. Разработаны принципы и теоретические положения решения задач функционирования малодеятельных железнодорожных линий и их взаимодействия с интенсивными.

Предложены сценарии функционирования малодеятельных линий. Реализация одного из них не исключает перехода между другими вариантами в зависимости от жизненного цикла малодеятельной линии. Современные экономические условия определяют постоянные колебания спроса на перевозки железнодорожным транспортом, в этой связи необходимо иметь эффективные решения для гибкого использования существующей инфраструктуры.

\section{Библиографический список}

1. Юшков М. Е. Организация использования инфраструктуры малодеятельных железнодорожных линий на основе интегральной оценки их деятельности : автореф. дис. ... канд. техн. наук / М. Е. Юшков.- Екатеринбург : Урал. гос. ун-т путей сообщения, 2015. $-22 \mathrm{c}$.

2. Кириленко О.Н. Экономическая эффективность методов эксплуатации малодеятельных линий / О.Н. Кириленко // Экономика железных дорог.2014. - № 8. - С. 79-85.

3. Вакуленко С. П. Малодеятельные линии: состояние и варианты оптимизации / С. П. Вакуленко, А. В. Колин, Н. Ю. Евреенова // Мир транспорта.2017. - T. 15. - № 3 (70). - С. 174-180.

4. Никитин А.Б. Возможность внедрения цифровой радиосвязи и организации передачи данных между станциями на малодеятельных линиях / А.Б. Никитин, И. В. Кушпиль // Автоматика на транспорте.2019. - Т. 5. - № 1. - С. 45-61.

5. Никитин А. Б. Новый подход к организации движения поездов на малодеятельных линиях ОАО «РЖД» / А. Б. Никитин, И. В. Кушпиль, И.М. Кокурин, В. А. Шаров // Автоматика на транспорте. - 2018.T. 4. - № 4. - C. 561-579.

6. Ковалев К. Е. Модель загруженности оперативно-диспетчерского персонала на малодеятельных ли- 
ниях / К. Е. Ковалев, В. Л. Белозеров, В. А. Шаров // Автоматика на транспорте. - 2020. - Т. 6. - № 3. C. 294-308.

7. Смирнов Н.В. Проблемы организации внешних железнодорожных перевозок / Н. В. Смирнов, А. В. Новичихин, В. А. Буйвис // Вестн. Сиб. индустриал. ун-та. - 2018. - № 2 (24). - С. 54-57.

8. Балаганская А. С. Организация работы железнодорожных участков малодеятельных линий // Научные труды SWorld. - 2016.- T. 1. - № 2 (43).- C. 23 28.

9. Епишкин И. А. Причины появления малодеятельных линий в РФ / И.А. Епишкин, К. В. Фио- нова // Транспортное дело России. - 2018. - № 6.C. 262-264.

10. Саати Т. Принятие решений. Метод анализа иерархий / Т. Саати.- М. : Радио и связь, 1993.$278 \mathrm{c}$.

Дата поступления: 19.04.2021

Решение о публикации: 12.05.2021

Контактная информация:

КОВАЛЕВ Константин Евгеньевич - канд. техн. наук; kovalev@pgups.ru

НОВИЧИХИН Алексей Викторович - д-р техн. наук, доц.; novitchihin@bk.ru

\section{Evolution of scientific and technical foundations for the transport system efficiency improvement with the interaction of heavy- and low-traffic lines}

\section{K. E. Kovalev, A. V. Novichikhin}

Emperor Alexander I Petersburg State Transport University, 9, Moskovsky pr., Saint Petersburg, 190031, Russian Federation

For citation: Kovalev K.E., Novichikhin A.V. Evolution of scientific and technical foundations for the transport system efficiency improvement with the interaction of heavy- and low-traffic lines. Proceedings of Petersburg Transport University]. Saint Petersburg, Petersburg State Transport University, 2021, vol. 18, iss. 2, pp. 169-176. (In Russian) DOI: 10.20295/1815-588X-2021-2-169-176

\section{Summary}

Objective: The solutions to the problem of low-traffic railway lines functioning has been considered, and the approach to improving the efficiency of the transport system with the interaction of heavyand low-traffic lines has been characterized. The transport network management principles have been developed and the mathematical formulation of the problem of increasing the low-traffic lines efficiency has been carried out. The authors have supplemented the classification of existing low-traffic lines in order to develop more accurate scenarios for increasing profitability and promoting development of low-traffic lines. The article provides a graphic model of heavy- and low-traffic lines management, a control system comprising structural divisions of JSC Russian Railways and regional authorities, taking into account external factors, the demands of the population and enterprises in transportation and their satisfaction, and technical, technological and information resources. Methods: Methods of analysis and synthesis, systems theory, and mathematical modeling have been used. Results: The conceptual structure of the management model for heavy- and low-traffic lines is proposed. Practical importance: A set of indicators for assessing the low-traffic lines performance characteristics is provided, including quantitative technical, technological and economic parameters, as well as indicators for assessing the quality of transport services. The railway line life cycle stages have been determined and the development and operation scenarios for the low-traffic lines have been given.

Keywords: Railway transport, management approach, low-traffic lines, heavy-traffic lines, traffic management. 


\section{References}

1. Yushkov M.E. Organizatsiya ispol'zovaniya infrastruktury malodeyatel'nykhzheleznodorozhnykh liniy na osnove integral'noy otsenki ikh deyatel'nosti. Avtoreferat dis.... kandidata tekhnicheskikh nauk [Organization of the low-traffic railway lines infrastructure operation based on an integral assessment of their activities. Abstract of thesis $\mathrm{PhD}$ in Engineering]. Yekaterinburg, Ural State Transport University Publ., 2015, 22 p. (In Russian)

2. Kirilenko O. N. Ekonomicheskaya effektivnost' metodov ekspluatatsii malodeyatel'nykh liniy [Economic efficiency of methods of operation of low-traffic lines]. Ekonomika zheleznykh dorog [Railway Economy], 2014, no. 8, pp. 79-85. (In Russian)

3. Vakulenko S. P., Kolin A. V. \& Evreenova N.Yu. Malodeyatel'nyye linii: sostoyaniye i varianty optimizatsii [Low-traffic lines: condition and optimization options]. Mir transporta [World of transport], 2017, vol. 15, no. 3 (70), pp. 174-180. (In Russian)

4. Nikitin A. B. \& Kushpil' I. V. Vozmozhnost' vnedreniya tsifrovoy radiosvyazi i organizatsii peredachi dannykh mezhdu stantsiyami na malodeyatel'nykh liniyakh [Possibility of introducing digital radio communication and organizing data exchange between stations on lowtraffic lines]. Avtomatika na transporte [Automatic Equipment in Transport], 2019, vol. 5, no. 1, pp. 45-61. (In Russian)

5. Nikitin A. B., Kushpil' I. V., Kokurin I. M. \& Sharov V.A. Novyy podkhod k organizatsii dvizheniya poyezdov na malodeyatel'nykh liniyakh OAO "RZhD" [A new approach to organizing the movement of trains on lowtraffic lines of JSC Russian Railways]. Avtomatika na transporte [Automatic Equipment in Transport], 2018, vol. 4, no. 4, pp. 561-579. (In Russian)
6. Kovalev K.E., Belozerov V.L. \& Sharov V.A. Model' zagruzhennosti operativno-dispetcherskogo personala na malodeyatel'nykh liniyakh [Workload model of the operational dispatching personnel on low-traffic lines]. Avtomatika na transporte [Automatic Equipment in Transport], 2020, vol. 6, no. 3, pp. 294-308. (In Russian)

7. Smirnov N. V., Novichikhin A. V. \& Buyvis V.A. Problemy organizatsii vneshnikh zheleznodorozhnykh perevozok [Problems of the organization of foreign railway transportation]. Bulletin of the Siberian State Industrial University, 2018, no. 2 (24), pp. 54-57. (In Russian)

8. Balaganskaya A. S. Organizatsiya raboty zheleznodorozhnykh uchastkov malodeyatel'nykh liniy [The organization of work of railway sections of low-active lines]. Research papers of SWorld, 2016, vol. 1, no. 2 (43), pp. 23-28. (In Russian)

9. Epishkin I.A. \& Fionova K. V. Prichiny poyavleniya malodeyatel'nykh liniy v RF [Causes of lowdensity lines in the Russian Federation]. Transportnoye delo Rossii [Transport business in Russia], 2018, no. 6, pp. 262-264. (In Russian)

10. Saaty T. Prinyatiye resheniy. Metod analiza iyerarkhiy [Decision making. The analytic hierarchy process]. Moscow, Radio i svyaz' Publ., 1993, 278 p. (In Russian)

Received: April 19, 2021

Accepted: May 12, 2021

\section{Author's information:}

Konstantin E. KOVALEV - PhD in Engineering; kovalev@pgups.ru

Aleksey V. NOVICHIKHIN - Dr. Sci. in Engineering, Associate Professor; novitchihin@bk.ru 
УДК 629.4.015:625.1.03

\title{
Напряженное состояние в контакте колеса и рельса при наличии скольжения и сцепления
}

\section{С. В. Кротов ${ }^{1}$, Д. П. Кононов ${ }^{2}$, Е. В. Пакулина ${ }^{2}$}

${ }^{1}$ Ростовский государственный университет путей сообщения, Российская Федерация, 344038, Ростов-на-Дону, пл. Ростовского Стрелкового Полка Народного Ополчения, 2

2 Петербургский государственный университет путей сообщения Императора Александра I, Российская Федерация, 190031, Санкт-Петербург, Московский пр., 9

Для цитирования: Кротов С. В., Кононов Д. П., Пакулина Е. В. Напряженное состояние в контакте колеса и рельса при наличии скольжения и сцепления // Известия Петербургского университета путей сообщения.- СПб.: ПГУПС, 2021. - Т. 18.- Вып. 2.- С. 177-187.

DOI: $10.20295 / 1815-588 X-2021-2-177-187$

\begin{abstract}
Аннотация
Цель: Прогнозирование напряженно-деформированного состояния колеса или рельса при их взаимодействии в зависимости от нормального давления. Методы: Проведено исследование напряженно-деформированного состояния в колесе вагона и в контакте его с рельсом с помощью метода конечных элементов при всевозможных сочетаниях нагружающих факторов, учете влияния температуры, динамических воздействий, параметров контакта, явлений усталости; рассчитаны силы взаимодействия колеса и рельса, обусловливающие напряженное состояние колеса, износ и разрушение контактирующих поверхностей, и как следствие надежность вагона и безопасность движения. Результаты: Оценено влияние касательных нагрузок на напряженно-деформированное состояние при наличии скольжения в зоне контакта колеса с рельсом. Приведены параметры опасных напряжений в зависимости от осевой нагрузки. Показаны экспериментальные и теоретические подходы к определению напряженно-деформированного состояния контактирующих тел при наличии как скольжения, так и сцепления в контакте колеса и рельса. Получены составляющие тензора напряжений в зависимости от контактного давления по расчетным формулам. Построены эпюры распределения касательных напряжений в контакте колеса с рельсом при наличии зон сцепления и скольжения. Рассчитана интенсивность изменения напряженного состояния в контакте колеса с рельсом. Практическая значимость: Полученные результаты показывают, как влияют зоны скольжения и сцепления на напряженное состояние в зоне контакта в сравнении с полным скольжением. Они полезны с точки зрения прогнозирования напряженно-деформированного состояния колеса или рельса при их взаимодействии в зависимости от нормального давления.
\end{abstract}

Ключевые слова: Касательная нагрузка, нормальное давление, скольжение, сцепление, напряженное состояние, контакт.

\section{Введение}

Известно, что микротрещины усталости зарождаются у самой поверхности контактирующих тел ввиду специфических условий напряженного состояния поверхности тела. Для оценки опасности напряженного состояния на поверхности контакта колеса с рельсом и оценки возможного появления микротрещин контактной усталости весьма полезно знание всех составляющих напряжений. Немаловажную роль здесь играют эксперименты при взаимодействии образцов, выполненных из рельсовой и колесной сталей, которое осуществляется при всевозможных сочетаниях нагрузок, скорости вращения, наличия или отсутствия смазки, проскальзыва- 
ния и т. П. Эти исследования с достаточной степенью точности воссоздают натурные условия взаимодействия колеса и рельса, и их результаты имеют значительную ценность в обеспечении безопасности движения железнодорожного транспорта.

\section{Учет влияния касательной нагрузки при наличии в контакте одной зоны скольжения}

При торможении на поверхности колеса и рельса возникают касательные усилия. Даже при перекатывании колесной пары происходит упругое скольжение колес, сопровождающееся возникновением касательных усилий в контакте. Задача установления зависимости касательных усилий в контакте от упругих скольжений очень сложна и до настоящего времени не имеет полного решения. При наличии видимого относительного скольжения принимается пропорциональная зависимость между касательными и нормальными усилиями, полагая для последних сохранение эллипсоидального закона и справедливости формул [1].

В таком случае

$$
\frac{q}{p}=\frac{q_{0}}{p_{0}}=\frac{Q}{P}=f=\text { const },
$$

где $q$ - интенсивность касательных усилий в произвольной точке площадки контакта; $q_{0}-$ их наибольшая интенсивность; $P$ - вертикальная составляющая нагрузки на колесо; $p_{0}-$ удельное давление в пятне контакта колеса с рельсом; $Q$ - горизонтальная составляющая нагрузки на колесо; $f$ - коэффициент трения качения. Так, в средних условиях эксплуатации сцепных колес локомотивов можно считать $f=0,15-0,20$. При более тяжелых условиях и на пределе (буксование) коэффициент трения достигает величины $f=0,30-0,33$ и может быть выше.

Практическое значение проблемы влияния на износ и прочность касательных нагрузок является очевидным и вполне оправдывает по- пытки решения этого вопроса, предпринятые рядом исследователей [2-4]. Касательные силы оказывают значительное влияние на напряженное состояние в непосредственной близости к контакту, особенно для точек самой поверхности.

Принимая, что соотношения (1) справедливы на всей площадке контакта, Б. С. Ковальский [5] ввел формулы для напряжений от касательных усилий. В случае эллиптической площадки контакта и направления касательных усилий в сторону отрицательной оси эти формулы имеют вид (для самой поверхности контакта)

$$
\left.\begin{array}{c}
\sigma_{x}^{q}=2 q_{0} \beta\left(D+\mu \frac{2 D-K}{l^{2}}\right) \cdot \frac{x}{a}=f p_{0} A_{1} \frac{x}{a} \\
\sigma_{y}^{q}=2 q_{0} \beta\left(\mu D-\mu \frac{2 D-K}{l^{2}}\right) \cdot \frac{x}{a}=f p_{0} B_{1} \frac{x}{a} \\
\tau_{y}^{q}=q_{0}\left(K-D-2 \mu\left(\frac{\beta}{l}\right)^{2} \cdot(2 D-K)\right) \times \\
\times \frac{y}{b}=f p_{0} C_{1} \frac{y}{b} \\
\tau_{x z}^{q}=f P_{0} \sqrt{1-\left(\frac{x}{a}\right)^{2}-\left(\frac{y}{b}\right)^{2}}=f p_{0} \gamma .
\end{array}\right\}
$$

Здесь $K$ - полный эллиптический интеграл первого рода по модулю $l, E$ - то же второго рода,

$$
D=\frac{K-E}{l^{2}} .
$$

Вычислим величины полуосей $a, b$, удельное давление $p_{0}$ и размеры площади контакта $F$, используя формулы из $[1$, с. 29$]$ соответственно:

$$
\begin{gathered}
a=0,91 \cdot 10^{-2} \cdot \sqrt[3]{P}, \mathrm{cм} \\
b=1,568 \cdot 10^{-2} \cdot \sqrt[3]{P}, \mathrm{~cm} \\
F=19,216 \cdot 10^{-4} \cdot \sqrt[3]{P^{2}}, \mathrm{~cm}^{2} \\
p_{0}=780,6 \cdot \sqrt[3]{P}, \kappa \Gamma / \mathrm{cm}^{2}
\end{gathered}
$$


ТАБЛИЦА 1. Результаты расчета параметров площадки контакта колеса с рельсом

\begin{tabular}{|c|c|c|c|c|c|c|}
\hline Случай & $r_{1} / r_{2}$ & $a \cdot 10^{2}, \mathrm{~cm}$ & $b \cdot 10^{2}, \mathrm{~cm}$ & $\beta=b / a$ & $F \cdot 10^{4}, \mathrm{~cm}^{2}$ & $p_{0}$, кг $/ \mathrm{cm}^{2}$ \\
\hline I & $\infty / 30$ & 3,434 & 2,529 & 0,7365 & 27,29 & 560,2 \\
\hline II & $20 / 30$ & 3,901 & 1,568 & 0,4020 & 19,22 & 780,6 \\
\hline III & $51 / 30$ & 3,942 & 2,965 & 0,7522 & 36,72 & 408,6 \\
\hline IV & $20 / 20$ & 3,990 & 1,424 & 0,3569 & 17,85 & 840,3 \\
\hline
\end{tabular}

Аналогично определим их и для остальных случаев контакта колеса и рельса [1]. Результаты приведем в табл. 1.

Вычислим напряжения в характерных точках площадки контакта для случая I, в котором эксцентриситет контурного эллипса при

$$
\beta=\frac{b}{a}=0,7365
$$

составляет

$$
\begin{gathered}
l^{2}=1-\beta^{2}=1-0,7365^{2}=1-0,5424=0,4576 \\
\text { и } l=0,676 .
\end{gathered}
$$

По таблицам полных эллиптических интегралов [6] находим при $l=\sin \alpha, \alpha=42^{\circ} 30^{\prime}$ значения $K=1,8189, E=0,3026, C_{1}=0,9376$.

Тогда

$$
D=\frac{K-E}{l^{2}}=0,9762 .
$$

Определим постоянные члены формул (2):

$$
A_{1}=1,5668, B_{1}=0,3026, C_{1}=0,9376 .
$$

Теперь формулы (2) для напряжений принимают вид

$$
\left.\begin{array}{c}
\frac{\sigma_{x}}{p_{0}}=1,5668 f \frac{x}{a}, \\
\frac{\sigma_{y}}{p_{0}}=0,3026 f \frac{x}{a}, \\
\frac{\tau_{x y}}{p_{0}}=0,9376 f \frac{y}{b}, \\
\frac{\tau_{x z}}{p_{0}}=f \sqrt{1-\left(\frac{x}{a}\right)^{2}-\left(\frac{y}{b}\right)^{2}} \cdot
\end{array}\right\}
$$

На конце большой полуоси $x=a, y=0$ и при $f=0,3$ будем иметь

$$
\begin{gathered}
\frac{\sigma_{x}}{p_{0}}=1,5668, f=0,47, \frac{\sigma_{y}}{p_{0}}=0,0908, \\
\frac{\tau_{x y}}{P_{0}}=0, \frac{\tau_{x z}}{p_{0}}=0 .
\end{gathered}
$$

От нормального давления в этой же точке возникнут напряжения [1]

$$
\begin{gathered}
\sigma_{x}^{p}=p_{0}(1-0,6) \cdot \frac{0,7365}{0,4576} \times \\
\times\left(1+\frac{2 a \cdot \operatorname{cth} 0,676}{0,676}\right)=0,1390 p_{0}, \\
\sigma_{y}^{p}=-0,1390 p_{0}, \\
\tau_{x y}^{p}=0 .
\end{gathered}
$$

При одновременном действии нормальной и касательной нагрузок суммарная величина напряжений на конце большой полуоси составит

$$
\begin{gathered}
\sigma_{x}=0,609 p_{0}, \\
\sigma_{y}=-0,048 p_{0} .
\end{gathered}
$$

Ввиду малой величины $\sigma_{y}$ в сравнении с $\sigma_{x}$ напряженное состояние на конце большой полуоси $(x=-a, y=0)$ является близким к линейному с растягивающим напряжением $\sigma_{x}^{q}=0,609 p_{0}$.

Заменяя $p_{0}$ его выражением через нагрузку $P$ на колесо, получим (в кг $\left./ \mathrm{cm}^{2}\right)$ 


$$
\sigma_{x}=0,609 \cdot 550,2 \sqrt[3]{P}
$$

Приведем значения суммарных напряжений на конце большой полуоси эллипса контакта колеса с рельсом при $f=0,3$ :

$\begin{array}{llllll}P, \text { кг... } & 10 \cdot 10^{3} & 12 \cdot 10^{3} & 14 \cdot 10^{3} & 16 \cdot 10^{3} & 20 \cdot 10^{3} \\ \sigma_{x} & & & & & \\ \text { Кг }_{\mathrm{cm}^{2}} & 7216 & 7668 & 8074 & 8442 & 9092\end{array}$

Таким образом, при перекатывании с проскальзыванием напряжения у поверхности контакта на большой его полуоси при максимально возможном контакте при максимально возможном значении $f=0,3$ увеличилось в $0,470 /$ $0,139=3,38 \cdot \frac{0,470}{0,139}=3,38$ раза. При достижении растягивающими напряжениями предела прочности здесь не исключена возможность зарождения трещины.

\section{Напряжения на площадке контакта при наличии зон скольжения и сцепления}

В общем случае перекатывания колеса по рельсу на поверхности контакта будут иметь место разные условия относительного упругого смещения соприкасающихся частиц. Там, где смещение частиц одного тела относительно другого отсутствует, между данными телами будет жесткое сцепление. На тех же участках, где отношение касательного усилия к нормальному давлению равно коэффициенту трения $(q / p=f)$, будет относительное проскальзывание частиц поверхностей контакта. По вопросам, касающихся размеров и расположения зон сцепления и скольжения и законов распределения усилий в этих зонах, до сих пор нет единого мнения. Согласно теоретическим исследованиям [7], упругое качение ведущего (а также и ведомого) диска по плоскому основанию всегда сопровождается возникновением зоны сцепления в центре контактной площадки, т. е. там, где контактное давление велико. Зоны же скольжения примыкают к граничным точкам контактной полости.К. Джонсон [8] установил, что зона сцепления примы- кает к набегающему краю контактного пятна, в остальной же части его контактирующие частицы тел будут скользить друг относительно друга. По-видимому, каждое из таких утверждений справедливо имеет место при определенных условиях контакта тел. В.И. Сакало [9] путем сравнения изохроматических полос, полученных поляризационно-оптическим методом при перекатывании дисков из эпоксидной смолы, доказал отсутствие скольжения на набегающем крае контакта $Q=0,3 P$ в диапазоне скоростей от нуля до 250 км/ч. Интенсивность распределенных касательных усилий в зоне сцепления определялась из условия постоянства линейных деформаций, вызванных данными усилиями, на этой части поверхности контакта.

Для упрощения расчетов предлагается зону сцепления считать эллиптической, подобной эллипсу всей контактной площадки. При действии касательной нагрузки $q=f P$, пропорциональной нормальному давлению (т. е. распределенной по закону эллипсоида), нормальные напряжения $\sigma_{x}^{q_{1}}$ и $\sigma_{y}^{q_{1}}$, а также вызванные ими деформации $E_{x}^{q_{1}}$ и $E_{y}^{q_{1}}$ изменяются в пределах контактной площадки по линейному закону. Это следует из формул, приведенных в [1]. Поэтому для получения постоянных деформаций в зоне сцепления надо из напряжений (деформаций), соответствующих нагрузке:

$$
q_{1}=q_{0}, \gamma_{1}=q_{0} \sqrt{1-\left(\frac{x}{a}\right)^{2}-\left(\frac{y}{b}\right)^{2}},
$$

вычесть напряжения (деформации) от нагрузок (рис. 1):

$$
q_{2}=K_{l} q_{01} \sqrt{1-\left(\frac{x}{a}\right)^{2}-\left(\frac{y}{b}\right)^{2}} .
$$

Здесь $K_{l}=\sqrt[3]{\frac{c d q_{02}}{a b q_{01}}}$ представляет собой коэффициент подобия вычитаемого эллипсоида. Из соотношения $Q=\mu P$ после подстановки выражения для $Q$ получим формулу 

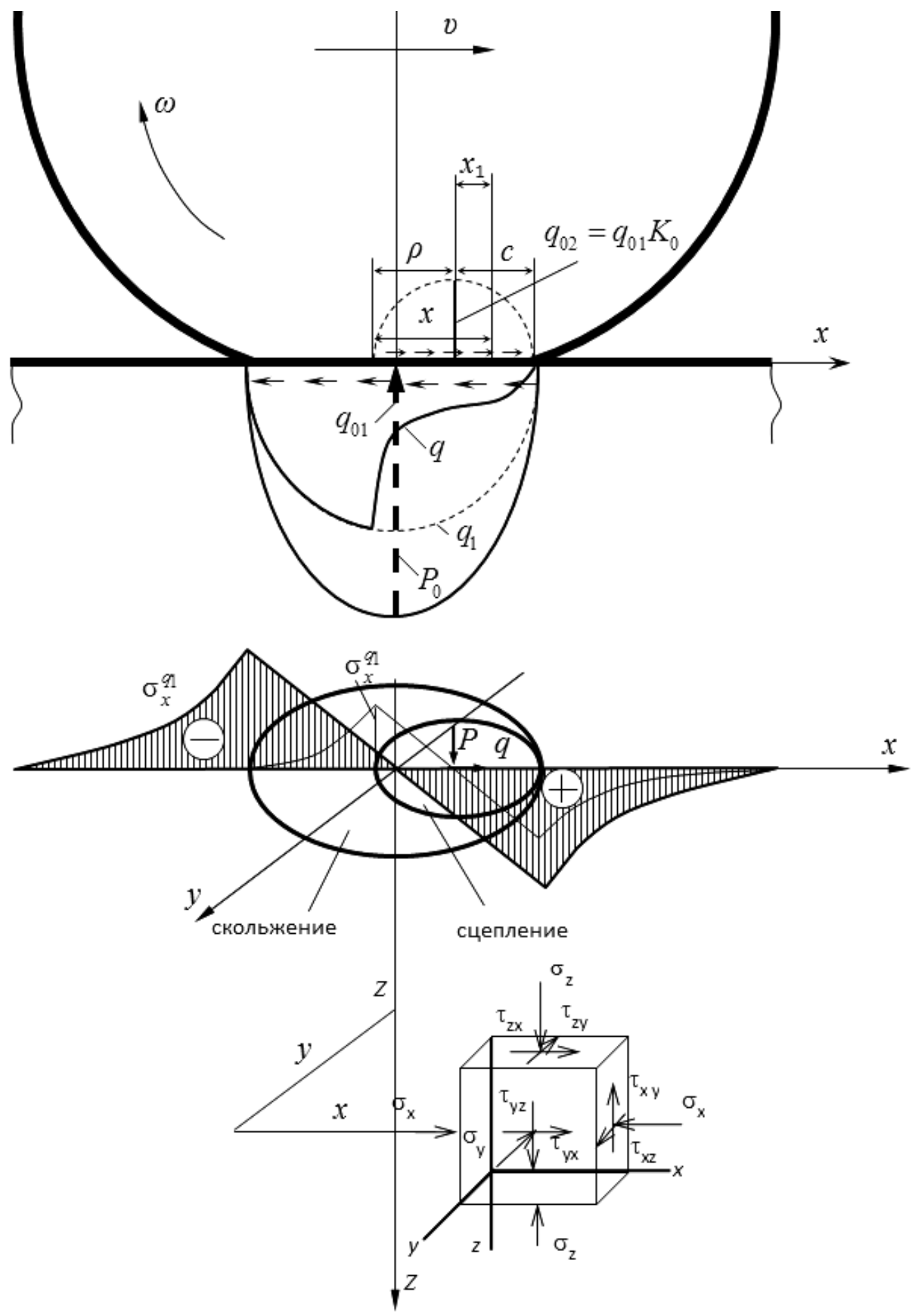

Рис. 1. Эпюры нагрузок и нормальных напряжений

$$
\begin{gathered}
Q=\frac{2}{3} \pi a b q_{01}-\frac{2}{3} \pi c d q_{02}= \\
=\frac{2}{3} \pi a b f P_{0}\left(1-K_{l}^{3}\right)=\operatorname{Pf}\left(1-K_{l}^{3}\right) .
\end{gathered}
$$

В итоге будем иметь, что $K_{l}=\sqrt[3]{1-\frac{\mu}{f}}$.

Таким образом, распределение касательных усилий в контакте при наличии зоны сцепле- 
ния, если считать в ней линейные деформации постоянными, находится по следующим выражениям:

$$
\begin{gathered}
\tau_{x z}=q_{1}-q_{2}= \\
=q_{01} \sqrt{1-\left(\frac{x}{a}\right)^{2}-\left(\frac{y}{b}\right)^{2}}- \\
-q_{02} \sqrt{1-\left(\frac{x_{1}}{c}\right)^{2}-\left(\frac{y_{1}}{d}\right)^{2}},
\end{gathered}
$$

в зоне скольжения - так:

$$
\tau_{x z}=q_{01} \sqrt{1-\left(\frac{x}{a}\right)^{2}-\left(\frac{y}{b}\right)^{2}}
$$

В точках оси $x$ выражение (4) примет вид

$$
\tau_{x z}=f p_{0}\left(\sqrt{1-\left(\frac{x}{a}\right)^{2}}-K_{l} \sqrt{1-\left(\frac{x-\rho}{c}\right)^{2}}\right)
$$

при $a-2 c \leq x \leq a$, где $c=a K_{l} ; \rho=a-c=a(1-$ $-K_{\text {) }}$.

Напряжения, обусловленные этими условиями, проще всего определить алгебраическим суммированием, например $\sigma_{x}^{q}=\sigma_{x}^{q_{1}}+\sigma_{x}^{q_{2}}$.

На контактной площадке в пределах малого «эллипса сцепления», включая и его контур, напряжения от $q_{2}$ можно вычислить по формулам (2).

Сделаем это для случая I.

Так как нормальные напряжения, вызванные действием касательной нагрузки, изменяются вдоль оси $x$ по линейному закону, то достаточно их найти для точек $x_{1}= \pm c, y_{1}=y=0$.

При направлении сил $q_{2}$, согласно рис. 1 , по формулам (2 и 3 ) получим

$$
\begin{aligned}
& \sigma_{x}^{q_{2}}= \pm q_{02} A_{1} \frac{x_{1}}{c}= \pm f P_{0} K_{l} A_{1}, \tau_{x y}^{q_{2}}=0, \\
& \sigma_{y}^{q_{2}}= \pm q_{02} B_{1} \frac{x_{1}}{c}= \pm f P_{0} K_{l} B_{1}, \tau_{x z}^{q_{2}}=0 .
\end{aligned}
$$

Постоянные $A_{1}$ и $B_{1}$ определяются через полные эллиптические интегралы по модулю $l$. Эксцентриситет $l$ зависит лишь от отношения $\beta=$ $=\frac{b}{a}=\frac{d}{c}$. Поэтому $A_{1}$ и $B_{1}$ сохраняют ранее найденные значения.

Продольная сила трения $Q$ при качении ведомого колеса в наиболее неблагоприятных случаях может достигать значений 0,15 P. Предполагая существование зоны сцепления у набегающего края контактного пятна и при $\frac{\mu}{f}=\frac{0,15}{0,30}$, найдем численные значения коэффициента подобия и нормальных напряжений:

$$
K_{l}=\sqrt[3]{1-\frac{0,15}{0,30}}=0,7940
$$

$$
\begin{aligned}
& \sigma_{x}^{q_{2}}= \pm 0,3 P_{0} \cdot 0,7940 \cdot 1,5668= \pm 0,3732 P_{0}, \\
& \sigma_{y}^{q_{2}}= \pm 0,3 P_{0} \cdot 0,7940 \cdot 0,3026= \pm 0,0721 P_{0} .
\end{aligned}
$$

В результате определим напряжения от действия продольных касательных сил. В пределах зоны сцепления они остаются постоянными и равными их значениям в точке $x=a, y=0$ :

$$
\left\{\begin{array}{l}
\sigma_{x}^{q}=f P_{0} A_{1}\left(1-K_{l}\right)=0,0968 p_{0}, \\
\sigma_{y}^{q}=f P_{0} B_{1}\left(1-K_{l}\right)=0,0187 p_{0} .
\end{array}\right.
$$

За пределами зоны сцепления напряжения измеряются по криволинейному закону. На рис. 1 приведены эпюры $\sigma_{x}^{q_{1}}$ и $\sigma_{x}^{q_{2}}$. Эпюра напряжений $\sigma_{x}^{q}$ получается путем наложения ее составляющих.

Для прочностной оценки напряженного состояния [10-12] при наличии в контакте сцепления вычислим наибольшее (главное) касательное напряжение $\tau_{\text {max }}$. Из кривых рис. 1 следует, что при отсутствии трения наибольшее касательное напряжение на поверхности контакта обусловливается полуразностью $\sigma_{x}$ и $\sigma_{z}$, т. е. 


$$
\tau_{\max }=\frac{\sigma_{x}-\sigma_{z}}{2} .
$$

В случае одновременного действия нормального давления $P$ и касательных усилий $q$ наибольшее касательное напряжение будет определяться полуразностью главных напряжений

$$
\sigma_{\text {гл }}=\frac{\sigma_{x}+\sigma_{z}}{2} \pm \sqrt{\left(\frac{\sigma_{x}-\sigma_{z}}{2}\right)^{2}+\tau_{x z}^{2}},
$$

поскольку величина $\sigma_{y}^{q}$ примерно в 5 раз меньше, чем $\sigma_{x}^{q}$.

Таким образом,

$$
\tau_{\max }=\sqrt{\left(\frac{\sigma_{x}-\sigma_{z}}{2}\right)^{2}+\tau_{x z}^{2}},
$$

и возникает оно в точках большой полуоси контактного эллипса. С целью определения расположения этой точки вычислим отдельные члены выражения (5). Представим разности $\left(\sigma_{x}-\sigma_{z}\right)$ в виде слагаемых от $P$ и $q$. Значения разности напряжений, обусловленных действием нормального давления $P$, вычислим по формуле

$$
\times\left(\gamma-\frac{\beta}{l^{2}}\left((1-\beta \gamma)-\frac{x}{a l} \operatorname{arcth} \frac{\frac{x}{a} l}{1+\beta \gamma}\right)\right),
$$

получающейся из [1, с. 31]. Поскольку $\sigma_{z}^{q}=0$, то разность $\left(\sigma_{x}-\sigma_{z}\right)_{q}=0,0968 p_{0}$ при $a-2 \leq$ $x \leq a$ нами была уже определена, при $x \leq-a$ и может быть подсчитана по формулам (2) и (3); на остальных участках ее величина мала. Касательные напряжения $\tau_{x z}^{q}$ на всей площадке контакта подсчитываем по выражению (4). Результаты вычислений компонентов для определения касательных напряжений в интересующем нас интервале изменения представлены на рис. 2 и приведены в табл. 2. Для удобства сравнения эпюра $\tau_{x z}^{q}$ построена внизу.

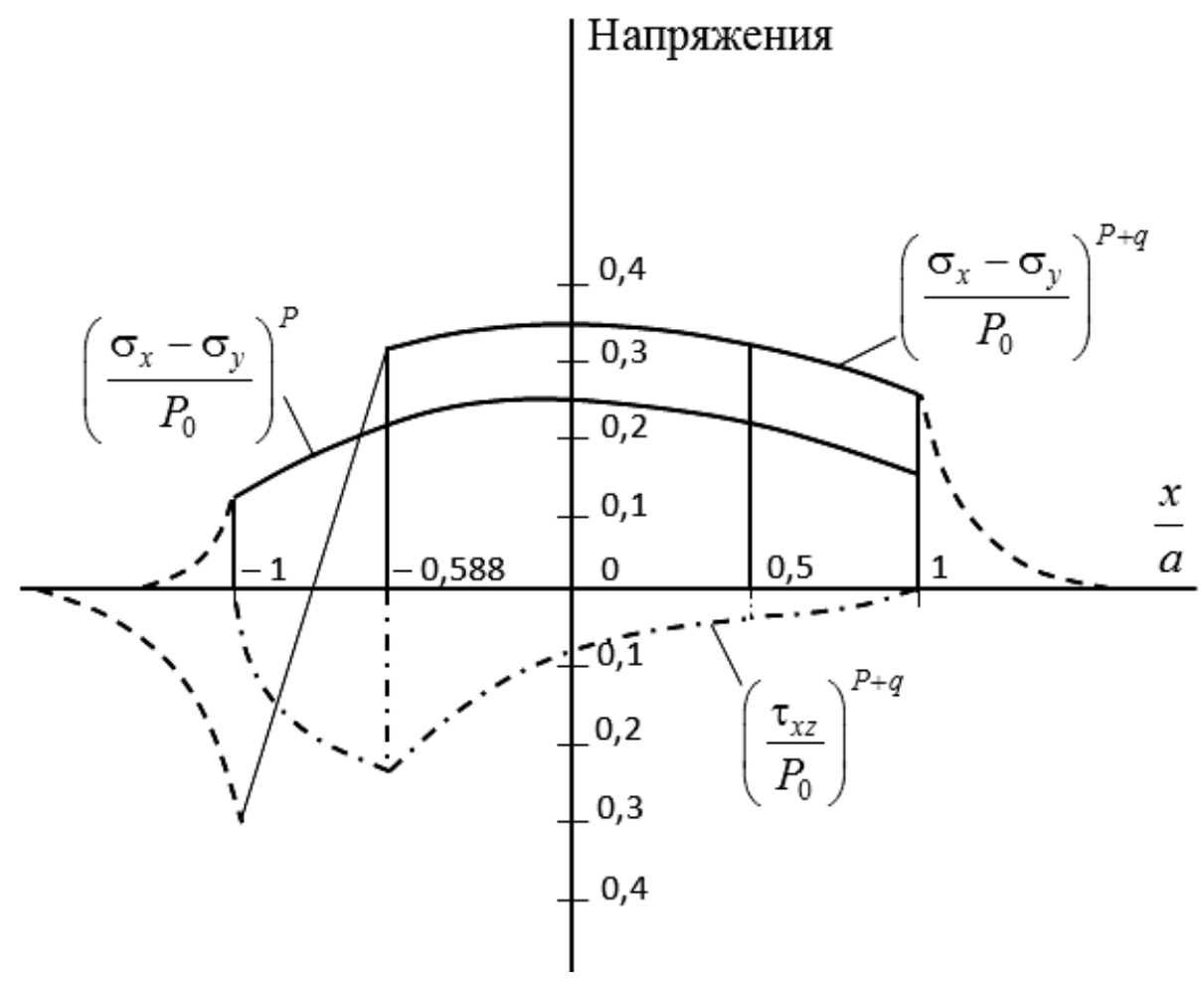

Рис. 2. Результаты вычислений компонентов для определения касательных напряжений 
ТАБЛИЦА 2. Компоненты, позволяющие определить касательные напряжения в заданных точках

\begin{tabular}{|l|c|c|c|c|c|}
\hline $\begin{array}{l}\text { Абсцисса точки } \\
\text { напряжения }\end{array}$ & 1 & 0,5 & 0 & $-0,588$ & -1 \\
\hline$\left(\frac{\sigma_{x}-\sigma_{z}}{p_{0}}\right)^{P}$ & 0,1390 & 0,2128 & 0,2303 & 0,2056 & 0,1390 \\
\hline$\left(\frac{\sigma_{x}-\sigma_{z}}{p_{0}}\right)^{P+q}$ & 0,2358 & 0,3096 & 0,3271 & 0,3024 & $-0,3310$ \\
\hline$\tau_{x z} / p_{0}$ & 0 & 0,0186 & 0,0700 & 0,2427 & 0 \\
\hline
\end{tabular}

Анализ приведенных результатов свидетельствует, что наибольшим будет касательное напряжение $\tau_{\max }$ в точке при $x=-0,588, y=0$ :

$$
\tau_{x z} / p_{0}=\sqrt{\left(\frac{0,3024}{2}\right)^{2}+0,2427^{2}}=0,286 .
$$

Его величина меньше, чем при действии только $P[13]$ и значительно меньше, чем при полном скольжении. Следовательно, напряженное состояние при наличии зон сцепления и скольжения не может быть более опасным, чем при полном скольжении по всему контакту. При этом интенсивность напряженного состояния возрастает с приближением $\mu f K$.

Опасность напряженного состояния в контакте усугубляется циклическим характером изменения напряжений по времени [13-15]. Поэтому способность сопротивляться действию таких напряжений определяется усталостными характеристиками материала колеса.

Полученные результаты имеют практическую значимость и могут применяться в инженерных расчетах оценки напряженно-деформированного состояния.

\section{Библиографический список}

1. Кротов С.В. Исследование напряженного состояния в колесе вагона / С. В. Кротов, Д.П. Кононов // Бюл. результатов науч. исследований.- 2020.- Вып. 3.C. $26-40$.
2. Воробьев А. А. Математическое моделирование параметров контакта колеса с рельсом для различных условий эксплуатации вагонов / А. А. Воробьев // Вестн. Ин-та проблем естественных монополий : Техника железных дорог.-М. : Ин-т проблем естественных монополий. -2016.--№ 1 (33).-С. 34-41.

3. Воробьев А. А. Контактное взаимодействие колеса и рельса / А. А. Воробьев // Вестн. Иркутск. гос. технич. ун-та. - Иркутск : ИСТУ, 2009.- № 3 (39).C. 42-47.

4. Орлова А. М. Определение параметров контакта колеса с рельсом для различных условий эксплуатации полувагона / А. М. Орлова, А. А. Воробьев, А. В. Саидова, Д. Е. Керенцев // Известия Петербургского университета путей сообщения. - СПб. : ПГУПС, 2015.Вып. 2 (43). - С. 74-84.

5. Ковальский Б. С. Расчет деталей на местное сжатие / Б. С. Ковальский. -Харьков : ХВКИУ, 1967.$222 \mathrm{c}$.

6. Градштейн И.С. Таблицы интегралов, сумм, рядов и произведений. - 7-е изд. / И.С. Градштейн, И. М. Рыжик. - СПб. : БХВ-Петербург, 2011. - 1182 c.

7. Глаголев Н. И. Трение качения, тяга, напряженное состояние и износ пар качения / Н. И. Глаголев, Э. А. Томило. - М. : Финпол, 1996. - 188 с.

8. Джонсон К. Механика контактного взаимодействия. - Пер. с англ. / К. Джонсон.- М. : Мир, 1989.$510 \mathrm{c}$.

9. Сакало В.И. Контактные задачи железнодорожного транспорта / В. И. Сакало, В.С. Коссов.- М. : Машиностроение, 2004.- 496 с.

10. Кротов С. В. Напряженно-деформированное состояние колесной пары вагона при повышении режи- 
мов нагружения / С. В. Кротов, В. П. Кротов // Вестн. Ростов. гос. ун-та путей сообщения. - Ростов-н./Д. : РГУПС, 2002. - № 2. - С. 36-39.

11. Кротов С. В. Классификация параметров несущей способности прессового соединения колесной пары железнодорожного транспортного средства / С. В. Кротов, В.П. Кротов // Вестн. Ростов. гос. ун-та путей сообщения.- Ростов-н./Д. : РГУПС, 2007.№ 2 (26). - С. 22-28.

12. Кротов С. В. Контактно-усталостная долговечность рельсовой и колесной сталей / С. В. Кротов, Д.П. Кононов // Известия Петербургского университета путей сообщения.-СПб. : ПГУПС, 2018.- Т. 15.Вып. 1.- С. 54-61.

13. Кононов Д. П. Использование фрактальных характеристик для анализа развития разрушения цельнокатаных колес / Д. П. Кононов, И. А. Иванов, С. В. Урушев, С. В. Кротов // Транспорт Российской Федерации. - 2018. - № 3 (76). - С. 68-71.
14. Krotov S. V. Application of the discriminant analysis at research of bearing ability of the wheel pair of the car / S. V. Krotov, V.P. Krotov // Transport problems (Poland, Gliwice).-2011.- Vol. 6. - N 1.- P. 43-49.

15. Кротов С. В. Влияние трения на контактноусталостную долговечность образцов из рельсовой и колесной стали / С. В. Кротов, Д. П. Кононов // Известия Петербургского университета путей сообщения.СПб. : ПГУПС, 2019.- Т. 16.- Вып. 2.- С. 212-219.

Дата поступления: 26.02.2021

Решение о публикации: 28.02.2021

\section{Контактная информация:}

КРОТОВ Сергей Викторович - канд. техн. наук, доц.; svk-19587@yandex.ru

КОНОНОВ Дмитрий Павлович - д-р техн. наук, проф.; d_kononov@mail.ru

ПАКУЛИНА Елена Вячеславовна - ассистент; elena_pakulina29@mail.ru

\title{
Stress state in contact between wheel and rail in the presence of slip and adhesion
}

\section{S. V. Krotov ${ }^{1}$, D. P. Kononov², E. V. Pakulina ${ }^{2}$}

\author{
${ }^{1}$ Rostov State Transport University, 2, pl. Rostovskogo Strelkovogo Polka Narodnogo Opolcheniya, \\ Rostov-na-Donu, 344038, Russian Federation \\ ${ }^{2}$ Emperor Alexander I Petersburg State Transport University, 9, Moskovsky pr., Saint Petersburg, \\ 190031, Russian Federation
}

For citation: Krotov S. V., Kononov D.P., Pakulina E. V. Stress state in contact between wheel and rail in the presence of slip and adhesion. Proceedings of Petersburg Transport University. Saint Petersburg, Petersburg State Transport University, vol. 18, no. 2, pp. 177-187. (In Russian)

DOI: $10.20295 / 1815-588 X-2021-2-177-187$

\begin{abstract}
Summary
Objective: Predicting the stress-strain state of a wheel or rail during their interaction depending on the normal pressure. Methods: The study of the stress-strain state in the car wheel and in its contact with the rail using the finite element method with all possible combinations of loading factors and taking into account the influence of temperature, dynamic influences, contact parameters, fatigue phenomena and the forces of interaction between the wheel and the rail are calculated, determining the stress state of the wheel, wear and deterioration of the contact surfaces and, as a consequence, the reliability of the carriage and traffic safety. Results: The effect of tangential loads on the stress-strain state when there is sliding in the wheel-rail contact zone was evaluated. The parameters of dangerous stresses are given depending on
\end{abstract}


the axial load. Experimental and theoretical approaches to determining the stress-strain state of contacting elements in the presence of both slip and adhesion in the wheel-rail contact are shown. The components of the stress tensor are obtained depending on the contact pressure according to the calculation formulas. Diagrams of the distribution of shear stresses in the contact of the wheel with the rail in the presence of a zone of adhesion and sliding are made. The intensity of the stress state change in the wheel-rail contact is calculated. Practical importance: The results obtained show how the slip and adhesion zones affect the stress state in the contact zone in comparison with full slip. They are useful from the point of view of predicting the stress-strain state of a wheel or rail during their interaction depending on the normal pressure.

Keywords: Shear load, normal pressure, slip, grip, stress, contact.

\section{References}

1. Krotov S. V. \& Kononov D.P. Issledovaniye napryazhennogo sostoyaniya $\mathrm{v}$ kolese vagona [Analysis of the stress state in a car wheel]. Byulleten'rezul'tatov nauchnykh issledovaniy [Research results bulletin], 2020, iss. 3, pp. 26-40. (In Russian)

2. Vorobyev A.A. Matematicheskoye modelirovaniye parametrov kontakta kolesa s rel'som dlya razlichnykh usloviy ekspluatatsii vagonov [Mathematical modeling of wheel-to-rail contact parameters for various conditions of carriage operation]. Vestnik Instituta problem yestestvennykh monopoliy: Railway engineering [Bulletin of the Institute for Problems of Natural Monopolies: Railway Engineering]. Moscow, Institute for Natural Monopoly Problems Publ., 2016, no. 1 (33), pp. 34-41. (In Russian)

3. Vorobyev A. A. Kontaktnoye vzaimodeystviye kolesa i relsa [Contact interaction of wheel and rail]. $I r$ kutsk State Technical University Bulletin, 2009, iss. 3 (39), pp. 42-47. (In Russian)

4. Orlova A. M., Vorobyev A. A, Saidova A.V. \& Kerentsev D. E. Opredeleniye parametrov kontakta kolesa s rel'som dlya razlichnykh usloviy ekspluatatsii poluvagona [Determination of wheel-rail contact parameters for various operating conditions of a gondola car]. Izvestiya Peterburgskogo universiteta putey soobshcheniya [Proceedings of Petersburg Transport University]. Saint Petersburg, Petersburg State Transport University Publ., 2015, iss. 2 (43), pp. 74-84. (In Russian)

5. Koval'skiy B. S. Raschet detaley na mestnoye szhatiye [Calculation of parts for local compression]. Kharkov, Kharkov Higher Military Command Engineering School Publ., 1967, 222 p. (In Russian)
6. Gradshteyn I. S. \& Ryzhik I. M. Tablitsy integralov, summ, ryadov i proizvedeniy [Tables of integrals, sums, series and products]. Saint Petersburg, BHV-Peterburg Publ., 2011, 1182 p. (In Russian)

7. Glagolev N.I. \& Tomilo E.A. Treniye kacheniya, tyaga, napryazhennoye sostoyaniye i iznos par kacheniya [Rolling friction, traction, stress state and wear of rolling pairs]. Moscow, Finpol Publ., 1996, 188 p. (In Russian)

8. Johnson K. Contact mechanics. Cambridge, Cambridge University Press, 1985, 452 p. (Russ. ed.: Johnson K. Mekhanika kontaktnogo vzaimodeystviya. Moscow, Mir Publ., 1989, 510 p.)

9. Sakalo V.I. \& Kossov V. S. Kontaktnyye zadachi zheleznodorozhnogo transporta [Contact problems of railway transport]. Moscow, Mashinostroenie Publ., 2004, 496 p. (In Russian)

10. Krotov S. V. \& Krotov V.P. Napryazhenno-deformirovannoye sostoyaniye kolesnoy pary vagona pri povyshenii rezhimov nagruzheniya [Stress-strain state of a wheelset of a car with increasing loading conditions]. Vestnik Rostovskogo gosudarstvennogo universiteta putey soobshcheniya [Bulletin of Rostov State Transport University]. Rostov-na-Donu, Rostov State Transport University Publ., 2002, no. 2, pp. 36-39 (In Russian)

11. Krotov S. V. \& Krotov V.P. Klassifikatsiya parametrov nesushchey sposobnosti pressovogo soyedineniya kolesnoy pary zheleznodorozhnogo transportnogo sredstva [Classification of the parameters of the bearing capacity of the press connection of the wheelset of a railway vehicle]. Vestnik Rostovskogo gosudarstvennogo universiteta putey soobshcheniya [Bulletin of Rostov State Transport University]. Rostov-na-Donu, Rostov State Transport University Publ., 2007, no. 2 (26), pp. 22-28. (In Russian) 
12. Krotov S. V. \& Kononov D. P. Kontaktno-ustalostnaya dolgovechnost' rel'sovoy i kolesnoy staley [Contact fatigue life of rail and wheel steels]. Izvestiya Peterburgskogo universiteta putey soobshcheniya [Proceedings of Petersburg State Transport University]. Saint Petersburg, Petersburg State Transport University Publ., 2018, vol. 15, iss. 1, pp. 54-61. (In Russian)

13. Kononov D. P., Ivanov I. A., Urushev S. V. \& Krotov S. V. Ispolzovaniye fraktal'nykh kharakteristik dlya analiza razvitiya razrusheniya tsel'nokatanykh koles [Using fractal characteristics for analyzing the development of destruction of solid-rolled wheels]. Transport of the Russian Federation, 2018, no. 3 (76), pp. 68-71. (In Russian)

14. Krotov S. V. \& Krotov V.P. Application of the discriminant analysis at research of bearing ability of the wheel pair of the car. Transport problems (Poland, Gliwise), 2011, vol. 6, no. 1, pp. 43-49.
15. Krotov S. V. \& Kononov D. P. Vliyaniye treniya na kontaktno-ustalostnuyu dolgovechnost' obraztsov iz relsovoy i kolesnoy stali [Influence of friction on the contact fatigue life of samples made from rail and wheel steel]. Izvestiya Peterburgskogo universiteta putey soobshcheniya [Proceedings of Petersburg State Transport University]. Saint Petersburg, Petersburg State Transport University Publ., 2019, vol. 16, iss. 2, pp. 212-219. (In Russian)

Received: February 26, 2021

Accepted: February 28, 2021

\section{Authors' information:}

Sergey V. KROTOV - PhD in Engineering, Associate Professor; svk-19587@yandex.ru

Dmitriy P. KONONOV - D. Sci. in Engineering, Professor; d_kononov@mail.ru

Elena V. PAKULINA - Teaching Assistant; elena_pakulina29@mail.ru 
УДК 625.033 .34

\title{
Повышение эффективности работы в пассажирском комплексе Октябрьской железной дороги за счет использования алгоритма принятия решений с помощью аналитических инструментов качества
}

\author{
Т. М. Шманёв ${ }^{1,2}$, В. И. Ульяницкая ${ }^{1}$, М. С. Пухова ${ }^{1}$ \\ ${ }^{1}$ Октябрьская региональная служба развития пассажирских сообщений и предоставления \\ доступа к инфраструктуре, Российская Федерация, 191036, Санкт-Петербург, Невский пр., \\ д. 85, корп. Д \\ ${ }^{2}$ Петербургский государственный университет путей сообщения Императора Александра I, \\ Российская Федерация, 190031, Санкт-Петербург, Московский пр., 9
}

Для цитирования: Шманёв Т. М., Ульяницкая В. И., Пухова М. С. Повышение эффективности работы в пассажирском комплексе Октябрьской железной дороги за счет использования алгоритма принятия решений с помощью аналитических инструментов качества // Известия Петербургского университета путей сообщения. - СПб.: ПГУПС, 2021.- Т. 18.- Вып. 2. - С. 188-200.

DOI: 10.20295/1815-588X-2021-2-188-200

\section{Аннотация}

Цель: Разработка аппарата формирования мероприятий, нацеленных на улучшение и контроль за их выполнением, который будет учитывать отступления от заданных параметров. Под аппаратом формирования понимается завершенная совокупность элементов для выполнения какой-либо функции, путем систематизации множества единиц (объектов, явлений), т. е. поэтапное применение инструментов, приведенных к единому алгоритму. Методы: Основными инструментами анализа и управления пассажирского комплекса при осуществлении постоянной деятельности служат: диаграмма Парето, причинно-следственная диаграмма (Исикава), корреляция, риск-менеджмент (метод 3-х карт), стратегическое управление (Х-матрица) и др. Результаты: Выявлено, что аппарат формирования состоит из последовательности систематического прогнозирования и оценки алгоритма последовательных действий: статистика, анализ, расчет рисков, проверка, контроль и др. Установлено, что необходимо стремиться к возможности приходить к заданному параметру устойчивости процесса в пассажирском комплексе, не допуская критических отклонений от желаемого результата. Практическая значимость: На примере организации процесса подготовки к зиме в 2019/2020 году пассажирского комплекса Октябрьской железной дороги показан принцип использования аппарата формирования, который является универсальным. Данный принцип можно применять не только к другим процессам работы пассажирского комплекса, но и использовать его в процессах других хозяйств на сети «Железные дороги России».

Ключевые слова: Инструменты качества, инструменты управления, диаграмма Парето, метод 3-х карт, риски, пассажирский комплекс, индекс удовлетворенности.

\section{Введение}

Основными категориями потребителей услуг ОАО «РЖД» являются: грузоотправители; грузополучатели; операторы железнодорожного под- вижного состава; пассажиры [1]. Пассажирские перевозки подразумевают перемещение людей, багажа различными видами транспорта: железнодорожным [2], автомобильным, воздушным, морским и речным. Железные дороги занимают 
лидирующую позицию, обеспечивая более 35 \% всех пассажирских перевозок в России.

Так, доля Октябрьской железной дороги в общем пассажирообороте по сети дорог по итогам в 2020 г. (2019 г. - 15,7\%) составила $15,6 \%$, по отправленным пассажирам - 13,6\% (2019 г. - 14,1\%). За 2010-2019 гг. доля отправленных пассажиров изменилась с 12,9 до 15,7\%. В 2019 г. было достигнуто рекордно высокое количество пассажиров за последние десять лет (рис. 1). В 2020 г. из-за ряда ограничений, связанных с глобальной пандемией коронавируса, количество отправленных пассажиров сократилось на 29,8 \% к итогам пассажирских перевозок 2019 г., но оказалось чуть выше ожиданий, чему способствовали своевременное реагирование на внешние изменения и оценка возможных рисков.

Среди пассажирских сообщений различают следующие виды: пригородный и дальний.

В дальнем сообщении выделяют условные группы:

1) внутренние, межгосударственные, международные;

2) высокоскоростные, скоростные, скорые и пассажирские.

Существуют и другие подразделения видов пассажирских перевозок. Для них актуальным является управление качеством оказываемых пассажирам услуг и предоставляемого им сер- виса. Под услугами подразумевается соответствие нормативным стандартам и ожиданиям клиента. К основным аспектам качественного удовлетворения потребностей пассажира в перевозках относятся: ориентация на клиента, соблюдение культуры обслуживания, ценовая стратегия, показатели безопасности, надежности, скорости, санитарно-гигиенические услуги, удобство цифровых технологий (система навигации, информирования, онлайн покупки) и др. [3]. Выполнение запланированных мероприятий для достижения поставленных целей - одно из важнейших условий работы железнодорожного транспорта. И поскольку отступления от плановых заданий неизбежны, перед специалистами часто стоит проблема в выработке комплексных мероприятий, которые позволили бы компенсировать эти отступления [4].

Из-за карантинных мер и как следствие частичной или полной приостановки части запланированных проектов, услуг пришлось столкнуться с оптимизацией индикаторов оценки удовлетворенности пассажиров. Оценка достоверности и значимости показателя должна учитывать пять этапов обслуживания пассажиров: выбор вида транспорта; покупка билета; ожидание поезда; обслуживание в пути; совершенствование процесса обратной связи с пассажирами [5].

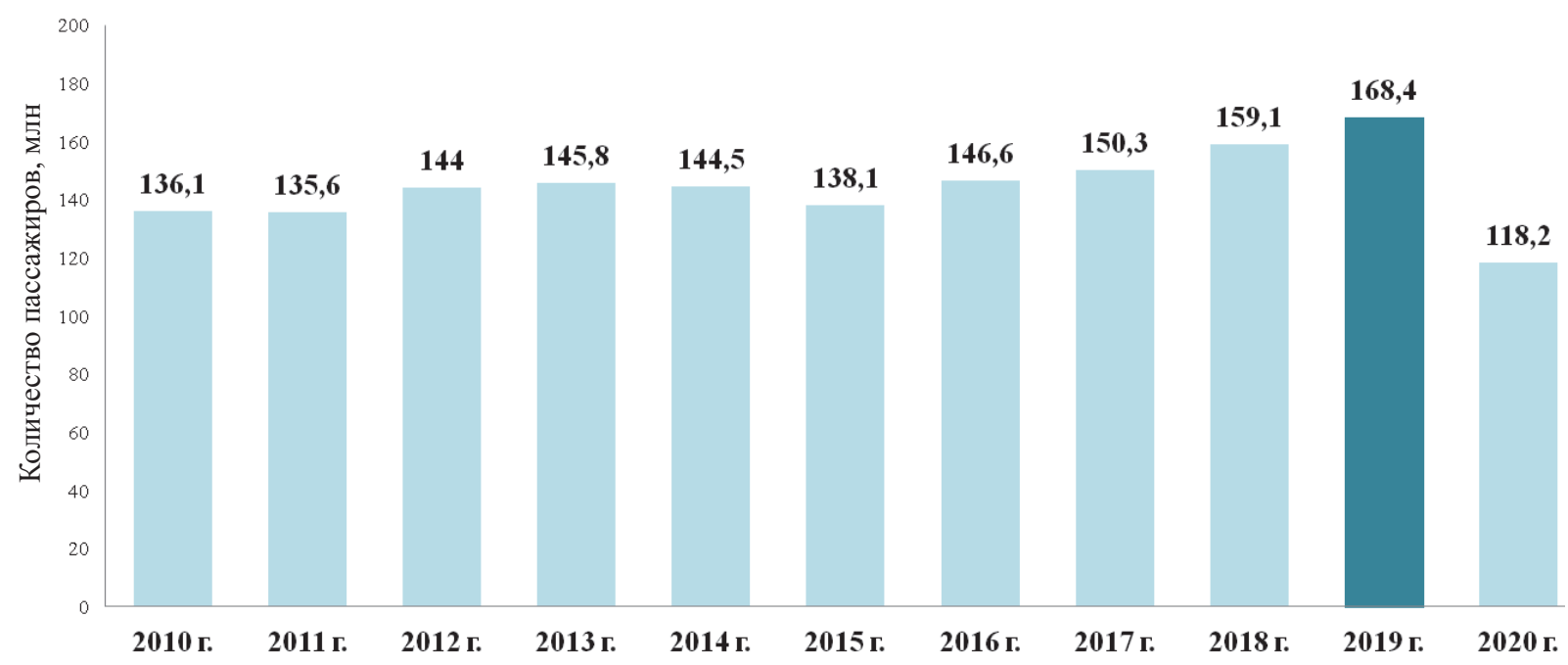

Рис. 1. Динамика количества отправленных пассажиров Октябрьской железной дороги за 2010-2020 гг., млн пассажиров 
Система оценки достигнутых результатов по принципу «клиент всегда прав», когда критерием оценки служило наличие или отсутствие жалоб, в настоящий момент устарела, так как она не отражает истинной оценки текущего состояния качества предоставляемых услуг. Для того чтобы понимать и правильно оценивать принимаемые решения по управлению качеством предоставляемых услуг, в компании ОАО «РЖД» принята система учета лояльности клиента, суть которого заключается в клиентоориентированности [6-9]. При этом принят подход «клиент всегда доволен», а критерием оценки является индекс удовлетворенности пассажиров.

Переход от учета количества жалоб от пассажиров к оценке индекса уровня удовлетворенности пассажиров позволяет оценить качество предоставляемых услуг в разрезе отдельных параметров, блоков параметров и этапов перевозки пассажиров.

В процессе работы пассажирского комплекса необходимо правильно расставлять приоритеты в отношении показателей, которые нужно контролировать. Так, в зависимости от внутреннего содержания обращения пассажиров определены две группы реагирования: первая - группа быстрого реагирования, куда относится порядка $35 \%$ от всех обращений, и вторая, нуждающаяся в тщательной проработке и внимательном контроле за устранением поступающих жалоб, 65 \% обращений соответственно. Необходимо определять, какие именно мероприятия и решения мы можем осуществить в оперативном режиме (1-я группа), тем самым устранив наиболее существенные замечания со стороны клиента, в лице пассажира, а какие требуют тщательной проработки и контроля (2-я группа) и соответственно больше растянуты во времени.

Группа 1 - в настоящее время на сети дорог внедрена система оперативного реагирования ситуационный центр быстрого реагирования, который обеспечивает более в короткие сроки среагировать на жалобу клиента. И по ряду запросов предоставлять ответ заявителю (проинформировать) в течение 3 ч после обращения. Рассмотрение обращений граждан осуществляется установленным порядком [10], где нормативное время на рассмотрение обращений граждан составляет до 30 суток. Благодаря оперативному реагированию, ускорение рассмотрения обращений пассажиров превышает нормативное время в 160 раз.

Группа 2 - одним из предложений, направленных на решение сложных или постояннодействующих факторов, относящихся к ряду новых, является разработка аппарата формирования мероприятий, нацеленных на улучшение и контроль за их выполнением, который будет учитывать отступления от заданных параметров. Под аппаратом формирования понимается завершенная совокупность элементов для выполнения какой-либо функции путем систематизации множества единиц (объектов, явлений), т. е. поэтапное применение инструментов, приведенных к единому алгоритму. Основными инструментами анализа и управления пассажирского комплекса при осуществлении постоянной деятельности служат: диаграмма Парето, причинно-следственная диаграмма (Исикава), корреляция, риск-менеджмент (метод 3-х карт), стратегическое управление (X-матрица) и др. $[7,11-14]$.

\section{Формирование, функционирование и развитие системы обслуживания клиентов}

Способность обеспечивать комплексное и качественное обслуживание клиентов в значительной мере зависит от стратегии управления, ее устойчивости, а также условий, учитывающих особенности поведения современных потребителей и их растущего ожидания.

Развивая на практике понимание данного определения, выделяется наличие закономерностей формирования, функционирования и развития в виде алгоритма (рис. 2).

Данный подход рассматривает любое действие, которое способствует повышению удовлетворенности и лояльности потребителя, как систему упорядоченности инструментов сбора 


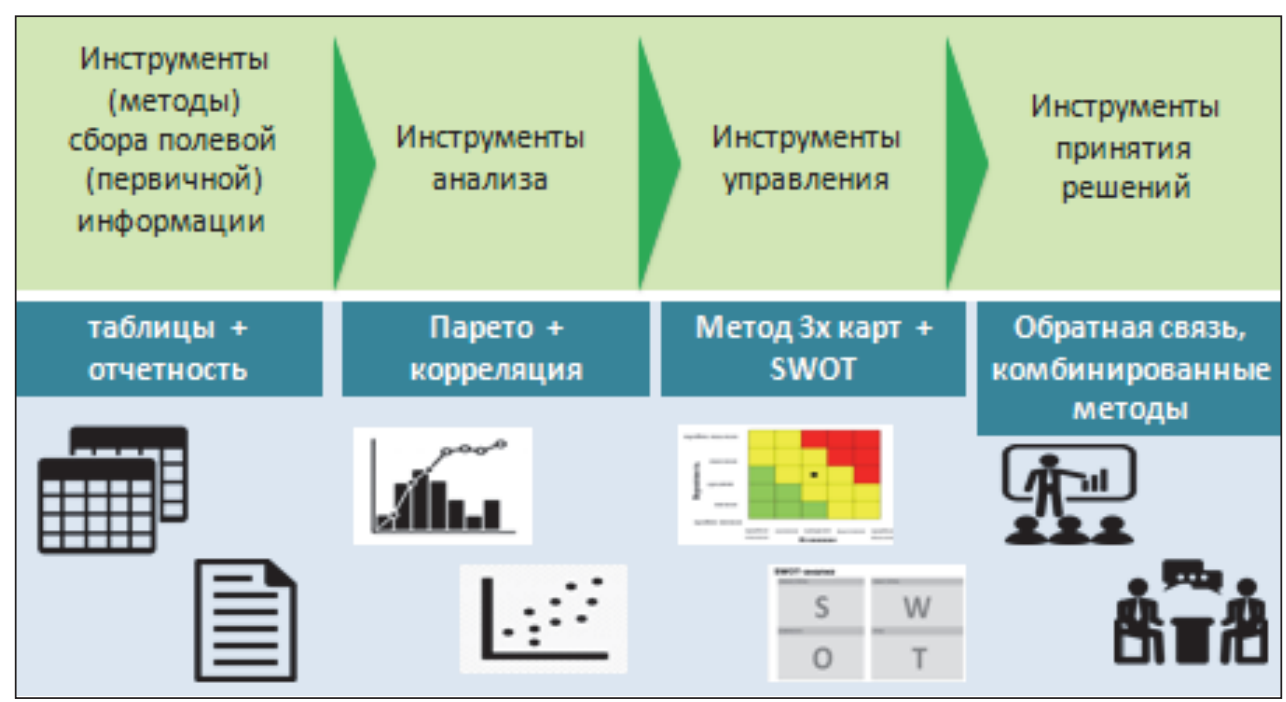

Рис. 2. Последовательность использования системы аналитических инструментов в Октябрьской региональной службе развития пассажирских сообщений и предоставления доступа к инфраструктуре

первичной информации, инструментов анализа, управления и принятия решения, через комбинированные элементы сопоставления отдельных вариаций системы. Значимость каждого шага устанавливается в процессе работы.

Например, анализируя процесс организации подготовки к зимнему периоду 2019/2020 года пассажирского комплекса Октябрьской железной дороги, за инструмент первичной информации были взяты следующие данные: обращения пассажиров, поступивших в предыдущий зимний период (табл. 1), материально-техническое снабжение подразделений, укомплектованность штата, подготовка подвижного состава, подготовка первозимников и другие источники.

Неотъемлемым преимуществом применения инструментов анализа с первоисточником является то, что предупреждение возникновения отступления от заданных параметров происходит еще в процессе сбора данных: период обращения, тип обращения, описание (суть), территориальное направление и контактные данные заявителя.

Оценка разброса данных часто дает возможность понять характер процесса (табл. 2). При этом неравномерность в группах будет учитываться не только числом роста или снижения в рамках одного направления (темы обращения), но и их изменчивостью в рассматриваемом периоде.

Вернемся к данным, приведенным в табл. 1 . Анализируя обращения пассажиров, прежде всего выделяем жалобы. Например, обращающихся пассажиров с жалобами на «перекрытие грузовым поездом переездов», как правило, немного от общего числа обращений, но зачастую именно они влияют на деятельность компании и связь с другими процессами и характеристиками компании ОАО «РЖД».

Для выявления основных причин потери качества был использован достаточно простой, но эффективный инструмент аналитической визуализации - диаграмма Парето (рис. 3) [11-13].

Анализ обращений пассажиров показывает, что группа «А» - наиболее важные, существенные причины жалоб пассажиров. В данном примере значимыми факторами являются: продажа билетов на станциях, стоимость проезда и возврат проездных документов (на нее приходится более 210 жалоб), порядок оформления проездных документов, льготный проезд (176 замечаний), санитарное состояние инфраструктуры (115) и график движения (68). Относительный процент группы «А» в общем количестве причин 





ТАБЛИЦА 2. Сводная таблица данных по темам обращений

\begin{tabular}{|l|c|c|c|}
\hline \multicolumn{1}{|c|}{ Тип обращения } & $\begin{array}{c}\text { С } 15.10 .2018 \text { г. } \\
\text { по 31.03.2019 г. }\end{array}$ & $\begin{array}{c}\text { С } 15.10 .2019 \text { г. } \\
\text { по 31.03.2020 г. }\end{array}$ & Количество, \% \\
\hline Жалобы & 1047 & 911 & $-13,0$ \\
\hline Запрос & 1803 & 1639 & $-9,0$ \\
\hline Предложения & 443 & 392 & $-11,5$ \\
\hline Благодарности & 494 & 535 & 8,5 \\
\hline Всего & 3787 & 3477 & $-8,0$ \\
\hline в том числе комплексных & 333 & 290 & $-12,9$ \\
\hline
\end{tabular}

обычно составляет от 60 до 80. Соответственно устранение причин группы «А» имеет наибольший приоритет, а связанные с этим мероприятия - самую высокую эффективность. В группы «В» и «С» включены причины, которые в сумме имеют не более $40 \%$, но при этом содержат не менее значимые причины и проблемы.

Собранные данные используются не только для принятия решений в момент их получения и анализа посредством диаграммы Парето, но и для оценки различных проблем, рассматриваемых на более долгий срок, например в течение нескольких зимних периодов. Диаграмма Парето позволяет выяснить причины появления существенно важных отклонений и систематизировать их по группе влияния, тем самым сосредоточить усилия на ликвидации именно этих причин [1].

Обладая данными о том, какие причины жалоб наиболее значимые и как они измеряются, возможно сфокусировать усилия и ресурсы на их устранение. При этом устранения причин и их последствий выгоднее рассматривать в комплексе с риск-ориентированным подходом (далее метод 3-х карт).

Исходными данными для построения матриц рисков относятся: перечень рисковых событий, допустимый уровень риска, фактическая частота событий и фактическая величина удельного ущерба по причине данного риска. В процессе идентификации риска также определяются уже существующие меры управления ими в части снижения вероятности возникновения риска или его последствия $[15,16]$.
Рассмотрим эффективность планирования рисков работы предприятий пассажирского комплекса Октябрьской железной дороги в зимний период 2019/2020 года методом 3-х карт (рис. 4).

На практике построение матрицы риска начинается с определения возможных рисковых событий и нанесением их на карту (матрица рисков № 1) [11]. Как правило, окончательное решение идентификации рисков остается за владельцем риска или лицом, которому делегирован процесс анализа рисков. При этом на карту наносятся риски, нумерация которых соответствует принятому значению рискового события. Так, общий вес матрицы рисков № 1 составляет 7,9 учетных единиц (далее - у. е.).

Затем формируется прогноз рисков с учетом разработанного плана мероприятий по управлению рисками (матрица рисков № 2). Для управления рисками на данном этапе необходимо в любом случае апробировать принятие и применение всех возможных мер управления. При таком подходе общий вес карты составляет 7 у.е. Последний этап - построение фактической картины последствий прогнозируемых нежелательных событий. Результаты фактической матрицы рисков по итогам работы предприятий пассажирского комплекса в зимний период 2019/2020 года и реализации принятых мероприятий иллюстрирует матрица рисков № 3 .

В результате соблюдение баланса методов исследования и анализа в предложенной последовательности позволяет добиться существенных улучшений основных параметров удовлетворенности пассажиров (табл. 3). 


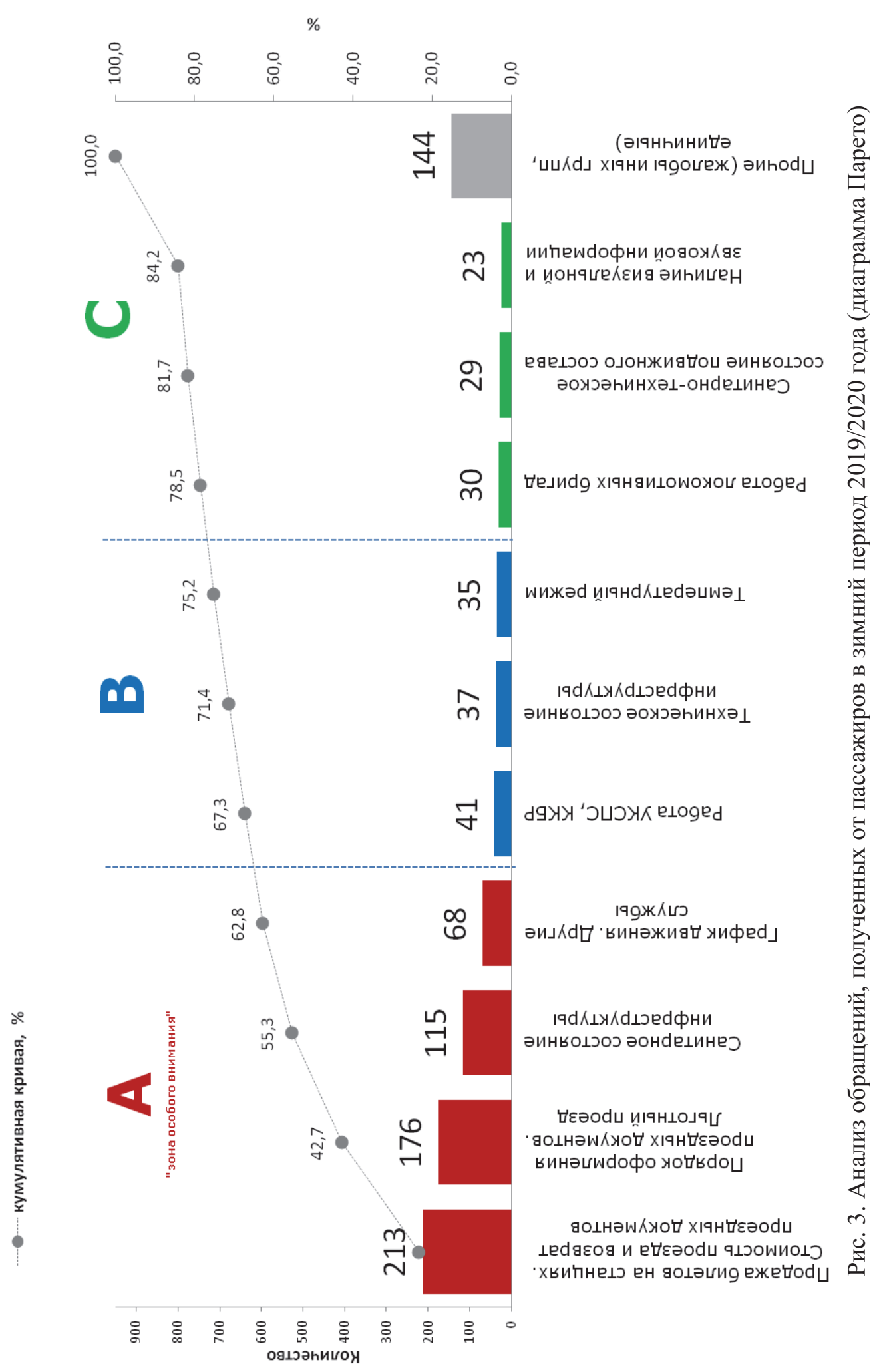



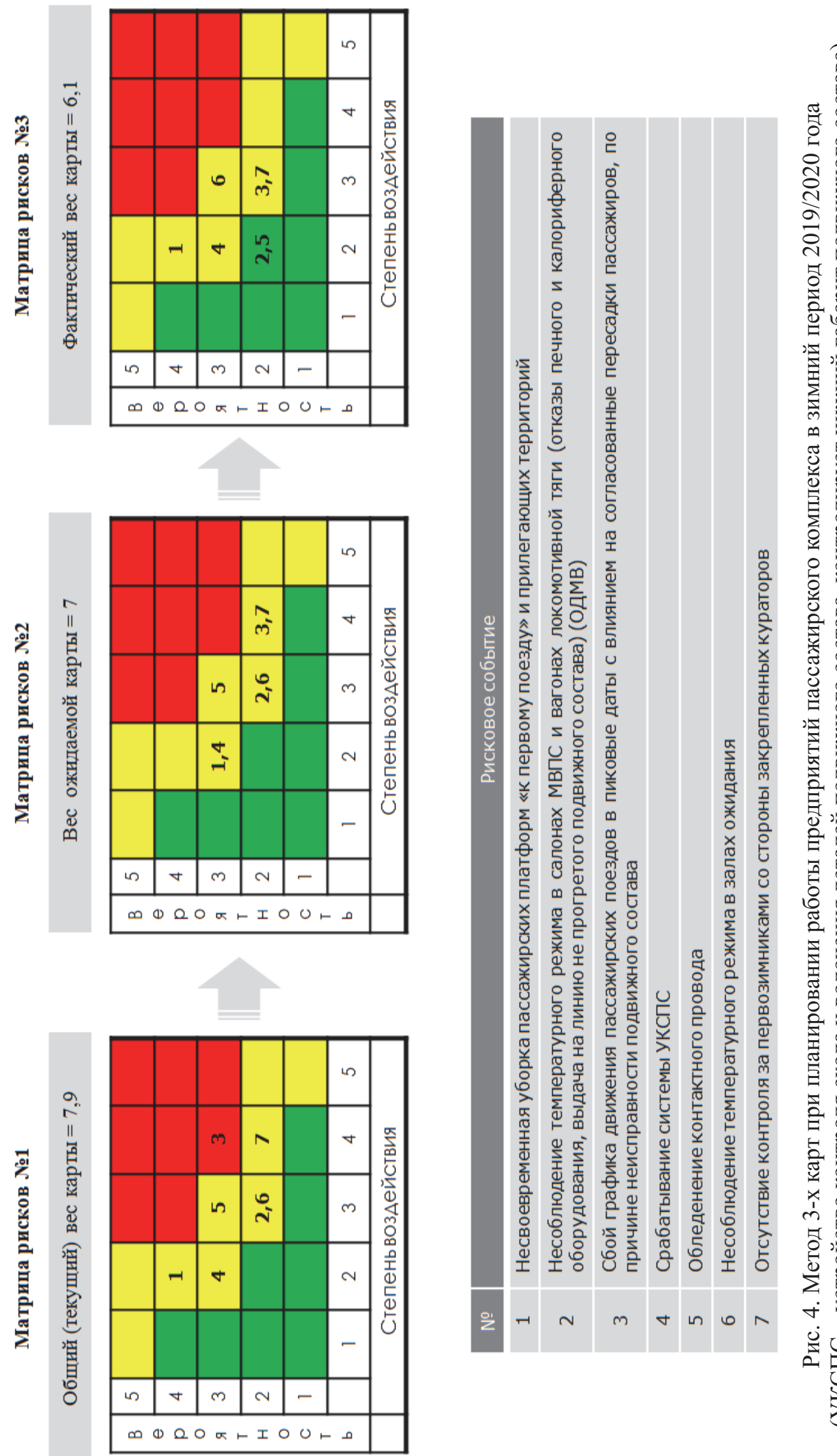

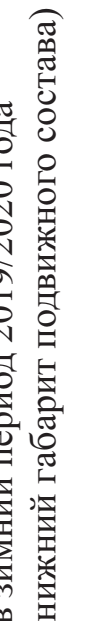

ชี

穴

宣

空

응

은

है

ग

త్ర

桪

突

읍

震

包

完



突

空

萦 
ТАБЛИЦА 3. Индекс удовлетворенности по восьми показателям в динамике на примере $\mathrm{AO}$ «Северо-Западная пригородная пассажирская компания»

\begin{tabular}{|c|c|c|c|c|c|c|c|}
\hline \multirow[b]{2}{*}{ № } & \multirow{2}{*}{$\begin{array}{c}\mathrm{AO} \text { «Северо-Западная пригородная } \\
\text { пассажирская компания» }\end{array}$} & \multicolumn{2}{|c|}{19 июля } & \multicolumn{2}{|c|}{20 июля } & \multicolumn{2}{|c|}{ Изменения } \\
\hline & & \begin{tabular}{|c|} 
ср. \\
оценка
\end{tabular} & баллы & $\begin{array}{c}\text { ср. } \\
\text { оценка }\end{array}$ & баллы & $\begin{array}{c}\text { ср. } \\
\text { оценка }\end{array}$ & баллы \\
\hline 1 & Удобство приобретения билетов & 4,5 & \multirow{8}{*}{79,8} & 4,6 & \multirow{8}{*}{82,8} & $+0,1$ & \multirow{8}{*}{+3} \\
\hline 2 & Условия нахождения на вокзалах & 4,2 & & 4,4 & & $+0,2$ & \\
\hline 3 & $\begin{array}{l}\text { Безопасность (на вокзалах } \\
\text { и при движении в поездах) }\end{array}$ & 3,7 & & 3,7 & & 0 & \\
\hline 4 & $\begin{array}{l}\text { Информация о расписании, услугах. Воз- } \\
\text { можность получить нужную информацию } \\
\text { о передвижении в поездах ОАО «РЖД» }\end{array}$ & 4,7 & & 4,8 & & $+0,1$ & \\
\hline 5 & $\begin{array}{l}\text { Техническое состояние пригородных } \\
\text { поездов }\end{array}$ & 3,9 & & 4 & & $+0,1$ & \\
\hline 6 & Стоимость услуг & 3,9 & & 4,1 & & $+0,2$ & \\
\hline 7 & Время в пути/Скорость передвижения & 4,2 & & 4,2 & & 0 & \\
\hline 8 & $\begin{array}{l}\text { Комфорт в пригородных поездах } \\
\text { при передвижении }\end{array}$ & 4,2 & & 4,4 & & $+0,2$ & \\
\hline
\end{tabular}

В рассмотренном случае выполнение необходимых условий и последовательности соблюдения методов по каждому из заявленных параметров или блоков параметров приводит систему в движение [5]. Так, прослеживая динамику по 8 показателям оценки клиентоориентированности пассажирского комплекса за год, наблюдается отчетливая результативность действий и эффективность предполагаемых решений (табл. 3) в АО «Северо-Западная пригородная пассажирская компания».

\section{Заключение}

Подводя итог вышесказанному, можно отметить, что в результате применения предложенного алгоритма последовательности использования данных инструментов технология управления приемлемого риска воспринимается как последовательная цепь трех больших этапов: оценки текущего состояния (готовность инфраструктуры и аналитика прошлого периода), планируемая карта (учет ряда мер, способных скоррек- тировать события) и фактическая картина (по истечению срока).

Унификация подхода к оценке и прогнозированию «поведения процесса», через уровень удовлетворенности пассажиров на всех этапах координации пассажирских перевозок, позволяет компенсировать пробелы функционирования процесса «Предоставление услуг пассажирского комплекса». Рассчитанные показатели по каждому из определенных параметров дают возможность выявить наиболее проблемные звенья в процессе взаимодействия с пассажирами и отдельными факторами неудовлетворенности. Соблюдая последовательность алгоритма, можно оценить значимость и правильность реализуемых мероприятий, программ, направленных на повышение качества транспортного обслуживания пассажиров.

Таким образом, аппарат формирования состоит из последовательности систематического прогнозирования и оценки алгоритма последовательных действий: статистика, анализ, расчет рисков, проверка, контроль и др. [1, 11-15]. При этом необходимо стремиться к возможности приходить к заданному параметру устойчи- 
вости процесса в пассажирском комплексе, не допуская критических отклонений от желаемого результата.

На примере организации подготовки к зимнему периоду 2019/2020 года пассажирского комплекса Октябрьской железной дороги описан принцип использования аппарата формирования, который является универсальным. Алгоритм определяет последовательность тактических действий (мероприятий) пассажирского комплекса Октябрьской железной дороги, направленных на повышение клиентоориентированности и удовлетворенности потребителя, в лице пассажира, через индекс удовлетворенности в тех блоках услуг, где определен периметр основополагающих мероприятий. Данный принцип можно применять не только к другим процессам работы пассажирского комплекса, но и на сети ОАО «РЖД» России.

\section{Библиографический список}

1. Положение о системе управления качеством ОАО «РЖД». - Утв. решением совета директоров $\mathrm{OAO}$ «РЖД» (протокол заседания от 23 сентября 2020 г. № 22).- М. : ОАО «РЖД», 2020.

2. Железнодорожный транспорт : энциклопедия / гл. ред. Н. С. Конарев. - М. : Изд-во «Большая Русская Энциклопедия», 1994.- 560 с.

3. Верховых Г.В. Железнодорожные пассажирские перевозки : монография / Г.В. Верховых, А.Г. Зайцев, А. Г. Котенко и др.- СПб. : Северо-Запад. регион. центр «РУСИЧ», «Паллада-медиа», 2012.- 520 с.

4. Детмер У. Теория ограничений Голдратта. Системный подход к непрерывному совершенствованию / пер. с англ. У. Саламатовой. - 2-е изд.- М. : Альпина Бизнес Букс, 2008. -444 c.

5. Единая методика оценки уровня удовлетворенности пассажиров качеством услуг железнодорожного транспорта. - Утв. распоряжением ОАО «РЖД» от 7 февраля 2018 г. № 227/p. - М. : ОАО «РЖД», 2018.

6. Программа повышения качества транспортного обслуживания пассажиров в 2017-2019 годах.Утв. распоряжением ОАО «РЖД» от 24 марта 2017 г. № 543 р (в редакции от 03.04.2019 г. № 659/p). - М. : ОАО «РЖД», 2019.
7. Стратегия развития железнодорожного транспорта в Российской Федерации до 2030 года.- Утв. распоряжением Правительства Российской Федерации от 17 июня 2008 г. № 877-р. - М. : ОАО «РЖД», 2008.

8. Долгосрочная программа развития ОАО «РЖД» до 2025 года.- Утв. распоряжением Правительства Российской Федерации от 19 марта 2019 г. № 466/p.М. : ОАО «РЖД», 2019.

9. Стратегия научно-технологического развития холдинга «РЖД» на период до 2025 года и на перспективу до 2030 года (Белая книга). - Утв. распоряжением ОАО «РЖД» от 17 апреля 2018 г. № 769/p.- М. : ОАО «РЖД», 2018.

10. Федеральный закон от 02.05.2006 г. № 59-Ф3 (ред. от 27.12.2018 г.). О порядке рассмотрения обращений граждан Российской Федерации // Собрание законодательства РФ. - 2006. - 08.05. - № 19. С. 2060.

11. Федосеев А. А. Статистические методы контроля и управления качеством продукции / А. А. Федосеев, В. И. Логанина. - Ростов-н./Д. : Изд-во «Феникс», 2007.- 220 c.

12. Урубков А.Р. Статистические методы и модели в бизнесе / А.Р. Урубков. - М. : Изд-во «Дело» РАНХиГС, 2011.- 324 с.

13. Шорохова И.С. Статистические методы анализа : учеб. пособие / И. С. Шорохова. - Екатеринбург : Изд-во Урал. гос. ун-та, 2015.- 300 с.

14. Методика расчета показателей допустимого уровня риска в области безопасности движения на инфраструктуре ОАО «РЖД».- Утв. распоряжением ОАО «РЖД» от 1 марта 2020 г. № 413/p.- М. : ОАО «РЖД», 2020.

15. ГОСТ 33433-2015. Безопасность функциональная. Управление рисками на железнодорожном транспорте. - М. : Стандартинформ, 2020.

16. ГОСТ 33432-2015. Безопасность функциональная. Политика, программа обеспечения безопасности. Доказательство безопасности объектов железнодорожного транспорта. - М. : Стандартинформ, 2019.

Дата поступления: 05.03.2021

Решение о публикации: 18.03.2021 
Контактная информация:

ШМАНЁВ Тимофей Михайлович - канд. техн.

наук, доц.; 1_shmanev@orw.ru,

t.schmaniov@yandex.ru

УЛЬЯНИЦКАЯ Виктория Игоревна -
1_UlyanitskayaVI@orw.ru,

ulyanickaya_viktoriya@mail.ru

ПУХОВА Марина Сергеевна -

1_PuhovaMS@orw.ru,

marinka96puhova@gmail.com

\title{
Improving the Oktyabrskaya Railway passenger complex performance with a decision-making algorithm using analytical quality tools
}

\author{
T. M. Shmanyov ${ }^{1,2}$, V. I. Ulyanitskaya ${ }^{1}$, M. S. Pukhova ${ }^{1}$ \\ ${ }^{1}$ Octyabrskaya Regional Service for the Development of Passenger Services and Providing Access \\ to Infrastructure, 85, bld. D, Nevsky pr., Saint Petersburg, 191036, Russian Federation \\ 2 Emperor Alexander I Petersburg State Transport University, 9, Moskovsky pr., Saint Petersburg, \\ 190031, Russian Federation
}

For citation: Shmanyov T.M., Ulyanitskaya V. I., Pukhova M.S. Improving the Oktyabrskaya Railway passenger complex performance with a decision-making algorithm using analytical quality tools. Proceedings of Petersburg Transport University. Saint Petersburg State Transport University, 2021, vol. 18, iss. 2, pp. 188-200. (In Russian) DOI: 10.20295/1815-588X-2021-2-188-200

\section{Summary}

Objective: Development of an instrument to form measures aimed at improving and monitoring their implementation, which will consider deviations from the specified parameters. The formation instrument is regarded as a complete set of elements for performing a function by systematizing a set of units (objects, phenomena), i.e., step-by-step application of tools compiled into a single algorithm. Methods: The main tools for analyzing and managing the passenger complex during ongoing activities are: Pareto chart, cause \& effect diagram (Ishikawa), correlation, risk management (3-map method), strategic management (X-matrix), etc. Results: The study has revealed that the formation instrument consists of a sequence of systematic forecasting and evaluation of the algorithm of sequential operations: statistics, analysis, risk calculation, verification, control, etc. It has been established that it is necessary to strive for the ability to achieve a given parameter of the process stability in the passenger complex avoiding critical deviations from the desired result. Practical importance: Using the example of the 2019/2020 Oktyabrskaya Railway passenger complex winterization, the apparently universal principle of using the formation instrument has been demonstrated. This principle can be not only applied to other passenger complex processes but also used in the processes of other facilities in the Russian Railways network.

Keywords: Quality tools, management tools, Pareto chart, 3-map method, risks, passenger complex, satisfaction index.

\section{References}

1. Polozheniye o sisteme upravleniya kachestvom $O A O$ "RZhD” [Regulation on the Quality Management System of JSC Russian Railways]. Utv. resheniyem soveta direktorov OAO "RZhD” (protokol zasedaniya ot 23 sentyabrya, 2020 g. no. 22) [Approved by JSC Russian Railways Board of Directors (minutes N 22 of the meeting as of September 
23, 2020)]. Moscow, JSC Russian Railways Publ., 2020. (In Russian)

2. Zheleznodorozhnyy transport. Entsiklopediya [Railway transport. Encyclopedia]. Ed.-in-chief N. S. Konarev. Moscow, Great Russian Encyclopedia Publishing House, 1994, 560 p. (In Russian)

3. Verkhovykh G. V., Zaitsev A.G., Kotenko A.G. et al. Zheleznodorozhnyye passazhirskiye perevozki. Monografiya [Rail passenger transportation. Monograph]. Saint Petersburg, Northwestern Regional Center "RUSICH," Pallada-media Publ., 2012, 520 p. (In Russian)

4. Dettmer W. Teoriya ogranicheniy Goldratta. Sistemnyy podkhod $k$ nepreryvnomu sovershenstvovaniyu [Goldratt's theory of constraints. A systems approach to continuous improvement]. Translated by U. Salamatova. Ed. 2. Moscow, Alpina Business Books Publ., 2008. 444 p. (In Russian)

5. Edinaya metodika otsenki urovnya udovletvorennosti passazhirov kachestvom uslug zheleznodorozhnogo transporta [Unified methodology for assessing the level of passenger satisfaction with the quality of railway transport services]. Utv. rasporyazheniyem OAO "RZhD" ot 07 fevralya 2018 g. no. 227/r. [Approved by JSC Russian Railways Order N 227/r as of February 07, 2018]. Moscow, JSC Russian Railways Publ., 2018. (In Russian)

6. Programma povysheniya kachestva transportnogo obshuzhivaniya passazhirov v 2017-2019 godakh [Passenger Transport Service Quality Improvement Programme for 2017-2019]. Utv. rasporyazheniyem OAO "RZhD" ot 24 marta 2017 g. no. $543 \mathrm{r}$ (v redaktsii ot $03.04 .2019 \mathrm{~g}$. N659/r) [Approved by JSC Russian Railways Orderno. 543r as of March 24, 2017 (revision N 659/r as of April 03, 2019)]. Moscow, JSC Russian Railways Publ., 2019. (In Russian)

7. Strategiya razvitiya zheleznodorozhnogo transporta $v$ Rossiyskoy Federatsii do 2030 goda [Railway Transport Development Strategy in the Russian Federation until 2030]. Utv. rasporyazheniyem Pravitel'stva Rossiyskoy Federatsii ot 17 iyunya 2008 g. no. 877-r [Approved by Decree of the Government of the Russian Federation N 877-r dated June 17, 2008]. Moscow, JSC Russian Railways Publ., 2008. (In Russian)

8. Dolgosrochnaya programma razvitiya OAO "RZhD" do 2025 goda [Russian Railways Long-Term Development Programme until 2025]. Utv. rasporyazheniyem Pravitel'stva Rossiyskoy Federatsii ot 19 marta 2019 g. no. 466/r [Approved by Decree of the Government of the Russian Federation N 466/r dated March 19, 2019]. Moscow, JSC Russian Railways Publ., 2019. (In Russian)

9. Strategiya nauchno-tekhnologicheskogo razvitiya kholdinga «RZhD» na period do 2025 goda i na perspektivu do 2030 goda (Belaya kniga) [The strategy of scientific and technological development of the Russian Railways Holding for the period up to 2025 and for the future up to 2030 (White Book)]. Utv. rasporyazheniyem OAO "RZhD" ot 17 aprelya 2018 g. no. 769/r [Approved by JSC Russian Railways Order N 769/r as of April 17, 2018]. Moscow, JSC Russian Railways Publ., 2018. (In Russian)

10. Federal'nyy zakon ot 02.05.2006 N 59-FZ (red. ot 27.12.2018). O poryadke rassmotreniya obrashcheniy grazhdan Rossiyskoy Federatsii. Sobraniye zakonodatel'stva RF, 08.05.2006, no. 19, st. 2060 [Federal Law N 59-FZ as of May 02, 2006 (as amended on December 27, 2018). On the Procedure for Considering Applications from Citizens of the Russian Federation]. Collected Legislation of the Russian Federation, May 08, 2006, no. 19, Art. 2060]. (In Russian)

11. Fedoseev A.A. \& Loganina V.I. Statisticheskiye metody kontrolya i upravleniya kachestvom produktsii [Statistical methods of product quality control and management]. Rostov-on-Don, Phoenix Publishing House, 2007, 220 p. (In Russian)

12. Urubkov A.R. Statisticheskiye metody i modeli v biznese [Statistical methods and models in business]. Moscow, Delo Publishing House, RANEPA, 2011, 324 p. (In Russian)

13. Shorokhova I. S. Statisticheskiye metody analiza. Ucheb. posobiye [Statistical analysis methods. Training manual]. Yekaterinburg, Publishing House of the Ural State University, 2015, 300 p. (In Russian)

14. Metodika rascheta pokazateley dopustimogo urovnya riska $v$ oblasti bezopasnosti dvizheniya na infrastrukture OAO "RZhD" [Methodology for calculating permissible risk indicators for traffic safety in the Russian Railways infrastructure]. Utv. rasporyazheniyem OAO "RZhD" ot 1 marta 2020 g. no. 413/r [Approved by JSC Russian Railways Order N 413/r as of March 01, 2020]. Moscow, JSC Russian Railways Publ., 2020. (In Russian)

15. GOST 33433-2015. Bezopasnost'funktsional'naya. Upravleniye riskami na zheleznodorozhnom transporte [State Standard GOST 33433-2015. Functional safety. Risk management on railway transport]. Moscow, Standartinform Publ., 2020. (In Russian) 
16. GOST 33432-2015. Bezopasnost'funktsional'naya. Politika, programma obespecheniya bezopasnosti. Dokazatel'stvo bezopasnosti ob" yektov zheleznodorozhnogo transporta [State Standard GOST 33432-2015. Functional safety. Policy and program of safety provision. Safety proof of the railway objects]. Moscow, Standartinform Publ., 2019. (In Russian)

Received: March 05, 2021

Accepted: March 18, 2021

\section{Author's information:}

Timofey M. SHMANYOV - PhD in Engineering, Associate Professor; 1_shmanev@orw.ru, t.schmaniov@yandex.ru Victoria I. ULYANITSKAYA 1_UlyanitskayaVI@orw.ru, ulyanickaya_viktoriya@mail.ru Marina S. PUKHOVA - 1_PuhovaMS@orw.ru, marinka96uhova@gmail.com 
УДК 629.423.1

\title{
Анализ нагруженности кожуха зубчатой передачи электровоза при условии ослабления затяжки болтов его крепления к тяговому двигателю
}

\author{
А. Г. Андриевский ${ }^{1}$, Е. А. Чабан ${ }^{1}$, В. В. Москвичев ${ }^{2}$ \\ ${ }^{1}$ Красноярский институт железнодорожного транспорта, филиал Иркутского государственного \\ университета путей сообщения, Российская Федерация, 660028, Красноярск, ул. Новой Зари, 2 И \\ ${ }^{2}$ Красноярский филиал Федерального исследовательского центра информационных и \\ вычислительных технологий Российской академии наук, Российская Федерация, \\ 660049, Красноярск, пр. Мира, 53
}

Для цитирования: Андриевский А.Г., Чабан Е.А., Москвичев В. В. Анализ нагруженности кожуха зубчатой передачи электровоза при условии ослабления затяжки болтов его крепления к тяговому двигателю // Известия Петербургского университета путей сообщения - СПб.: ПГУПС, 2021.T. 18. - Вып. 2.- C. 201-210. DOI: 10.20295/1815-588X-2021-2-201-210

\begin{abstract}
Аннотация
Цель: Исследовать зависимость численных величин опорных реакций, возникающих в болтовых креплениях кожуха зубчатой передачи (КЗП), от условий его закрепления к тяговому двигателю. Показать возникающее перераспределение величин опорных реакций в случае невосприятия нагрузки одним или двумя болтовыми креплениями из существующих трех проектных. Рассчитать эквивалентные напряжения, появляющиеся в конструкции кожуха зубчатой передачи при различных нештатных условиях его крепления к тяговому двигателю при статическом нагружении. Методы: Использовались уравнения статики для пространственной системы сил, включающую три вертикальных опорных реакции и собственный вес кожуха. Для исследования напряженнодеформированного состояния кожуха в случае его статического нагружения применен метод конечных элементов, реализованный в программном комплексе ANSYS Workbench. Результаты: Обнаружена причина возникающих повреждений КЗП при эксплуатации, связанная с его конструктивными недостатками. Получены расчетные формулы для определения вертикальных опорных реакций КЗП. Обнаружена необходимость учета нагруженности КЗП в случае перераспределения нагрузок, обусловленных ослаблением затяжки болтов его крепления. Указана необходимость совершенствования конструкции кожуха зубчатой передачи. Практическая значимость: Установлена вероятная причина образования повреждений КЗП в эксплуатации. Предложена методика оценки нагруженности КЗП в случае перераспределения нагрузок между его опорными точками.
\end{abstract}

Ключевые слова: Кожух зубчатой передачи, болтовое крепление, опорная реакция, нагруженность, перераспределение нагрузки.

\section{Введение}

Зубчатые колеса тягового редуктора электровозов с опорно-осевым подвешиванием тяговых двигателей заключены в кожух, который не является несущей конструкцией и выполняет функцию защиты зубчатой пары от внешних воздействий, а также служит резервуаром для хранения запаса смазки. В практике отечественного электровозостроения принято консольное (на- 
$a$

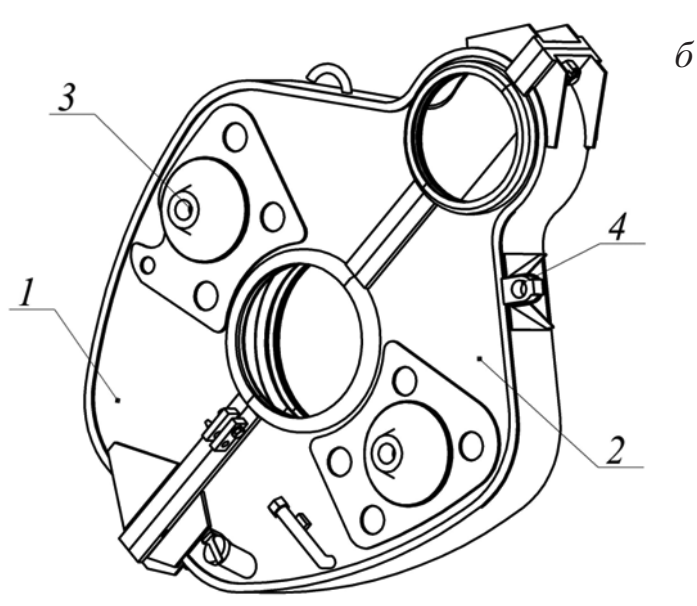

$\sigma$

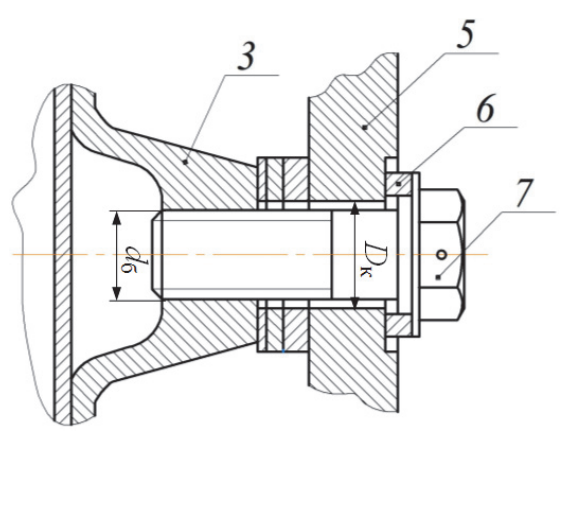

Рис. 1. Кожух зубчатой передачи $(a)$, эскиз болтового соединения бобышка-кронштейн тягового двигателя (б): 1 - верхняя разъемная часть; 2 - нижняя разъемная часть; 3 - бобышка; 4 - кронштейн кожуха; 5 - кронштейн двигателя; 6 - упругая шайба; 7 - болт

весное) крепление кожуха к тяговому двигателю в трех точках с помощью болтов, установленных со стороны боковины в бобышки и кронштейн (рис. 1). Применение такого способа крепления кожуха прежде всего продиктовано необходимостью соблюдения жестких габаритных ограничений, присущих тяговому приводу на электровозе, и обеспечивает более простую, компактную и удобную для сборки колесно-моторного блока конструкцию. В машиностроении консольные схемы соединения деталей являются вполне закономерным элементом конструирования и широко используются на практике, хотя и имеют ряд недостатков, которые частично или полностью можно устранить с помощью конструктивных методов [1]. Применение консольного (навесного) крепления кожуха передачи в колесномоторных блоках электровозов имеет существенный недостаток, заключающийся в том, что кожух крепится болтами, которые установлены с зазором в отверстиях кронштейнов двигателя и подвержены вибрационным нагрузкам, которые вызывают ослабление их затяжки в условиях эксплуатации [2-5]. Случай ослабления затяжки болта в одной из точек крепления кожуха зубчатой передачи (КЗП) может приводить к невосприятию этим болтовым креплением нагрузки, т. е. происходит выключение данной точки крепления из работы из-за наличия зазора между телом болта и краем отверстия в кронштейне двигателя. В таком случае связь может теряться полностью или становится неудерживающей. Вследствие этого происходит перераспределение воспринимаемой нагрузки на оставшиеся два болтовых крепления, что может вызвать существенное увеличение напряжений в области крепления конструкции вплоть до ее разрушения.

Ослабление соединения бобышка КЗП-кронштейн тягового двигателя может быть связано с осадкой сопрягаемых деталей, причем количество контактных поверхностей соединения может возрасти ввиду необходимости установки регулировочных шайб, количество которых, согласно конструкторской документации, не должно быть более трех единиц. Кроме того, соединение подвержено вибрационной нагрузке, что способствует процессу самоотвинчивания болтов крепления КЗП. Определим зазор между телом болта и посадочным отверстием в кронштейне:

$$
\delta=D_{\text {к }}-d_{\text {б }}
$$

где $\delta$ - зазор между телом болта и посадочным отверстием в кронштейне; $D_{\text {к }}=48^{+0,62}$ мм - диаметр посадочного отверстия в кронштейне; $d_{\sigma}=$ $=42^{+0,62} \mathrm{Mм}-$ диаметр болта. Таким образом, максимальный зазор $\delta$ с учетом допусков составит 
6,62 мм. Сила трения, возникающая в стыке деталей и препятствующая взаимному смещению деталей стыка, определяется по формуле

$$
F_{\text {тр }}=f_{\text {тр }} \cdot F_{3},
$$

в которой $F_{\text {тр }}$ - сила трения в стыке сопрягаемых деталей, $f_{\text {тр }}$ коэффициент трения стали о сталь; $F_{3}$ - усилие затяжки болта. Таким образом, воспринимаемая точкой крепления внешняя нагрузка, действующая в плоскости стыка, ограничивается величиной силы трения $F_{\text {тр }}$. Усилие затяжки болта можно рассчитать следующим образом [6]:

$$
F_{3}=\frac{M_{3}}{\left[0,5 \cdot d \cdot\left(\frac{p}{\pi d}+1,15 f\right)+f \cdot R_{\mathrm{Tp}}\right]} .
$$

Здесь $M_{\text {з }}$ - момент затяжки болта, $f$ - приведенный коэффициент трения, $p$ - шаг резьбы болта, $R_{\text {тр }}$ - радиус трения опорной поверхности головки болта, $d$ - диаметр стержня болта. Согласно технической документации [7], рекомендуемый момент затяжки болтов крепления КЗП должен находиться в пределах от 0,9 до 1 кН·м. Однако следует отметить отсутствие должного контроля момента затяжки болтов при производстве ремонта и технического обслуживания электровозов в условиях локомотивного депо.

Сформулируем необходимые и достаточные условия невосприятия нагрузки точкой опоры.

Достаточные условия:

1) ослабление затяжки болтового соединения;

2) раскрытие стыка соединения бобышкакронштейн тягового двигателя, т. е. появление зазора в стыке;

3) функция зазора $R(t)$ между телом болта и отверстием кронштейна тягового двигателя не равна нулю, $R(t)=z_{\text {к }}(t)-z_{\text {б}}(t)$, где $z_{\text {к }}(t)$ и $z_{\text {б}}(t)-$ координаты вертикального перемещения кронштейна и тела болта соответственно.

Необходимые условия:

1) сила трения в стыке соединения бобышкакронштейн двигателя незначительна или равна нулю;
2) опорная реакция болтового крепления равна нулю.

\section{Расчет вертикальных опорных реакций, возникающих в болтовых креплениях КЗП к тяговому двигателю}

Накопленный опыт проектирования корпусных конструкций рекомендует рациональные сечения для обеспечения наибольшей жесткости и прочности при наименьшей массе изделия. Такими свойствами обладают развитые по периферии полые тонкостенные детали типа коробок, труб и оболочек $[1,8]$. Кожух зубчатой передачи имеет коробчатое сечение, т. е. изготовлен согласно принятым канонам проектирования корпусных конструкций. Однако в напряженнодеформированном состоянии (НДС) деталей, как правило, есть локальные области, в которых значения уровня возникающего напряжения более высокие по сравнению с уровнями напряжения в основной конструкции. Такое явление появляется не только по причине наличия концентраторов напряжения, но и из-за количества и положения точек, где на конструкцию действуют реактивные усилия (рис. 2).

Для определения вертикальных реакций в принятой расчетной схеме на рис. 2 составим систему уравнений статического равновесия для полученной пространственной параллельной системы сил:

$$
\begin{gathered}
\sum F_{y i}=0, R_{I}+R_{I I}+R_{I I I}-G=0, \\
\sum M_{I}=0, \\
R_{I I}(a+b)+R_{I I I} \sqrt{e^{2}+c^{2}}- \\
-G \sqrt{b^{2}+(e+d)^{2}}=0, \\
\sum M_{I I}=0 \\
R_{I}(a+b)+R_{I I} \sqrt{e^{2}+(a+b+c)^{2}}- \\
-G \sqrt{a^{2}+(e+d)^{2}}=0
\end{gathered}
$$




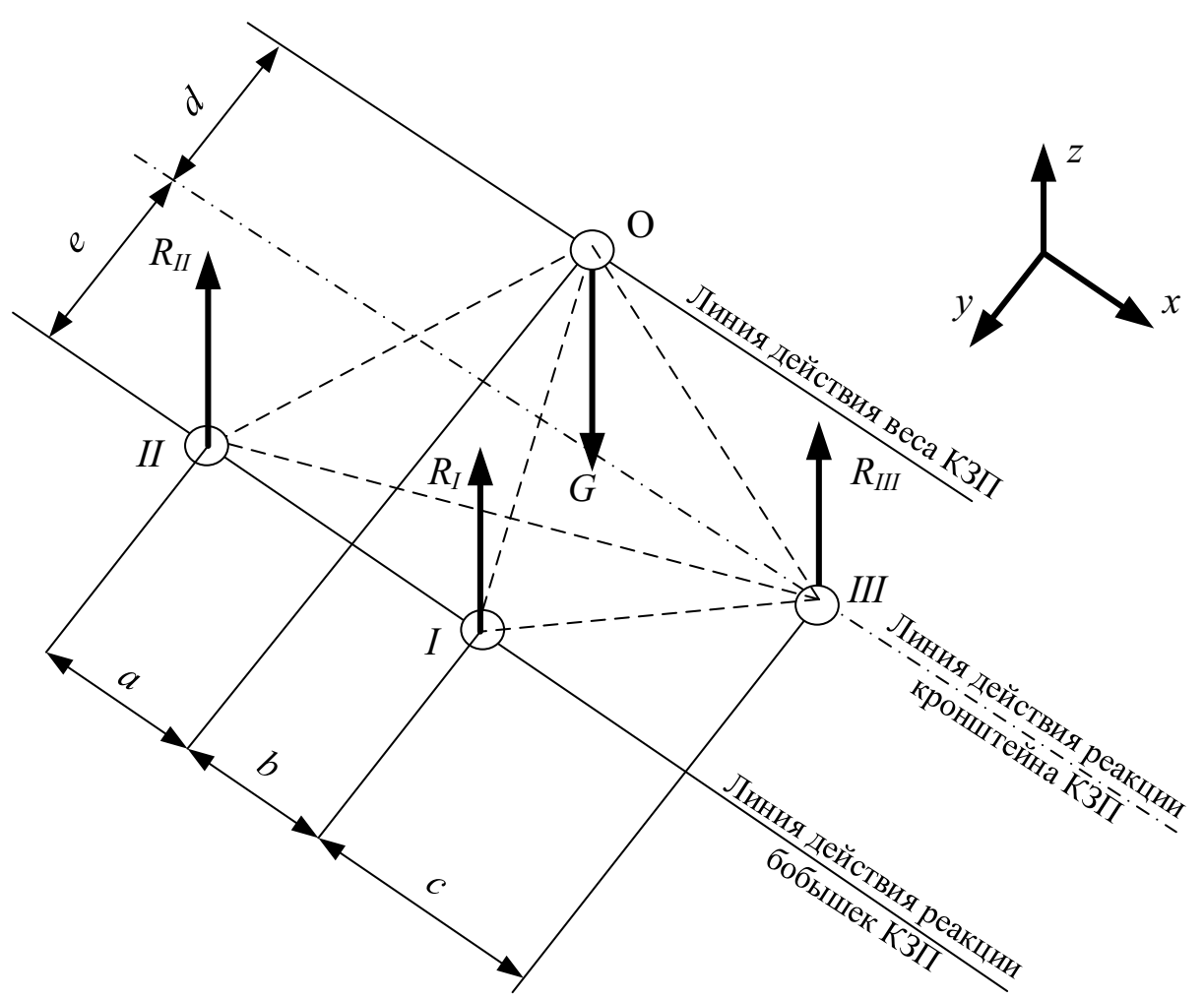

Рис. 2. Пространственная расчетная схема для определения вертикальных реакций в точках крепления КЗП:

I - нижняя бобышка; II - верхняя бобышка; III - кронштейн КЗП

где $a, b, c, e$ и $d$ - геометрические параметры, задающие положение точек крепления КЗП; $R_{l}$, $R_{I I}, R_{I I I}$ - вертикальные опорные реакции.
После преобразований для определения вертикальных реакций, действующих на конструкцию КЗП в случае восприятия нагрузки всеми тремя точками крепления, имеем

$$
\begin{gathered}
R_{I}=G\left(1-\frac{\sqrt{b^{2}+(e+d)^{2}}-\left(\frac{\left(\sqrt{b^{2}+(e+d)^{2}}+\sqrt{a^{2}+(e+d)^{2}}-a-b\right)}{\sqrt{e^{2}+(a+b+c)^{2}}+\sqrt{e^{2}+c^{2}}-a-b}\right) \sqrt{e^{2}+c^{2}}}{a+b}-\frac{\left(\sqrt{b^{2}+(e+d)^{2}}+\sqrt{a^{2}+(e+d)^{2}}-a-b\right)}{\sqrt{\mathrm{e}^{2}+(a+b+c)^{2}}+\sqrt{e^{2}+c^{2}}-a-b}\right), \\
R_{I I}=\frac{G \sqrt{b^{2}+(e+d)^{2}}-\left(\frac{\left(\sqrt{b^{2}+(e+d)^{2}}+\sqrt{a^{2}+(e+d)^{2}}-a-b\right) G}{\sqrt{e^{2}+(a+b+c)^{2}}+\sqrt{e^{2}+c^{2}}-a-b}\right) \sqrt{e^{2}+c^{2}}}{a+b}- \\
R_{I I I}=\frac{\left(\sqrt{b^{2}+(e+d)^{2}}+\sqrt{a^{2}+(e+d)^{2}}-a-b\right) G}{\sqrt{e^{2}+(a+b+c)^{2}}+\sqrt{e^{2}+c^{2}}-a-b .} .
\end{gathered}
$$


Рассмотрим случай закрепления КЗП, когда $R_{I I}=0$. В этом случае система уравнений статического равновесия (1) примет вид

$$
\begin{gathered}
R_{I}+R_{I I I}-G=0, \\
R_{I I I} \sqrt{e^{2}+c^{2}}-G \sqrt{b^{2}+(e+d)^{2}}=0 .
\end{gathered}
$$

Выражения для определения возникающих в таком случае вертикальных реакций запишем следующим образом:

$$
\begin{gathered}
R_{I}=G\left(1-\frac{\sqrt{b^{2}+(e+d)^{2}}}{\sqrt{e^{2}+c^{2}}}\right), \\
R_{I I I}=\frac{G \sqrt{b^{2}+(e+d)^{2}}}{\sqrt{e^{2}+c^{2}}} .
\end{gathered}
$$

Рассмотрим случай, когда $R_{I}=0$. Здесь система уравнений статического равновесия (1) примет вид

$$
\begin{gathered}
R_{I I}+R_{I I I}-G=0, \\
R_{I I I} \sqrt{e^{2}+(a+b+c)^{2}}- \\
-G \sqrt{a^{2}+(e+d)^{2}}=0 .
\end{gathered}
$$

Возникающие вертикальные реакции определим по формулам

$$
\begin{gathered}
R_{I I}=G\left(1-\frac{\sqrt{a^{2}+(e+d)^{2}}}{\sqrt{e^{2}+(a+b+c)^{2}}}\right), \\
R_{I I I}=\frac{G \sqrt{a^{2}+(e+d)^{2}}}{\sqrt{e^{2}+(a+b+c)^{2}}} .
\end{gathered}
$$

Рассмотрим случай, когда точка крепления III кронштейн КЗП-подшипниковый щит тягового двигателя перестанет воспринимать нагрузку, т. е. $R_{I I I}=0$. В этом случае система уравнений статического равновесия (1) будет такой:

$$
R_{I}+R_{I I}-G=0,
$$

$$
R_{I}(a+b)-G \sqrt{a^{2}+(e+d)^{2}}=0 .
$$

Выражения для определения возникающих в этом случае вертикальных реакций примут вид

$$
\begin{gathered}
R_{I}=\frac{G \sqrt{a^{2}+(e+d)^{2}}}{a+b}, \\
R_{I I}=G\left(1-\frac{\sqrt{a^{2}+(e+d)^{2}}}{a+b}\right) .
\end{gathered}
$$

Рассмотрим случай, когда точки крепления нижняя и верхняя бобышки КЗП-кронштейн тягового двигателя перестанут воспринимать нагрузку, т. е. $R_{I}=0$ и $R_{I I}=0$. В этом случае получим уравнение

$$
R_{I I I}=G
$$

Рассмотрим случай, когда нагрузку воспринимает точка крепления верхней бобышки КЗП, т.е. $R_{I}=0$ и $R_{I I I}=0$. В таком случае имеем уравнение

$$
R_{I I}=G
$$

Используя выражения (1)-(13) выполним расчет опорных реакций болтовых креплений КЗП при разных случаях его закрепления и представим его результаты:

$R_{P}$

$\begin{array}{lllllll}\text { кH... } & 0 & 0,772 & 1,172 & 0 & 0 & 0,687\end{array}$

$R_{I I}$,

$\begin{array}{llllllll}\text { кН... } & 0,966 & 0 & 0,337 & 0 & & 1,510 & 0,597\end{array}$

$R_{\text {III }}$,

$\begin{array}{lllllll}\text { кН... } & 0,543 & 0,737 & 0 & 1,510 & 0 & 0,225\end{array}$

\section{Методика оценки пробега КЗП в условиях перераспределения нагрузки в случае ослабления затяжки болтов его крепления}

При непрерывном мониторинге технического состояния можно своевременно обнаружить 
появившиеся нарушения в работе оборудования, однако такой процесс дорогостоящий и не всегда целесообразен $[9,10]$. Оценка пробега (наработки) с определенным значением нагруженности позволяет более точно оценить ресурс КЗП. Примем, что в интервале времени $t_{i}$ для выборки из $N_{i}$ кожухов будет выявлено $n_{i}$ кожухов с ослаблением болтов крепления. Тогда для определения вероятности ослабления болтов в рассматриваемом интервале наработки $t_{i}$ можно записать выражение

$$
P\left(t_{i}\right)=\frac{n_{i}}{N_{i}} .
$$

С учетом этого суммарный пробег КЗП с повышенными нагрузками в интервале времени $t_{i}$ составит

$$
\sum l_{i}=P\left(t_{i}\right) k \sum L_{i}=\frac{n_{i}}{N_{i}} k \sum L_{i},
$$

где $\sum l_{i}$ - суммарный пробег КЗП с повышенными нагрузками; $\sum L_{i}-$ суммарный пробег локомотивов в интервале времени $t ; k$ - количество КЗП на одном локомотиве.

Рассчитаем средний пробег, с повышенными нагрузками приходящийся на один КЗП выборки:

$$
L_{\mathrm{cp}}=\frac{\sum l_{i}}{\sum N_{i}}=P\left(t_{i}\right) k \frac{\sum L_{i}}{\sum N_{i}}=\frac{n_{i}}{N_{i}} k \frac{\sum L_{i}}{\sum N_{i}} .
$$

\section{Численное исследование \\ НДС КЗП в случае его статического нагружения}

Для численного исследования НДС КЗП была разработана твердотельная модель в программном комплексе ANSYS. Напряженное состояние кожуха оценивалось в условиях статического нагружения модели кожуха собственным весом при описанных выше условиях его закрепления (рис. 3).

В результате проведенного численного исследования НДС КЗП были получены поля распре- деления эквивалентных напряжений. Для всех случаев нагружения характерна локализация возникновения напряжений в области болтовых креплений. При штатном закреплении КЗП максимальное напряжение появляется в области кронштейна кожуха и составляет 1,53 МПа. Наиболее неблагоприятный из остальных рассматриваемых случаев нагружения КЗП - восприятие нагрузки только одним кронштейном КЗП, для которого максимальное напряжение равно 44,3 МПа. Максимальные эквивалентные напряжения, возникающие для каждого расчетного случая нагружения, будут следующими (рис. 3):

Случай

нагруже-

$\begin{array}{lllllll}\text { ния... } & a & \sigma & 6 & 2 & \partial & e\end{array}$

Уровень

напря-

жения $\sigma$,

$\begin{array}{lllllll}\text { МПа... } & 1,53 & 1,74 & 6,03 & 44,3 & 5,09 & 5,46\end{array}$

В случаях закрепления, где имеется кронштейн кожуха, область проявления максимальных эквивалентных напряжений в стенке кожуха находится в непосредственной близости к кронштейну.

\section{Заключение}

Проведенный анализ величин опорных реакций болтовых креплений КЗП показал, что при условии невосприятия нагрузки одним из болтовых креплений происходит перераспределение численных значений опорных реакций и соответственно полей эквивалентных напряжений, возникающих в конструкции КЗП.

По результатам анализа нагруженности КЗП для всех рассматриваемых случаев закрепления кожуха наиболее нагруженной является область стенки, находящаяся в непосредственной близости с кронштейном кожуха. Данное обстоятельство подтверждается наиболее частым выявлением повреждений для кожуха именно в этой области стенки.

Таким образом, для обеспечения надежности восприятия нагрузок болтовыми крепления- 
A: Static Structural

Equivalent Stress

Type: Equivalent (von-Mises) Stress

Unit: $\mathrm{Pa}$

Time: 1

$1,5378 \mathrm{eg} \mathrm{Max}$

$1,428 \mathrm{e} 6$

$1,3182 \mathrm{e} 6$

$1,2084 \mathrm{e} 6$

1,0985 e

$9,8871 \mathrm{e} 5$

$8,7889 \mathrm{e} 5$

$7,6907 \mathrm{e} 5$

$6.5925 \mathrm{e} 5$

$5,4943 \mathrm{e} 5$

$4,3961 \mathrm{e} 5$

$3,2978 \mathrm{e} 5$

$2,1996 \mathrm{e} 5$

$1,1014 \mathrm{e} 5$

$318,82 \mathrm{Min}$


B

\section{A: Static Structural}

Equivalent Stress

Type: Equivalent (von-Mises) Stress

Unit: $\mathrm{Pa}$

Time: 1

6.0366e6 Max

$5,6055 e 6$

$5,1744 e 6$

$4,7433 \mathrm{e} 6$

$4,3122 \mathrm{e} 6$

$3,8811 \mathrm{e} 6$

$3,45 \mathrm{e} 6$

$3,0189 \mathrm{e} 6$

$2,5878 \mathrm{e}$

$2,1567 \mathrm{e} 6$

$1,7256 \mathrm{e} 6$

1,2945 e6

$8,6339 \mathrm{e} 5$

4,3229e5

1187.9 Min



$\partial$

A: Static Structural

Equivalent Stress

Type: Equivalent (von-Mises) Stress

Unit: $\mathrm{Pa}$

Time: 1


$\sigma$

A: Static Structural

Equivalent Stres

Type: Equivalent (von-Mises) Stress

Unit: $\mathrm{Pa}$

Time: 1


Equivalent Stress

Type: Equivalent (von-Mises) Stress

Unit: $\mathrm{Pa}$

Time: 1


\section{A: Static Structura}

Equivalent Stress

Type: Equivalent (von-Mises) Stress

Unit: $\mathrm{Pa}$

Time: 1

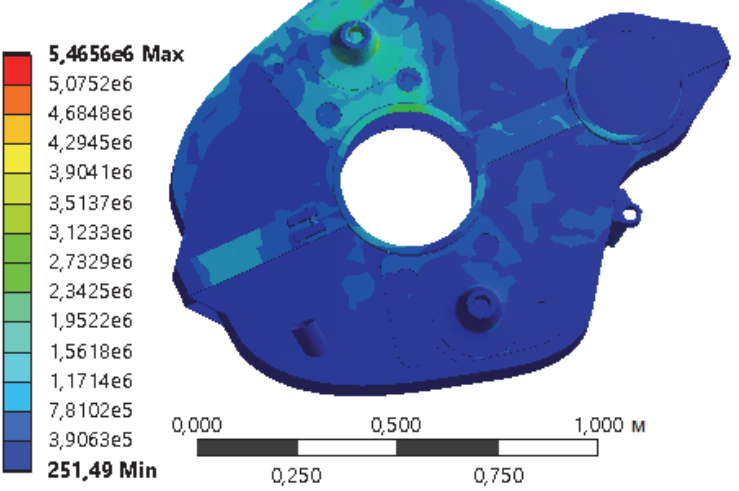

Рис. 3. Определение напряженного состояния конструкции КЗП

при различных условиях его закрепления:

$a$ - штатное закрепление всеми болтовыми креплениями; воспринимают нагрузку:

$\sigma$ - верхняя и нижняя бобышки, 8 - нижняя бобышка и кронштейн, 2 - только кронштейн

кожуха, $\partial-$ верхняя бобышка и кронштейн, $e$ - верхняя бобышка 
ми КЗП в случае ослабления затяжки одного из болтов, которое может произойти с вероятностью $P(L)$, и во избежание при этом возникновения опасных (высоких) уровней напряжения необходимо увеличение количества точек крепления кожуха. Это может привести к некоторым конструктивным ограничениям со стороны колесно-моторного блока, однако возможность увеличить закрепление КЗП до четырех точек существует.

\section{Библиографический список}

1. Орлов П.И. Основы конструирования : справ.метод. пособие : в 3 кн.- Кн. 1. - Изд. 2-е, перераб. и доп. / П. И. Орлов. - М. : Машиностроение, 1977.$623 \mathrm{c}$.

2. Москвичев В.В. Проблемы кожухов зубчатой передачи электровозов : отказы, нагруженность, виброзащита / В. В. Москвичев, Е. А. Чабан, А.Г. Андриевский // Современные технологии. Системный анализ. Моделирование.- 2020.- Т. 65.- № 1.- С. 3142.

3. Андриевский А.Г. Анализ конструктивных решений, принятых для кожухов зубчатой передачи электровозов серии ВЛ80 и 2ЭС5К / А.Г. Андриевский, Е. А. Чабан // Технологическое обеспечение ремонта и повышение динамических качеств железнодорожного подвижного состава : Материалы V Bсерос. науч.-технич. конференции с международным участием.-Омск : Омск. гос. ун-т путей сообщения, 2019.C. $50-57$.

4. Пахомов М.П. Предупреждение неисправностей кожухов зубчатой передачи электровозов / М.П. Пахомов, В. П. Богданов, И. И. Галиев, Г. А. Чистяков // Же- лезнодорожный транспорт. - 1971. - № 11.- С. 4344.

5. Школьный М. И. Кожухи зубчатых передач. Проблемы и альтернативные конструкции / М. И. Школьный, Г. Г. Ахмедов, И. П. Демченко // Вестн. Всерос. науч.-исслед. и проект.-конструкт. ин-та электровозостроения. - 2017. - № 2 (76). - С. 43-51.

6. Биргер И. А. Резьбовые и фланцевые соединения / И. А. Биргер, Г. Б. Иосилевич. - М. : Машиностроение, 1990.-368 с.

7. Электровоз ВЛ 85 : руководство по эксплуатации. - Всесоюз. науч.-исслед., проект.-конструкт. и технол. ин-т электровозостроения ; Новочеркаск. электровозостроит. завод.- М. : Транспорт, 1992.- 479 с.

8. Иосилевич Г.Б. Детали машин : учебник для машиностроит. специальностей вузов / Г.Б. Иосилевич.- М. : Машиностроение, 1988.- 366 с.

9. Галкин В. Г. Надежность тягового подвижного состава : учеб. пособие для вузов ж.-д. транспорта / В. Г. Галкин, В.П. Парамзин, В. А Четвергов.-М. : Транспорт, 1981.- 184 с.

10. Швалов Д. В. Системы диагностики подвижного состава : учебник / Д. В. Швалов, В. В. Шаповалов ; под ред. Д. В. Швалова. - М. : Изд-во «Лань», 2005.268 c. - URL : https://e.lanbook.com/book/59148 (дата обращения : 02.12.2020).

Дата поступления: 03.03.2021

Решение о публикации: 24.03.2021

\section{Контактная информация:}

АНДРИЕВСКИЙ Анатолий Геннадьевич - преподаватель; Andrievs1@yandex.ru

ЧАБАН Елена Анатольевна - канд. техн. наук, доц.; chaban_tm@mail.ru

МОСКВИЧЕВ Владимир Викторович - д-р техн. наук, проф.; krasn@ict.nsc.ru 


\title{
Analysis of the loading of the gear casing of an electric locomotive provided that the bolts fastening it to traction motor are loosened
}

\author{
A. G. Andrievsky ${ }^{1}$, E. A. Chaban ${ }^{1}$, V. V. Moskvichev ${ }^{2}$ \\ ${ }^{1}$ Krasnoyarsk Institute of Rail Transport, branch of the Irkutsk State Transport University, 2I, Novoy \\ Zari ul., Krasnoyarsk, 660028, Russian Federation \\ ${ }^{2}$ Krasnoyarsk branch of the Federal Research Center for Information and Computational \\ Technologies, Russian Academy of Sciences, 53, Mira pr., Krasnoyarsk, 660049, Russian Federation
}

For citation: Andrievsky A. G., Chaban E.A., Moskvichev V.V. Analysis of the loading of the gear casing of an electric locomotive provided that the bolts fastening it to traction motor are loosened. Proceedings of Petersburg Transport University. Saint Petersburg, Petersburg State Transport University, 2021, vol. 18, iss. 2, pp. 201-210. (In Russian) DOI: 10.20295/1815-588X-2021-2-201-210

\section{Summary}

Objective: To study the dependence of the numerical values of the bearing reactions occurring in the bolted fasteners of the gear casing $(\mathrm{GC})$ on the conditions of its fastening to the traction motor. To show the resulting redistribution of the bearing reaction values in the case of the lack of load bearing in one or two bolted fasteners from the three existing design ones. To calculate the equivalent stresses that appear in the gear casing structure under various abnormal conditions of its fastening to the traction motor under static loading. Methods: The equations of statics were used for the spatial system of forces, including three vertical bearing reactions and the weight of the casing itself. To study the stress-strain state of the casing in the case of its static loading, the finite element method was used, implemented in the ANSYS Workbench software package. Results: The cause of damage to the GC during operation has been found associated with its design flaws. Calculation formulas have been obtained for determining the vertical bearing reactions of the GC. The need to take into account the GC loading in the case of redistribution of loads due to the loosening of its fastening bolts has been found. The need to improve the design of the gear casing has been indicated. Practical importance: The probable cause of damage to the GC during operation has been found. A method is proposed for assessing the GC loading in the case of redistribution of loads between its bearing points.

Keywords: Gear casing, bolted fastener, bearing reaction, loading, load redistribution.

\section{References}

1. Orlov P.I. Osnovy konstruirovaniya. Sprav.-metod. posobiye. V $3 \mathrm{kn}$. [Basics of design. Reference and methodological manual. In 3 books], Book 1, Ed. 2, revised and amended. Moscow, Mashinostroyeniye Publ., 1977, 623 p. (In Russian)

2. Moskvichev V.V., Chaban E.A. \& Andrievsky A.G. Problemy kozhukhov zubchatoy peredachi elektrovozov: otkazy, nagruzhennost', vibrozashchita [Problems of gear casings of electric locomotives: failures, loading, vibration protection]. Sovremennyye tekhnologii. Sistemnyy analiz. Modelirovaniye [Modern technologies. System analysis. Modeling], 2020, vol. 65, no. 1, pp. 31-42. (In Russian)

3. Andrievsky A. G. \& Chaban E. A. Analiz konstruktivnykh resheniy, prinyatykh dlya kozhukhov zubchatoy peredachi elektrovozov serii VL80 i 2ES5K [Analysis of design solutions adopted for gear casings of electric locomotives of the VL80 and 2ES5K series]. Tekhnologicheskoye obespecheniye remonta i povysheniye dinamicheskikh kachestv zheleznodorozhnogo podvizhnogo sostava. Materialy V Vseros. nauch.-tekhnich. konferentsii s mezhdunarodnym uchastiyem [Engineering support for repairs and improving the dynamic properties of the railway rolling stock. Proceedings of the V All-Russia 
Scientific and Technical Conference with International Participation]. Omsk, Omsk State Transport University Publ., 2019, pp. 50-57. (In Russian)

4. Pakhomov M.P., Bogdanov V.P., Galiev I. I. \& Chistyakov G.A. Preduprezhdeniye neispravnostey kozhukhov zubchatoy peredachi elektrovozov [Prevention of malfunctions of gear casings of electric locomotives]. Zheleznodorozhnyy transport [The Railway Transport Magazine], 1971, no. 11, pp. 43-44. (In Russian)

5. Shkol'nyy M. I., Akhmedov G. G. \& Demchenko I.P. Kozhukhi zubchatykh peredach. Problemy i al'ternativnyye konstruktsii [Gear casings. Problems and alternative designs]. Proceedings of the All-Russian Scientific Research and Design Institute of Electric Locomotive Engineering, 2017, no. 2 (76), pp. 43-51. (In Russian)

6. Birger I.A. \& Iosilevich G. B. Rez'bovyye i flantsevyye soyedineniya [Threaded and flange connections]. Moscow, Mashinostroyeniye Publ., 1990, 368 p. (In Russian)

7. Elektrovoz VL85. Rukovodstvo po ekspluatatsii [Electric locomotive VL85. Operation manual]. All-Union Scientific Research, Design and Technological Institute of Electric Locomotive Engineering; Novocherkassk Electric Locomotive Plant. Moscow, Transport Publ., 1992, 479 p. (In Russian)
8. Iosilevich G. B. Detali mashin. Uchebnik dlya mashinostroit. spetsial'nostey vuzov [Machine parts. A textbook for mechanical engineering specialties of universities]. Moscow, Mashinostroyeniye Publ., 1988, 366 p. (In Russian)

9. Galkin V. G., Paramzin V.P. \& Chetvergov V.A. Nadezhnost'tyagovogo podvizhnogo sostava. Ucheb. posobiye dlya vuzov zh.-d. transporta [Reliability of traction rolling stock. Training manual for railway transport universities]. Moscow, Transport Publ., 1981, 184 p. (In Russian)

10. Shvalov D. V. \& Shapovalov V.V. Sistemy diagnostiki podvizhnogo sostava. Uchebnik [Diagnostic systems of rolling stock. Textbook]. Ed. by D. V. Shvalov. Moscow, Lan' Publishing House, 2005, 268 p. Available at: https://e.lanbook.com/book/59148 (accessed: December 02, 2020). (In Russian)

Received: March 03, 2021

Accepted: March 24, 2021

\section{Author's information:}

Anatoly G. ANDRIEVSKY - Lecturer; Andrievs1@yandex.ru

Elena A. CHABAN - PhD in Engineering, Associate Professor; chaban_tm@mail.ru

Vladimir V. MOSKVICHEV - Dr. Sci. in Engineering, Professor; krasn@ict.nsc.ru 
УДК 528.48

\title{
Сравнительная оценка мобильного лазерного сканирования, аэрофотосъемки с беспилотной авиационной системы и съемки с комплексной дорожной лаборатории при выполнении диагностики автомобильных дорог
}

\author{
М. Я. Брынь ${ }^{1}$, Д. Р. Баширова ${ }^{1}$, А. Г. Багишян ${ }^{2}$ \\ ${ }^{1}$ Петербургский государственный университет путей сообщения Императора Александра I, \\ Российская Федерация, 190031, Санкт-Петербург, Московский пр., 9 \\ 2 ООО «Мосты и инженерные проекты», Российская Федерация, 197101, Санкт-Петербург, \\ Монетная ул., 16, лит. В
}

Для цитирования: Брынь М.Я., Баширова Д.Р., Багишян А.Г. Сравнительная оценка мобильного лазерного сканирования, аэрофотосъемки с беспилотной авиационной системы и съемки с комплексной дорожной лаборатории при выполнении диагностики автомобильных дорог // Известия Петербургского университета путей сообщения.- СПб.: ПГУПС, 2021.- Т. 18. - Вып. 2.- С. 211221. DOI: $10.20295 / 1815-588 X-2021-2-211-221$

\section{Аннотация}

Цель: Сравнить возможности применения мобильного лазерного сканирования (МЛС), аэрофотосъемки (АФС) с беспилотной авиационной системы (БАС) и съемки с комплексной дорожной лаборатории при выполнении диагностики автомобильных дорог. Методы: Для анализа был выбран участок региональной автомобильной дороги Курской области, на котором проводилась съемка с использованием рассмотренных методов. Для решения поставленной цели были выделены основные характеристики, определяемые при выполнении диагностики, получены их значения на основе данных комплексной дорожной лаборатории, аэрофотосъемки с БАС, а также МЛС и оценена точность полученных результатов, соответствие данных требованиям нормативных документов. Результаты: На основании выполненных работ сделаны следующие выводы: определение выделенных параметров диагностики по методам МЛС и АФС с БАС является корректным, аэрофотосъемка с БАС по цене оборудования, стоимости съемки наиболее выгодна при составлении топографических планов автодорог. Отмечено, что по точности метод АФС соответствуют требованиям, предъявляемым к планам масштаба 1:500, МЛС - 1:1000. Практическая значимость: Не все показатели, требуемые при проведении диагностики, могут быть получены при АФС с БАС и МЛС, так как требуют специализированного оборудования и непосредственного взаимодействия с дорожным покрытием, однако спектр применения выделенных методов может быть существенно расширен. Такой показатель как коэффициент сцепления измеряется с помощью комплексной передвижной дорожной лаборатории, поэтому отказаться от нее нецелесообразно. Отмечено, что комплектация лаборатории в зависимости от стоимости может быть разной.

Ключевые слова: Диагностика автомобильных дорог, комплексная передвижная дорожная лаборатория, аэрофотосъемка, беспилотная авиационная система, ортофотоплан, топографический план, мобильное лазерное сканирование, мобильный лазерный сканер, экспериментальный участок автомобильной дороги.

\section{Введение}

В Российской Федерации на 2019 г. протяженность автомобильных дорог общего пользования составляла 1542,2 тыс. км [1] и с каждым годом она растет. Отметим, что безопасная эксплуатация автомобильных дорог предполагает проведение контроля и разного вида ремонтов [2-7]. 
В связи с этим важно своевременно осуществлять работы по диагностике автомобильных дорог, которые являются неотъемлемой частью контроля их состояния. Цель проведения диагностики - получение полной и актуальной информации о транспортно-эксплуатационном состоянии дорог, на основе которой принимаются решения о планировании ремонтов. Подчеркнем, что диагностика автомобильных дорог проводится на основании отраслевого методического документа (ОДМ) [8], согласно которому выделяются следующие виды диагностики:

- полная (проводится с целью определения фактического технического уровня и эксплуатационного состояния);

- приемочная (выполняется при сдаче автомобильной дороги);

- плановая (осуществляется при определении показателей эксплуатационного состояния с заданной периодичностью);

- специализированная (проводится при планировании реконструкции и капитального ремонта).

Отметим, что материалами специализированной диагностики являются: видеоряд с метрической калибровкой, ортофотопланы автомобильной дороги и придорожной полосы, цифровые модели рельефа (ЦМР), цифровые модели местности (ЦММ) придорожной полосы.
Информация, собираемая в ходе проведения работ по диагностике автомобильных дорог, может быть получена как из внешних источников, например, технических паспортов, баз дорожных данных, так и при выполнении полевых работ. Основными получаемыми данными являются: общие данные по дороге, геометрические параметры и характеристики, характеристики дорожной одежды и покрытия, информация об искусственных дорожных сооружениях, обустройстве автомобильных дорог, защитных сооружениях, объектах придорожного сервиса, объектах дорожной службы, данные о дорожнотранспортных происшествиях.

Выделим основные параметры, получаемые при диагностике автомобильной дороги, и соотнесем их с требуемой точностью определения (табл. 1) [8].

В настоящее время в автодорожной отрасли для решения различных задач, в том числе проведения диагностики, все чаще используются высокопроизводительные системы, например мобильные лазерные сканеры, комплексные дорожные лаборатории, беспилотные авиационные системы, позволяющие не только значительно уменьшить влияние человеческого фактора в процессе сбора данных, но и существенно повысить безопасность проведения съемочных работ [2-7].

ТАБЛИЦА 1. Оцениваемые параметры и точность их определения

\begin{tabular}{|l|c|}
\hline \multicolumn{1}{|c|}{ Оцениваемый параметр } & Требования к точности \\
\hline Ширина проезжей части & 0,1 м [9] \\
\hline Ось дороги & $\begin{array}{c}\text { Точность измерений должна соответствовать } \\
\text { точности, предъявляемой к топографическим } \\
\text { планам масштаба 1:2000 [9] }\end{array}$ \\
\hline Координаты километровых столбов & 1 м в плане [8] \\
\hline Угол поворота трассы & $0,4^{\circ}[9]$ \\
\hline $\begin{array}{l}\text { Продольный и поперечный уклоны } \\
\text { проезжей части }\end{array}$ & $2 \%$ [9] \\
\hline Пройденный путь & $0,05 \%$ [8] \\
\hline Расстояние видимости & $5 \%[10]$ \\
\hline Глубина колеи & 1 мм [11] \\
\hline Координаты инженерного обустройства & 1 м [8] \\
\hline
\end{tabular}


Цель статьи - проведение сравнительной оценки систем мобильного лазерного сканирования (МЛС), аэрофотосъемки (АФС) с беспилотной авиационной системы (БАС) [12] и съемки с помощью комплексной дорожной лаборатории для получения основных характеристик автомобильных дорог, а также оценка степени пригодности и соответствия данных требованиям нормативных документов. Для решения поставленной цели предлагается выделить основные характеристики, определяемые при выполнении диагностики, получить их значения на основе данных комплексной дорожной лаборатории, аэрофотосъемки с БАС, а также МЛС и оценить точность результатов.

\section{Участок работ}

Для анализа был отобран участок региональной автомобильной дороги Курской области Фатеж-Дмитриев 41+500-45+100 км, который относился к 5-й категории автомобильных дорог [13]. Отметим, что этот участок был обеспечен контрольными точками, координаты которых были определены с помощью ГНССприемников в кинематическом режиме.

\section{Съемка с передвижной дорожной лаборатории}

На исследуемом участке выполнялась съемка с помощью комплексной передвижной дорожной лаборатории на основе измерительного комплекса КП-514 РДТ «RDT line» на базе автомобиля Renault Duster (рис. 1).

В состав комплекса входили следующие измерительные системы:

1) система измерения геометрических параметров (компактная инерциально-спутниковая навигационная система);

2) система определения продольной ровности по международному показателю IRI (International Roughness Index);



Рис. 1. Передвижная дорожная лаборатория на базе Renault Duster

3) система измерения коэффициента сцепления покрытий (ПКРС-2 РДТ);

4) система видеосъемки.

Система определения геометрических параметров дает возможность установить параметры плана (радиусы горизонтальных кривых, углы поворота), параметры продольного и поперечного профилей, расстояние видимости до встречного автомобиля и препятствия. Отметим, что интервал записи данных составлял 1 м, а скорость движения дорожной лаборатории не превышала 50 км/ч.

Система измерения продольной ровности обладала следующими техническими характеристиками: шаг измерения неровностей $-0,125$ и 0,25 м, диапазон измерения продольной ровности - 1-10 мм/м, погрешность измерения продольной ровности $-5 \%$.

Система видеосъемки позволяла получать кадры с геодезическими координатами, также осуществлялась привязка к объектам и дате проведения съемки. Купольная видеокамера располагалась в передней части автомобиля. Отметим, что используемая камера была откалибрована, поэтому по данным видеосъемки было возможно выполнять ряд линейных измерений.

Приведем основные погрешности систем измерений комплекса КП-514 РДТ [14]:

Относительная погрешность пройденного расстояния . . . . . . . . 0,08\% 
Средняя квадратическая

ошибка (СКО) определения

продольного уклона . . . . . . . . . . . . . . . 1,5\% \%

СКО определения

поперечного уклона . . . . . . . . . . . . . . 2,1\%o

Относительная погрешность

определения ровности . . . . . . . . . . 4,6\%

Траектория движения дорожной лаборатории вычислялась в автономном режиме с помощью ГНСС-оборудования, базовые станции не требовались.

\section{Аэрофотосъемка с БАС}

Для проведения аэрофотосъемочных работ был задействован БАС Геоскан-201 Геодезия (рис. 2). В комплектацию входили: фотокамеpa Sony RXIR, двухчастотный бортовой ГНCCприемник Topcon, аккумуляторная батарея, раскладная подставка для сборки, транспортировочный кейс.

Представим основные технические характеристики Геоскан 201:

Максимальная протяженность маршрута.................. . 210 км

Максимальная масса полезной нагрузки . . . . . . . . . . . . . . . . 1,5 кг Продолжительность полета. . . . . . . . . . До До 3 ч Скорость полета . . . . . . . . . . . . 64-130 км/ч Минимальная безопасная высота полета . . . . . . . . . . . . . . . . . . . . . . 100 м Максимальная высота полета . . . . . . . . 4000 м
Перечислим характеристики установленной на БАС фотокамеры Sony RXIR:

Фокусное расстояние, $f$. . . . . . . . . 35 мм Продольный размер, $l_{x}$, светочувствительной матрицы . . . . . 4000 пкс Поперечный размер, $l$, светочувствительной матрицы . . . . . 6000 пкс Физический размер пикселя . . . . . 0,0060 мм Тип затвора . . . . . . . . . . . . Центральный Объектив . . . . . . . . . CarlZeiss Vario Sonnar T

Отметим, что в настоящее время стоимость комплекса Геоскан 201 Геодезия составляет свыше 2 млн руб. [15].

Обратим внимание на то, что параметры аэрофотосъемки считались с учетом выполнения полёта при условии захвата всей протяженности дороги и полосы отвода, а в процесс обработки результатов был включен только предложенный участок.

Авторами были рассчитаны параметры АФС (табл. 2), при этом значение GSD (Ground sample distance - размер пиксела на местности) принималось равным 2,6 см/пкс, что не превышало значение предельной графической точности $(0,1$ мм) для создания топографического плана масштаба 1:500. Длина маршрута $L$ составляла 34,2 км (1 пролёт), крейсерская скорость БАС $-V=80$ км/ч. Фокусное расстояние, продольный и поперечный размеры матрицы указаны в табл. 2.

Отметим, что все рассчитанные параметры АФС соответствуют вычисленным в ПО Geoscan Planner, в котором также было составлено

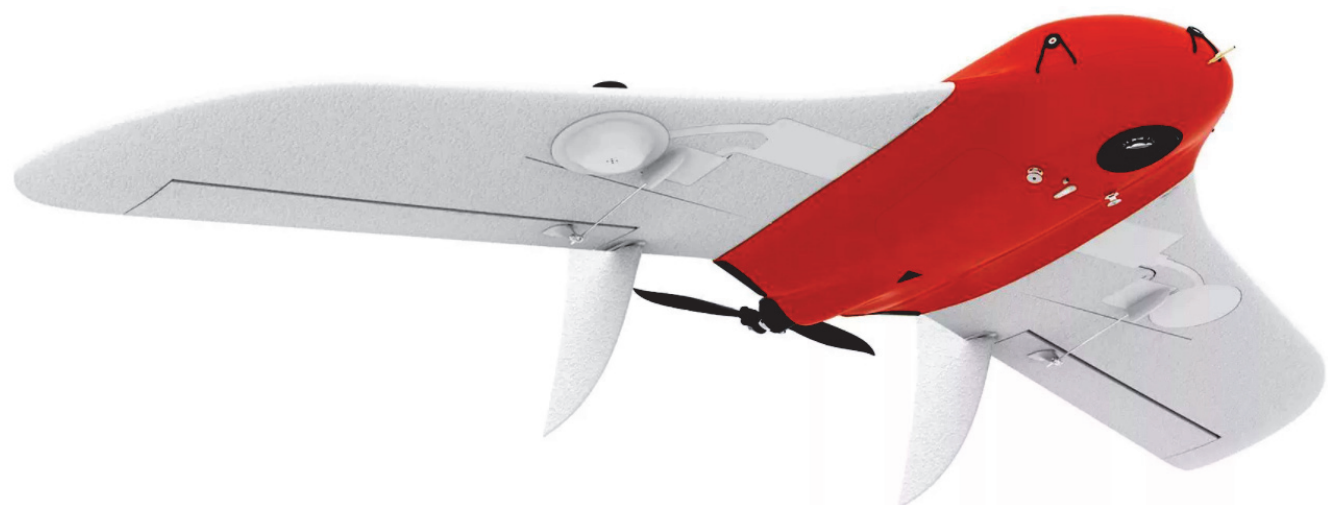

Рис. 2. Беспилотный летательный аппарат Геоскан 201 
ТАБЛИЦА 2. Расчет параметров аэрофотосъемки

\begin{tabular}{|l|c|c|}
\hline \multicolumn{1}{|c|}{ Параметры } & Формула & Значение \\
\hline Высота фотографирования $H(f=5833$ пкс) & $H=f \cdot \mathrm{GSD}$ & 152 м \\
\hline $\begin{array}{l}\text { Время подъема и спуска } T_{\text {Пс }} \text { (скорость подъема } \\
\text { и спуска }-V_{\text {П }}=V_{\mathrm{C}}=4 \text { м/с) }\end{array}$ & $T_{\text {пс }} \frac{H}{V_{\text {П}}}+\frac{H}{V_{\mathrm{C}}}$ & 1,22 мин \\
\hline Заданное продольное перекрытие $P$ аэрофотоснимков & $P=70 \%$ & $70 \%$ \\
\hline Заданное поперечное перекрытие $Q$ аэрофотоснимков & $Q=50 \%$ & $50 \%$ \\
\hline Расстояние $D$ между маршрутами на местности, м & $D=\frac{100-Q}{100} \cdot l_{y} \cdot \mathrm{GSD}$ & 78 \\
\hline Количество $N$ пролетов & $N=2$ & 2 \\
\hline Базис $B$ фотографирования & $B=\frac{100-P}{100} \cdot l_{x} \cdot \mathrm{GSD}$ & $31 \mathrm{м}$ \\
\hline Количество снимков $n$ в маршруте & $n=\frac{L}{B}+3$ & 1107 \\
\hline Общее количество $\Sigma$ снимков & $\Sigma=N \cdot n$ & 2214 \\
\hline Продолжительность $T$ съемки участка & $T=\frac{L}{V}$ & 0,86 ч \\
\hline Интервал $t$ между экспозициями & $t=\frac{B}{V}$ & $1,40 \mathrm{c}$ \\
\hline $\begin{array}{l}\text { Предельно допустимая выдержка } \tau \text { при фотографировании } \\
\text { (величина допустимого смаза изображения } \delta=0,5 \text { пкс) }\end{array}$ & $\tau=\frac{\delta \cdot \mathrm{GSD}}{V}$ & $1 / 1780 \mathrm{c}-1$ \\
\hline
\end{tabular}

полётное задание и выполнялся контроль за выполнением полёта.

На первом этапе камеральной обработки было проведено уравнивание спутниковых измерений для получения высокоточных координат центров проектирования в программном обеспечении (ПО) Topcon Magnet Tools: выполнено уравнивание полётной базы относительно сети референцных станций EFT-CORS, затем уравнивались данные с мобильного ГНСС-приемника и выполнялась замена координат навигационного журнала на уравненные координаты, полученные в ПО Topcon Magnet Tools.

Далее выполнялась обработка в программном продукте Agisoft Metashape: определялись положение и ориентация камеры для каждого кадра, в результате чего построено разреженное облако точек, далее подгружено планово-высотное обоснование, затем выполнялось построение плотного облака точек, ЦМР, ортофотоплана. Подчеркнем, что пространственное разрешение ортофотоплана составило $2,7 \mathrm{~cm} /$ пкс, результат построения карты высот -9 cм/пкс. СКО определения планового положения объекта местности, посчитанного на основе контрольных точек, не превышали 5 см, СКО определения геодезических высот также были не более 5 см. Плотность полученного облака точек составила 0,136 точек/ $\mathrm{cm}^{2}$.

\section{Мобильное лазерное сканирование}

При выполнении сканирования участка автомобильной дороги использовалась система MЛC Topcon IP-S2 Compact, закрепленная на автомобиле Renault Duster. Основными элементами системы МЛС являлись: ГНСС-приемник, блок инерциальных измерений, панорамная цифровая камера, блок лазерных сканеров, одометры, блок управления. Блок инерциальных измерений позволял во время приостановки сигнала 
спутниковых приемников вычислять координаты транспортного средства. Панорамная камера Ladybug 3 способствовала получению цветных изображений высокого разрешения, а также применялась для выполнения RGB окрашивания облаков точек лазерных отражений, полученных в ходе сканирования. Блок лазерных сканеров включал в себя два сканера с углом обзора $180^{\circ}$, с помощью которых проводилась съемка по обе стороны относительно траектории движения системы, и один с углом обзора $90^{\circ}$. Установленные одометры служили для определения длины пути и скорости движения. Вся полученная информация объединялась в блоке управления. Приведем основные технические характеристики системы МЛС Topcon IP-S2:


один $\mathrm{SICK}^{\mathrm{TM}} \mathrm{LMS} 291-\mathrm{S} 14$

Дальность .................... 30 м

Точность определения

положения точки . . . . . . . . . . . . .45 мм Каналы. . . . . . . . . . . . . . . . . . . 40 каналов Частота передачи данных . . . . . . . . . 100 Гц Дополнительные функции. . . . . . . . . . Multipath Mitigation, Co-Op Tracking

Отметим, что примененная на контрольном участке модель МЛС в настоящее время снята с производства, сейчас стоимость оборудования оценивается в 9 млн руб.

При выполнении МЛС использовались две базовые станции ГНСС, которые располагались в начале и конце участка съемки, для этого был применен технологичный приемник Торcon Hipper V, имеющий при выполнении статических наблюдений точность 3,0 мм $+0,4 \mathrm{ppm}$ (в плане) и 5,0 мм+0,5ppm (по высоте) [16]. Станции были подключены к федеральной сети референцных станций EFT-CORS [17].

Для обработки данных МЛС было применено ПО Geoclean Workstation 4.1.8, а также Spatial Factory. В результате обработки было получено плотное облако точек лазерных отражений в системе координат (CK) WGS-84, затем был выполнен пересчет в CK UTM Zone 37N. Оценка точности измерений на контрольных точках проводилась в ПО КРЕДО ЗD СКАН. Плотность облака составила 120 точек/M² на дорожном покрытии. С помощью ПО также удалялись выпадающие точки ниже рельефа, использовались фильтр изолированных точек и адаптивное прореживание.

\section{Определение ширины проезжей части по результатам съемки с различной аппаратуры}

Проведем сравнение данных, полученных с помощью комплексной дорожной лаборатории, аэрофотосъемки с БАС и выполнении МЛС.

Отметим, что при применении автоматизированной дорожной лаборатории определение ширины проезжей части (ПЧ) производится по данным фото-, видеофиксации в ПО RDT-Line. Обратим внимание, что линейные измерения выполнялись на небольшом отдалении от камеры, для того чтобы минимизировать искажения.

Затем определялась ширина ПЧ по данным аэрофотосъемки в программном продукте ArcGIS 10.2.2. Отметим, что при использовании ортофотоплана определение ширины ПЧ на диагностируемом участке автомобильной дороги происходит быстрее, так как пользователь может оперативно перемещаться по маршруту, а не только с заданной скоростью просмотра видеоданных, что, несомненно, является преимуществом применения данных АФС.

Для измерения ширины проезжей части по МЛС было решено использовать растр, построенный по данным сканирования. В ПО ArcGIS 10.2.2 на растровое изображение был наложен маршрут из-за необходимости указания абсолютного местоположения по оси дороги.

Значения ширины ПЧ по данным съемки с различной аппаратуры на 10 контрольных участках, округленные до 0,1 м, были одинаковыми.

Таким образом, определение ширины ПЧ возможно выбранными методами с требуемой точностью, однако отметим, что если принимать во внимание скорость выполнения работ, то эффективнее измерять ширину по данным АФС и МЛС. Обратим внимание, что при наличии 
сложных развязок и переходно-скоростных полос целесообразнее использовать результаты АФС и МЛС, а при наличии тоннелей и путепроводов только данные сканирования и съемки с комплексной дорожной лаборатории дадут информацию о ширине ПЧ, тогда как при выполнении АФС с БАС не будет осуществляться видимость дорожного полотна.

\section{Определение продольных и поперечных уклонов ПЧ по результатам съемки различной аппаратурой}

Отметим, что процесс получения значений продольных и поперечных уклонов ПЧ с помощью съемки с передвижной дорожной лаборатории полностью автоматизирован. Продольные уклоны проезжей части измерялись через $50 \mathrm{M}$.

Для определения продольных и поперечных уклонов по данным АФС были построены плотное облако точек и карта высот. Необходимо учесть, что эти уклоны привязывались к местоположению относительно маршрута автомобильной дороги. Для выполнения измерений была смоделирована трехметровая виртуальная рейка с привязкой к местоположению. Виртуальная рейка «прикладывалась» в продольном и поперечном направлениях. Измерения проводились по краям проезжей части на расстоянии не менее 0,5 м от кромки и по середине каждой из полос движения, что соответствует требованиям [9]. Схема измерения предусматривала, что на каждом участке рейки, разбитой на 6 интервалов через 50 см, находились высоты точек. Таким образом, смоделированная рейка каждый раз смещалась на величину заданного интервала.
Для оценки точности измерений было рассчитано значение СКО определения высот по формуле Бесселя. Оно составило 2,1 мм. Результатом измерения параметров продольного и поперечного уклонов на каждом участке являлось среднее арифметическое значение из измерений. Аналогично проводились измерения по данным МЛС.

Далее сравнивались величины продольных и поперечных уклонов на участке 44882-44932 м, полученных с помощью данных комплексной дорожной лаборатории, аэрофотосъемки с БАС, МЛС. Результаты представлены в табл. 3.

Таким образом, можно сделать вывод, что данные аэрофотосъемки с БПЛА, МЛС и собранные с помощью комплексной дорожной лаборатории согласуются друг с другом. На основе полученных результатов показано, что значения уклонов можно определять по данным АФС и МЛС, при этом вычисленные значения не противоречат данным дорожной лаборатории, применение которой регламентировано в [9].

\section{Сравнение материалов, полученных в рамках специализированной диагностики}

При занесении результатов съемки в геоинформационные автоматизированные базы дорожных данных, как правило, необходим растр, поэтому рассмотрим задачу получения его по данным МЛС и сравнения с ортофотопланом, построенным при АФС. Отметим, что по данным примененной комплексной дорожной лаборатории создание ортофотоплана не предполагалось.

ТАБЛИЦА 3. Сравнение значений продольных и поперечных уклонов

\begin{tabular}{|l|c|c|c|}
\hline \multicolumn{1}{|c|}{ Наименование показателя } & $\begin{array}{l}\text { Съемка с комплексной } \\
\text { дорожной лаборатории }\end{array}$ & АФС с БАС & МЛС \\
\hline Продольный уклон,\%о & $-2,5$ & $-2,7$ & $-1,9$ \\
\hline $\begin{array}{l}\text { Поперечный уклон } \\
\text { по прямому ходу,\%о }\end{array}$ & 25,6 & 25,8 & 26,0 \\
\hline
\end{tabular}


По данным МЛС в программном продукте КРЕДО 3D СКАН был построен ортофотоплан. Отметим, что одним из важных критериев создания ортофотоплана по данным сканирования являлся выбор необходимого пространственного разрешения, так как важно было избежать как потери данных, так и неправильного заполнения пустот. Подчеркнем, что заданное пространственное разрешение изображения составило $5 \mathrm{~cm} /$ пкс.

Таким образом, пространственное разрешение ортофотоплана, построенного по данным АФС с БАС, в 1,8 раз выше, чем при МЛС. Отметим, что такой результат прежде всего связан с плотностью облака точек сканирования, так как улучшение пространственного разрешения ортофотоплана привело бы к неправильному заполнению пустот. При использовании обоих растров возможна измерительная информация о ширине ПЧ, но отметим, что по растру, полученному при выполнении МЛС, дешифрировались только проезжая часть и укрепленные обочины в связи с тем, что детальность и достоверность изображения во многом зависят от дальности действия сканирующей системы, а в тех областях, где плотность точек была низкой, выполнялось автоматическое заполнение пустот.

\section{Заключение}

По результатам исследований можно сделать следующие выводы:

1. Определение выделенных параметров диагностики по методам МЛС и АФС с БАС является корректным.

2. По данным АФС, МЛС возможен расчет следующих показателей: ширины ПЧ, координат километровых столбов, углов поворота трассы, расстояния видимости, геодезических координат положения инженерного обустройства с требуемой точностью. Также отметим, что по точности метод АФС соответствует требованиям, предъявляемым к планам масштаба 1:500, МЛС$1: 1000$.
3. Аэрофотосъемка с БАС по цене оборудования, стоимости съемки наиболее выгодна при составлении топографических планов автодорог. Спектр задач, решаемых при выполнении АФС с БАС, может быть расширен.

4. Обратим внимание на то, что не все показатели, требуемые при проведении диагностики, могут быть получены при АФС с БАС и МЛС, так как требуют специализированного оборудования и непосредственного взаимодействия с дорожным покрытием. Такой показатель как коэффициент сцепления измеряется с помощью комплексной передвижной дорожной лаборатории, поэтому отказаться от ее использования нецелесообразно, однако отметим, что комплектация лаборатории в зависимости от стоимости может быть разной.

\section{Библиографический список}

1. Федеральная служба государственной статистики. - URL : https://rosstat.gov.ru (дата обращения : 18.10.2020 г.).

2. Алтынцев М.Н. Применение беспилотных летательных аппаратов для исполнительной съемки железных дорог / М.Н. Алтынцев, И. В. Щербаков, С. А. Третьяков // Интерэкспо ГЕО-Сибирь. XV Междунар. науч. конгресс : Междунар. науч. конференция «Недропользование. Горное дело. Направления и технологии поиска, разведки и разработки месторождений полезных ископаемых. Экономика. Геоэкология» : сб. материалов : в 9 т. (Новосибирск 2426 апреля 2019 г.).- Новосибирск : СГУГиТ, 2019.T. 1.- № 1.- C. 111-118.

3. Вальков В.А. Методика автоматического моделирования дефектов покрытия автодорог по данным мобильного лазерного сканирования / В.А. Вальков, К. П. Виноградов // Материалы III Всерос. науч.практич. конференции (Санкт-Петербург, 6-8 ноября 2019 г.).- СПб. : РГПУ им. А. И. Герцена, 2019.C. 209-214.

4. Кузнецов А.О. Современные системы мобильного лазерного сканирования и особенности их применения на автомобильных дорогах / А. О. Кузнецов // Дороги и мосты. - 2020. - № 42. - С. 56-76. 
5. Середа П. О. Оценка транспортно-эксплуатационного состояния автомобильной дороги по информации, полученной с использованием беспилотного летательного аппарата / П. О. Середа. - URL : http:// www.ivdon.ru/uploads/article/pdf/IVD_15_Sereda_N. pdf_29e677c575.pdf (дата обращения : 11.10 .2020 г.).

6. Середович В.А. Обоснование возможности использования лазерного сканирования для решения проблем в транспортной сфере / В. А. Середович, А. К. Егоров // Интерэкспо ГЕО-Сибирь-2015. XI Междунар. науч. конгресс : Междунар. науч. конференция «Геодезия, геоинформатика, картография, маркшейдерия» : сб. материалов : в 2 т. (Новосибирск, 13-25 апреля 2015 г.).- Новосибирск : СГУГиТ, 2015.T. 2.- C. 144-148.

7. Сарычев Д. С. Мобильное лазерное сканирование / Д. С. Сарычев // САПР и ГИС автомобильных дорог. - 2013. - № 1.- С. 36-41.

8. Отраслевой дорожный методический документ ОДМ 218.4.039-2018. Рекомендации по диагностике и оценке технического состояния автомобильных дорог.- М. : Росавтодор, 2018.- 55 с.

9. ГОСТ 33383-2015. Дороги автомобильные общего пользования. Геометрические элементы. Методы определения параметров.-М. : Стандартинформ, 2016.- $11 \mathrm{c}$.

10. ГОСТ 32963-2014. Дороги автомобильные общего пользования. Расстояние видимости. Методы измерений (переиздание).-- М. : Стандартинформ, 2019. -18 c.

11. ГОСТ 32825-2014. Дороги автомобильные общего пользования. Дорожные покрытия. Методы измерения геометрических параметров повреждений (переиздание).- М. : Стандартинформ, 2019.- 19 с.

12. ГОСТ Р 57258-2016. Системы беспилотные авиационные. Термины и определения.- М. : Стандартинформ, 2018.- $12 \mathrm{c}$.

13. ГОСТ Р 52398-2005. Классификация автомобильных дорог. Основные параметры и требования.М. : Стандартинформ, 2006. -5 c.

14. Росдортех. - URL : https://rosdorteh.ru/catalog/ 25/ (дата обращения : 28.12.2020 г.).

15. Официальный сайт ГК «Геоскан».- URL : https://www.geoscan.aero/ru/products/geoscan201/geo (дата обращения : 10.01.2021 г.).

16. Versatile GNSS receiver for everyday fieldwork. - URL : https://www.topconpositioning.com/ gnss/integratedgnss-receivers/hiper-v (дата обращения : 14.01.2021 г.).

17. EFT-CORS. Федеральная сеть базовых станций. - URL : https://eft-cors.ru (дата обращения : 21.12.2021 г.).

Дата поступления: 29.03.2021

Решение о публикации 15.04.2021

\section{Контактная информация:}

БРЫНЬ Михаил Ярославович - д-р техн. наук, проф.; bryn@pgups.ru

БАШИРОВА Динара Ринатовна - аспирант; bashirovadinara97@gmail.com

БАГИШЯН Артур Гегамонович - начальник отдела геоинформационного моделирования; arthos96@yandex.ru

\section{Comparative evaluation of mobile laser scanning, aerial photography from an unmanned aircraft system and surveying from an integrated road laboratory when performing diagnostics of highways}

\section{Ya. Bryn ', D. R. Bashirova ', A. G. Bagishyan ${ }^{2}$}

${ }^{1}$ Emperor Alexander I Petersburg State Transport University, 9, Moskovsky pr., Saint Petersburg, 190031, Russian Federation

${ }^{2}$ LLC "Bridges and Engineering Projects", 16, lit. B, Monetnaya ul., Saint Petersburg, 197101, Russian Federation 
For citation: Bryn M. Yar., Bashirova D. R., Bagishyan A. G. Comparative evaluation of mobile laser scanning, aerial photography from an unmanned aircraft system and surveying from an integrated road laboratory when performing diagnostics of highways. Proceedings of Petersburg Transport University. Saint Petersburg, Petersburg State Transport University, 2021, vol. 18, iss. 2, pp. 211-221. (In Russian) DOI: 10.20295/1815-588X-2021-2-211-221

\section{Summary}

Objective: To compare the possibilities of using mobile laser scanning (MLS) and aerial photography (AFS) from an unmanned aircraft system (UAS) and to make a survey from an integrated road laboratory when performing diagnostics of highways. Methods: For the analysis, a section of the regional road in the Kursk region was selected, on which the survey was carried out using considered methods. The main characteristics were identified when performing the diagnostics, their values were obtained on the basis of data from the integrated road laboratory, aerial photography with UAS, as well as ILS, and the accuracy of the results obtained, the compliance of the data with the requirements of regulatory documents were assessed. Results: Based on the work performed, the following conclusions were made: the determination of identified diagnostic parameters by the methods of ILS and APS with UAS is correct and aerial photography with UAS at the cost of equipment, the cost of shooting is the most profitable when drawing up topographic road plans. It is noted that in terms of accuracy, the APS method meets the requirements for plans at a scale of 1:500, MLS - 1:1000. Practical importance: Not all indicators required for diagnostics can be obtained with APS with ALS and MLS, since they require specialized equipment and direct interaction with the road surface, however, the range of application of the selected methods can be significantly expanded. Adhesion coefficient is measured using an integrated mobile road laboratory, so it is not advisable to abandon it. It was noted that the equipment of the laboratory, depending on the cost, may be different.

Keywords: Diagnostics of highways, complex mobile road laboratory, aerial photography, unmanned aerial system, orthophotomap, topographic plan, mobile laser scanning, mobile laser scanner, experimental section of the road.

\section{References}

1. Federal'naya sluzhba gosudarstvennoy statistiki [Federal State Statistics Service]. Available at: https://rosstat.gov.ru (accessed: October 18, 2020) (In Russian)

2. Altyntsev M. N., Shcherbakov I.V. \& Tretyakov S. A. Primeneniye bespilotnykh letatel'nykh apparatov dlya ispolnitel'noy s"yemki zheleznykh dorog [The use of unmanned aerial vehicles for executive shooting of railways]. Interekspo GEO-Sibir'. XV Mezhdunar. nauch. kongress: Mezhdunar. nauch. konferentsiya "Nedropol'zovaniye. Gornoye delo. Napravleniya $i$ tekhnologii poiska, razvedki i razrabotki mestorozhdeniy poleznykh iskopayemykh. Ekonomika. Geoekologiya”. Sb. materialov. V 9 t. (Novosibirsk 24-26 aprelya 2019 g.) [Interexpo GEO-Siberia. XV Intern. scientific congress: Intern. scientific. conference "Subsoil Use. Mining. Directions and technologies of prospecting, exploration and development of mineral deposits. Economy. Geoecology". Sat. materials. In 9 vol. (Novosibirsk, April 24-26, 2019)]. Novosibirsk, Siberian State University of Geosystems and Technologies Publ., 2019, vol. 1, no. 1, pp. 111-118. (In Russian)

3. Valkov V.A. \& Vinogradov K.P. Metodika avtomaticheskogo modelirovaniya defektov pokrytiya avtodorog po dannym mobil'nogo lazernogo skanirovaniya [A technique for automatic modeling of road surface defects based on mobile laser scanning data]. Materialy III Vseros. nauch.-praktich. konferentsii (Sankt-Peterburg, 6-8 noyabrya $2019 \mathrm{~g}$. [Materials of the III All-Russia scientific and practical conferences (St. Petersburg, November 6-8, 2019)]. Saint Petersburg, Herzen State Pedagogical University Publ., 2019, pp. 209-214. (In Russian)

4. Kuznetsov A. O. Sovremennyye sistemy mobil'nogo lazernogo skanirovaniya i osobennosti ikh primeneniya na avtomobil'nykh dorogakh [Modern systems of mo- 
bile laser scanning and features of their application on highways]. Dorogi i mosty [Roads and bridges], 2020, no. 42, pp. 56-76. (In Russian)

5. Sereda P. O. Otsenka transportno-ekspluatatsionnogo sostoyaniya avtomobil'noy dorogi po informatsii, poluchennoy s ispol'zovaniyem bespilotnogo letatel'nogo apparata [Assessment of the transport and operational state of the road according to information obtained using an unmanned aerial vehicle]. Available at: http://www.ivdon.ru/uploads/article/pdf/IVD_15 Sereda_N.pdf_29e677c575.pdf (accessed: October 11, 2020). (In Russian)

6. Seredovich V.A. \& Egorov A. K. Obosnovaniye vozmozhnosti ispol'zovaniya lazernogo skanirovaniya dlya resheniya problem $\mathrm{v}$ transportnoy sfere [Substantiation of the possibility of using laser scanning to solve problems in the transport sector]. Interexpo GEO-Siberia-2015. XI Intern. scientific. congress: Intern. scientific. conference "Geodesy, Geoinformatics, Cartography, Mine Surveying”. Sat. materials. In 2 vol. (Novosibirsk, April 13-25, 2015). Novosibirsk, Siberian State University of Geosystems and Technologies Publ., 2015, vol. 2, pp. 144-148. (In Russian)

7. Sarychev D. S. Mobilnoye lazernoye skanirovaniye [Mobile laser scanning]. CAD and GIS of roads, 2013, no. 1, pp. 36-41. (In Russian)

8. Otraslevoy dorozhnyy metodicheskiy dokument ODM 218.4.039-2018. Rekomendatsii po diagnostike $i$ otsenke tekhnicheskogo sostoyaniya avtomobil'nykh dorog [Industry road methodological document ODM 218.4.039-2018. Recommendations for the diagnosis and assessment of the technical condition of highways]. Moscow, Rosavtodor Publ., 2018, 55 p. (In Russian)

9. GOST 33383-2015. Dorogi avtomobil'nyye obshchego pol'zovaniya. Geometricheskiye elementy. Metody opredeleniya parametrov [GOST 33383-2015. Automobile roads for general use. Geometric elements. Methods for determining parameters]. Moscow, Standartinform Publ., 2016, 11 p. (In Russian)

10. GOST 32963-2014. Dorogi avtomobil'nyye obshchego pol'zovaniya. Rasstoyaniye vidimosti. Meto- dy izmereniy (pereizdaniye) [GOST 32963-2014. Automobile roads for general use. Visibility distance. Measurement Methods (reprint)]. Moscow, Standartinform Publ., 2019, 18 p. (In Russian)

11. GOST 32825-2014. Dorogi avtomobil'nyye obshchego pol'zovaniya. Dorozhnyye pokrytiya. Metody izmereniya geometricheskikh parametrov povrezhdeniy (pereizdaniye) [GOST 32825-2014. Automobile roads for general use. Road surfaces. Methods for measuring the geometric parameters of damage (reprint)]. Moscow, Standartinform Publ., 2019, 19 p. (In Russian)

12. GOSTR 57258-2016. Sistemy bespilotnyye aviatsionnyye. Terminy i opredeleniya. [GOST R 57258-2016. Unmanned aerial systems. Terms and Definitions]. Moscow, Standartinform Publ., 2018, 12 p. (In Russian)

13. GOST R 52398-2005. Klassifikatsiya avtomobil'nykh dorog. Osnovnyye parametry i trebovaniya [GOST R 52398-2005. Classification of highways. Basic parameters and requirements]. Moscow, Standartinform Publ., 2006, 5 p. (In Russian)

14. Rosdortech. Available at: https://rosdorteh.ru/ catalog/25 (accessed: December 28, 2020). (In Russian)

15. The official site of the GC "Geoscan". Available at: https://www.geoscan.aero/ru/products/geoscan201/geo (accessed: January 10, 2021). (In Russian)

16. Versatile GNSS receiver for everyday fieldwork. Available at: https://www.topconpositioning.com/gnss/integratedgnss-receivers/hiper-v (accessed: January 14, 2021).

17. EFT-CORS. Federal network of base stations. Available at: https://eft-cors.ru/(accessed: Deecember, 21, 2021).

Received: March 23, 2021

Accepted: April 15, 2021

\section{Authors' information:}

Mikhail Ya. BRYN - D. Sci. in Engineering, Professor; bryn@pgups.ru

Dinara R. BASHIROVA - Postgraduate Student; bashirovadinara97@gmail.com

Artur G. BAGISHYAN - Head of Geoinformation Modeling Department; arthos96@yandex.ru 


\title{
Влияние геоиндуцированных токов на дроссель-трансформаторы рельсовых цепей железнодорожной автоматики
}

\section{А. М. Костроминов, Р. О. Ложкин}

Петербургский государственный университет путей сообщения Императора Александра I, Российская Федерация, 190031, Санкт-Петербург, Московский пр., 9

Для цитирования: Костроминов А. М., Ложкин Р. О. Влияние геоиндуцированных токов на дроссель-трансформаторы рельсовых цепей железнодорожной автоматики // Известия Петербургского университета путей сообщения.- СПб.: ПГУПС, 2021.- Т. 18. - Вып. 2. - С. 222-228.

DOI: $10.20295 / 1815-588 X-2021-2-222-228$

\begin{abstract}
Аннотация
Цель: Рассмотреть возможность подмагничивания сердечника дроссель-трансформатора постоянным током при использовании электротяги переменным током. Определить возможность влияния солнечной активности, в частности геоиндуцированных токов, на устройства систем сигнализации, централизации и блокировки. Методы: Проведен анализ условий и причин, при которых сердечник дроссель-трансформатора намагничивается, что является причиной уменьшения его индуктивного сопротивления и изменения коэффициента передачи рельсовой цепи. Применяются описание влияния геоиндуцированных токов на работу силовых трансформаторов тяговых подстанций и проекция данного сценария на работу дроссель-трансформаторов. Результаты: Изложены условия и причины некорректной работы дроссель-трансформаторов, связанной с подмагничиванием сердечника постоянным током, при использовании электротяги переменным током; проанализирована возможность насыщения магнитной системы дроссель-трансформатора геоиндуцированным током; определены возможные последствия при переходе дроссель-трансформатора в режим насыщения. Практическая значимость: Полученные результаты способствуют углублению знаний о возможности влияния солнечной активности на объекты железнодорожной инфраструктуры, что, в свою очередь, необходимо для разработки методов и средств, направленных на обеспечение бесперебойной работы железнодорожного транспорта.
\end{abstract}

Ключевые слова: Дроссель-трансформатор, силовой трансформатор, насыщение трансформатоpa, геоиндуцированные токи, квазипостоянный ток.

\section{Введение}

Многолетний опыт наблюдения и изучения солнечной активности помог определить частоту возникновения на Земле геомагнитных бурь (ГМБ). В течение одиннадцатилетнего солнечного цикла насчитывается около 9,5 тыс. ч геомагнитных возмущений [1]. Сильные ГМБ оказывают пагубное воздействие на техносферу, и связано это прежде всего с генерируемыми ими переменными магнитными полями и геоиндуцированными токами (ГИТ), которые распростра- няются по протяженным металлическим проводникам. В качестве таких проводников выступают линии электропередачи, металлические трубопроводы, железнодорожные пути и т.п. Так как на объектах железнодорожного транспорта применяются тяговые устройства и рельсовые цепи в качестве проводника для передачи сигналов управления системами автоматики, справедливо считать, что железнодорожный транспорт в наибольшей степени подвержен влиянию солнечной активности [2]. Внезапные прекращения функционирования систем управления движением 
поездов, повлекшие за собой нарушения графика движения, неоднократно фиксировались на Октябрьской железной дороге. При этом характерной чертой таких событий являлось дальнейшее самовосстановление работоспособности систем без вмешательства оперативно-ремонтного персонала. В конечном итоге причины нарушений не были до конца установлены.

\section{Характеристики ГИТ}

Во время солнечной активности наблюдается изменение магнитного поля планеты, что происходит в результате обтекания магнитосферы плазмой солнечного ветра, которая представляет собой поток заряженных частиц, исходящих от Солнца. Согласно закону электромагнитной индукции Фарадея, в проводнике возникает ток, электродвижущая сила (ЭДС) которого зависит от скорости изменения магнитного потока и угла между проводником и полем и вычисляется по формуле

$$
\varepsilon=-\frac{\Delta \Phi}{\Delta t}=-L \frac{\Delta I}{\Delta t}
$$

где $\Phi$ - изменяющийся магнитный поток через контур, Вб; $I$ - изменяющийся электрический ток через контур, А; $L$ - индуктивность контуpa, Гн.

Таким образом, электрические токи, известные как ГИТ, способные течь в любой проводя- щей структуре, например в линиях электропередач или рельсовых цепях, порождаются изменением магнитного поля Земли и обусловлены законом электромагнитной индукции Фарадея [3].

Высокоинтенсивные ГМБ характерны для полосы широт между $60^{\circ}$ и $70^{\circ}$. Индикатором данного явления может служить северное сияние, которое нередко встречается в северной части России [4].

Наблюдение за геомагнитной активностью в Мурманске с 17 сентября по 14 ноября 2019 г. помогло определить, что за это время насчитывалось около 57 ч магнитных бурь продолжительностью от 3 до 12 ч [5].

Геоэлектрические поля, создаваемые на Земле изменениями геомагнитного поля во время ГМБ, имеют напряженность от 1 до 20 В/км. Расчетным путем получены значения ГИТ в линиях электропередачи в зависимости от напряженности геоэлектрического поля (рисунок) $[6,7]$.

При проведении расчетов ГИТ, наводимых в линиях электропередачи, использовался частный случай, при котором вектор напряженности геоэлектрического поля направлен вдоль линий электропередач.

Анализируя полученную зависимость и предполагая ее прямолинейный характер, уместно считать, что при напряженности геоэлектрического поля, равной 20 В/км (это характерно при сильных ГМБ), значение ГИТ будет около 40 А $[6,7]$.

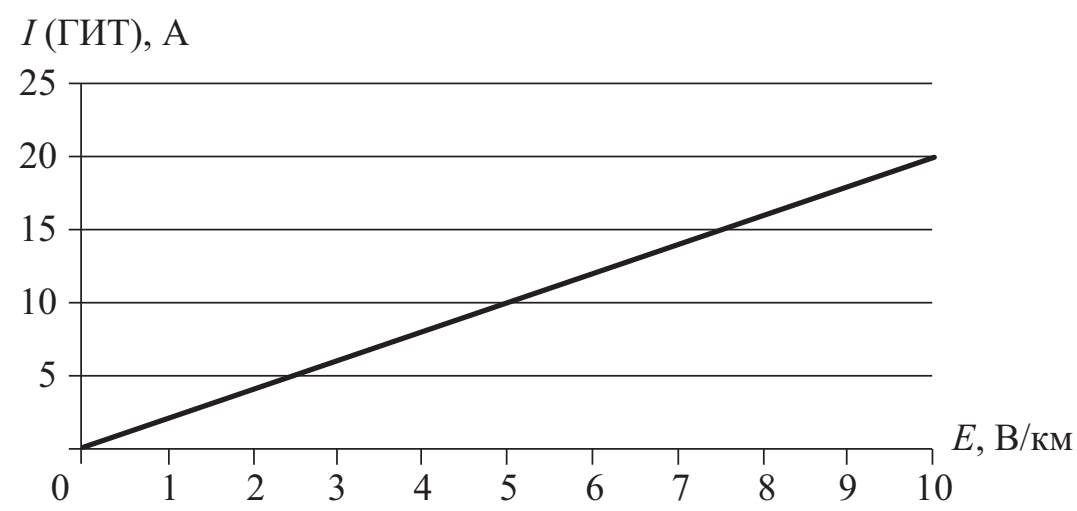

Зависимость ГИТ от напряженности геоэлектрического поля 


\section{Подмагничивание силовых трансформаторов ГИТ}

Во времена сильных ГМБ индуцированные ГИТ протекают по линиям электропередачи совместно с переменным током и попадают в обмотки высокого напряжения силовых трансформаторов. По сравнению с несущей частотой передачи электроэнергии 50 Гц частоты ГИТ очень малы - от 0,0001 до 0,1 Гц и потому его стоит рассматривать как квазипостоянный ток. ГИТ, протекая по обмоткам силового трансформатора, не трансформируются, а полностью участвуют в процессе намагничивания стали магнитопровода, что вызывает смещение рабочей точки в область насыщения. При этом форма кривой тока намагничивания сильно искажается и становится сильно несимметричной в течение полупериодов [8].

С увеличением ГИТ возрастает и ток намагничивания силового трансформатора, что приводит к уменьшению времени, при котором наступает процесс насыщения магнитной системы силового трансформатора. При ГИТ = $1 \mathrm{~A}$ насыщение магнитопровода трансформатора ТРДН 63000/110/6,3/6,3 наступает через 24 c, при $15 \mathrm{~A}$ - через 3 с. С учетом того факта, что ГМБ могут продолжаться часами, даже слабые бури, при которых ГИТ не превышают 5 A, могут стать причиной некорректной работы силовых трансформаторов [8].

Так как протяженность железнодорожных путей сопоставима с протяженностью линий электропередач, допустимо считать, что наводимые в них ГИТ будут иметь похожие характеристики.

\section{Насыщение магнитной системы дроссель-трансформаторов рельсовых цепей постоянным током}

Симметричный режим работы двухниточной рельсовой цепи гарантирует надежную защиту систем управления движением поездов от влияния любых гармоник тягового тока, в том чис- ле и постоянно составляющей. Это реализуется благодаря встречному включению первичных полуобмоток дроссель-трансформатора. Проходя по ним, тяговый ток не наводит ЭДС во вторичной обмотке и не способен подмагничивать сердечник дроссель-трансформатора.

Асимметричный режим работы рельсовойцепи приводит к тому, что тяговые токи, протекающие по полуобмоткам, имеют разные значения. Сердечник дроссель-трансформатора подмагничивается, а наличие постоянной составляющей усиливает данный процесс, так как постоянный ток не трансформируется, а полностью участвует в насыщении. Происходит уменьшение индуктивного сопротивления сердечника дроссельтрансформатора и, следовательно, снижение коэффициента передачи рельсовой цепи. Результатом этого являются понижение напряжения на путевом реле свободной рельсовой цепи и ее ложная занятость $[9,10]$.

Проводимые в МИИТе экспериментальные исследования показали, что при подмагничивании сердечника дроссель-трансформатора ДТ-1-150 постоянным током 17 А наблюдается уменьшение его входного сопротивления в 7 раз [11-13].

При электротяге переменного тока значение асимметрии рельсовой цепи должно быть менее $4 \%$. Данный параметр оценивается по тяговому току, проходящему по первичным полуобмоткам дроссель-трансформаторов. Необходимо учитывать, что асимметрия по постоянному току может иметь другие значения. Связано это прежде всего с тем, что при продольной асимметрии рельсовой линии удельное сопротивление рельсов на постоянном токе в 6-8 раз ниже, чем на частоте 50 Гц. Следует также указать, что штатными приборами на переменном тяговом токе асимметрию по постоянной составляющей можно не обнаружить, а сама процедура измерения асимметрии по постоянному току сложна и в графике обслуживания рельсовых линий не предусмотрена.

Стоит отметить, что при подмагничивании сердечника дроссель-трансформатора рабочая точка на кривой намагничивания смещается за 
пределы линейной части петли гистерезиса в область насыщения. Это приводит к изменению формы и фазы выходного сигнала. Для широко используемых в качестве путевых приемников станционных рельсовых цепей реле ДСШ подъем сектора (замыкание фронтовых контактов) обеспечивается лишь при заданном значении разности фаз между токами, проходящими по катушкам местного и путевого элементов. Формула вращающего момента выглядит следующим образом:

$$
M=I_{\mathrm{\Pi}} I_{\mathrm{M}} \sin \varphi,
$$

где $I_{\text {м }}$ - ток в катушке местного элемента, А; $I_{\text {п }}$ ток в катушке путевого элемента, $\mathrm{A} ; \varphi$ - угол сдвига фаз между токами путевого и местного элементов, град.

Легко заметить, что для достижения максимального вращающего момента угол между токами должен быть равен $90^{\circ}$. В условиях эксплуатации допустимо изменение угла $\varphi$ на $30^{\circ}$, при этом изменение вращающего момента можно считать незначительным. Дальнейшее увеличение разности фаз приводит к неустойчивой работе рельсовой цепи [14].

Таким образом, появление постоянной составляющей, обусловленной наличием ГИТ, в обратной тяговой сети и асимметрия рельсовой цепи, в том числе и по постоянному току, способствуют насыщению магнитной системы дроссель-трансформаторов. В результате наблюдаются снижение напряжения сигнального тока и изменение его фазы, что приводит к опусканию сектора путевого приемника рельсовых цепей и, как следствие, к появлению ложной занятости рельсовой цепи.

\section{Заключение}

Процессы космической погоды могут вносить перебои не только в системы электропитания, но и в системы управления движением на участках железных дорог с электротягой, где рельсовые линии имеют непрерывность про- водимости. Наведенные в них изменяющимися магнитными полями ГИТ вызывают насыщение дроссель-трансформаторов рельсовых цепей (такие случаи неоднократно отмечались на Октябрьской железной дороге). При подмагничивании дроссель-трансформаторов напряжение сигнального тока в рельсовой цепи уменьшается, а также изменяется его фаза, в результате путевые реле выключаются. Возникает ложная занятость путей. Как следствие, это ведет к простоям поездов, нарушениям графика перевозочного процесса и, следовательно, к дополнительным расходам. Кроме того, внезапные перемежающиеся отказы устройств автоматики существенно увеличивают психологическую нагрузку на оперативный персонал, что повышает риски, связанные с обеспечением безопасности движения поездов.

Для уменьшения негативного влияния космической погоды на психологическое состояние эксплуатационного персонала может оказаться полезным его превентивное оповещение о предстоящей магнитной буре. Однако полностью избавиться от влияния ГИТ на системы железнодорожной автоматики на участках с электротягой можно только при переходе там, где возможно, на интервальное регулирование движения поездов с минимальным участием рельсовых цепей.

\section{Библиографический список}

1. NERC. Special reliability assessment interim report: Effects of geomagnetic disturbances on the Bulk Power System. - Atlanta : North American electric reliability corporation, 2012.- P. 2-3.

2. Касинский В.В. Влияние геомагнитных возмущений на работу систем железнодорожной автоматики и телемеханики / В.В. Касинский, Н. Г. Птицына, Н.Н. Ляхов, М.И. Тясто, Дж. Виллорези // Геомагнетизм и аэрономия. -2007 . - Т. 47.- № 5.- С. 714-718.

3. Александров О.Ю. Совершенствование проектных решений и методик эксплуатации магистральных газонефтепроводов, подверженных воздействию теллурических блуждающих токов : дис. ... канд. техн. 
наук, специальность : 25.00.19 / О.Ю. Александров. Ухта : Ухт. гос. техн. ун-т, 2018.- 159 с.

4. Чистяков Г.Н. Экспериментальное исследование тока в нейтрали трансформатора в период геомагнитных бурь / Г.Н. Чистяков, С.Н. Сигаев // Изв. Томск. политех. ун-та. - 2011. - Т. 318. - № 4. - С. 122-127.

5. Гильдунина Д. С. Влияние геоиндуцированных токов на энергосистемы // Материалы XIV Bceрос. науч.-технич. конференции с международным участием, посвященной 85-летию со дня рождения заслуженного работника ВШ РФ, доктора физикоматематических наук, профессора М.И. Киселёва.М. : МГТУ им. Н. Э. Баумана, 2020.- С. 79-82.

6. Самородов А. В. Исследование и расчет геоиндуцированных токов линий электропередач при геомагнитных бурях / А. В. Самородов, Л. Ф. Копелевич, Д. Л. Ампар, Е. С. Крутенко // Булатовские чтения.2017.- Т. 5.- С. 105-108.

7. Кувшинов А.А. Анализ механизмов распространения геоиндуцированных токов в системообразующих электрических сетях различной топологии / А. А. Кувшинов, В. В. Вахнина, В. А. Кузнецов, Т. А. Рыбалко, М. О. Зюзин // Электричество. - 2015. - № 5. - С. 36-46.

8. Вахнина В. В. Влияние геоиндуцированных токов на насыщение магнитной системы силовых трансформаторов / В. В. Вахнина, А. Н. Черненко, В. А. Кузнецов // Вектор науки Тольят. гос. ун-та. - 2012. № 3 (21).- С. 65-69.

9. Кириленко А. Г. Электрические рельсовые цепи : учеб. пособие / А.Г. Кириленко, Н. А. Пельменева // Хабаровск : Изд-во ДВПГУПС, 2006.- 95 с.
10. Бушуев А. В. Рельсовые цепи: теоретические основы и эксплуатация : монография / А.В. Бушуев, В. И. Бушуев, С. В. Бушуев. - Екатеринбург : Изд-во УрГУПС, 2014.-312 с.

11. Зенкович Ю. И. Анализ электромагнитной совместимости рельсовых цепей и тягового электроснабжения / Ю.И. Зенкович, А.А. Иваненко // Мир транспорта.-2017.- Т. 15. - № 1.- С. 40-46.

12. Зенкович Ю. И. Защита рельсовых цепей от ложной занятости при гололёдообразовании на контактном проводе / Ю. И. Зенкович, А. А. Иваненко, Е. Г. Щербина // Автоматика, телемеханика, информатика. - 2012. - № 3 (21). - С. 65-69.

13. Зенкович Ю. И. Защита рельсовых цепей от ложной занятости при гололёдообразовании на контактном проводе / Ю. И. Зенкович, А. А. Иваненко, Е. Г. Щербина // Автоматика, телемеханика, информатика. - 2011. - № 4.- С. 29-31.

14. Виноградова В. Ю. Технология ремонтнорегулировочных работ устройств и приборов систем СЦБ и ЖАТ / В. Ю. Виноградова. - М. : Учеб.-метод. центр по образованию на железнодорожном транспорте, 2015.- 190 c.

Дата поступления: 21.01.2021

Решение о публикации: 25.02.2021

\section{Контактная информация:}

ЛОЖКИН Роман Олегович - аспирант; mrromanspb@yandex.ru

КОСТРОМИНОВ Александр Михайлович - д-р техн. наук, проф.; triak@grozon.spb.ru

\section{Influence of geoinduced currents on impedance bonds with secondary windings used in railway automation circuits}

\section{A. M. Kostrominov, R. O. Lozhkin}

Emperor Alexander I Petersburg State Transport University, 9, Moskovsky pr., Saint Petersburg, 190031, Russian Federation

For citation: Kostrominov A. M., Lozhkin R. O. Influence of geoinduced currents on impedance bonds with secondary windings used in railway automation circuits. Proceedings of Petersburg Transport University. Saint Petersburg, Petersburg State Transport University, 2021, vol. 18, iss. 2, pp. $222-228$. (In Russian) DOI: 10.20295/1815-588X-2021-2-222-228 


\section{Summary}

Objective: To consider the possibility of DC magnetization of the core of the impedance bond with secondary winding when using AC electric traction. To determine the possible influence of solar activity, and in particular the geoinduced currents, on the signaling arrangements (SAs). Methods: Analysis of the conditions and causes of magnetization of the core of the impedance bond with a secondary winding, which is the reason for a decrease in its inductance and a change in the track circuit coefficient of transmission. Description of the influence of geoinduced currents on the operation of traction substation power transformers and the using this scenario for modeling the operation of impedance bonds with secondary windings. Results: The conditions and reasons for the incorrect operation of the impedance bonds with secondary windings associated with the magnetization of the core by direct current, when using electric traction with alternating currents, have been stated; the possibility of saturation of the magnetic system of the impedance bond with geoinduced current has been analyzed; the possible consequences of the transition of the impedance bond to the saturation mode have been determined.

Practical importance: The study findings broaden the knowledge about the possible influence of solar activity on the railway infrastructure facilities, which in its turn is necessary for the development of methods and means aimed at ensuring the uninterrupted operation of railway transport.

Keywords: Impedance bond with secondary winding, power transformer, transformer saturation, geoinduced currents, quasi-constant current.

\section{References}

1. NERC. Special Reliability Assessment Interim Report: Effects of Geomagnetic Disturbances on the Bulk Power System. Atlanta, North American electric reliability corporation Publ., 2012, pp. 2-3.

2. Kasinsky V.V., Ptitsyna N. G., Lyakhov N. N., Tyasto M.I. \& Villoresi G. Vliyaniye geomagnitnykh vozmushcheniy na rabotu sistem zheleznodorozhnoy avtomatiki i telemekhaniki [Influence of geomagnetic disturbances on the operation of railway automation and remote control systems]. Geomagnetizm i aeronomiya [Geomagnetism and Aeronomy], 2007, vol. 47, no. 5, pp. 714-718. (In Russian)

3. Aleksandrov O. Yu. Sovershenstvovaniye proyektnykh resheniy i metodik ekspluatatsii magistral'nykh gazonefteprovodov, podverzhennykh vozdeystviyu telluricheskikh bluzhdayushchikh tokov. Dis. kand. tekhn. nauk, spetzial'nost: 25.00 .19 [Improvement of design solutions and methods of operation of main gas and oil pipelines exposed to telluric stray currents. Dis. for $\mathrm{PhD}$ in Engineering, speciality: 25.00.19]. Ukhta, Ukhta State Technics University Publ., 2018, 159 p. (In Russian)

4. Chistyakov G. N. \& Sigaev S. N. Eksperimental'noye issledovaniye toka $\mathrm{v}$ neytrali transformatora $\mathrm{v}$ period geomagnitnykh bur' [Experimental study of the current in the transformer neutral during geomagnetic storms]. Bulletin of the Tomsk Polytechnic University, 2011, vol. 318, no. 4, pp. 122-127. (In Russian)

5. Gil'dunina D. S. Vliyaniye geoindutsirovannykh tokov na energosistemy [Influence of geoinduced currents on power systems]. Sbornik materialov XIV Vserossiyskoy nauchno-tekhnicheskoy konferentsii s mezhdunarodnym uchastiyem, posvyashchyonnoy 85-letiyu so dnya rozhdeniya zasluzhennogo rabotnika VSh RF, doktora fizikomatematicheskikh nauk, professora M. I. Kiselyova [Collection of materials of the XIV All-Russian Scientific and Technical Conference with International Participation, dedicated to the 85th anniversary of the Honored Employee of the Higher School of the Russian Federation, Doctor of Sciences in Physics and Mathematics, Professor M. I. Kiselyov]. Moscow, MGTU namer N. E. Bauman, 2020, pp. 79-82. (In Russian)

6. Samorodov A. V., Kopelevich L. F., Ampar D. L. \& Krutenko E. S. Issledovaniye i raschet geoindutsirovannykh tokov liniy elektroperedach pri geomagnitnykh buryakh [Research and calculation of geoinduced currents of power lines during geomagnetic storms]. Bulatovskiye chteniya [Readings of A. I. Bulatov], 2017, vol. 5, pp. 105-108. (In Russian)

7. Kuvshinov A.A., Vakhnina V. V., Kuznetsov V.A., Rybalko T.A. \& Zyuzin M. O. Analiz mekhanizmov 
rasprostraneniya geoindutsirovannykh tokov v sistemoobrazuyushchikh elektricheskikh setyakh razlichnoy topologii [Analysis of the mechanisms of propagation of geoinduced currents in backbone electric power systems of various topologies]. Elektrichestvo [Electricity], 2015, no. 5, pp. 36-46. (In Russian)

8. Vakhnina V.V., Chernenko A. N. \& Kuznetsov V.A. Vliyaniye geoindutsirovannykh tokov na nasyshcheniye magnitnoy sistemy silovykh transformatorov [Influence of geoinduced currents on the power transformer magnetic system saturation]. Science Vector of Togliatti State University, 2012, no. 3 (21), pp. 65-69. (In Russian)

9. Kirilenko A. G. \& Pel'meneva N.A. Elektricheskiye rel'sovyye tsepi [Electric track circuits]. Uchebnoye posobiye [Training manual]. Khabarovsk, Far Eastern State Transport University Publ., 2006, 95 p. (In Russian)

10. Bushuev A. V., Bushuev V.I. \& Bushuev S. V. Rel'sovyye tsepi: teoreticheskiye osnovy i ekspluatatsiya. Monografia [Rail circuits: theoretical foundations and operation. Monograph]. Yekaterinburg, Ural State University of Railway Transport Publ., 2014, 312 p. (In Russian)

11. Zenkovich Yu. I. \& Ivanenko A.A. Analiz elektromagnitnoy sovmestimosti rel'sovykh tsepey i tyagovogo elektrosnabzheniya [Analysis of electromagnetic compatibility of rail circuits and traction power supply]. Mir transporta [The world of transport], 2017, vol. 15, no. 1, pp. 40-46. (In Russian)

12. Zenkovich Yu. I., Ivanenko A.A. \& Shcherbina E. G. Zashchita rel'sovykh tsepey ot lozhnoy zanyatosti pri gololedoobrazovanii na kontaktnom provode [Protection of track circuits from false actuation in case of icing of a contact wire]. Avtomatika, telemekhanika, informatika [Automation, Remote Control, Informatics], 2012, no. 3 (21), pp. 65-69. (In Russian)

13. Zenkovich Yu. I., Ivanenko A.A. \& Shcherbina E. G. Zashchita rel'sovykh tsepey ot lozhnoy zanyatosti pri gololedoobrazovanii na kontaktnom provode [Protection of track circuits from false actuation in case of icing of a contact wire]. Avtomatika, telemekhanika, informatika [Automation, Remote Control, Informatics], 2011, no. 4, pp. 29-31. (In Russian)

14. Vinogradova V. Yu. Tekhnologiya remontno-regulirovochnykh rabot ustroystv i priborov sisem STsB i ZhAT [The repair and adjustment technology for apparatus and devices of the signaling arrangements and railroad automation and telemechanics systems]. Moscow, Uchebno-metodicheskiy tsentr po obrazovaniyu na zheleznodorozhnom transporte [Railway educational training center] Publ., 2015, 190 p. (In Russian)

Accepted: January 21, 2021

Received: February 25, 2021

\section{Author's information:}

Aleksandr M. KOSTROMINOV - Dr. Sci. in Engineering, Professor; triak@grozon.spb.ru

Roman O. LOZHKIN - Postgraduate Student; mrromanspb@yandex.ru 
УДК 004.056.2

\title{
Модель процесса доставки пакетов по каналу передачи данных в условиях компьютерных атак нарушителя
}

\section{В. Л. Лукичева, А. А. Привалов, Д.Д. Титов}

Петербургский государственный университет путей сообщения Императора Александра I, Российская Федерация, 190031, Санкт-Петербург, Московский пр., 9

Для цитирования: Лукичева В. Л., Привалов А. А., Титов Д. Д. Модель процесса доставки пакетов по каналу передачи данных в условиях компьютерных атак нарушителя // Известия Петербургского университета путей сообщения.- СПб.: ПГУПС, 2021. - Т. 18. - Вып. 2.- С. 229-241.

DOI: 10.20295/1815-588X-2021-2-229-241

\begin{abstract}
Аннотация
Цель: Произвести анализ влияния компьютерных атак на параметры качества функционирования каналов передачи данных и каналообразующие системы. При этом требуется учитывать возможности нарушителя по внедрению вредоносных программ в каналообразующие системы при реализации компьютерной атаки. Методы: Для определения искомых расчетных соотношений рассмотрены несколько вариантов задания различных функций распределения, характеризующих параметры, используемые в качестве исходных данных и видов входящего потока с учетом параметров модели компьютерной атаки нарушителя, задаваемых значениями вероятности успешной реализации атаки. Математическое моделирование осуществляется с помощью метода топологического преобразования стохастических сетей. В качестве функций распределения случайных величин применяется экспоненциальное, импульсное и гамма-распределение. Решения представлены для входящих потоков, соответствующих моделям Пуассона, Вейбулла и Парето. Результаты: Предложенный подход позволяет получить оценки качества функционирования каналов передачи данных в условиях компьютерных атак. С помощью этих оценок можно анализировать состояние и вырабатывать направления по повышению качества функционирования каналов связи в условиях деструктивного информационного воздействия нарушителя. При моделировании использованы различные варианты функций распределения случайных величин и видов входящего потока, что дает возможность их сравнить, а также оценить возможность применения в каналах, предоставляющих пользователям разные виды услуг. Практическая значимость: Полученные в процессе моделирования результаты могут быть использованы при построении систем поддержки принятия решения по управлению связью, а также для обнаружения попыток несанкционированного доступа к телекоммуникационному ресурсу систем управления перевозками. Предложенный подход может быть применен при разработке моделей угроз для описания возможностей нарушителя (модель нарушителя).
\end{abstract}

Ключевые слова: Компьютерная атака, телекоммуникационная сеть, функция распределения, стохастическая сеть, уязвимость.

\section{Введение}

Глобальная информатизация подразумевает предоставление пользователям телекоммуникационными системами услуг заданного качества. При этом количество сервисов, получаемых пользователями через каналы передачи данных, возрастает, что приводит к увеличению инфор- 
мационных угроз [1], которые требуется своевременно обнаружить, нейтрализовать, а также оценить степень их влияния на качество информационного обмена.

Для реализации комплексов обнаружения вторжений следует проводить предварительное моделирование компьютерных атак (КА) на каналообразующее оборудование. При этом модель должна учитывать возможности нарушителя по реализации атаки.

Представленный в статье подход основан на представлении процесса функционирования канала передачи данных в виде стохастической сети с последующим определением ее эквивалентной функции, а также начальных и центральных моментов случайного времени успешной доставки пакетов данных.

Результатом моделирования является функция распределения времени доставки пакетов в канале передачи данных в условиях деструктивного информационного воздействия, при заданной вероятности успешной реализации КА на каналообразующее оборудование. Это позволяет достаточно полно учесть результаты моделирования кибервоздействия нарушителя при оценке качества функционирования каналов передачи данных.

При моделировании важно установить параметры моделируемого объекта с целью получения объективных данных, имеющих высокую степень корреляции с реальными процессами, происходящими в телекоммуникационной сети. В [2] выделены основные причины возникновения долговременной зависимости в сетевом трафике, что также необходимо учитывать при оценке качества функционирования каналов и сетей передачи данных.

Поскольку при применении метода топологического преобразования стохастических сетей с целью упрощения вычислений наиболее часто используется допущение об экспоненциальном распределении случайных значений параметров, используемых в качестве исходных данных, то сложилось ложное представление о невозможности применения данного метода при других видах распределений. Поэтому рассмотрим варианты использования различных функций распределения исходных параметров и видов канального трафика, в том числе и самоподобного.

\section{Постановка задачи}

Пусть имеется канал связи, обеспечивающий передачу потока пакетов данных с интенсивностью $\lambda_{\text {вх }}$ и функционирующий в условиях технических отказов и КА на каналообразующее оборудование.

Если технический отказ происходит во время передачи пакета данных, то этот пакет теряется. При этом вероятность безотказной работы канального оборудования полагается равной $K_{\mathrm{r}}=$ $=\left(1-K_{\text {п }}\right)$, где $K_{\mathrm{r}}$ и $K_{\text {п }}-$ коэффициенты готовности и простоя соответственно, определяется методами, известными из теории надежности.

Под КА на каналообразующее оборудование понимается процесс преднамеренного воздействия нарушителя, использующего уязвимости канального оборудования и приводящего к затруднению или блокированию возможности передачи информации независимо от факта передачи информации по каналу связи в данный момент времени. Положим, что нарушитель способен успешно осуществить КА с вероятностью $P_{A}[3,4]$.

Если работоспособность канала связи не нарушена и нарушителю не удалось успешно осуществить КА, а вероятность этого события равна $\left(1-P_{A}\right)$, то пакет данных будет успешно передан за случайное время $t_{\text {оп }}$ с функцией распределения $B(t)$. В противном случае с вероятностью $P_{A}$ через случайное время $t_{\text {в }}$ ф функцией распределения $D(t)$ КА будет нейтрализована, и пакет данных поступит на передачу повторно. 
Поступающие на вход этого канала связи пакеты данных ожидают обслуживания некоторое время $t_{\text {ож }}$ с функцией распределения $W(t)$. При этом считается, что количество мест для ожидания обслуживания ограничено емкостью накопителя, обеспечивающего хранение $K$ пакетов данных.

Требуется определить функцию распределения времени успешной доставки пакета данных по изучаемому каналу связи.

\section{Решение задачи}

В соответствии с описанным алгоритмом процесс доставки пакета данных представлен в виде стохастической сети (рис. 1) и включает процесс ожидания в очереди на обслуживание, который характеризуется функцией распределения $W(t)$, и процесс обслуживания, характеризующийся функцией распределения времени передачи пакета $H(t)$ в условиях технических отказов и КА нарушителя, т.е.

$$
t_{\text {д }}=t_{\text {ож }}+t_{\text {П }},
$$

где $t_{\text {ож }}$ и $t_{\text {п }}-$ случайное время ожидания и времени обслуживания соответственно.

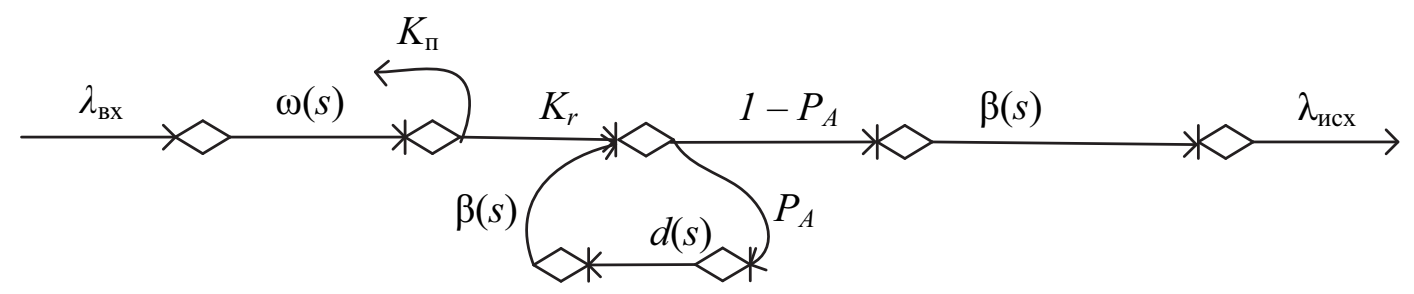

Рис. 1. Стохастическая сеть процесса доставки пакетов данных по каналу связи в условиях технических отказов и КА нарушителя

В стохастической сети $\omega(s), d(s), \beta(s)$ - преобразование Лапласа-Стилтьеса функций распределения времени ожидания $W(t)$, нейтрализации КА $D(t)$ и передачи пакета данных $B(t)$ соответственно.

Согласно топологическому уравнению Мэйсона [5] эквивалентная функция стохастической сети имеет вид

$$
Q(s)=\frac{w(s) \beta(s)\left(1-P_{A}\right) K_{r}}{1-P_{A} d(s) \beta(s)}=w(s) h(s) .
$$

Для определения искомых расчетных соотношений рассмотрим несколько вариантов задания различных функций распределения соответствующих случайных величин и видов входящего потока пакетов данных.

Вариант 1. Функции распределения случайных величин относятся к классу экспоненциальных, T.e.

$$
F(t)=1-\exp \left\{-\frac{t}{\overline{t_{f}}}\right\},
$$

а входящий поток пакетов является простейшим. 
В этом случае, учитывая результат [6], эквивалентную функцию (1) запишем следующим образом:

$$
Q_{1}(s)=\left(\frac{w}{w+s}\right)^{\alpha} \cdot \frac{K_{\mathrm{r}}\left(1-P_{A}\right) b(d+s)}{s^{2}+s(d+b)+P_{A} d b}
$$

а искомую функцию распределения времени доставки - так:

$$
Q(t)=\int_{0}^{t} \frac{\mu^{\beta}}{\Gamma(\beta)} t^{\beta-1} \exp \{-\mu t\} d t .
$$

В (2) и (3) $b={\overline{T_{\text {оп }}}}^{-1}, d=\bar{T}_{\text {в }}^{-1}, \overline{T_{\text {оп }}}, \overline{T_{\text {в }}}$ - среднее время однократной передачи пакета данных и нейтрализации КА соответственно; $\lambda$ - интенсивность входящего потока пакетов данных; $w=\frac{T_{0}}{D_{0}}$, $\alpha=\frac{T_{0}^{2}}{D_{0}}-$ параметры масштаба и формы $\gamma$-распределения времени ожидания обслуживания; $\mu=\frac{T_{\text {д }}}{D_{\text {д }}}, \beta=\frac{T_{\text {д }}^{2}}{D_{\text {д }}}-$ параметры масштаба и формы $\gamma$-распределения времени доставки пакета данных;

$$
\begin{gathered}
h_{1}=T_{\text {п }}=-\frac{d}{d s}\left[\frac{K_{\text {г }}\left(1-P_{A}\right) b(d+s)}{s^{2}+s(d+b)+P_{A} d b}\right]_{s=0}=\frac{\left(P_{A} b+d\right) K_{\text {г }}}{b d\left(1-P_{A}\right)}, \\
h_{2}=\frac{d^{2}}{d s^{2}}\left[\frac{K_{\text {г }}\left(1-P_{A}\right) b(d+s)}{s^{2}+s(d+b)+P_{A} d b}\right]_{s=0}=\frac{2 \cdot\left(b^{2}\left(1-P_{A}\right)+d^{2}+2 b d\left(1-P_{A}\right)\right)}{b^{2} d^{2} P_{A}^{2}}, \\
D_{\text {п }}=h_{2}-h_{1}, T_{\text {д }}=T_{\text {п }}+T_{0}, \quad D_{\text {д }}=D_{\text {п }}+D_{0}, \\
T_{0}=\frac{\lambda h_{1}-\left(\lambda h_{1}\right)^{K+2}}{1-\left(\lambda h_{1}\right)^{K+2}} \cdot \frac{1-(K+1)\left(\lambda h_{1}\right)^{K}+K\left(\lambda h_{1}\right)^{K+1}}{h_{1}^{-1}\left(1-\lambda h_{1}\right)\left[1-\left(\lambda h_{1}\right)^{K+2}\right]} ;
\end{gathered}
$$

$D_{0}=T_{0}^{2}$ - математическое ожидание и дисперсия времени ожидания обслуживания [7] соответственно.

Вариант 2. Функции распределения относятся к импульсным, а значит, входящие в модель (рис. 1) величины являются детерминированными, т.е.

$$
F(t)= \begin{cases}0, & t<t_{a} \\ 1, & t \geq t_{a}\end{cases}
$$

а изображение по Лапласу функции $F(t)$ имеет вид

$$
f(s)=\exp \left(-s t_{a}\right)
$$


В данном варианте предполагаем, что входящий поток пакетов простейший. Эквивалентная функция (1) в этом случае равна

$$
Q_{2}(s)=\left(\frac{w}{w+s}\right)^{\alpha} \cdot \frac{K_{\mathrm{\Gamma}}\left(1-P_{A}\right) \exp \left(-t_{\text {оп }} s\right)}{1-P_{A} \exp \left[\left(-\left(t_{\text {оп }}+t_{\mathrm{B}}\right)\right)\right]},
$$

а функция распределения

$$
Q_{2}(t)=\left\{\begin{array}{l}
0, t \prec t_{\text {оп }}, \\
\int_{0}^{t} \frac{\mu^{\beta}}{\Gamma(\beta)} t^{\beta-1} \exp \left\{-\mu\left(t-t_{\text {оп }}\right)\right\} d t, t \geq t_{\text {оп }} .
\end{array}\right.
$$

В (4) и (5) $\mu=\frac{T_{\text {д }}}{D_{\text {д }}}, \beta=\frac{T_{\text {д }}^{2}}{D_{\text {д }}}-$ параметры масштаба и формы $\gamma$-распределения времени доставки
пакета;

$$
\begin{gathered}
h_{1}=T_{\text {п }}=-\frac{d}{d s}\left[\frac{Q_{2}(s)}{Q_{2}(0)}\right]_{s=0}=\frac{T_{\mathrm{B}}+T_{\text {оп }}}{\left(1-P_{A}\right)}+T_{\mathrm{в}}, \\
D_{i}=\frac{d^{2}}{d s^{2}}\left[\frac{Q_{2}(s)}{Q_{2}(0)}\right]_{s=0}-h_{1}^{2}=\frac{P_{A}\left(T_{\text {оп }}+T_{\mathrm{B}}\right)^{2}}{\left(1-P_{A}\right)^{2}}, \\
T_{0}=\frac{\lambda h_{1}-\left(\lambda h_{1}\right)^{K+2}}{1-\left(\lambda h_{1}\right)^{K+2}} \cdot \frac{1-(K+1)\left(\lambda h_{1}\right)^{K}+K\left(\lambda h_{1}\right)^{K+1}}{h_{1}^{-1}\left(1-\lambda h_{1}\right)\left[1-\left(\lambda h_{1}\right)^{K+2}\right]}, \\
T_{\text {д }}=T_{\text {п }}+T_{0}, D_{\text {д }}=D_{\text {п }}+D_{0}, D_{0}=T_{0}^{2} .
\end{gathered}
$$

Вариант 3. Функции распределения случайных величин описываются $\gamma$-распределением, T.e.

$$
F(t)=\int_{0}^{t} \frac{g^{\varepsilon}}{\Gamma(\varepsilon)} t^{\varepsilon-1} \exp \{-g t\} d t
$$

где $g=\frac{T}{D}, \varepsilon=\frac{T^{2}}{D}-$ параметры масштаба и формы $\gamma$-распределения; $T, D$ - математическое ожидание и дисперсия случайного времени реализации элементарного процесса соответственно рассматриваемым (в нашем случае времени однократной передачи или восстановления работоспособности после КА).

Изображение по Лапласу функции $F(t)$ имеет вид

$$
f(s)=\left(\frac{g}{g+s}\right)^{\varepsilon}
$$


В данном варианте предполагаем, что входящий поток пакетов также является простейшим. Эквивалентная функция (1) в этом случае равна

а функция распределения

$$
Q_{2}(s)=\left(\frac{\omega}{\omega+s}\right)^{\alpha} \frac{K_{\mathrm{r}}\left(1-P_{A}\right)\left(\frac{\vartheta}{\vartheta+s}\right)^{\varphi}}{1-P_{A}\left(\frac{\vartheta}{\vartheta+s}\right)^{\varphi}\left(\frac{d}{d+s}\right)^{\delta}},
$$

$$
Q_{2}(t)=\int_{0}^{t} \frac{\mu^{\beta}}{\Gamma(\beta)} t^{\beta-1} \exp \left\{-\mu\left(t-t_{\text {оп }}\right)\right\} .
$$

В (6) и (7) $\vartheta=\frac{T_{\text {оп }}}{D_{\text {оп }}}, \varphi=\frac{T_{\text {оп }}^{2}}{D_{\text {оп }}}-$ параметры масштаба и формы $\gamma$-распределения времени передачи пакета данных, имеющего случайный объем; $d=\frac{T_{\text {в }}}{D_{\text {в }}}, \delta=\frac{T_{\text {в }}}{D_{\text {в }}}$ параметры масштаба и формы $\gamma$-распределения времени обнаружения и нейтрализации КА; $T_{\text {оп, }} D_{\text {оп }}-$ среднее время и дисперсия времени передачи пакета данных случайного объема; $T_{\text {в }}, D_{\text {в }}$ - среднее время и дисперсия времени обнаружения и нейтрализации КА;

$$
\begin{gathered}
T_{\text {п }}=h_{1}-\frac{d}{d s}\left[\frac{Q_{2}(s)}{Q_{2}(0)}\right]_{s=0}=\frac{T_{\text {в }}+T_{\text {оп }}}{\left(1-P_{A}\right)}+T_{\text {в }}, \\
D_{\text {п }}=\frac{d^{2}}{d s^{2}}\left[\frac{Q_{2}(s)}{Q_{2}(0)}\right]_{s=0}-h_{1}^{2}=\frac{\left(T_{\text {оп }}+T_{\text {в }}\right)^{2}-\left(1-P_{A}\right)\left[\left(T_{\text {оп }}+t_{\text {в }}\right)^{2}-D_{\text {оп }}-D_{\text {в }}\right]-D_{\text {в }}\left(1-P_{A}\right)}{\left(1-P_{A}\right)^{2}}, \\
T_{0}=\frac{\lambda h_{1}-\left(\lambda h_{1}\right)^{K+2}}{1-\left(\lambda h_{1}\right)^{K+2}} \cdot \frac{1-(K+1)\left(\lambda h_{1}\right)^{K}+K\left(\lambda h_{1}\right)^{K+1}}{h_{1}^{-1}\left(1-\lambda h_{1}\right)\left[1-\left(\lambda h_{1}\right)^{K+2}\right]}, D_{0}=T_{0}^{2}, \\
T_{\text {д }}=T_{\text {п }}+T_{0}, D_{\text {д }}=D_{\text {п }}+D_{0} ;
\end{gathered}
$$

$\mu=\frac{T_{\text {д }}}{D_{\text {д }}}, \beta=\frac{T_{\text {д }}^{2}}{D_{\text {д }}}-$ параметры масштаба и формы $\gamma$-распределения времени доставки пакета.

Вариант 4. Функции распределения случайных величин описываются $\gamma$-распределением, а входящий поток пакетов - распределениями Вейбулла или Парето.

Основной особенностью данного варианта является самоподобность входящего потока пакетов данных, поэтому его отличие состоит в определении математического ожидания и дисперсии времени ожидания с учетом вариативности входящего потока.

В [8] было получено преобразование Лапласа-Стилтьеса для функции распределения времени ожидания, учитывающее емкость накопителя и вариативность потока:

$$
w(s)=\frac{\theta \rho(1-\rho)}{1-\rho^{K+2}} C^{2} \frac{1-\left(\frac{\lambda}{s+\theta}\right)}{(s+\theta-\lambda)}
$$


дифференцирование которого позволяет рассчитать математическое ожидание [9]

$$
T_{0}=\frac{T_{\Pi} C^{2} \rho\left(1-\rho^{\frac{K}{C^{2}+1}}\right)\left[K \rho^{K}(1-\rho)+\rho^{K}-1\right]}{\left(1-\rho^{\frac{K}{C^{2}}+2}\right)\left(1-\rho^{K}\right)(\rho-1)}
$$

и дисперсию времени ожидания обслуживания [9]

$$
D_{o}=\frac{T_{\Pi}^{2} C^{4} \rho\left(1-\rho^{\frac{K}{C^{2}}+1}\right)\left[2\left(1-\rho^{K}\right)+K \rho^{K}(1-\rho)[\rho(K+1)-K-3]\right]}{\left(1-\rho^{\frac{K}{C^{2}}+2}\right)\left(1-\rho^{K+1}\right)(1-\rho)^{2}}-T_{o}^{2} .
$$

В (8) и (9) $C^{2}=\frac{C_{\lambda}^{2}+C_{h}^{2}}{2}, \theta=T_{\text {п }}^{-1}, C_{h}^{2}=\frac{D_{\Pi}}{T_{\Pi}^{2}}, C_{\lambda}^{2}-$ квадратичный коэффициент вариации входящего потока данных.

Квадратичный коэффициент $C_{\lambda}^{2}$ определяется исходя из используемой модели потока данных. Так, для потока Вейбулла [10-13]

$$
C_{\lambda w}^{2}=\frac{\Gamma\left(1+2 / \alpha_{w}\right)}{\Gamma^{2}\left(1+1 / \alpha_{w}\right)}-1,
$$

а для потока Парето [10-13]

$$
C_{\lambda p}^{2}=\frac{1}{\alpha_{p}\left(\alpha_{p}-2\right)} .
$$

В (10) и (11) $\alpha_{p}=2-2 H ; \alpha_{w}=3-2 H-$ параметры формы распределения Парето и Вейбулла соответственно; $H$ - индекс Херста.

Таким образом, функция распределения времени доставки пакетов данных находится следующим образом:

$$
Q_{4}(t)=\int_{0}^{t} \frac{\mu^{\beta}}{\Gamma(\beta)} t^{\beta-1} \exp \left\{-\mu\left(t-t_{\text {оп }}\right)\right\} d t
$$

В (12) $d=\frac{T_{\mathrm{B}}}{D_{\mathrm{B}}}, \delta=\frac{T_{\mathrm{B}}}{D_{\mathrm{B}}}-$ параметры масштаба и формы $\gamma$-распределения времени обнаружения и нейтрализации КА; $T_{\text {в }}, D_{\text {в }}$ - среднее время и дисперсия времени обнаружения и нейтрализации КА; $\mu=\frac{T_{\text {д }}}{D_{\text {д }}}, \beta=\frac{T_{\text {д }}^{2}}{D_{\text {д }}}-$ параметры масштаба и формы $\gamma$-распределения времени доставки;

$$
\begin{gathered}
T_{\text {п }}=h_{1}-\frac{d}{d s}\left[\frac{Q_{2}(s)}{Q_{2}(0)}\right]_{s=0}=\frac{T_{\mathrm{B}}+T_{\text {оп }}}{\left(1-P_{A}\right)}+T_{\mathrm{B}}, \\
D_{\text {п }}=\frac{d^{2}}{d s^{2}}\left[\frac{Q_{2}(s)}{Q_{2}(0)}\right]_{s=0}-h_{1}^{2}=\frac{\left(T_{\text {оп }}+T_{\mathrm{B}}\right)^{2}-\left(1-P_{A}\right)\left[\left(T_{\text {оп }}+t_{\mathrm{B}}\right)^{2}-D_{\text {оп }}-D_{\mathrm{B}}\right]-D_{\mathrm{B}}\left(1-P_{A}\right)}{\left(1-P_{A}\right)^{2}},
\end{gathered}
$$




$$
T_{\text {д }}=T_{\text {п }}+T_{0}, D_{\text {д }}=D_{\text {п }}+D_{0} ;
$$

$T_{\text {оп, }} D_{\text {оп }}$ - среднее время и дисперсия времени передачи пакета данных случайного объема.

По соотношениям (3), (5), (7) и (12) были произведены расчеты, результаты которых представлены на рис. 2 и 3.

Расчеты производились при следующих исходных данных: среднее время и дисперсия однократной передачи пакета данных равны $T_{\text {оп }}=1,1$ с и $D_{\text {в }}=3 \mathrm{c}^{2}$; среднее время и дисперсия времени

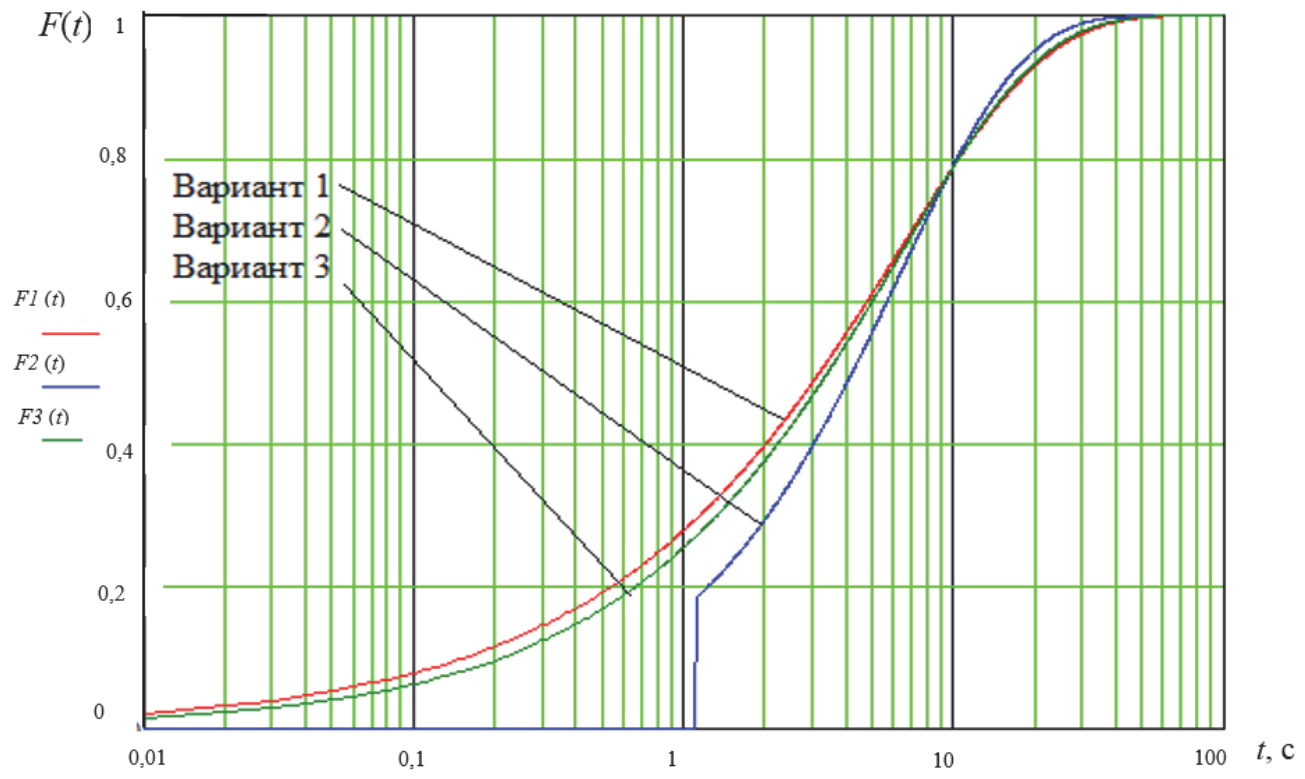

Рис. 2. Графики функций распределения времени доставки пакетов данных в канале связи в условиях КА нарушителя



Рис. 3. Графики функции распределения времени доставки пакетов данных в условиях КА нарушителя 
обнаружения и нейтрализации КА $T_{\text {в }}=3 \mathrm{c}, D_{\text {в }}=5 \mathrm{c}^{2}$; коэффициент готовности каналообразующей аппаратуры $K_{\mathrm{r}}=0,997$; вероятность успешной реализации нарушителем КА $P_{A}=0,2$; интенсивность входящего потока $\lambda=0,1$ пакетов/с, а емкость накопителя $K=50$.

При расчете по варианту 4 (рис. 3) предполагалось, что поток пакетов описывается моделями Вейбулла и Парето с индексом Херста $H=0,75$.

Анализ полученных результатов:

1. Результаты расчетов, полученные по вариантам 1-3, достаточно близки и полностью совпадают при дисперсиях исходных случайных величин, равных квадрату их математического ожидания. То есть в этом случае прилагать усилия по обоснованию и выбору вида функций распределений исходных случайных величин не имеет смысла. С увеличением дисперсий исходных случайных величин более точные результаты позволяет получить вариант 3 решения задачи. С уменьшением дисперсий до сотых долей исходных величин увеличивается разница между значениями функций распределений, соответствующих вариантам 1 и 2, в то время как указанная разница уменьшается при использовании для расчетов по вариантам 2 и 3 . Таким образом, наиболее общим является вариант решения задачи 3 .

Сопоставление вариантов 3 и 4 показывает, что при $H=0,5$, что соответствует пуассоновскому потоку данных, результаты расчетов совпадают. С увеличением значения Н увеличивается квадратичный коэффициент вариации, что приводит к существенному росту среднего и дисперсии времени доставки. При этом наиболее сложные условия для доставки данных возникают при потоке Парето. Так как вариант 4 позволяет учитывать характеристики трафика и дисперсии исходных случайных величин, то он дает возможность получать более обоснованные оценки вероятности и времени доставки, а потому является и более предпочтительным в использовании при оценке времени доведения данных до исполнительных подсистем.

2. С повышением вероятности успешной реализации нарушителем КА резко возрастает время и снижается вероятность успешной доставки пакетов данных. Следовательно, наблюдаемое на практике внезапное увеличение задержки данных может служить признаком деструктивного кибервоздействия нарушителя на каналообразующие системы и актуализирует решение задачи раннего обнаружения КА нарушителя, например, методами, описанными в [14]. Кроме того, в условиях КА резко возрастает влияние на значения вероятности и дисперсии времени доставки среднего времени обнаружения и нейтрализации КА. При этом влияние дисперсии времени восстановления работоспособности канала связи на вероятность и время доставки данных незначительно, что позволяет использовать в качестве исходного экспоненциальное распределение времени восстановления работоспособности канала связи после КА.

3. Реализация КА злоумышленником на каналообразующее оборудование оказывает влияние не только на время доставки пакетов данных, но и на реальную пропускную способность канала связи, определяемую как $\lambda_{p}=\lim _{t \rightarrow \infty} \frac{\frac{d}{d t} F(t)}{1-F(t)} \approx \frac{1}{T_{\text {д }}}$. Слабая зависимость интенсивности потока успешно доставленных пакетов и их близость к $\left(1 / T_{\text {п }}\right)$ показывает, что при функционировании в условиях информационных воздействий злоумышленника поток данных на выходе канала связи и входе оконечного оборудования пользователя можно считать пуассоновским. Результаты расчетов показывают: при успешной реализации КА интенсивность потока доставленных пакетов резко уменьшается, а это может служить дополнительным признаком для администратора сети и пользователей, что оборудование подверглось КА и необходима реализация мер по защите от информационного воздействия нарушителя. Это может позволить сократить время восстановления функционирования канала передачи данных после реализации КА нарушителем. 


\section{Заключение}

На основании общих принципов построения и функционирования современных телекоммуникационных сетей и обеспечения качества предоставляемых услуг пользователям при передаче разнородного трафика предложен подход для учета процессов функционирования каналов передачи информации в сети передачи данных при произвольных распределениях времени поступления и обслуживания пакетов.

Подход основан на представлении процесса доставки данных в виде стохастической сети, определении ее эквивалентной функции, вычислении начальных и центральных моментов времени ожидания и обслуживания, расчете параметров масштаба и формы неполной $\gamma$-функции с последующим нахождением значений функции распределения времени успешной доставки пакетов данных (см. формулы (2)-(12)).

Новизна предложенного подхода заключается в учете параметров модели реализации КА злоумышленником, задаваемых в виде вероятности реализации атаки на каналообразующее оборудование. Показаны преимущества использования в качестве исходных распределений $\gamma$-распределения как наиболее общего из распределений случайного времени реализации частных процессов, реализуемых при установлении и ведении связи в действующих и перспективных системах обмена данными.

Такой подход позволяет получать оценки качества функционирования каналов связи в условиях КА как при передаче стационарного пуассоновского, так и самоподобного трафика, представляемого моделями потоков Вейбулла и Парето.

Предложенный подход показал, что получаемые результаты оценки хорошо согласуются с данными, приведенными в ранее опубликованных работах $[10-13,15]$, а это дает возможность анализировать и вырабатывать направления по повышению качества функционирования каналов связи в условиях деструктивного информационного воздействия нарушителя.

\section{Библиографический список}

1. Журнал «Международная жизнь». - URL : https://interaffairs.ru/jauthor/material/2453 (дата обращения : 06.02.2021 г).

2. Шелухин О. И. Причины самоподобия телетрафика и методы оценки показателя Херста / О. И. Шелухин // Электротехнические и информационные комплексы и системы. - 2007. - Т. 3. - № 1. - С. 5-14.

3. Босько В.В. Математическая GERT-модель технологии передачи метаданных в облачные антивирусные системы / В. В. Босько, А. А. Смирнов, И. А. Березюк, М. Абу Таам Гани // Збірник наукових праць «Системи обробки інформації». - Харьков : ХУПС, 2014. - Вып. 1 (117). - С. 137-141.

4. Коцыняк М. А. Киберустойчивость информационно-телекоммуникационной сети / М. А. Коцыняк, И. А. Кулешов, А. М. Кудрявцев, О. С. Лаута. - СПб. : Бостон-спектр, 2015. -150 с.
5. Привалов А. А. Метод топологического преобразования стохастических сетей и его использование для анализа систем связи ВМФ / А. А. Привалов.СПб. : ВМА, 2000.- 166 с.

6. Куделя В.Н. Методы математического моделирования систем и процессов связи / В.Н. Куделя, А. А. Привалов.- СПб. : Изд-во Политехн. ун-та, 2009. $-368 \mathrm{c}$.

7. Назаров А.Н. Модели и методы расчета показателей качества функционирования узлового оборудования и структурно-сетевых параметров сетей связи следующего поколения. - 2-е изд., доп. и перераб. / А. Н. Назаров, К. И. Сычев.- Красноярск : Издво ООО «Поликом», 2011.- $491 \mathrm{c}$.

8. Кучерявый А.Е. Сети связи следующего поколения / А.Е. Кучерявый, А. Л. Цуприков. - М. : ФГУП ЦНИИС, 2006.- 278 с.

9. Назаров А.Н. Модели и методы исследования процессов функционирования узлов коммутации се- 
тей связи следующего поколения при произвольных распределениях поступления и обслуживания заявок различных классов качества / А.Н. Назаров, К. И. Сычев // Телекоммуникации и транспорт. - 2012. - № 7. C. 135-140.

10. Norros I. On the use of fractional brownian motion in the theory of connectionless networks / I. Norros // IEEE Journal on Selected Areas in Communications. 1995. - Vol. 13. - P. 953-962.

11. Крылов В. В. Теория телетрафика и ее приложения / В. В. Крылов, С. С. Самохвалова. - СПб. БХВ-Петербург, 2005. - 288 с.

12. Симонина О.А. Характеристики трафика в сетях IP / О.А. Симонина, Г. Г. Яновский // Труды учебных заведений связи. - СПб. : СПБГУТ, 2004.- № 171.C. $7-15$.

13. Одоевский С.М. Методы прогнозирования качества обслуживания самоподобного трафика в устройствах коммутации мультисервисной сети / С.М. Одоевский, В.П. Хоборова // Труды учебных заведений связи. $-2017 .-$ Т. 3. - № 3.- С. 86-92.
14. Privalov A. Increasing the sensitivity of the method of early detection of cyber-attacks in telecommunication networks based on traffic analysis by extreme filtering / A. Privalov, V. Lukicheva, I. Kotenko, I. Saenko // Energies. - 2020. - Vol. 13. - N 11. - P. 2774-2792.

15. Бельков Д. В. Актуальность исследования фрактального трафика / Д. В. Бельков // Материалы IV Междунар. науч.-практич. конференции «Постигането на висшето образование - 2008». - 2008. - Т. 12.C. $44-46$.

Дата поступления: 08.02.2021

Решение о публикации: 03.03.2021

\section{Контактная информация:}

ЛУКИЧЕВА Вера Леонидовна - соискатель; fireses@ya.ru

ПРИВАЛОВ Андрей Андреевич - д-р воен. наук, проф.; aprivalov@inbox.ru

ТИТОВ Даниил Дмитриевич - аспирант; titovdd178@gmail.ru

\title{
A model of the process of package delivering over a data transmission channel in the context of computer attacks by an intruder
}

\author{
V. L. Lukicheva, A. A. Privalov, D. D. Titov
}

Emperor Alexander I Petersburg State Transport University, 9, Moskovsky pr., Saint Petersburg, 190031, Russian Federation

For citation: Lukicheva V.L., Privalov A.A., Titov D.D. A model of the process of package delivering over a data transmission channel in the context of computer attacks by an intruder. Proceedings of Petersburg Transport University. Saint Petersburg, Petersburg State Transport University, 2021, vol. 18, iss. 2, pp. $229-241$. (In Russian) DOI: 10.20295/1815-588X-2021-2-229-241

\section{Summary}

Objective: To analyze the impact of computer attacks on the performance quality of data transmission channels and channeling systems. It is also necessary to take into account the capabilities of an intruder to introduce malware into channeling systems when committing a computer attack. Methods: To determine the required design ratios, several options for setting various distribution functions characterizing the parameters used as input data and types of inbound streams have been considered, taking into account the parameters of the intruder's computer attack model set by the values of the probability of successful attack. Mathematical modeling is carried out using the method of topological transformation of stochastic networks. The exponential, momentum and gamma distributions are considered as distribution functions of random variables. The solutions are presented for inbound streams corresponding to the Poisson, Weibull, 
and Pareto models. Results: The proposed approach makes it possible to assess the performance quality of data transmission channels in the context of computer attacks. These assessments make it possible to analyze the state and develop guidelines for improving the performance quality of communication channels against the destructive information impact of the intruder. Various variants of the functions of random variables distribution and various types of the inbound stream were used for modeling, making it possible to compare them, as well as to assess the possibility of using them in channels that provide users with different services. Practical importance: The modeling results can be used to build communication management decision support systems, as well as to detect attempts of unauthorized access to the telecommunications resource of transportation management systems. The proposed approach can be applied in the development of threat models to describe the capabilities of the intruder (the 'Intruder Model').

Keywords: Computer attack, telecommunication network, distribution function, stochastic network, vulnerability.

\section{References}

1. The International Affairs journal. Available at: https://interaffairs.ru/jauthor/material/2453 (accessed: February 06, 2021). (In Russian)

2. Shelukhin O.I. Prichiny samopodobiya teletrafika i metody otsenki pokazatelya Khersta [Reasons for teletraffic self-similarity and methods for assessing the Hurst exponent]. Elektrotekhnicheskiye i informatsionnyye kompleksy i sistemy [Electromechanical and information complexes and systems], 2007, vol. 3, no. 1, pp. 5-14. (In Russian)

3. Bos'ko V.V., Smirnov A.A., Berezyuk I.A. \& Abu Taam Gani M. Matematicheskaya GERT-model' tekhnologii peredachi metadannykh $\mathrm{v}$ oblachnyye antivirusnyye sistemy [Mathematical GERT model of metadata transfer technology to cloud anti-virus systems]. Zbirnik naukovikh prats' "Sistemi obrobki informatsii"' [Collection of scientific works "Information processing systems"]. Kharkov, KhUPS Publ., 2014, iss. 1 (117), pp. 137-141. (In Russian)

4. Kotsynyak M.A., Kuleshov I.A., Kudryavtsev A.M. \& Lauta O. S. Kiberustoychi-vost' informatsionno-telekommunikatsionnoy seti [Cyber-resistance of the information and telecommunication network]. Saint Petersburg, Boston-Spektr Publ., 2015, 150 p. (In Russian)

5. Privalov A.A. Metod topologicheskogo preobrazovaniya stokhasticheskikh setey $i$ ego ispol'zovaniye dlya analiza sistem svyazi VMF [A method of topological transformation of stochastic networks and its use for the analysis of communication systems of the Navy]. Saint
Petersburg, VMA [Naval Academy] Publ., 2000, 166 p. (In Russian)

6. Kudelya V.N. \& Privalov A.A. Metody matematicheskogo modelirovaniya sistem i protsessov svyazi [Methods of mathematical modeling of communication systems and processes]. Saint Petersburg, Polytechnic University Publishing House, 2009, 368 p. (In Russian)

7. Nazarov A.N. \& Sychev K. I. Modeli i metody rascheta pokazateley kachestva funktsionirovaniya uzlovogo oborudovaniya i strukturno-setevykh parametrov setey svyazi sleduyushchego pokoleniya [Models and methods for calculating performance indicators of hub equipment and structural and network parameters of the next generation communication networks]. 2-e izd., dop. i pererab. Krasnoyarsk, OOO "Polikom" Publishing House, 2011, 491 p. (In Russian)

8. Kucheryavyy A. E. \& Tsuprikov A. L. Seti svyazi sleduyushchego pokoleniya [Next generation communication networks]. Moscow, FSUE Central Research Institute of Communications Publ., 2006, 278 p. (In Russian)

9. Nazarov A. N. \& Sychev K. I. Modeli i metody issledovaniya protsessov funktsionirovaniya uzlov kommutatsii setey svyazi sleduyushchego pokoleniya pri proizvol'nykh raspredeleniyakh postupleniya i obsluzhivaniya zayavok razlichnykh klassov kachestva [Models and methods for studying the functioning of switching nodes of next generation communication networks with arbitrary distributions of receipt and management of claims of various quality grades]. "T-Comm - Telecommunications and Transport" Magazine, 2012, no. 7, pp. 135-140 (In Russian) 
10. Norros I. On the use of fractional brownian motion in the theory of connectionless networks. IEEE Journal on Selected Areas in Communications, 1995, vol. 13, pp. 953-962.

11. Krylov V.V. \& Samokhvalova S. S. Teoriya teletrafika i eye prilozheniya [Teletraffic theory and its applications]. Saint Petersburg, BHV-Petersburg Publ., 2005, 288 p. (In Russian)

12. Simonina O.A. \& Yanovskiy G. G. Kharakteristiki trafika v setyakh IP [Traffic characteristics in IP networks]. Trudy uchebnykh zavedeniy svyazi [Proceedings of Educational Institutions of Communication]. Saint Petersburg, Bonch-Bruevich St. Petersburg State University of Telecommunications, 2004, no. 171, pp. 7-15. (In Russian)

13. Odoevsky S. M. \& Khoborova V.P. Metody prognozirovaniya kachestva obsluzhivaniya samopodobnogo trafika v ustroystvakh kommutatsii mul'tiservisnoy seti [Methods for predicting the quality of self-similar traffic management in switching devices of a multiservice network]. Trudy uchebnykh zavedeniy svyazi [Proceedings of Educational Institutions of Communication], 2017, vol. 3, no. 3, pp. 86-92. (In Russian)
14. Privalov A., Lukicheva V., Kotenko I. \& Saenko I. Increasing the sensitivity of the method of early detection of cyber-attacks in telecommunication networks based on traffic analysis by extreme filtering. Energies, 2020, vol. 13, no. 11, pp. 2774-2792.

15. Bel'kov D. V. Aktual'nost' issledovaniya fraktal'nogo trafika [Relevance of fractal traffic research]. Materialy IV Mezhdunar. nauchno-praktich. konferentsii "Postiganeto na vissheto obrazovaniye - 2008" [Proceedings of the IV International Scientific and Practical Conference “Achieving Higher Education - 2008”], 2008, vol. 12, pp. 44-46. (In Russian)

Received: February 08, 2021

Accepted: March 03, 2021

\section{Author's information:}

Vera L. LUKICHEVA - Applicant; fireses@ya.ru Andrey A. PRIVALOV - Dr. Sci. of Warfare, Professor; aprivalov@inbox.ru

Daniil D. TITOV - Postgraduate Student; titovdd178@gmail.ru 
УДК 624.021

\section{Предложения по проектированию пролётных строений мостовых сооружений эстакадного типа с учетом резонансных явлений на высокоскоростной железнодорожной магистрали Москва-Петербург}

\section{В. Н. Смирнов, Л. К. Дьяченко}

Петербургский государственный университет путей сообщения Императора Александра I, Российская Федерация, 190031, Санкт-Петербург, Московский пр., 9

Для цитирования: Смирнов В.Н., Дьяченко Л.К. Предложения по проектированию пролётных строений мостовых сооружений эстакадного типа с учетом резонансных явлений на высокоскоростной железнодорожной магистрали Москва-Петербург // Известия Петербургского университета путей сообщения.-СПб.: ПГУПС, 2021.- Т. 18.- Вып. 2.- С. 242-250.

DOI: $10.20295 / 1815-588 X-2021-2-242-250$

\section{Аннотация}

Цель: Разработать предложения по проектированию инфраструктуры высокоскоростной железнодорожной магистрали (BCM) Москва-Петербург с учетом резонансных режимов, определяемых конструктивными решениями пролётных строений мостовых сооружений. Методы: Использовался анализ проектных разработок мостовых сооружений на ВСМ. Результаты: Разработаны предложения по учету резонансных режимов движения высокоскоростных поездов по мостовым сооружениям с пролётными строениями проектировки Мосгипротранса. Практическая значимость: Разработанные предложения дают возможность способствовать недопущению первого резонанса при высокоскоростном движении по ВСМ с пролётными строениями Мосгипротранса.

Ключевые слова: Высокоскоростная железнодорожная магистраль, мостовые сооружения, резонансные режимы движения.

\section{Введение}

Проблема возведения искусственных сооружений на высокоскоростных железнодорожных магистралях (BCM) имеет ряд аспектов, среди которых следует отметить недопущение работы пролётных строений мостовых сооружений ВСМ в резонансном режиме [1], которое характеризуется повышенным динамическим воздействием на мост.

\section{Резонансные режимы движения высокоскоростных поездов на мостах ВСM}

При следовании по мостовому сооружению поезда, состоящего из однотипных экипажей, пролётное строение совершает вынужденные колебания с первой частотой:

$$
v=V / B,
$$

где $B$ - длина экипажа, м; $V$ - скорость движения поезда, м/с.

Наибольшие воздействия на пролётное строение будут при совпадении частот вынуждающих колебаний подвижной нагрузки с собственной частотой самого пролётного строения. Скорость движения подвижного состава, как известно, в этом случае называется критической. Следовательно, учитывая (1), первую критическую скорость в рассматриваемом случае находим по формуле

$$
V_{\mathrm{KP}}=B v_{\text {ПС }},
$$






Рис. 1. Рекомендуемые Еврокодами частоты свободных колебаний пролётных строений

где $v_{\text {пс }}$ - собственная первая частота пролётного строения, $\mathrm{c}^{-1}$.

Задача проектировщика - запроектировать пролётное строение таким образом, чтобы установленная на участке эксплуатационная скорость движения поездов не была близкой к критической, вычисляемой по формуле (2). Для расчета критических скоростей, как это следует из (2), надо знать длину экипажа временной подвижной нагрузки $B$ и собственную частоту пролётного строения $v$.

Еврокоды [2] рекомендуют проектировать пролётные строения с собственной частотой, определяемой по рис. 1.

К сожалению, тип и параметры экипажей в настоящее время не определены, т.е. длина экипажа $B$ неизвестна, поэтому рекомендованы в виде временной подвижной, в частности, нагрузки 10 возможных поездов, с длиной экипажей от 18 до 27 м (табл. 1), что вносит существенную неопределенность при проектировании пролётного строения.

Из проектных материалов Мосгипротранса, разработанных на основе СП 453.1325800.2019
ТАБЛИЦА 1. Характеристика поездов А1-А10

\begin{tabular}{|c|c|c|c|c|}
\hline $\begin{array}{c}\text { Вариан- } \\
\text { ты по- } \\
\text { езда }\end{array}$ & $\begin{array}{c}\text { Число } \\
\text { вагоно, } \\
\text { шт. }\end{array}$ & $\begin{array}{c}\text { Длина } \\
\text { вагона, } \\
\text { м }\end{array}$ & $\begin{array}{c}\text { База } \\
\text { тележ- } \\
\text { ки, м }\end{array}$ & $\begin{array}{c}\text { Времен- } \\
\text { ная на- } \\
\text { грузка } \\
\text { на ось, } \\
\text { кН }\end{array}$ \\
\hline A1 & 18 & 18 & 2 & 170 \\
\hline A2 & 17 & 19 & 3,5 & 200 \\
\hline A3 & 16 & 20 & 2 & 180 \\
\hline A4 & 15 & 21 & 3 & 190 \\
\hline A5 & 14 & 22 & 2 & 170 \\
\hline A6 & 13 & 23 & 2 & 180 \\
\hline A7 & 13 & 24 & 2 & 190 \\
\hline A8 & 12 & 25 & 2,5 & 190 \\
\hline A9 & 11 & 26 & 2 & 210 \\
\hline A10 & 11 & 27 & 2 & 210 \\
\hline
\end{tabular}

[3], установлено, что собственным частотам пролётных строений соответствуют критические скорости при нагрузках поездов, например, A1 (длина экипажа 18 м) и A10 (длина экипажа 26 м) (табл. 2). 
ТАБЛИЦА 2. Критические скорости при подвижной нагрузке А1 и A 10

\begin{tabular}{|c|c|c|c|}
\hline \multirow{2}{*}{\begin{tabular}{|c|} 
Про- \\
лёт, \\
м
\end{tabular}} & \multirow{2}{*}{$\begin{array}{l}\text { Собствен- } \\
\text { ная } \\
\text { частота, Гц }\end{array}$} & \multicolumn{2}{|c|}{ Критическая скорость } \\
\hline & & $\begin{array}{c}\text { при нагрузке } \\
\text { A1 }\end{array}$ & $\begin{array}{c}\text { при нагрузке } \\
\text { A10 }\end{array}$ \\
\hline 22,5 & 9 & $\begin{array}{c}18 \times 9,09= \\
162 \mathrm{M} / \mathrm{c} \\
(583 \mathrm{KM} / \mathrm{ч})\end{array}$ & $\begin{array}{c}26 \times 9= \\
234 \mathrm{м} / \mathrm{c} \\
(842 \mathrm{\kappa м} / \mathrm{u})\end{array}$ \\
\hline 26,5 & 6,7 & $\begin{array}{c}18 \times 6,7= \\
120,6 \mathrm{M} / \mathrm{c} \\
(434 \text { км/ч) }\end{array}$ & $\begin{array}{c}26 \times 6,7= \\
174 \mathrm{M} / \mathrm{c} \\
(174,2 \text { км/ч) }\end{array}$ \\
\hline 33,1 & 4,5 & $\begin{array}{c}18 \times 4,5= \\
81,0 \mathrm{M} / \mathrm{c} \\
(292 \mathrm{\kappa м} / \mathrm{ч})\end{array}$ & $\begin{array}{c}26 \times 4,5= \\
117 \mathrm{M} / \mathrm{c} \\
(421 \mathrm{\kappa M} / \mathrm{ч})\end{array}$ \\
\hline 48,9 & 3,3 & $\begin{array}{c}18 \times 3,3= \\
59,4 \mathrm{~m} / \mathrm{c} \\
(214 \mathrm{\kappa м} / \mathrm{ч})\end{array}$ & $\begin{array}{c}26 \times 3,3= \\
86 \mathrm{~m} / \mathrm{c} \\
(310 \mathrm{\kappa м} / \mathrm{u})\end{array}$ \\
\hline
\end{tabular}

Как видно, в связи с неопределенностью в части параметров временной подвижной нагрузки (длин экипажей) имеет место чрезвычайно большой диапазон величин критических скоростей, откуда вытекает, что целесообразно точно установить вид временной подвижной нагрузки, которая будет курсировать по отечественным мостам ВСМ.

В соответствии с «Техническими требованиями на разработку высокоскоростного же-

ТАБЛИЦА 3. Определение первой критической скорости следования подвижного состава

\begin{tabular}{|c|c|c|}
\hline $\begin{array}{c}\text { Пролёт, } \\
\text { м }\end{array}$ & $\begin{array}{c}\text { Собственная } \\
\text { частота } \\
\text { пролётного } \\
\text { строения, Гц }\end{array}$ & $\begin{array}{c}\text { Первая } \\
\text { критическая } \\
\text { скорость при длине } \\
\text { вагона } 25 \mathrm{~m}\end{array}$ \\
\hline 22,5 & 9 & $\begin{array}{c}25 \times 9,0=225 \mathrm{~m} / \mathrm{c} \\
(810 \text { км/ч) }\end{array}$ \\
\hline 26,5 & 6,7 & $\begin{array}{c}25 \times 6,7=167,5 \mathrm{M} / \mathrm{c} \\
(603 \mathrm{\kappa м} / \mathrm{u})\end{array}$ \\
\hline 33,1 & 4,5 & $\begin{array}{c}25 \times 4,5=112,5 \mathrm{M} / \mathrm{c} \\
(405 \mathrm{\kappa м} / \mathrm{u})\end{array}$ \\
\hline 48,9 & 3,3 & $\begin{array}{c}25 \times 3,3=82,5 \mathrm{~m} / \mathrm{c} \\
(297 \mathrm{\kappa M} / \mathrm{ч})\end{array}$ \\
\hline
\end{tabular}

лезнодорожного подвижного состава» [4] при конструкционной скорости 360 км/ч рекомендуемая длина вагона по осям автосцепки составляет $25 \pm 1,0$ м. (Правда, отмечается, что по согласованию с заказчиком разработчик может предложить отличную от рекомендованной длину вагонов). Если допустить, что будет принята длина вагона 25 м, то первая критическая скорость следования высокоскоростного состава по пролётным строениям Мосгипротранса будет определяться в соответствии с табл. 3. Как из нее видно, при скорости движения 350 км/ч (примерно равной конструкционной скорости) первый резонанс для запроектированных Мосгипротрансом пролётных строений будет недостижим, но второй и третий резонансы вполне вероятны. Целесообразно сдвинуть резонансную зону пролётных строений длиной 50 м в зону более высоких скоростей, потому что при переходе к заданной скорости 350 км/ч становится возможной работа пролётного строения в резонансном режиме.

Если рассматривать нижние и верхние пределы рекомендуемых Еврокодом собственных частот пролётных строений и соответствующих им критических скоростей, то для рассматриваемых Мосгипротрансом пролётных строений получим результаты, приведенные в табл. 4.

ТАБЛИЦА 4. Верхние и нижние пределы рекомендуемых Еврокодом собственных частот пролётных строений

и соответствующих им критических скоростей

\begin{tabular}{|c|c|c|c|c|}
\hline $\begin{array}{c}\text { Про-- } \\
\text { лет, } \\
\text { м }\end{array}$ & $\begin{array}{c}\text { Соб- } \\
\text { ственная } \\
\text { частота, } \\
\text { верхний } \\
\text { предел, } \\
\text { Гц }\end{array}$ & $\begin{array}{c}\text { Крити- } \\
\text { скорость } \\
\text { при } \\
\text { длине } \\
\text { вагона } \\
25 \text { м, } \\
\text { км/ч }\end{array}$ & $\begin{array}{c}\text { Соб- } \\
\text { ственная } \\
\text { частота, } \\
\text { нижний } \\
\text { предел, } \\
\text { Гц }\end{array}$ & $\begin{array}{c}\text { Крити- } \\
\text { сеская } \\
\text { скорость } \\
\text { при } \\
\text { длине } \\
\text { вагона } \\
25 \text { м, } \\
\text { км/ч }\end{array}$ \\
\hline 22,5 & 9 & 810 & 3.9 & 351 \\
\hline 26,5 & 8,1 & 729 & 3,4 & 306 \\
\hline 33,1 & 6,8 & 612 & 3,0 & 270 \\
\hline 48,9 & 5,0 & 450 & 2,2 & 198 \\
\hline
\end{tabular}


Диапазон критических (резонансных) скоростей движения для указанных пролетов при длине экипажа 25 м представлен в табл. 5. Видно, что в зависимости от собственной частоты каждого пролётного строения диапазон критических (резонансных) скоростей в рамках пролёта весьма велик, потому иногда приходится, регулируя инерционно-жесткостные характеристики пролётного строения, добиваться при необходимости исключения резонансных явлений.

ТАБЛИЦА 5. Критические (резонансные) скорости движения для изучаемых пролетов

\begin{tabular}{|c|c|c|}
\hline $\begin{array}{c}\text { Пролёт, } \\
\text { м }\end{array}$ & $\begin{array}{c}\text { Диапазон } \\
\text { допустимых } \\
\text { по Еврокоду } \\
\text { собственных } \\
\text { частот, Гц }\end{array}$ & $\begin{array}{c}\text { Диапазон } \\
\text { первых } \\
\text { критических } \\
\text { скоростей, } \\
\text { км/ч }\end{array}$ \\
\hline 22,5 & $3,9-9,0$ & $351-810$ \\
\hline 26,5 & $3,4-8,1$ & $305-729$ \\
\hline 33,1 & $3,0-6,8$ & $270-612$ \\
\hline 48,9 & $2,2-5,0$ & $198-450$ \\
\hline
\end{tabular}

\section{Динамические коэффициенты}

Представляют интерес изменения динамических коэффициентов при следовании поездов по многопролётным мостам с критическими (резонансными) скоростями. На рис. 2 приведены данные по величинам динамического коэффициента в случае следования поезда «Сапсан» (длина вагона составляет 25,26 м) по пролётным строениям длиной по 34,2 м [2].

Пролётное строение запроектировано с собственной частотой $v_{\text {пс }}=3,94$ Гц (что укладывается в зону частот, рекомендуемых Еврокодами по рис. 1). В этом случае первая критическая скорость для пролётных строений такой длины составляет для принятого примера 3,94×25,26 = $=99,4 \mathrm{~m} / \mathrm{c}(312$ км/ч). Расчеты показывают [5-10], что при этих условиях значения динамического коэффициента в зависимости от скорости движения могут быть весьма значительными (рис. 2).

Из рис. 2 видно, что при скорости движения около 300 км/ч величина динамического коэффициента к временной подвижной нагрузке доходит до 6,8. Для недопущения этого при установленной временной подвижной нагрузке следует регулировать жесткостные и инерционные параметры пролётных строений, что делается при их проектировании.

При заданной на высокоскоростной линии скорости движения, например 350 км/ч, должны быть определены длина пролёта, изгибная жесткость и масса балок пролётных строений.



Рис. 2. Зависимость величины динамического коэффициента по прогибам середины пролётного строения длиной 34,2 м от скорости поезда «Сапсан» 
Длина пролёта мостовых сооружений эстакадного типа устанавливается по экономическим показателям (ориентировочно наименьшая стоимость сооружения достигается при равенстве стоимостей промежуточной опоры и пролётного строения). Далее необходимо тем или иным способом вывести эстакады с такими пролётами из резонансного режима (по крайней мере, уйти от первого резонанса). Методы такого выведения вытекают из обеспечения соответствующей собственной частоты пролётного строения, определяемой по формуле

$$
w^{2}=C / M,
$$

где $C$ - жесткость пролётного строения (величина, обратная прогибу балки от единичной нагрузки); $M$ - приведенная к середине пролёта масса пролётного строения; $w$ - круговая частота:

$$
w=2 \pi v
$$

Здесь $v$ - линейная частота (число колебаний в 1 с, Гц), величина, обратная периоду колебаний; $\pi=3,14$.
Изменяя инерционные $(M)$ и жесткостные $(C)$ параметры пролётного строения, можно добиться изменения величины собственной частоты и выведения пролётного строения из резонансной зоны.

Критические скорости и соответствующие им динамические коэффициенты перемещаются на графике (рис. 3) по оси абсцисс в нужном проектировщику направлении. Например, при необходимости переместить резонансный режим вертикальных колебаний пролётного строения из критической скорости 300 км/ч следует увеличить жесткость балки, поскольку критические (резонансные) скорости возрастают пропорционально квадратному корню изгибной жесткости балки.

На рис. 3 показано, что увеличение изгибной жесткости балки пролётного строения на $16 \%$ позволило сместить резонансную зону примерно на 50 км/ч, что даст возможность повысить эксплуатационные скорости до 300 км/ч без значительного увеличения динамического коэффициента.

Однако надо учитывать, что, если наряду с увеличением жесткости пролётного строения изменяется и его масса, то это влияет на значения

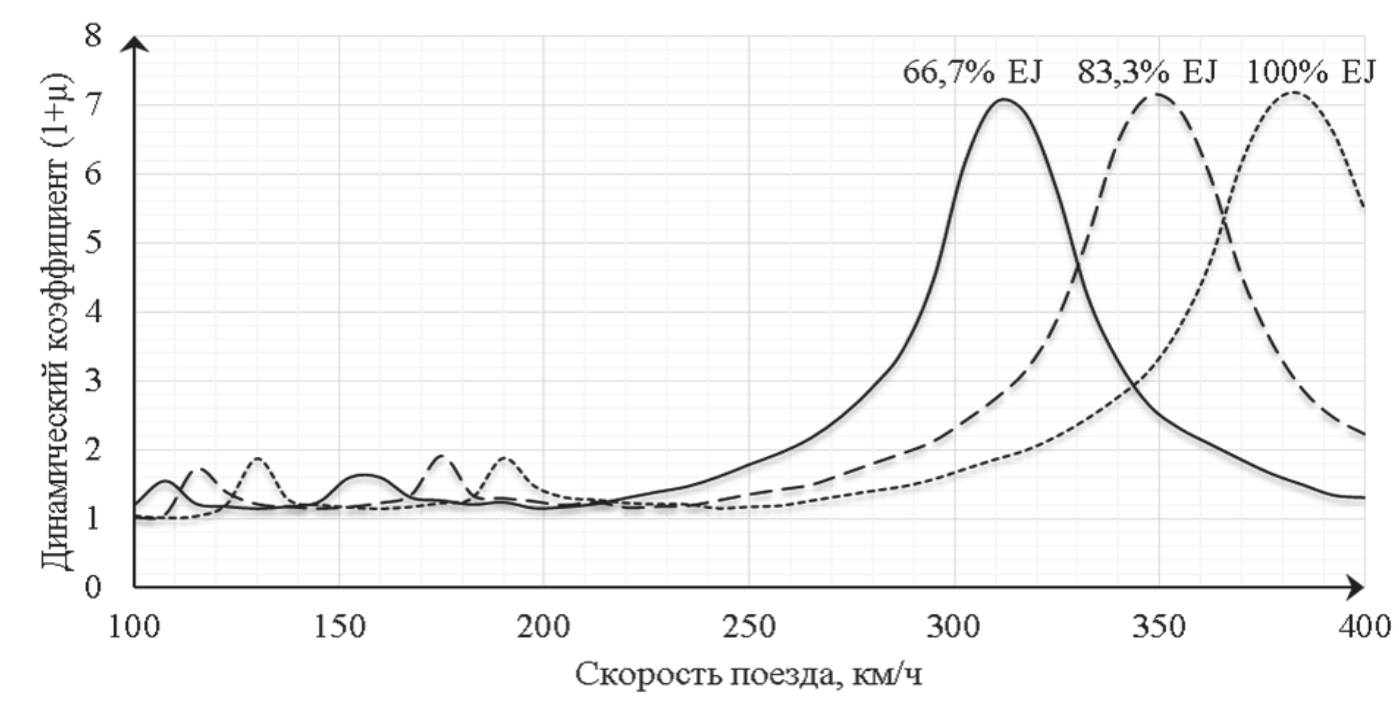

Рис. 3. Зависимость величины динамического коэффициента по прогибам середины пролётного строения длиной 34,2 м от скорости поезда Сапсан и от изгибной жесткости $(E J)$ пролётных строений 




Рис. 4. Изменение динамического коэффициента по прогибам середины пролётного строения длиной 34,2 м в зависимости от скорости поезда «Сапсан» и массы пролётных строений $(m)$

собственных частот и, как следствие, на резонансные скорости (рис. 4).

Таким образом, регулируя инерционножесткостные параметры пролётных строений, можно изменять критические скорости $V_{\text {кр }}$ и при необходимости выводить колебания пролётных строений из резонансной зоны и обеспечивать отсутствие резонанса при регламентируемых (заданных заказчиком) скоростях движения. Зону резонанса можно, следовательно, как бы переместить в область других, недостижимых, скоростей.

Надо иметь в виду, что в новой области скоростей эти меры не уменьшают динамику пролётных строений. Для снижения динамического коэффициента требуется принятие специальных мер, повышающих диссипацию (рассеяние энергии) конструкции. Следовательно, целесообразен следующий алгоритм проектирования пролётного строения под высокоскоростную нагрузку:

- устанавливается заказчиком эксплуатационная скорость движения высокоскоростной подвижной нагрузки $V_{\text {экспл }}$ по участку ВСМ (например, 350 км/ч);

- устанавливается тип экипажа на ВСМ (длина экипажа $B$ );
- конструируется пролётное строение с определением его собственных частот $v_{\text {пс1 }}, v_{\text {пс2}}, v_{\text {псз }}$; - определяются критические скорости движения временной подвижной нагрузки $V_{\text {кр1 }}=$ $=B v_{\text {ПС1 }}, V_{\mathrm{\kappa p} 2}=B v_{\text {ПС } 2}, V_{\mathrm{\kappa p} 3}=B v_{\text {ПС } 3} ;$

- полученные значения $V_{\text {кр1 }}, V_{\text {кр2 }}, V_{\text {кр3 }}$ срав-

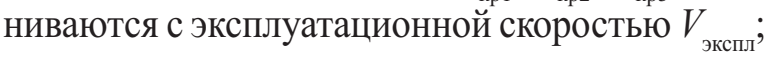

- при близости значений $V_{\text {кр1 }} V_{\text {кр2 }} V_{\text {кр3 }}$ с эксплуатационной скоростью критические скорости выводятся из резонансной зоны путем изменения жесткостных и инерционных параметров пролётного строения (пролётное строение перепроектируется).

\section{Заключение}

При проектировании мостовых сооружений эстакадного типа на ВСМ желательно точно знать тип временной подвижной нагрузки и характеристики подвижного состава. Следует также в качестве исходных данных со стороны заказчика установить требуемую эксплуатационную скорость движения на участках достаточно большой протяженности ВСМ (например, Москва-Тверь). 
Исходя из такой информации, для мостовых сооружений эстакадного типа определяется величина оптимального по экономическим соображениям пролёта, после чего выбираются жесткостные, инерционные и диссипативные параметры пролётного строения с длиной, одинаковой для эстакад всего участка трассы. Цель этого - не допустить резонансные режимы движения на данном участке и обеспечить минимальные величины динамических коэффициентов.

Предлагается использовать для всех эстакад участка одинаковые по длине пролётные строения, имеющие оптимальные инерционножесткостные и диссипативные характеристики. Это позволит на всем участке следовать с заданной постоянной скоростью при исключении неблагоприятных резонансных режимов и, следовательно, значительных по величине динамических коэффициентов.

\section{Библиографический список}

1. Смирнов В.Н. Резонансные колебания пролётных строений мостов на высокоскоростных железнодорожных магистралях / В.Н. Смирнов, Л. К. Дьяченко, Е. А. Евстигнеев // Новые технологии в мостостроении (от прошлого к будущему) : сб. трудов Междунар. науч.-технич. конференции. - Санкт-Петербург, 2122 апреля 2015 г. - СПб. : ПГУПС, 2015.- С. 67-74.

2. EN 1991-2:2003 Eurocode 1 : Actions on structures. - Pt 2 : Traffic loads on bridges. - Brussels, 2003.

3. СП 453.1325800.2019. Свод правил «Сооружения искусственные высокоскоростных железнодорожных линий. - Правила проектирования и строительства». - Утв. приказом Минстроя России от 16.12. 2019 г. - М. : Минстрой России, 2019.

4. Высокоскоростной железнодорожный подвижной состав для ВСМ. Технические требования. - М. : ОАО «РЖД», 2020.- 208 с. (проект)
5. Дьяченко Л.К. Динамические расчеты пролётных строений мостов ВСМ при движении пассажирских поездов со скоростью до 400 км/ч / Л.К. Дьяченко // Новые технологии в мостостроении (от прошлого к будущему) : сб. трудов Междунар. науч.-технич. конференции, 21-22 апреля 2015 г.-Санкт-Петербург, 2122 апреля 2015 г. - СПб. : ПГУПС, 2015. - С. 85-91.

6. Смирнов В.Н. Мосты на высокоскоростных железнодорожных магистралях / В.Н. Смирнов, А.А. Барановский, Г.И. Богданов, Д.Е. Воробьев, Л.К. Дьяченко, В. В. Кондратов. - СПб. : ПГУПС, 2015. - 274 с.

7. Бенин А. В. Особенности проектирования и строительства мостов высокоскоростной железнодорожной магистрали «Москва-Казань» / А. В. Бенин, Л. К. Дьяченко, В.Н. Смирнов // Известия Петербургского университета путей сообщения. - СПб. : ПГУПС, 2015. - № 4 (45). - С. 15-20.

8. Смирнов В.Н. Взаимодействие бесстыкового пути с мостовым сооружением на высокоскоростных магистралях / В.Н. Смирнов. - М. : Учеб.-метод. центр по образованию на железнодорожном транспорте, 2015. - 96 с.

9. Специальные технические условия «Сооружения искусственные участка Москва-Казань высокоскоростной железнодорожной магистрали “МоскваКазань-Екатеринбург”. Технические нормы и требования к проектированию и строительству». - СПб., 2014.

10. Смирнов В.Н. Динамическое взаимодействие высокоскоростного подвижного состава и пролётных строений мостов / В.Н. Смирнов, Л.К. Дьяченко // Путь и путевое хозяйство. - 2018. - № 11. - С. 16-21.

Дата поступления: 16.02.2021

Решение о публикации: 03.03.2021

\section{Контактная информация:}

СМИРНОВ Владимир Николаевич - д-р техн. наук, проф.; leonid_dyachenko@mail.ru ДьяЧЕНКО Леонид Константинович - канд. техн. наук, доц.; svn193921@rambler.ru 


\section{Proposals for the design of overhead bridge span superstructures in view of the resonance phenomena on the Moscow - Petersburg High-Speed Railway}

\section{N. Smirnov, L. K. D'yachenko}

Emperor Alexander I Petersburg State Transport University, 9, Moskovsky pr., Saint Petersburg, 190031, Russian Federation

For citation: Smirnov V.N., D'yachenko L.K. Proposals for the design of overhead bridge span superstructures in view of the resonance phenomena on the Moscow-Petersburg High-Speed Railway. Proceedings of Petersburg Transport University. Saint Petersburg, Petersburg State Transport University, 2021, vol. 18, iss. 2, pp. 242-250. (In Russian) DOI: 10.20295/1815-588X-2021-2-242-250

\section{Summary}

Objective: To develop proposals for designing the infrastructure of the Moscow - Petersburg HighSpeed Railway (HSR) in view of the resonance patterns defined by the design solutions of the overhead bridge span superstructures. Methods: The HSR bridge project designs have been analyzed. Results: Proposals have been developed to account for the resonance patterns of high-speed trains movement along overhead bridge span superstructures designed by Mosgiprotrans JSC. Practical importance: The developed proposals make it possible to prevent the primary resonance during high-speed train movement along the HSR with superstructures designed by Mosgiprotrans JSC.

Keywords: High-Speed Railway, overhead bridge, resonance patterns of movement.

\section{References}

1. Smirnov V.N., D'yachenko L.K. \& Evstigneyev E.A. Rezonansnyye kolebaniya prolyotnykh stroyeniy mostov na vysokoskorostnykh zheleznodorozhnykh magistralyakh [Resonant vibrations of bridge span superstructures on high-speed railways]. Novyye tekhnologii v mostostroyenii (ot proshlogo $\mathrm{k}$ budushchemu). Sb. trudov Mezhdunar. nauch.-tekhnicheskoy konferentsii. SanktPeterburg, 21-22 aprelya $2015 \mathrm{~g}$. [New technologies in bridge building (from the past to the future). Collection of articles. Proceedings of International Scientific and Technical Conference. St. Petersburg, April 21-22, 2015]. Saint Petersburg, PGUPS [Petersburg State Transport University] Publ., 2015, pp. 67-74. (In Russian)

2. EN 1991-2:2003 Eurocode 1: Actions on structures. - Pt 2: Traffic loads on bridges. Brussels, 2003.

3. SP 453.1325800.2019. Svod pravil "Sooruzheniya iskusstvennyye vysokoskorostnykh zheleznodorozhnykh liniy. Pravila proyektirovaniya i stroitel'stva" [Set of rules
453.1325800.2019. Engineering structures of high speed railway lines. Rules of design and construction]. Utverzhdeny prikazom Minstroya Rossii ot 16.12. 2019 [Approved by the Minstroy of Russia as of December 16, 2019]. Moscow, the Ministry of Construction of the Russian Federation Publ., 2019. (In Russian)

4. Vysokoskorostnoy zheleznodorozhnyy podvizhnoy sostav dlya VSM. Technicheskie trebovaniya [High-speed railway rolling stock for HSR. Technical requirements]. Moscow, JSC Russian Railways Publ., 2020, 208 p. (draft)

5. D'yachenko L. K. Dinamicheskiye raschety proletnykh stroyeniy mostov VSM pri dvizhenii passazhirskikh poyezdov so skorost'yu do $400 \mathrm{~km} / \mathrm{ch}$ [Dynamic calculations of the HSR bridge span superstructures during the movement of passenger trains at speeds up to $400 \mathrm{~km} / \mathrm{h}$ ]. Novyye tekhnologii v mostostroyenii (ot proshlogo k budushchemu). Sb. trudov Mezhdunar. nauch.-tekhnicheskoy konferentsii, 21-22 aprelya 2015 g. [New technologies in bridge building (from the past to the future). Collection of 
articles. Proceedings of International Scientific and Technical Conference, April 21-22, 2015]. Saint Petersburg, PGUPS [Petersburg State Transport University] Publ., 2015, pp. 85-91. (In Russian)

6. Smirnov V.N., Baranovsky A.A., Bogdanov G.I., Vorob'yev D.E., D'yachenko L. K. \& Kondratov V.V. Mosty na vysokoskorostnykh zheleznodorozhnykh magistralyakh [Bridges on high-speed railways]. Saint Petersburg, PGUPS [Petersburg State Transport University] Publ., 2015, 274 p. (In Russian)

7. Benin A. V., D'yachenko L.K. \& Smirnov V.N. Osobennosti proyektirovaniya i stroitel'stva mostov vysokoskorostnoy zheleznodorozhnoy magistrali "MoskvaKazan" [Features of design and construction of bridges of the Moscow-Kazan High-Speed Railway]. Izvestiya Peterburgskogo universiteta putey soobshcheniya [Proceedings of Petersburg Transport University]. Saint Petersburg, PGUPS [Petersburg State Transport University] Publ., 2015, no. 4 (45), pp. 15-20. (In Russian)

8. Smirnov V. N. Vzaimodeystviye besstykovogo puti s mostovym sooruzheniyem na vysokoskorostnykh magistralyakh [Interaction of a continuous welded track with a bridge on high-speed railways]. Moscow, Uchebnometodicheskiy tsentr po obrazovaniyu na zheleznodoro- zhnom transporte [Railway educational training center] Publ., 2015, 96 p. (In Russian)

9. Spetsial'nyye tekhnicheskiye usloviya "Sooruzheniya iskusstvennyye uchastka Moskva-Kazan' vysokoskorostnoy zheleznodorozhnoy magistrali Moskva-Kazan'Ekaterinburg”. Tekhnicheskiye normy i trebovaniya $k$ proyektirovaniyu i stroitel'stvu [Special technical conditions "Artificial structures of the Moscow-Kazan section of the Moscow-Kazan-Yekaterinburg High-Speed Railway". Technical standards and requirements for design and construction], 2014. (In Russian)

10. Smirnov V.N. \& D'yachenko L. K. Dinamicheskoye vzaimodeystviye vysokoskorostnogo podvizhnogo sostava i proletnykh stroyeniy mostov [Dynamic interaction of high-speed rolling stock and bridge span superstructures]. Put' i putevoye khozyaystvo [Railway Track and Facilities], 2018, no. 11, pp. 16-21. (In Russian)

Received: February 16, 2021

Accepted: March 03, 2021

\section{Author's information:}

Vladimir N. SMIRNOV - Dr. Sci. in Engineering, Professor; leonid_dyachenko@mail.ru

Leonid K. D'YACHENKO - PhD in Engineering, Associate Professor; svn193921@rambler.ru 
УДК 629.42-192(075)

\title{
Анализ надежности узлов подвижного состава на основе эксплуатационных данных
}

\author{
А. Е. Цаплин ${ }^{1}$, Ж. О. Кувондиков ${ }^{2}$ \\ ${ }^{1}$ Петербургский государственный университет путей сообщения Императора Александра I, \\ Российская Федерация, 190031, Санкт-Петербург, Московский пр., 9 \\ 2 Ташкентский государственный транспортный университет, Республика Узбекистан, \\ 100167, Ташкент, ул. Темирйулчилар, 1
}

Для цитирования: Цаплин А. Е., Кувондиков Ж. О. Анализ надежности узлов подвижного состава на основе эксплуатационных данных // Известия Петербургского университета путей сообщения. - СПб.: ПГУПС, 2021. - Т. 18. - Вып. 2 - С. 251-260.

DOI: $10.20295 / 1815-588 X-2021-2-251-260$

\section{Аннотация}

Цель: Определение узлов и агрегатов подвижного состава, которые наиболее склонны к отказам, путем обработки статистических данных, полученных при эксплуатации с использованием классической теории надежности, разработка рекомендаций по поддержанию работоспособного состояния отдельных узлов подвижного состава. Методы: Применяются методы расчета количественных характеристик надежности на основе статистических данных эксплуатации подвижного состава. Результаты: Используя данные 5-летней эксплуатации, составлена таблица, включающая статистику по частоте отказов различного оборудования подвижного состава. Вычислены показатели надежности для различных типов оборудования подвижного состава и построены соответствующие графики. Исходя из сделанных расчетов, разработаны рекомендации по техническому обслуживанию подвижного состава. Практическая значимость: Произведенные расчеты и описанные рекомендации определяют типы оборудования подвижного состава, которым следует уделять больше внимания в процессе технического обслуживания.

Ключевые слова: Надежность подвижного состава, механическое оборудование, пневматическое оборудование, тепловое оборудование, электрооборудование, среднее время до отказа, среднее время восстановления.

\section{Введение}

Возрастающая сложность технических систем определяет актуальность увеличения числа исследований в области надежности.

Параметры режима эксплуатации становятся все более интенсивными и сложными, что приводит к необходимости масштабной автоматизации производственных процессов, а также управления ими, в том числе с использованием мощных технологических компьютеров $[1,2]$. Промышленные изделия, механическое обору- дование и устройства, различные компоненты машин и т. Д.- все они могут рассматриваться как базовые единицы с автономной работой, встроенные в сложные агрегаты или установки [3].

Например, тепловоз ТЭ10 представляет собой сложный комплекс узлов и агрегатов, работающих совместно, и любой случайный отказ одного из них может привести к полному или частичному выводу локомотива из эксплуатации или к его неправильной эксплуатации. Предметом настоящей статьи является анализ надежно- 
сти важнейших узлов и агрегатов конструкции тепловоза ТЭ10 [4].

\section{Применение методики оценки надежности при диагностике системы}

Количественное понятие надежности определяется как вероятность того, что объект будет выполнять функции, для которых он предназначен, на требуемом уровне производительности в течение определенного времени при заранее установленных условиях эксплуатации [5]. Правильная работа любой технической системы характеризуется ее эксплуатационными параметрами: хорошей эксплуатационной надежностью, целостностью ее компонентов, сроком службы, свободной эксплуатацией, готовностью, работоспособностью, возможностью ремонта и восстановления [6].

В физическом подходе способность правильно управлять механическим компонентом моделируется с помощью случайной величины $S$ (прочность); компонент должен поддерживать нагрузку $L$, также определяемую как случайную величину. Допускается, что неисправность компонента возникает, как только нагрузка становится выше прочности, поэтому его надежность $R$ - это вероятность того, что прочность будет больше нагрузки:

$$
R=P_{r}(S>L),
$$

где $P_{r}(A)$ - вероятность наступления определенного события $A$ [7].

Нагрузка обычно изменяется в зависимости от времени, $L(t)$, а также от прочности элемента, $S(t)$, потому что компонент со временем ухудшается в результате действия механизмов разрушения, таких как коррозия, эрозия, износ, переутомление и т. д. На рис. 1 показана возможная зависимость от времени обеих указанных переменных величин $-S(t)$ и $L(t)$.

Длительность времени до отказа $T$ для рассматриваемого компонента - наименьшее, которое проходит до достижения условия $S(t)<L(t)$, и оно задается соотношением

$$
T=\min \{t ; S(t)<L(t)\} .
$$

В этом случае надежность компонента $R(t)$ может быть определена как

$$
R(t)=p(t)=P_{r}(T>t),
$$

где $p(t)$ - функция надежности, выражающая вероятность корректной работы, а $T$-предельное время, заданное для корректной работы [8].

\section{Показатели надежности}

Показатели (или характеристики) надежности - это определенные параметры, которые качественно и количественно выражают тот факт,



Рис. 1. Изменения нагрузки (1) и прочности компонента (2) 
что технический компонент или конструкция могут считаться надежными или нет. Данные характеристики обычно относятся к некоторым ремонтируемым элементам или некоторым компонентам (включая сложные системы), предназначенным для ремонта [9].

Если длительность времени до отказа $T$ непрерывно распределена с функцией $F(t)$ плотности надежности, то функция отказа $f(t)$, обеспечивающая вероятность отказа (вероятность того, что компонент выйдет из строя в течение периода времени $\{0, \ldots, t\})$, задается соотношением

$$
F(t)=P_{r}(T \leq t)=\int_{0}^{t} f(u) d u \text { при } t>0 .
$$

В результате функция надежности $R(t)$ из уравнения (1) можно представить в виде

$$
R(t)=1-F(t)=p(t)=P,(t>T) \text { для } t>0 .
$$

Можно сделать вывод, что $R(t)$ - это вероятность того, что рассматриваемый элемент не выйдет из строя или не будет работать нестабильно в течение периода времени $(0, t)$. Следовательно, надежность компонента $R(t)$ также известна как его функция долговечности [10].

Среднее время корректной работы представляет собой среднее арифметическое значение ее продолжительности для обследуемого статистического периода:

$$
T M B F=\frac{\sum_{i=1}^{N} t_{F_{i}}}{N},
$$

где $t_{F_{i}}$ - продолжительность корректной работы для каждого из $N$ рассматриваемых компонентов [11].

Учитывая количество отказов $N_{f}$ за общее время $T$, другой показатель надежности, а именно интенсивность отказов $\lambda$, может быть установлен так:

$$
\lambda=\frac{N_{f}}{T} .
$$

В связи с надежностью и техническим обслуживанием механических, электрических и электронных систем скорость ремонта также считается важным параметром, который рассчитывается по формуле

$$
\mu=\frac{N_{r}}{T},
$$

в которой $N_{r}$ - количество ремонтов рассматриваемого компонента в течение заданного интервала времени $T[7]$.

Интенсивность отказов (см. (2)) обычно может быть выражена как математическая функция $l(u)$ или может быть постоянной на интервале времени $(0, t)$, так что функция надежности задается соотношением

$$
R(t)=e^{\left(-\int^{t} \lambda(u) d u\right)}=e^{(-\lambda t)} .
$$

Недоступность компонента $Q(t)$ в момент $t$ или вероятность отказа в конце интервала времени $(0, t)$ может быть установлена в зависимости от интенсивности отказов и скорости ремонта для соответствующего компонента следующим образом:

$$
Q(t)=\frac{\lambda}{\lambda+\mu}\left[1-e^{-(\lambda+\mu) t}\right] .
$$

На этой основе определяется частота отказов $w(t)$ на временном интервале $(0, t)$ :

$$
w(t)=(1-Q(t)) \cdot \lambda .
$$

\section{Анализ отказов оборудования за 5-летний период для тепловоза ТЭ10}

В ходе исследований для детального анализа отказов различного рода узлов локомотива были изучены данные из рядовой эксплуатации за 2014-2018 гг. и учитывались только отказы оборудования, которые привели к некорректной работе или остановке тепловоза ТЭ10. 
Рассматривалось оборудование тепловоза следующих категорий:

1) механическое - тележки и буксовый узел, корпус локомотива, сцепные устройства;

2) пневматическое - установка производства сжатого воздуха и тормозная установка;

3) тепловое - дизельный двигатель и его вспомогательные установки;

4) электрооборудование - система электроснабжения (в том числе силовые электрические машины), электрическая система вспомогательных машин.

Количество отказов по каждой из вышеназванных категорий оборудования приведено в табл. 1. Диаграмма на рис. 2 иллюстрирует для рассматриваемого временного интервала временную зависимость числа отказов, соответствующую каждой из четырех категорий оборудования (включая электрооборудование и систему вспомогательных машин).

С одной стороны, по эксплуатационным данным можно сделать вывод, что у тепловоза ТЭ10 число отказов в электрооборудовании значительно больше, чем в остальных категориях оборудования, а пневматических дефектов меньше всего. С другой стороны, можно заметить, что количество отказов не сильно меняется от года к году для каждой категории оборудования.

ТАБЛИЦА 1. Изменения числа отказов в разных типах оборудования

\begin{tabular}{|l|c|c|c|c|c|}
\hline \multirow{2}{*}{\multicolumn{1}{|c|}{ Тип оборудования }} & \multicolumn{5}{c|}{ Число отказов за год } \\
\cline { 2 - 7 } & 2014 г. & 2015 г. & 2016 г. & 2017 г. & 2018 г. \\
\hline Механическое оборудование & 6 & 5 & 5 & 5 & 3 \\
\hline Пневматическое оборудование & 3 & 1 & 3 & 2 & 2 \\
\hline Тепловое оборудование & 12 & 6 & 7 & 7 & 7 \\
\hline Электрооборудование & 25 & 25 & 30 & 23 & 32 \\
\hline
\end{tabular}

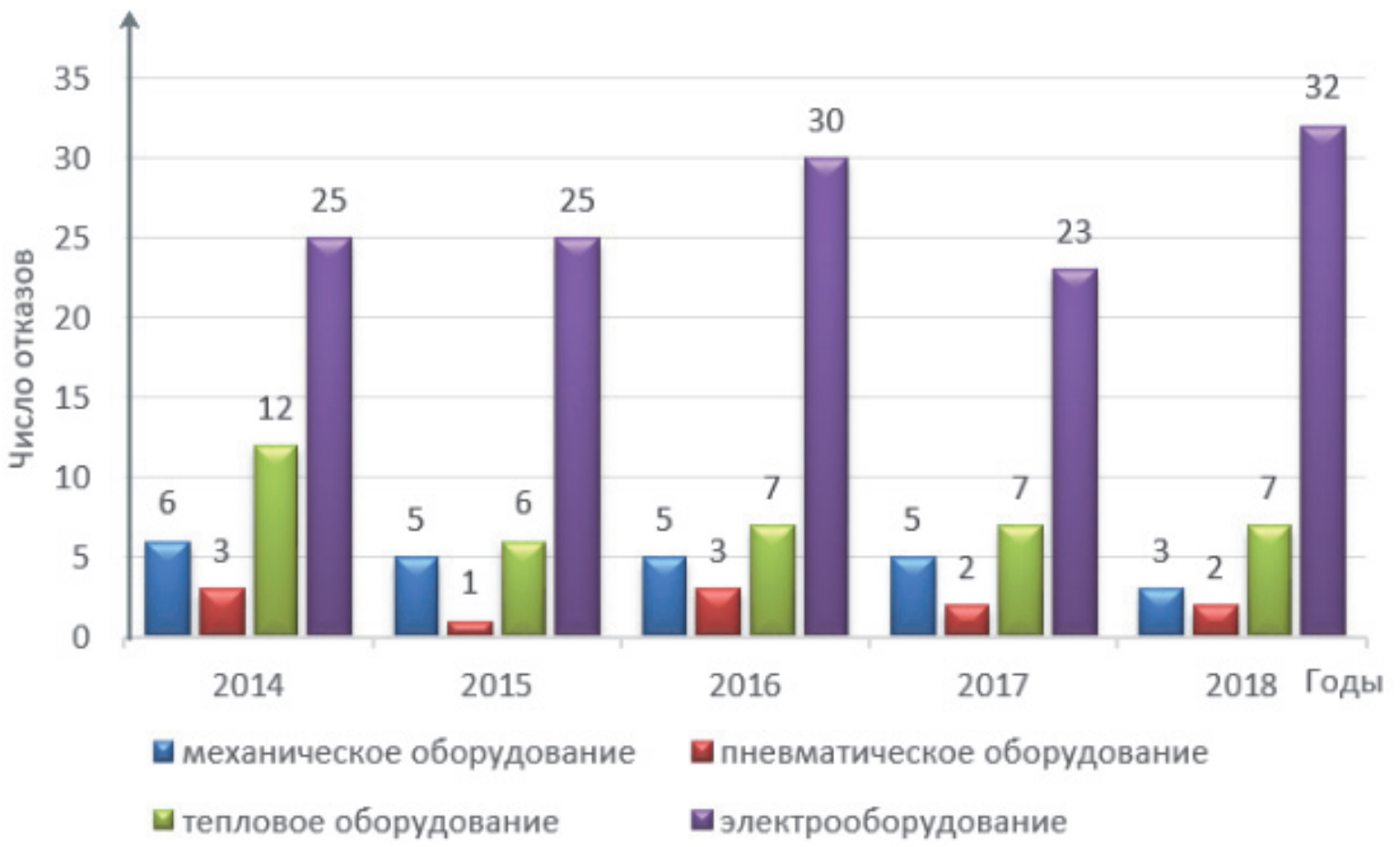

Рис. 2. Временная зависимость отказов различного оборудования 


\section{Расчет надежности \\ некоторых узлов \\ и агрегатов тепловоза ТЭ10}

Приведем типичный пример расчета надежности для механического оборудования, состоящего из подшипников буксового узла, шестерни колесно-моторного блока, элементов подвески и тормозных колодок [12].

В связи с этим количество отказов и количество ремонтов представлены в табл. 2 для каждого из упомянутых механических компонентов вместе с интенсивностью отказов и соответственно интенсивностью ремонта, которая необходима для расчета надежности компонентов. Из таблицы видно, что больше всего отказов приходится на подшипники буксового узла, а меньше всего на тормозные колодки.

Используя эти данные и принимая некоторые приблизительные, но постоянные значения по рассматриваемой длительности времени для интенсивности отказов и скорости ремонтов, были получены значения надежности и соответствующие функции отказов, относящихся к описанным элементам механического оборудования.

Данные табл. 3 были использованы для построения графических функций зависимости от времени (рис. 3) показателей надежности указанных компонентов механического оборудования для тепловоза ТЭ10.

Те же принципы были применены для определения кривых зависимости надежности от времени (рис. 4) для других рассматриваемых систем локомотива: пневматического, теплово- го, электрического и вспомогательного электрооборудования.

Проанализировав представленные графики, можно сделать следующие выводы:

- неисправности электрооборудования являются основными для рассматриваемого типа тепловоза;

- для силового оборудования чаще всего встречаются неисправности, возникающие на генераторах электроэнергии, в виде обрывов катушек на основных или вспомогательных полюсах; в первую очередь они вызваны сильными вибрациями двухтактного дизельного двигателя, приводящими к ослаблению крепежных винтов основных или вспомогательных полюсов;

- небольшое количество отказов было зарегистрировано на вспомогательном оборудовании, что можно объяснить наличием незначительного количества механических нагрузок на нем.

\section{Заключение}

Характеристики надежности устанавливаются с использованием данных, относящихся к зарегистрированным отказам компонентов для определенного временного периода [13]. Из приведенных выше фактов можно заметить, что для анализа надежности технических систем используется информация из различных областей: требуется детальное знание технической структуры системы и отдельных механизмов, которые могут привести к отказу или некорректной работе исследуемого объекта [14].

ТАБЛИЦА 2. Отказы механического оборудования

\begin{tabular}{|l|c|c|c|c|c|c|c|c|c|}
\hline \multirow{2}{*}{$\begin{array}{c}\text { Тип механического } \\
\text { оборудования }\end{array}$} & \multicolumn{3}{|c|}{ Количество отказов за год } & \multicolumn{5}{|c|}{ Общее время 43824 ч } \\
\cline { 2 - 11 } & 2014 & 2015 & 2016 & 2017 & 2018 & $\begin{array}{c}\text { Общ. } \\
\text { число } \\
\text { отказов }\end{array}$ & $\lambda$ & $\mu$ & $\begin{array}{c}\text { Общ. } \\
\text { число } \\
\text { ремонтов }\end{array}$ \\
\hline Ось двигателя & 2 & 3 & 4 & 2 & 3 & 14 & 0,0003194 & 0,00057 & 25 \\
\hline Буксовый узел & 3 & 1 & 1 & 1 & - & 6 & 0,0001369 & 0,000273 & 12 \\
\hline Элементы подвески & 1 & 1 & - & 1 & - & 3 & $6,845 \cdot 10^{-5}$ & 0,000228 & 10 \\
\hline Тормозные колодки & - & - & - & 1 & - & 1 & $2,281 \cdot 10^{-5}$ & $3,12 \cdot 10^{-5}$ & 4 \\
\hline
\end{tabular}


ТАБЛИЦА 3. Расчет надежности механических компонентов

\begin{tabular}{|c|c|c|c|c|}
\hline Механическое оборудование & Ось двигателя & Буксовый узел & $\begin{array}{l}\text { Элементы } \\
\text { подвески }\end{array}$ & $\begin{array}{c}\text { Тормозные } \\
\text { колодки }\end{array}$ \\
\hline $\begin{array}{l}\text { Общее время корректной ра- } \\
\text { боты, } \lambda, \text { ч }\end{array}$ & 0,00031946 & 0,000136911 & $6,8455 \cdot 10^{-5}$ & $2,28185 \cdot 10^{-5}$ \\
\hline Дискретное время, ч & \multicolumn{4}{|c|}{$R(t)=e^{(-\lambda t)}$} \\
\hline 0 & 1 & 1 & 1 & 1 \\
\hline 4382,4 & 0,248937733 & 0,551038244 & 0,742319503 & 0,905448229 \\
\hline 8764,8 & 0,061969995 & 0,303643146 & 0,551038244 & 0,819836495 \\
\hline 13147,2 & 0,01542667 & 0,167318986 & 0,409046435 & 0,742319503 \\
\hline 17529,6 & 0,00384028 & 0,09219916 & 0,303643146 & 0,672131879 \\
\hline 21912 & 0,000955991 & 0,050805263 & 0,225400229 & 0,608580619 \\
\hline 26294,4 & 0,000237982 & 0,027995643 & 0,167318986 & 0,551038244 \\
\hline 30676,8 & $5,92427 \cdot 10^{-5}$ & 0,01542667 & 0,124204147 & 0,498936602 \\
\hline 35059,2 & $1,47478 \cdot 10^{-5}$ & 0,008500685 & 0,09219916 & 0,451761263 \\
\hline 39441,6 & $3,67127 \cdot 10^{-6}$ & 0,004684203 & 0,068441235 & 0,409046435 \\
\hline 43824 & $9,13918 \cdot 10^{-7}$ & 0,002581175 & 0,050805263 & 0,37037037 \\
\hline$Q(t)=\frac{\lambda}{\lambda+\mu}\left[1-e^{-(\lambda+\mu) t}\right]$ & 0,000317164 & 0,00013594 & $6,7972 \cdot 10^{-5}$ & $2,2657 \cdot 10^{-5}$ \\
\hline$w(t)=(1-Q(t)) \cdot \lambda$ & 0,000319358 & 0,000136893 & $6,8451 \cdot 10^{-5}$ & $2,2818 \cdot 10^{-5}$ \\
\hline$Q_{\text {общий }}$ & 0,000543733 & & & \\
\hline$W_{\text {общий }}$ & 0,00054752 & & & \\
\hline
\end{tabular}

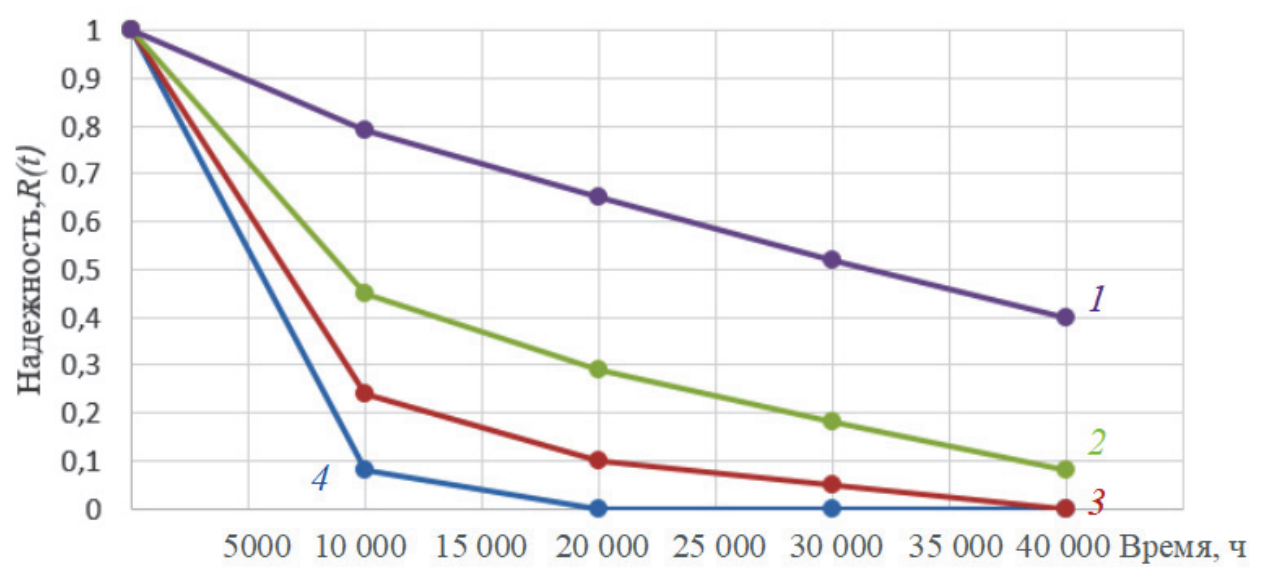

Рис. 3. Зависимость надежности от времени для механических компонентов:

1 - тормозные колодки; 2 - элементы рессорного подвешивания;

3 - буксовый узел; 4 - ось якоря 
$a$

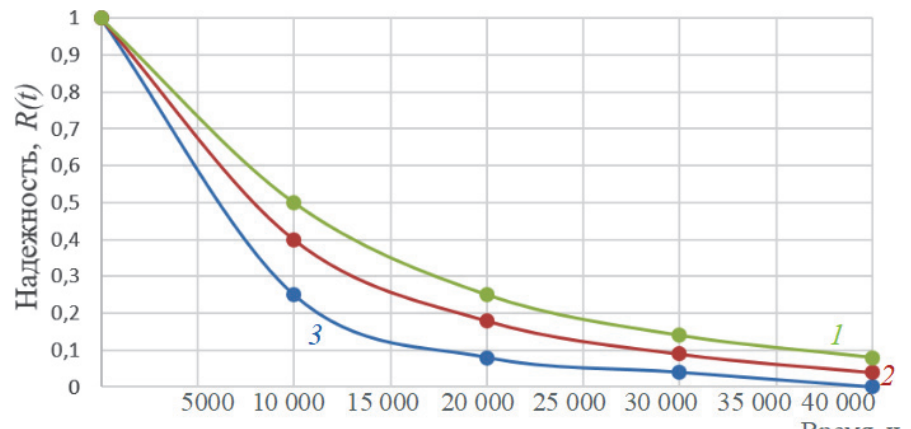

$\sigma$

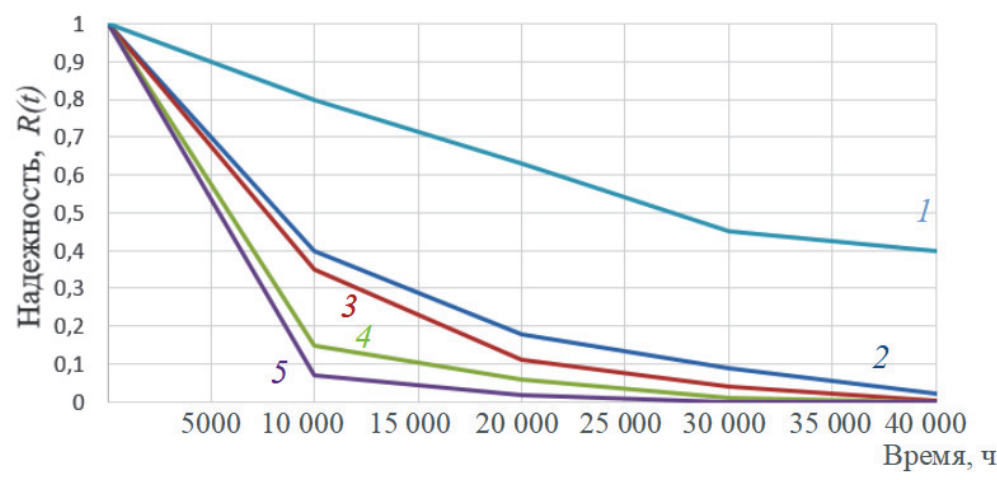

b

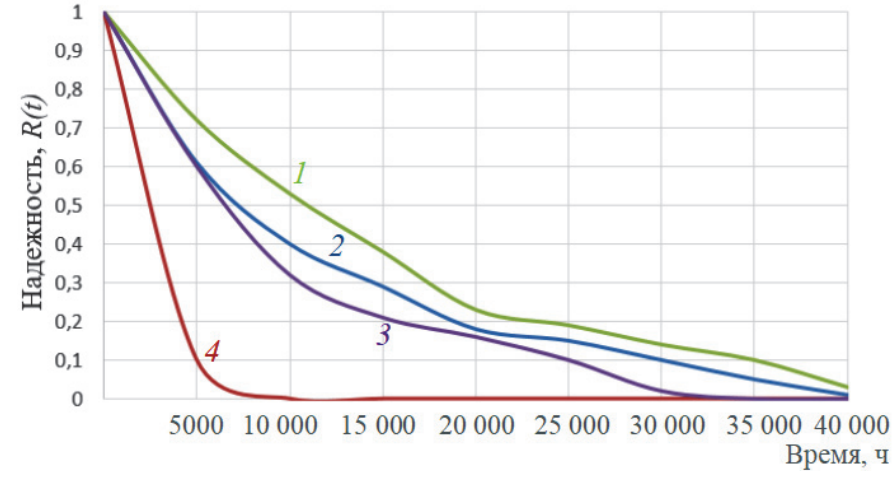

2

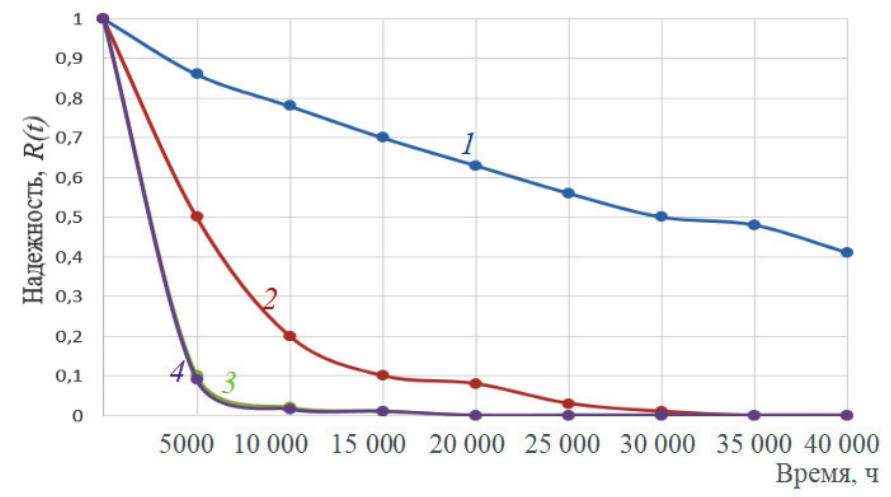

Рис. 4. Изменения надежности пневматического ( $a)$, теплового (б), электрического тягового (в) и вспомогательного оборудования (2):

$a: 1$ - тормозные цилиндры, 2 - магистраль сжатого воздуха, 3 - компрессор сжатого воздуха;

б: 1 - система подачи воздуха, 2 - дизельный двигатель, 3 - система смазки, 4 - топливная система, 5 - система охлаждения; $6: 1$ - основной генератор, 2 - силовые выключатели, 3 - установка обогрева локомотива, 4 - тяговые двигатели; г: 1 - вспомогательный генератор, 2 - предохранители и выключатели, 3 - аккумуляторы, 4 - контакторы и реле 
Представленный в статье подход дает возможность анализировать типы отказов и способствует выявлению компонентов, склонных к отказу в кратчайшие сроки эксплуатации. Результаты анализа позволяют принять некоторые дополнительные меры по ремонту и техническому обслуживанию в соответствии с вероятностью отказа для каждого из компонентов технической системы. В связи с этим было замечено, что для рассматриваемого тепловоза необходимо более частое техническое обслуживание вспомогательного электрического оборудования (рис. 4,2$)$ и электрогенератора (рис. 4, в).

\section{Библиографический список}

1. UNIFE World Rail Market Study // Status quo and outlook 2020.-3rd ed. - Brussels : UNIFE, 2010.-P. 23 24.

2. Marktvolumen im Neu- und Servicegeschaeft sowie Perspektiven der Marktentwick - lung bei Infrastruktur und Schienenfahrzeugen // Weltmarkt Bahntechnik, 2009-2014. - Koeln : SCI Verkehr GmbH Publ., 2010.$250 \mathrm{p}$.

3. Райншке К. Оценка надежности систем с использованием графов / К. Райншке, И. А. Ушаков ; под ред. И. А. Ушакова. - М. : Радио и связь, 1988. - 145 с.

4. Годовалый А. Т. Электроподвижной состав. Эксплуатация, надежность и ремонт : учебник для вузов ж.-д. транспорта / А. Т. Годовалый, И.П. Исав, П.И. Борцов и др.- М. : Транспорт, 1983. - 106 с.

5. Дружинин Г.В. Надежность автоматизированных производственных систем. - 4-е изд. / Г. В. Дружинин. - М. : Энергоатомиздат, 1986.- 360 с.

6. Горский А. В. Методика расчета надежности электроподвижного состава как сложной системы : дис. ... канд. техн. наук, специальность : 05.22.07/ А. В. Горский.- М. : МИИТ, 1968.- 168 с.
7. Исаев И. П. Определение эксплуатационных коэффициентов электроподвижного состава с учетом последействия в процессе его функционирования / И. П. Исаев, А. В. Горский, В. А. Козырев // Труды МИИТ.- 1976. - Вып. 524. - С. 66-73.

8. Пузанков А. Д. Методы расчета и использования показателей надежности в эксплуатации : учеб. пособие для вузов ж.-д. транспорта / А. Д. Пузанков. - М. : МИИТ, 2004. - 49 с.

9. Горский А. В. Оптимизация системы ремонта локомотивов / А. В. Горский, А. А. Воробьев.- М. : Транспорт, 1994.- 83 с.

10. Плохих И. В. Совершенствование методики оценки показателей готовности и их анализ для высокоскоростного поезда Velaro Rus - Сапсан с учетом опыта России и Германии : дис. ... канд. техн. наук, специальность : 05.22.07 / И.В. Плохих.- М. : МИИТ, 2013.- $217 \mathrm{c}$.

11. Гнеденко Б. В. Математические методы в теории надежности / Б. В. Гнеденко, Ю. К. Беляев, А. Д. Соловьев. - М. : Наука, 1965.- 26 с.

12. Штраус П. Надежность и техническое обслуживание железнодорожного подвижного состава : отчет о НИР / П. Штраус. - Дрезден : Высшая школа техники и экономики города, 2010.- 91 c.

13. Надежность в технике. Планы испытаний для контроля коэффициента готовности. - М. : Стандартинформ, 2010.- $16 \mathrm{c}$.

14. Elsayed A. Reliability engineering / A. Elsayed.Massachusetts : Addison Wesley Longman Inc., 1996.$113 \mathrm{p}$.

Дата поступления: 01.03.2021

Решение о публикации: 15.04.2021

\section{Контактная информация:}

ЦАПЛИН Алексей Евгеньевич - канд. техн. наук, доц.; tsaplin.alexey@mail.ru

КУВОНДИКОВ Жалолиддин Олимбой угли аспирант, ассистент; jaloliddin1690@gmail.com 


\title{
Analyzing the reliability of rolling stock units based on operational data
}

\author{
A. E. Tsaplin ${ }^{1}$, Zh. O. Kuvondikov² \\ ${ }^{1}$ Emperor Alexander I Petersburg State Transport University, 9, Moskovsky pr., Saint Petersburg, \\ 190031, Russian Federation \\ ${ }^{2}$ Tashkent State Transport University, 1, Temiryulchilar ul., Tashkent, 100167, Republic of Uzbekistan
}

For citation: Tsaplin A.E., Kuvondikov Zh. O. Analyzing the reliability of rolling stock units based on operational data. Proceedings of Petersburg Transport University. Saint Petersburg, Petersburg State Transport University, 2021, vol. 18, iss. 2, pp. 251-260. (In Russian)

DOI: $10.20295 / 1815-588 X-2021-2-251-260$

\section{Summary}

Objective: To determine the most failure-prone rolling stock components and assemblies by processing statistical data obtained during operation using the classical reliability theory; to develop recommendations for maintaining the operational state of individual rolling stock components. Methods: Methods for calculating the quantitative reliability characteristics are used based on the rolling stock operational statistical data. Results: The 5-year operational data have been used to provide tabulated statistics on the failure rate of various rolling stock equipment. Reliability indicators have been calculated for various types of rolling stock equipment and the corresponding graphs have been plotted. Based on the calculations, the recommendations for the rolling stock maintenance have been developed. Practical importance: The calculations and the recommendations described determine the types of rolling stock equipment requiring more attention during maintenance.

Keywords: Rolling stock reliability, mechanical equipment, pneumatic equipment, heating equipment, electric equipment, mean time-to-failure, mean recovery time.

\section{References}

1. UNIFE World Rail Market Study. Status quo and outlook 2020. 3rd ed. Brussels, UNIFE Publ., 2010, pp. 23-24.

2. Marktvolumen im Neu- und Servicegeschaeft sowie Perspektiven der Marktentwick - lung bei Infrastruktur und Schienenfahrzeugen. Weltmarkt Bahntechnik, 20092014. Koeln, SCI Verkehr GmbH Publ., 2010, 250 p.

3. Reinschke K. \& Ushakov I.A. Otsenka nadezhnosti sistem s ispol'zovaniyem grafov [Application of graph theory for reliability analysis]. Ed. by I.A. Ushakov. Moscow, Radio i svyaz' Publ., 1988, 145 p. (In Russian)

4. Golovatyy A. T., Isaev I.P., Bortsov P. I. et al. Elektropodvizhnoy sostav. Ekspluatatsiya, nadezhnost'i remont. Uchebnik dlya vuzov zh.-d. transporta [Electric rolling stock. Operation, reliability, and repair. Textbook for railway transport universities]. Moscow, Transport Publ., 1983, 106 p. (In Russian)
5. Druzhinin G. V. Nadezhnost'avtomatizirovannykh proizvodstvennykh sistem [Reliability of automated production systems]. Ed. 4. Moscow, Energoatomizdat Publ., 1986, 360 p. (In Russian)

6. Gorskiy A. V. Metodika rascheta nadezhnosti elektropodvizhnogo sostava kak slozhnoy sistemy. Dis. kand. tekhn. nauk, spetsial'nost': 05.22.07 [Methodology for calculating the reliability of electric rolling stock as a complex system. Dis. for PhD in Engineering, speciality: 05.22.07]. Moscow, MIIT Publ., 1968, 168 p. (In Russian)

7. Isaev I. P., Gorskiy A. V. \& Kozyrev V.A. Opredeleniye ekspluatatsionnykh koeffitsiyentov elektropodvizhnogo sostava s uchetom posledeystviya $\mathrm{v}$ protsesse ego funktsionirovaniya [Determining the operational coefficients of electric rolling stock taking into account its operation aftereffects]. Proceedings of MIIT, 1976, iss. 524, pp. 66-73. (In Russian) 
8. Puzankov A.D. Metody rascheta i ispol'zovaniya pokazateley nadezhnosti vekspluatatsii. Ucheb. posobiye dlya vuzov zh.-d. transporta [Methods for calculating and applying reliability indicators in operation. Training manual for railway transport universities]. Moscow, MIIT Publ., 2004, 49 p. (In Russian)

9. Gorskiy A. V. \& Vorob'yev A.A. Optimizatsiya sistemy remonta lokomotivov [Optimization of the locomotive repair system]. Moscow, Transport Publ., 1994, 83 p. (In Russian)

10. Plokhikh I. V. Sovershenstvovaniye metodiki otsenki pokazateley gotovnosti i ikh analiz dlya vysokoskorostnogo poyezda Velaro Rus - Sapsan s uchetom opyta Rossii i Germanii. Dis. kand. tekhn. nauk, spetsial'nost': 05.22.07 [Improving the methodology for assessing readiness indicators and their analysis for the high-speed train Velaro Rus - Sapsan taking into account the Russian and German experience. Dis. for $\mathrm{PhD}$ in Engineering, speciality: 05.22.07]. Moscow, MIIT Publ., 2013, 217 p. (In Russian)

11. Gnedenko B. V., Belyaev Yu. K. \& Solov'yev A.D. Matematicheskiye metody $v$ teorii nadezhnosti [Mathe- matical methods in the reliability theory]. Moscow, Nauka Publ., 1965, 26 p. (In Russian)

12. Strauss P. Nadezhnost'i tekhnicheskoye obsluzhivaniye zheleznodorozhnogo podvizhnogo sostava. Otchet o NIR [Reliability and maintenance of railway rolling stock. Research report]. Dresden, University of Applied Sciences [HTW Dresden] Publ., 2010, 91 p. (In Russian)

13. Nadezhnost'v tekhnike. Plany ispytaniy dlya kontrolya koeffitsiyenta gotovnosti [Reliability in technology. Test plans for monitoring availability]. Moscow, Standartinform Publ., 2010, 16 p. (In Russian)

14. Elsayed A. Reliability engineering.- Massachusetts, Addison Wesley Longman Inc. Publ., 1996, $113 \mathrm{p}$.

Received: March 01, 2021

Accepted: April 15, 2021

\section{Author's information:}

Aleksey E. TSAPLIN - PhD in Engineering, Associate Professor; tsaplin.alexey@mail.ru

Zhaloliddin O. ugli KUVONDIKOV - Postgraduate Student; jaloliddin1690@gmail.com 
УДК 625.031 .1

\title{
О влиянии эквивалентной конусности колесной пары на напряженно-деформированное состояние рельсов
}

\author{
Л. С. Блажко, А. А. Киселев, И. П. Киселев, А. В. Романов \\ Петербургский государственный университет путей сообщения Императора Александра I, \\ Российская Федерация, 190031, Санкт-Петербург, Московский пр., 9
}

Для цитирования: Блажко Л. С., Киселев А.А., Киселев И.П., Романов А. В. О влиянии эквивалентной конусности колесной пары на напряженно-деформированное состояние рельсов // Известия Петербургского университета путей сообщения.- СПб.: ПГУПС, 2021. - Т. 18. - Вып. 2.C. 261-272. DOI: 10.20295/1815-588X-2021-2-261-272

\begin{abstract}
Аннотация
Цель: Оценка влияния эквивалентной конусности колесной пары на напряженно-деформированное состояние рельсов. Методы: Были применены численные методы интегрирования систем нелинейных дифференциальных уравнений движения в программном комплексе «Универсальный механизм». Экспериментальные исследования проводились на высокоскоростной линии «СанктПетербург-Москва» с помощью многоканальной тензометрической станции. Обработка результатов численного моделирования и натурного эксперимента выполнена с использованием методов математической статистики. Результаты: Определены напряжения и деформации в зоне контакта колеса с рельсом, а также их зависимость от величины эквивалентной конусности колесной пары. Результаты численного моделирования и натурного эксперимента показали сходимость в пределах $15 \%$. Практическая значимость: Выявлена необходимость корректировки нормативов содержания рельсовой колеи на высокоскоростных магистралях. При учете эквивалентной конусности колесной пары риск возникновения интенсивных колебаний виляния понижается, что позволит уменьшить динамическое воздействие колеса на рельс. При проведении мобильной обработки рельсов в пути можно добиться увеличения ресурса надежной работы рельсов и снизить силы сопротивления движению подвижного состава.
\end{abstract}

Ключевые слова: Эквивалентная конусность колесной пары, взаимодействие колеса с рельсом, нормативы содержания рельсовой колеи, экспериментальные исследования, скоростные и высокоскоростные магистрали.

\section{Введение}

Обеспечение устойчивого и плавного движения высокоскоростного подвижного состава относится к приоритетным задачам для развития современного пассажирского транспорта. Коли- чество случаев нарушения устойчивости хода на существующей высокоскоростной магистрали «Санкт-Петербург-Москва» из года в год растет. В свою очередь, эти нарушения могут приводить к сверхнормативным расстройствам рельсовой колеи [1]. В настоящее время осуществляется 
разработка проектной документации для строительства высокоскоростной магистрали между Москвой и Санкт-Петербургом со скоростями до 400 км/ч. Сложность для российских железных дорог состоит в том, что до конца не решены вопросы с конструкцией как подвижного состава, так и верхнего строения пути, ни, тем более, с нормативами содержания рельсовой колеи.

Мировой опыт показывает, что для обеспечения плавного хода высокоскоростного подвижного состава необходимо учитывать параметр эквивалентной конусности колесной пары.

Виляние кузова и тележек подвижного состава возникает при движении по пути, даже не имеющем вертикальные и горизонтальные неровности. При движении колесо не только смещается поперек рельса в пределах зазора между гребнем колеса и рабочей гранью рельса, но и совершает вращение относительно вертикальной оси пути. Это приводит к изменению точек контакта колеса с рельсом. Управляя эквивалентной конусностью колесной пары, можно уменьшить частоту и амплитуду колебаний высокоскоростного подвижного состава в горизонтальной плоскости, обеспечить одноточечный контакт колеса вблизи оси симметрии рельса и тем самым снизить динамическое воздействие подвижного состава на железнодорожный путь [2, 3].

\section{Экспериментальные исследования}

С целью определения зависимости параметров напряженно-деформированного состояния рельсов от изменения эквивалентной конусности колесных пар были выполнены экспериментальные исследования.

Эксперимент проводился на 46 км 4 ПК І главного пути перегона Саблино-Тосно. Установленные скорости на участке составляют 220 км/ч. Конструкция верхнего строения пути на участке следующая:

- рельсы Р65 1-й группы, сваренные в плети;

- железобетонные шпалы со скреплением APC-4;

- эпюра шпал - 2000 шп./км.
В ходе эксперимента были измерены:

- вертикальные динамические силы, идущие от воздействия скоростного поезда «Невский экспресс» и высокоскоростного поезда «Сапсан»;

- напряжения изгиба и кручения в кромках подошвы рельса;

- упругие вертикальные прогибы подошвы рельса.

Измерение вертикальных динамических сил и напряжений изгиба и кручения в кромках подошвы рельса выполнялись при помощи тензометрических датчиков, наклеенных соответственно на шейку и подошву рельса, упругих прогибов рельса - индуктивными датчиками линейных перемещений. Схема размещения датчиков представлена на рис. 1. Тарировка измерительных схем для измерения вертикальных динамических сил проводилась путем прохождения по измерительному сечению подвижного состава с известной осевой нагрузкой со скоростью не более 10 км/ч, тарировка измерительных схем для измерения напряжений изгиба и кручения в кромках подошвы рельса - при помощи балки равного сопротивления.

Измеренные силы, напряжения и прогибы были обработаны методами математической статистики и теории вероятности.

Результаты измерений представлены в табл. 1.

Для построения эпюры напряжений изгиба и кручения в кромках подошвы рельса напряжения одновременно записывались в восьми датчиках, как показано на рис. 1. Эпюры напряжений от воздействия поездов, проходивших по экспериментальному участку, представлены на рис. 2.

По результатам выполненного эксперимента установлено, что напряжения и деформации, возникающие в рельсах, зависят от эквивалентной конусности колесной пары, так как подвижной состав, обращающийся на линии, имеет различную эквивалентную конусность.

Вертикальные динамические силы от поездов «Невский экспресс» при движении со скоростью 180 км/ч выше в 1,5 раза, чем от поездов «Сапсан» при движении со скоростью 220 км/ч. Мак- 

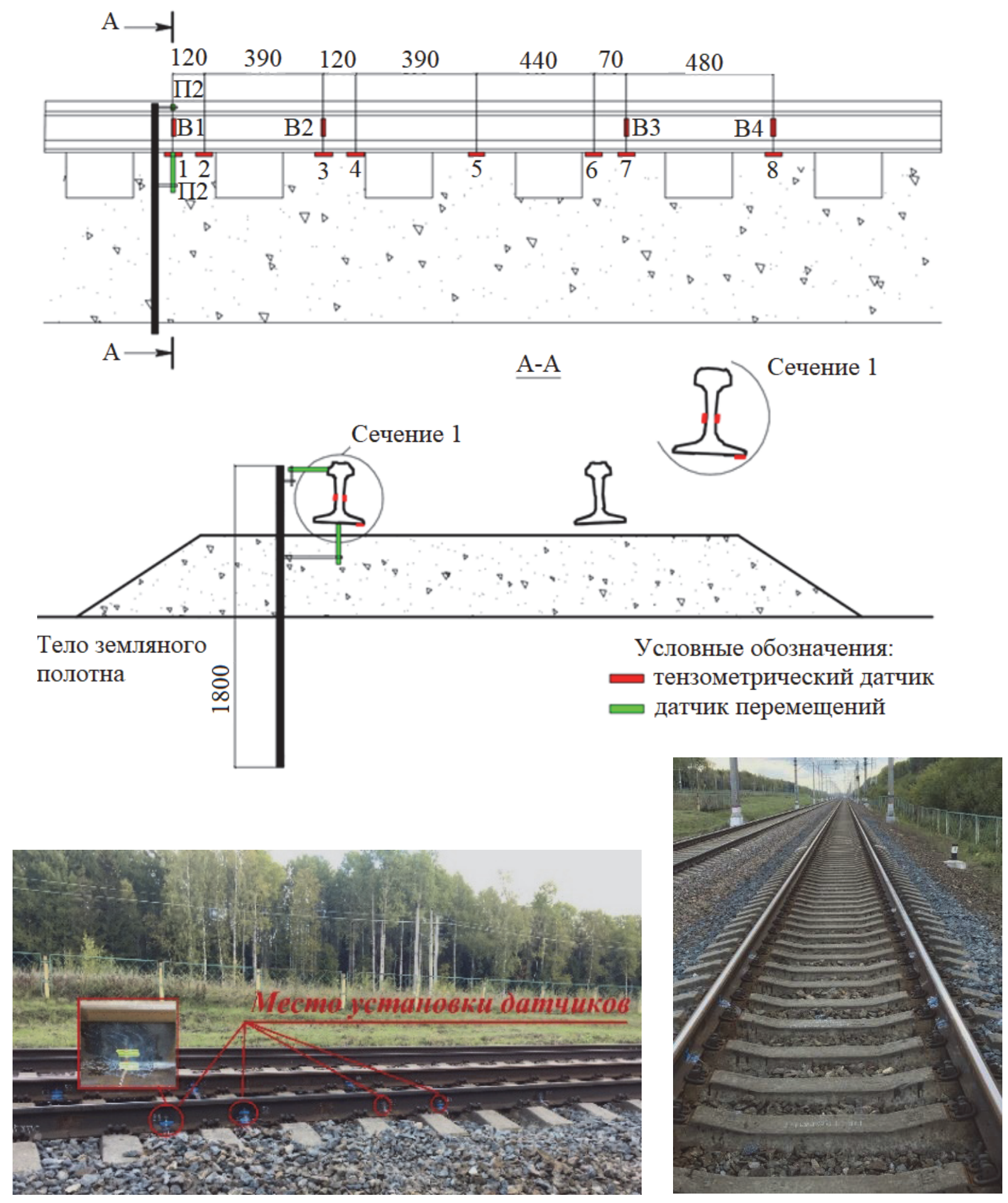

Рис. 1. Схема размещения датчиков на экспериментальном участке

симально вероятное значение вертикальных прогибов подошвы рельса от электровоза ЧС-200 оказались максимальными и составили 1,32 мм, что в 1,1 раза выше, чем от воздействия поезда
«Невский экспресс», и в 1,15 раз выше, чем от поездов «Сапсан».

Данные факты объясняются различной осевой нагрузкой, конструкцией рессорного под- 
ТАБЛИЦА 1. Результаты измерений вертикальных сил и упругих перемещений подошвы рельса в вертикальной плоскости

\begin{tabular}{|l|c|c|c|}
\hline \multicolumn{1}{|c|}{ Статистические параметры } & $\begin{array}{c}\text { Высокоскоростной } \\
\text { поезд «Сапсан» }\end{array}$ & $\begin{array}{c}\text { Локомотив } \\
\text { ЧС-200 }\end{array}$ & $\begin{array}{c}\text { Скоростной поезд } \\
\text { «Невский экспресс» }\end{array}$ \\
\hline \multicolumn{4}{|c|}{ Вертикальные сильl, $P_{\text {дин }}$} \\
Среднее статистическое значение, кН & 81,12 & 120,31 & 116,59 \\
Объем выборки, шт. & 247 & 61 & 132 \\
Среднеквадратическое отклонение, кН & 15,01 & 36,42 & 38,32 \\
Максимальное вероятное значение, кН & 117,94 & 208,84 & 220,08 \\
\hline \multicolumn{4}{|c|}{ Упругие деформации рельса в вертикальной плоскости } \\
Среднее статистическое значение, мм & 0,95 & 1,03 & 0,97 \\
Объем выборки, шт. & 352 & 77 & 139 \\
Среднеквадратическое отклонение, мм & 0,08 & 0,12 & 0,09 \\
Максимальное вероятное значение, мм & 1,15 & 1,32 & 1,20 \\
\hline
\end{tabular}

$a$

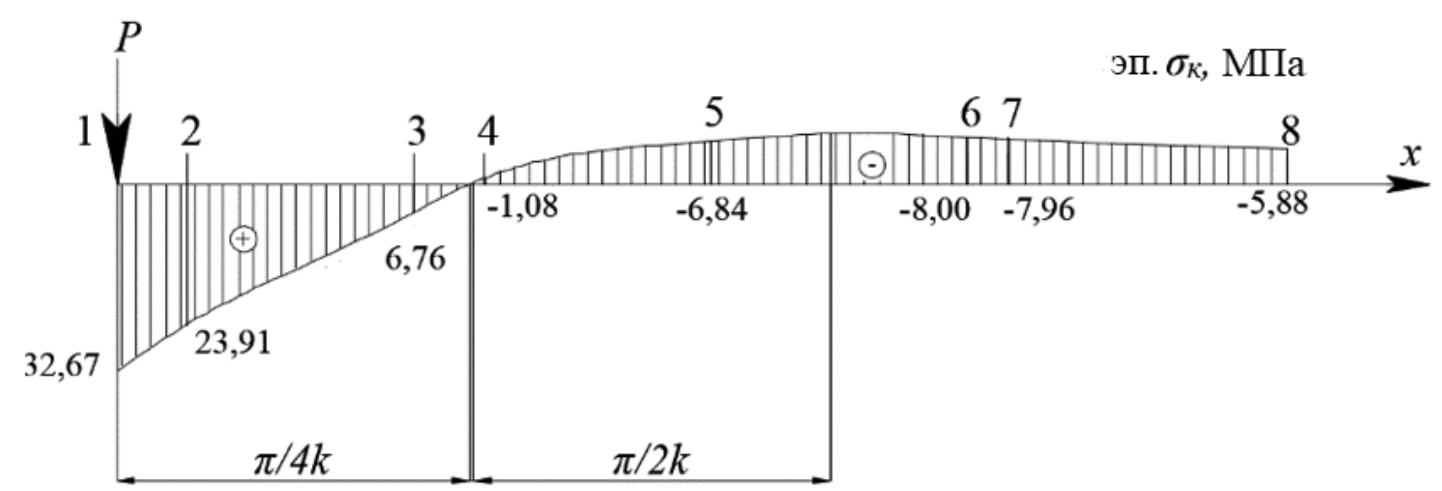

6

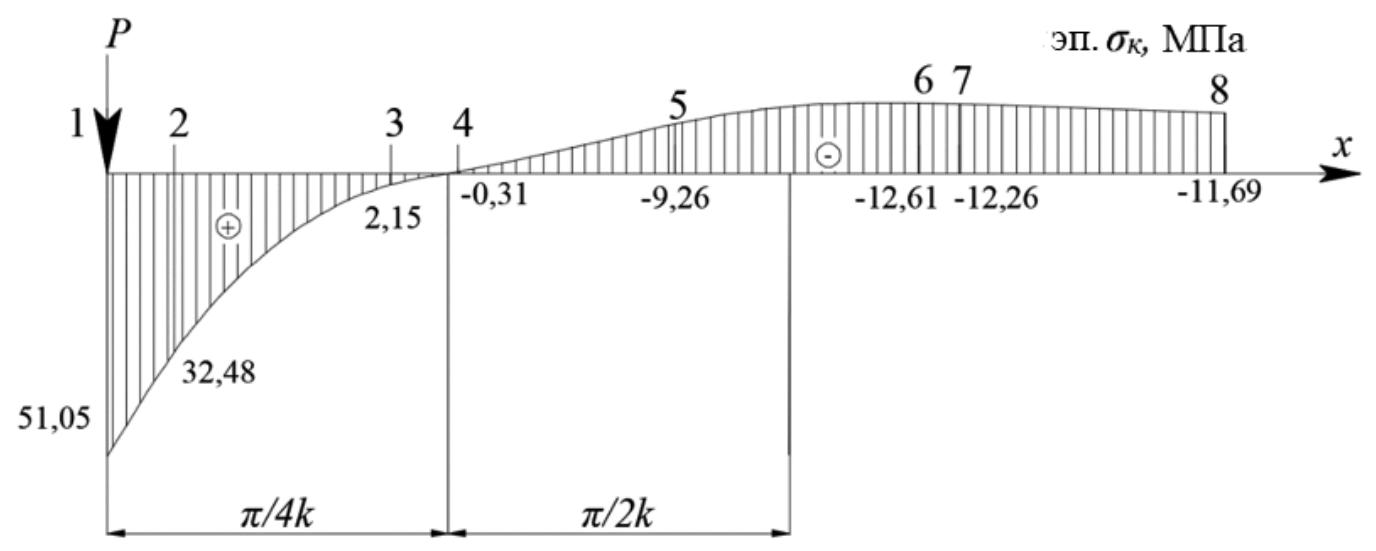

Рис. 2. Эпюры напряжений в кромках подошвы рельса от воздействия высокоскоростных поездов «Сапсан» (a) и скоростных поездов «Невский экспресс» (б):

$1-8$ - тензометрические датчики 
вешивания тележек и аэродинамических характеристик подвижного состава.

Напряжения изгиба и кручения в кромках подошвы рельса, которые возникают от воздействия скоростного поезда «Невский экспресс», выше в 1,37-1,68 раза, чем от воздействия высокоскоростного поезда «Сапсан».

Также по результатам измерения вертикальных прогибов подошвы рельса и напряжений изгиба и кручения в кромках подошвы рельса были рассчитаны упругие характеристики пути. Среднее значение жесткости пути составляет 117,31 MH/M.

\section{Расчет напряжений и деформаций в элементах верхнего строения пути}

Расчет размеров площадки контакта, контактного давления и касательных напряжений, сил крипа, возникающих в зоне контакта колеса с рельсом, был выполнен с помощью алгоритма FASTSIM, разработанного в [4].

Математическая модель (рис. 3) состоит из кузова и двухосных тележек, которые имеют двойное рессорное подвешивание. Первичное рессорное подвешивание выполнено гидравлическими гасителями вертикальных колебаний

$a$

6
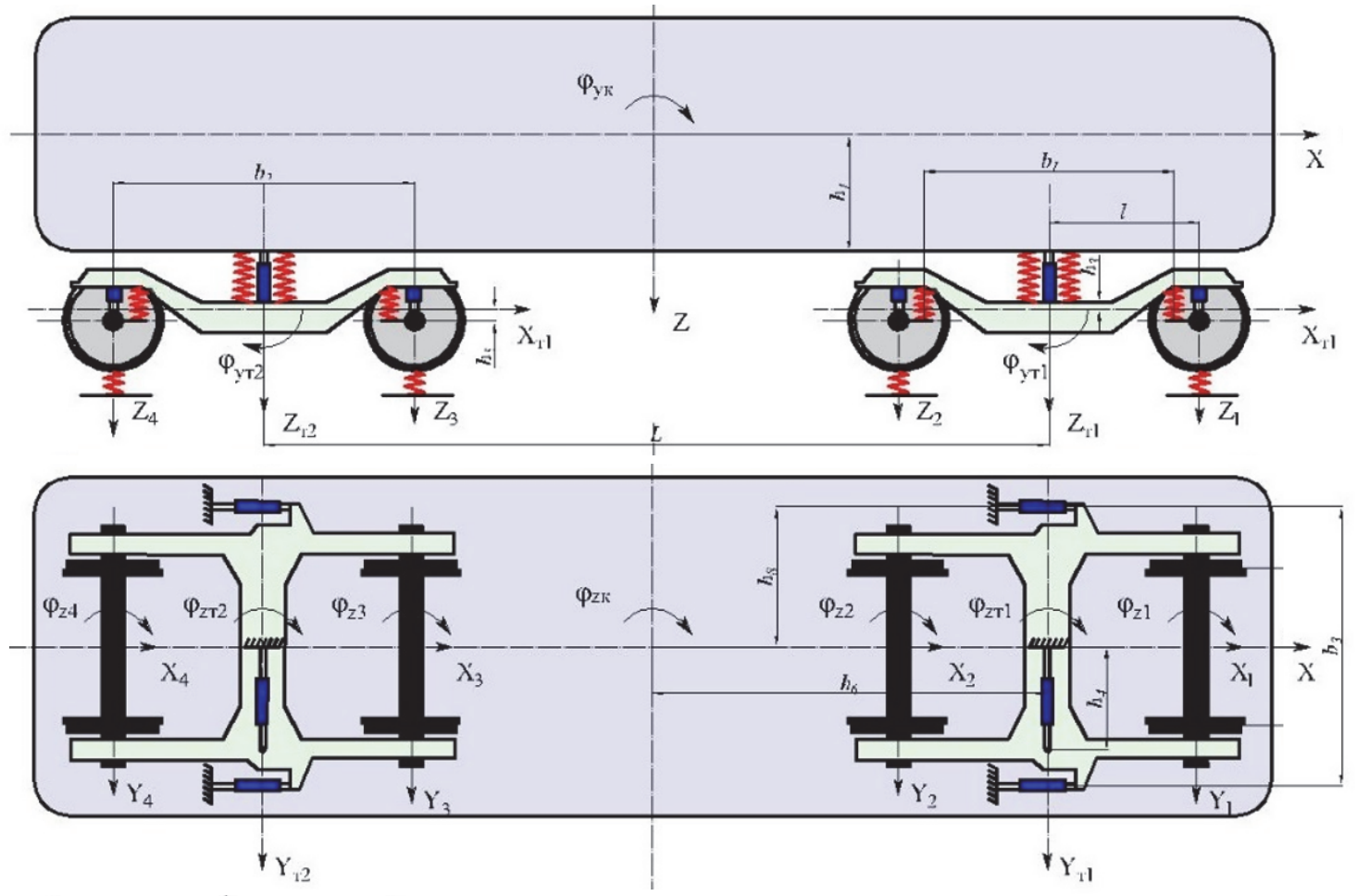

B

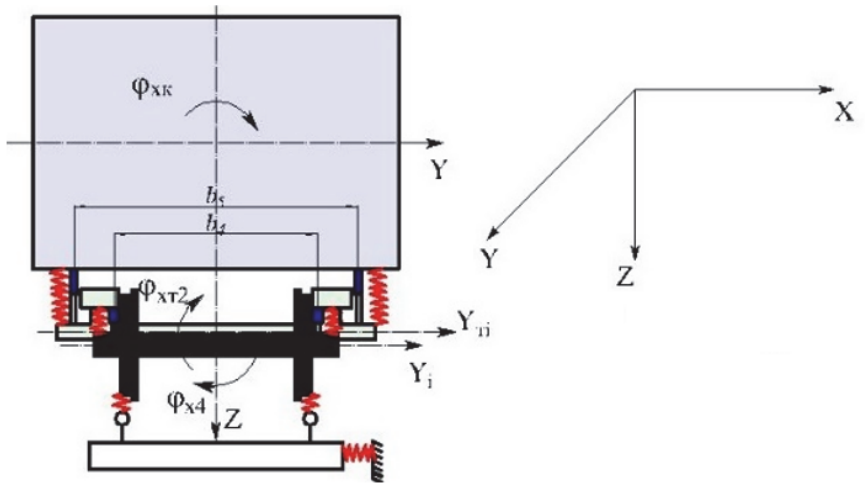

Рис. 3. Расчетная математическая модель вагона высокоскоростного подвижного состава: $a$ - вид спереди; $\sigma$ - вид сверху; в - вид сбоку 
и цилиндрическими пружинами, вторичное гидравлическими гасителями вертикальных, поперечных колебаний, виляния и цилиндрическими пружинами. Верхнее строение пути представлено как балка, лежащая на сплошном упругом основании с заданными характеристиками.

При моделировании движения математическая модель совершает основные колебания кузова, тележек и колесных пар (подпрыгивание, относ, подергивание, галопирование, виляние и боковую качку). Движение математической модели описывается дифференциальными уравнениями Лагранжа второй степени:

$$
\begin{gathered}
M(q, t) \ddot{q}+k(q, \dot{q}, t)=Q(q, \dot{q}, t)+G^{t}(q) \lambda, \\
h(q, p)=0,
\end{gathered}
$$

где $M$ - матрица масс; $q$ - основные координаты объекта; $p$ - вспомогательные координаты (локальные координаты в разрезанных шарни$\operatorname{pax}) ; k, Q$ - столбцы сил инерции и обобщенных сил; $\lambda$ - множители Лагранжа, соответствующие силам реакции в разрезанных шарнирах; $G$ - матрица Якоби уравнений связей после исключения из них вспомогательных координат; $h(q, p)=0$ - алгебраические уравнения связей или условий замыкания разрезанных шарниров.

В модель железнодорожного пути вводились случайные горизонтальные и вертикальные неровности 2-й степени. Коэффициенты демпфирования и значения вертикальной и поперечной жесткостей в модель пути вводились по результатам экспериментальных данных. Движение модели вагона высокоскоростного подвижного состава по модели железнодорожного пути моделировалось путем интегрирования дифференциальных уравнений движения. Результаты расчета и сравнение их с данными натурного эксперимента представлены в табл. 2 .

Расхождение результатов моделирования и эксперимента не превышает 15\%, что позволяет говорить об адекватности разработанной математической модели.
Ранее $[5,6]$ было установлено, что по условиям эквивалентной конусности движение высокоскоростного поезда «Сапсан» с профилем колеса ВНИИЖИТ-РМ-70 по рельсам, радиус по поверхности катания которых составляет 300 мм, будет устойчивое со скоростями свыше 350 км/ч. Таким образом, для оценки влияния эквивалентной конусности на напряженнодеформированное состояние рельсов профиль колеса был принят ВНИИЖТ-РМ-70, а в модель железнодорожного пути вводились два профиля рельса: рельс Р65 и ремонтный профиль рельса Р65 с радиусом по поверхности катания 300 мм. Скорости движения математической модели задавались 220 и 250 км/ч.

Изменение точек контакта колеса с рельсом при поперечном смещении представлено на рис. 4. При приближении точки контакта к рабочей грани рельсов величина контактных напряжений возрастает, так как площадь контакта уменьшается.

При поперечном смещении колеса ВНИИЖТРМ-70 по рельсу Р65 контактное давление изменяется от 780 МПа у нерабочей грани и до 1600 МПа у рабочей грани рельсов. На рис. 5 и 6 видно, что колесо ВНИИЖТ-РМ-70 сохраняет центральное положение относительно рельса Р65 с ремонтным профилем при поперечном смещении от -8 до 8 мм. Площадь контакта при смещении колеса по ремонтному профилю рельса Р65 существенно не изменяется. Контактное давление изменяется от 950 МПа при смещении к нерабочей грани и до 1200 МПа при смещении к рабочей грани ремонтного профиля рельca P65.

На рис. 7 представлена зависимость касательных напряжений от смещения колеса по рельсу в поперечном направлении. При центральном положении колеса относительно рельса касательные напряжения оказались минимальными и не превышают 100 МПа. При смещении колеса по рельсу от -8 до 8 мм касательные напряжения увеличиваются в 3-3,5 раза.

Дефекты рельсов контактно-усталостного характера развиваются из-за исчерпания пластичности и предельных остаточных деформа- 
ТАБЛИЦА 2. Сравнение результатов расчета и эксперимента

\begin{tabular}{|l|l|c|c|c|}
\hline \multicolumn{2}{|c|}{ Характеристика } & Эксперимент & Расчет & Отклонение, \% \\
\hline $\begin{array}{l}\text { Вертикальная динамическая } \\
\text { сила, кН }\end{array}$ & Среднее & 80,42 & 81,52 & 1,4 \\
& Максимально вероятное & 117,94 & 116,89 & 0,9 \\
\hline $\begin{array}{l}\text { Упругие деформации рельса в } \\
\text { вертикальной плоскости, мм }\end{array}$ & Среднее & 0,95 & 0,90 & 5,2 \\
\hline Упругие деформации рельса в & Мреднально вероятное & 1,15 & 1,22 & 6,1 \\
\hline горизонтальной плоскости, мм & Максимально вероятное & 0,78 & 0,16 & 12,5 \\
\hline Жесткость пути, МН/м & 123,44 & 104,42 & 14,1 \\
\hline \multicolumn{2}{|l|}{ Модуль упругости подрельсового основания, МПа } & 81,36 & 79,71 & 2,0 \\
\hline $\begin{array}{l}\text { Коэффициент относительной жесткости подрельсового } \\
\text { основания и рельса, м }\end{array}$ & 1,32 & 1,15 & 12,8 \\
\hline Напряжения в кромках подошвы рельса, МПа & 37,37 & 37,48 & 0,3 \\
\hline
\end{tabular}

$a$

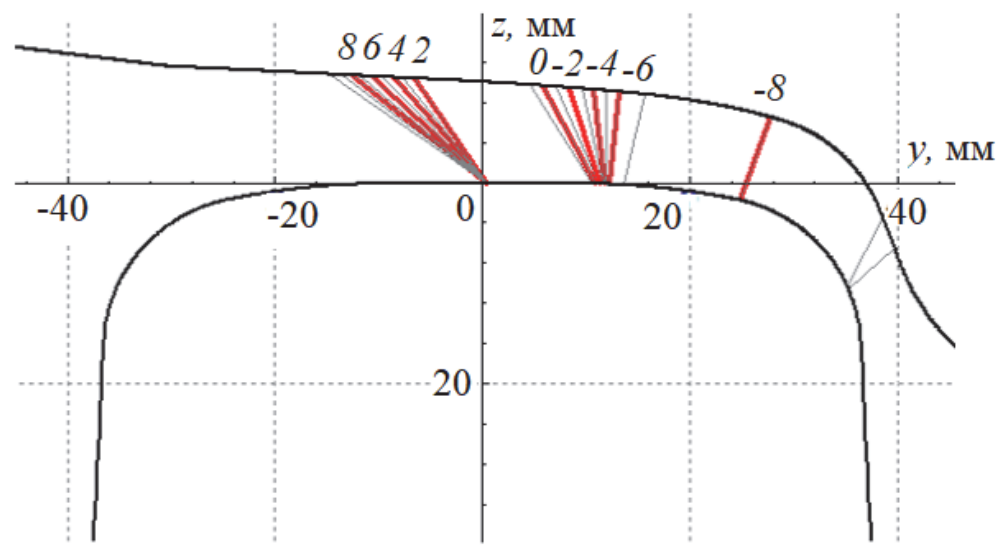

6



Рис. 4. Точки контакта колеса ВНИИЖТ-РМ-70 при поперечном смещении от 1 до 8 мм с рельсом Р65 (a) и с ремонтным профилем рельса Р65 (б) 

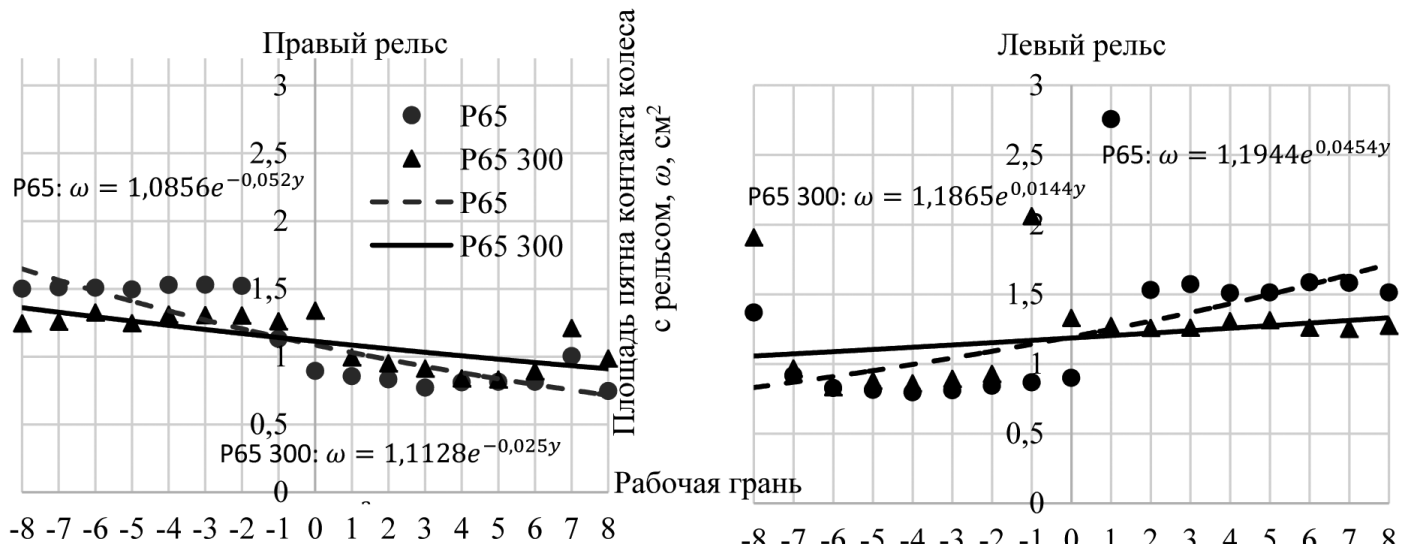

Поперечное смещение колеса по рельсу, $y$, мм

Рис. 5. Зависимости площади пятна контакта от поперечного смещения колеса по рельсу

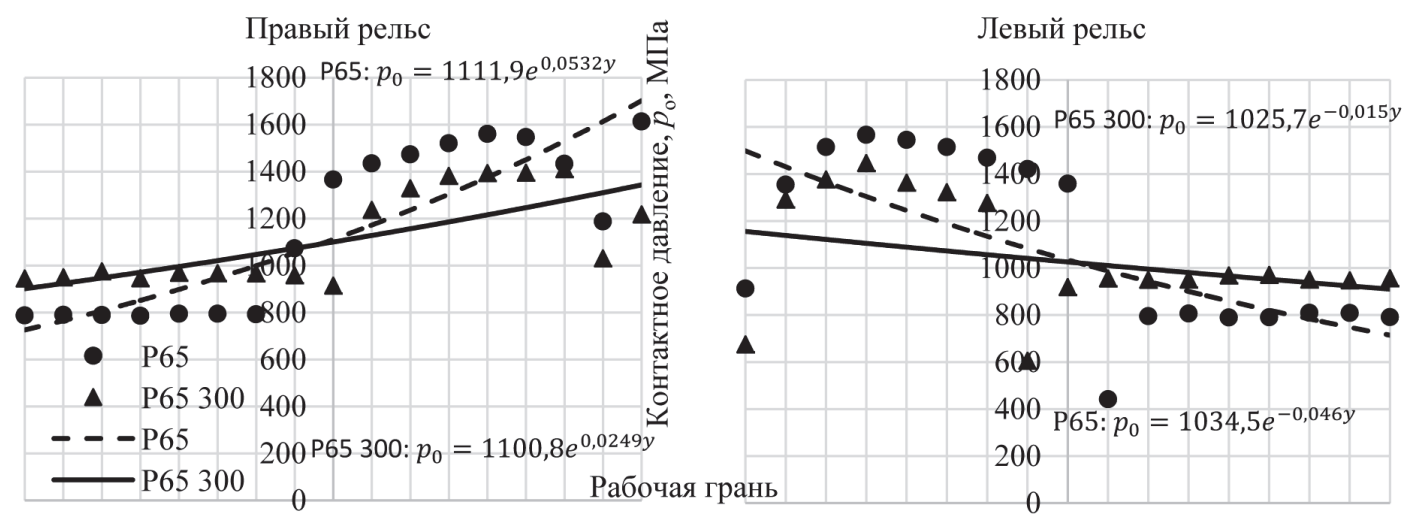

$\begin{array}{lllllllllllllllll}-8 & -7 & -6 & -5 & -4 & -3 & -2 & -1 & 0 & 1 & 2 & 3 & 4 & 5 & 6 & 7 & 8\end{array}$

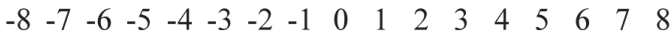

Поперечное смещение колеса по рельсу, $y$, мм

Рис. 6. Зависимости контактного давления в центре площадки от поперечного смещения колеса по рельсу



Рис. 7. Зависимости касательных напряжений в зоне контакта от поперечного смещения колеса по рельсу 



P65 300: $F_{x}=-0,0018 y^{3}+0,0011 y^{2}+1,6258 y-0,1791$

Рис. 8. Зависимости сил крипа, действующих по площадке контакта, от поперечного смещения колеса по рельсу: $a$ - сила поперечного крипа; $\sigma$ - сила продольного крипа

$a$

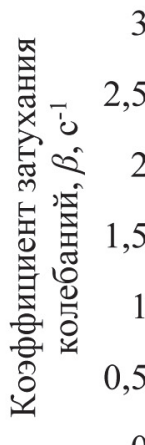

3

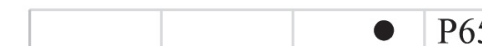



2

, 5

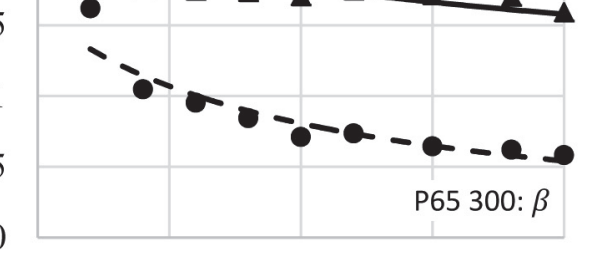

100

150

200

250

300

$\sigma$

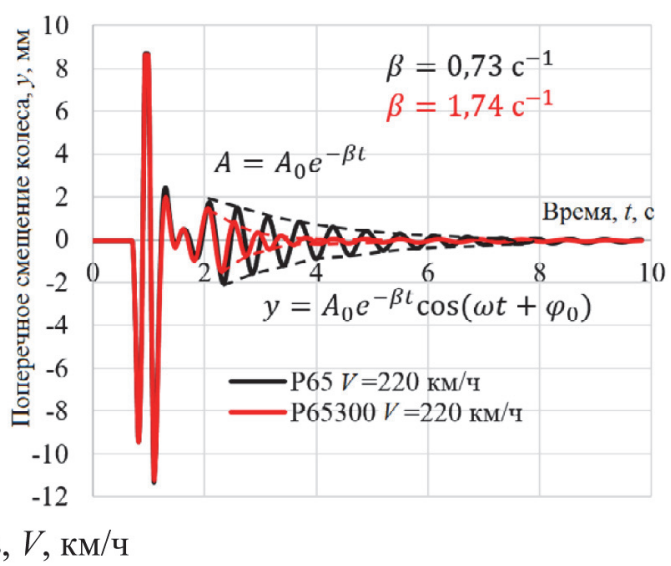

Рис. 9. Колебания тележки разработанной математической модели вагона высокоскоростного

подвижного состава в горизонтальной плоскости $(a)$ и изменение коэффициентов затухания колебаний тележки подвижного состава в горизонтальной плоскости в зависимости от скорости движения (б)

ций, которые, в свою очередь, возникают из-за высоких контактных и касательных напряжений [7]. Высокоскоростные магистрали характеризуются небольшим количеством кривых. При этом у имеющихся кривых радиус превышает 2000 м, поэтому колесо преимущественно занимает центральное положение относительно оси рельса. Нагрузка на ось высокоскоростного подвижного состава составляет 170-180 кН/ось. Учитывая параметры эквивалентной конусности колесной пары, можно обеспечить одното- чечный контакт колеса, близкий к оси симметрии рельса, снизить риски возникновения интенсивных колебаний виляния. Применение на высокоскоростных магистралях профиля рельса с радиусом по поверхности катания 300 мм не вызовет резкого увеличения интенсивности развития дефектов контактно-усталостного происхождения.

Выполняя профилактическую шлифовку поверхности катания головки рельсов по условиям эквивалентной конусности колесной пары, мож- 
но добиться повышения ресурса надежной работы рельсов.

При взаимодействии колеса с рельсом по площадке контакта возникают силы крипа, которыми можно управлять, изменяя параметры эквивалентной конусности колесной пары [8]. На рис. 8 представлены результаты расчета сил крипа по предлагаемой методике, анализ которых показывает, что при учете параметров эквивалентной конусности колесной пары можно снизить величины сил крипа. При центральном расположении колеса у оси симметрии ремонтного профиля рельса Р65 силы продольного и поперечного крипа практически равны нулю. В свою очередь, это приводит к уменьшению величины силы сопротивления движению, которое появляется из-за виляния, и позволит минимизировать потери энергии, связанные с преодолением сил сопротивления движению.

Эквивалентная конусность способствует самоцентрированию колесной пары в рельсовой колее и противостоит действию центробежных сил при движении. Моделирование движения математической модели по пути, имеющим резкое отступление в плане, показывает, что после прохождения неровности поперечные колебания колеса относительно рельса приобретают затухающий характер (рис. 9,a).

Движение колеса ВНИИЖТ-РМ-70 по рельсам Р65 с ремонтным профилем более устойчивое, амплитуда и частота поперечных колебаний снизилась, что видно на рис. 9, $a$. На рис. 9, $б$ представлены зависимости коэффициентов затухания колебаний колеса относительно рельса от скорости движения высокоскоростного подвижного состава. При движении колеса ВНИИЖТРМ-70 по рельсам Р65 с ремонтным профилем коэффициенты затухания колебаний оказались выше в 1,5-2,7 раза и колесная пара быстрее возвращается в центральное положение относительно рельсовой колеи.

\section{Заключение}

При учете параметра эквивалентной конусности колесной пары движение высокоскорост- ного подвижного состава будет более плавным и можно добиться существенного снижения динамического воздействия подвижного состава на путь.

При использовании на высокоскоростных магистралях профиля рельса с радиусом по поверхности катания 300 мм амплитуда и частота поперечных колебаний подвижного состава снизятся. Выполняя превентивную мобильную обработку рельсов с учетом эквивалентной конусности колесной пары, можно существенно повысить ресурс надежной работы рельсов.

Расчеты эквивалентной конусности колесной пары показывают, что при наклоне поверхности катания рельсов менее $1 / 30$ и более $1 / 16$ вероятность появления интенсивных колебаний виляния возрастает. В работах $[9,10]$ установлено, что контактные напряжения при изменении в рамках допусков наклона поверхности катания рельсов от $1 / 12$ до $1 / 60$ увеличиваются в 1,7 2,0 раза.

Все вышесказанное позволяет рассматривать вопрос об изменении нормативов содержания рельсовой колеи на участках высокоскоростного движения и о создании малодеформируемых конструкций подрельсового основания со стабильными по длине пути упругими характеристиками.

\section{Библиографический список}

1. Романов А. В. Причины нарушения плавности хода поездов / А. В. Романов, А. Ф. Колос, А. А. Киселев, С.В. Романов // Путь и путевое хозяйство. - 2020.№ 7.- C. 29-31.

2. Pascal J.P. About Multi Hertzian contact hypothesis and equivalent conicity in the case of S1002 and UIC60 analytical wheel/rail profiles / J.P. Pascal // Vehicle System Dynamics. - 1993.- Vol. 22 (2). - P. 57-78.

3. Santamaria J. Equivalent conicity and curve radius influence on dynamic performance of unconventional bogies comparison analysis / J. Santamaria, E. G. Vadillo // Vehicle System Dynamics. - 2004. - Vol. 41.P. 133-142. 
4. Kalker J. J. Some new results in rolling contact / J. J. Kalker, J. Piotrowski // Vehicle System Dynamics. 1989. - Vol. 18. - P. 223-242.

5. Киселев А. А. Эквивалентная конусность и ее влияние на движение подвижного состава / А. А. Киселев, Л. С. Блажко, А. В. Романов // Известия Петербургского университета путей сообщения.-СПб. : ПГУПС, 2017.- Т. 14. - Вып. 2.- С. 247-255.

6. Киселев А. А. Влияние геометрических параметров железнодорожного пути на величину эквивалентной коничности колесной пары / А. А. Киселев, Л. С. Блажко, А. С. Гапоненко, А. В. Романов // Известия Петербургского университета путей сообщения.СПб. : ПГУПС, 2019. - Т. 16.- Вып. 2.- С. 202-211.

7. Марков Д.П. Контактная усталость колес и рельсов / Д. П. Марков // Вестн. ВНИИЖТ.-2001.- № 6.C. 8-14.

8. Гарг В.К. Динамика подвижного состава / В. К. Гарг, Р. В. Дуккипати ; пер. с англ. Н. А. Панькина. - М. : Транспорт, 1988. - 391 с.
9. Лисицын А.И. О взаимодействии в системе «колесо-рельс» на участках высокоскоростного движения / А.И. Лисицын, А. Ю. Абдурашитов // Путь и путевое хозяйство. - 2020. - № 3.- С. 2-6.

10. Покацкий В. А. Контактные напряжения при различном расположении колеса и рельса / В. А. Покацкий, Д. В. Овчинников, Д. И. Галлямов // Путь и путевое хозяйство. - 2020.- № 3.- С. 7-10.

Дата поступления: 29.04.2021

Решение о публикации: 11.05.2021

\section{Контактная информация:}

БЛАЖКО Людмила Сергеевна - д-р техн. наук, проф.; blazhko@pgups.ru

КИСЕЛЕВ Артем Александрович - инженер; zhdp10@gmail.com

КИСЕЛЕВ Игорь ПавЛович - д-р ист. наук, доц.; kiselev@pgups.ru

РОМАНОВ Андрей Валерьевич - канд. техн. наук, доц.; andrey.romanov@mail.ru

\section{Discussing the effect of the wheelset equivalent conicity on the stress-strain state of the rails}

\section{S. Blazhko, A. A. Kiselev, I. P. Kiselev, A. V. Romanov}

Emperor Alexander I Petersburg State Transport University, 9, Moskovsky pr., Saint Petersburg, 190031, Russian Federation

For citation: Blazhko L.S., Kiselev A.A., Kiselev I. P., Romanov A. V. Discussing the effect of the wheelset equivalent conicity on the stress-strain state of the rails. Proceedings of Petersburg Transport University. Saint Petersburg, Petersburg State Transport University, 2021, vol. 18, iss. 2, pp. 261-272 (In Russian) DOI: 10.20295/1815-588X-2021-2-261-272

\section{Summary}

Objective: To assess the effect of the wheelset equivalent conicity on the stress-strain state of the rails. Methods: Authors used numerical integration methods for systems of nonlinear differential equations of motion in the Universal Mechanism software package. Experimental studies were carried out on the St. Petersburg - Moscow high-speed line using a multichannel strain-gauge station. Methods of mathematical statistics have been used to process the results of numerical simulation and field experiment. Results: The stresses and strains in the wheel-rail contact area and their dependence on the wheelset equivalent conicity have been determined. According to numerical simulation and field experiment, the convergence was within $15 \%$. Practical importance: The need for updating the standards for the maintenance of a rail track on high-speed lines has been revealed. Allowing for the wheelset equivalent conicity decreases the risk of intense hunting oscillation, which would reduce the dynamic wheel-rail 
effect. Mobile treatment of rails on the way makes it possible to extend the safe operation time and reduce the rolling stock motion resistance force of the track.

Keywords: Wheelset equivalent conicity, wheel-rail interaction, standards for the maintenance of a rail track, experimental studies, express and high-speed railways.

\section{References}

1. Romanov A. V., Kolos A. F., Kiselev A.A. \& Romanov S.V. Prichiny narusheniya plavnosti khoda poyezdov [Causes of disturbance in smoothness of the train movement]. Put'i putevoye khozyaystvo [Railway Track and Facilities], 2020, no. 7, pp. 29-31. (In Russian)

2. Pascal J.P. About Multi Hertzian contact hypothesis and equivalent conicity in the case of S1002 and UIC60 analytical wheel/rail profiles. Vehicle System Dynamics, 1993, vol. 22 (2), pp. 57-78.

3. Santamaria J. \& Vadillo E. G. Equivalent conicity and curve radius influence on dynamic performance of unconventional bogies comparison analysis. Vehicle System Dynamics, 2004, vol. 41, pp. 133-142.

4. Kalker J. J. \& Piotrowski J. Some new results in rolling contact. Vehicle System Dynamics, 1989, vol. 18, pp. 223-242.

5. Kiselev A.A., Blazhko L. S. \& Romanov A. V. Ekvivalentnaya konusnost' $i$ eye vliyaniye na dvizheniye podvizhnogo sostava [Equivalent conicity and its influence on the movement of rolling stock]. Izvestiya Peterburgskogo universiteta putey soobshcheniya [Proceedings of Petersburg Transport University]. Saint Petersburg, PGUPS [Petersburg State Transport University] Publ., 2017, vol. 14, iss. 2, pp. 247-255. (In Russian)

6. Kiselev A.A., Blazhko L. S. \& Romanov A. V. Vliyaniye geometricheskikh parametrov zheleznodorozhnogo puti na velichinu ekvivalentnoy konichnosti kolesnoy pary [Influence of the railway track geometry on the wheelset equivalent conicity]. Izvestiya Peterburgskogo universiteta putey soobshcheniya [Proceedings of Petersburg Transport University]. Saint Petersburg, PGUPS
[Petersburg State Transport University] Publ., 2019, vol. 16, iss. 2, pp. 202-211. (In Russian)

7. Markov D. P. Kontaktnaya ustalost' koles i rel'sov [Contact fatigue of wheels and rails]. Vestnik VNIIZhT [Bulletin of the Railway Research Institute], 2001, no. 6, pp. 8-14. (In Russian)

8. Garg V.K. \& Dukkipati R.V. Dinamika podvizhnogo sostava [Dynamics of railway vehicle systems]. Translated from English by N.A. Pan'kina. Moscow, Transport Publ., 1988, 391 p. (In Russian)

9. Lisitsyn A. I. \& Abdurashitov A. Yu. O vzaimodeystvii v sisteme "koleso-rel's" na uchastkakh vysokoskorostnogo dvizheniya [On the interaction in the wheelrail system in high-speed traffic areas]. Put' i putevoye khozyaystvo [Railway Track and Facilities], 2020, no. 3, pp. 2-6. (In Russian)

10. Pokatskiy V.A., Ovchinnikov D. V. \& Gallyamov D. I. Kontaktnyye napryazheniya pri razlichnom raspolozhenii kolesa i rel'sa [Contact stresses at different positions of the wheel and rail]. Put' i putevoye khozyaystvo [Railway Track and Facilities], 2020, no. 3, pp. 7-10. (In Russian)

Received: April 29, 2021

Accepted: May 11, 2021

\section{Author's information:}

Lyudmila S. BLAZHKO - Dr. Sci. in Engineering, Professor; blazhko@pgups.ru

Artem A. KISELEV - Engineer; zhdp10@gmail.com Igor P. KISELEV - Dr. Sci. in History, Associate Professor; kiselev@pgups.ru

Andrey V. ROMANOV - PhD in Engineering, Associate Professor; andrey.romanov@mail.ru 
УДК 629.014

\title{
Выбор и анализ конструктивных решений основания съемного кузова
}

\section{Ю.П. Бороненко, О.И. Зайнитдинов}

Петербургский государственный университет путей сообщения Императора Александра I, Российская Федерация, 190031, Санкт-Петербург, Московский пр., 9

Для цитирования: Бороненко Ю. П., Зайнитдинов О. И. Выбор и анализ конструктивных решений основания съемного кузова // Известия Петербургского университета путей сообщения.- СПб.: ПГУПС, 2021.- Т. 18. - Вып. 2.- С. 273-282. DOI: 10.20295/1815-588X-2021-2-273-282

\begin{abstract}
Аннотация
Цель: Выбор наиболее оптимальной и прочной конструкции основания для дальнейшего проектирования съемного кузова крытого типа с раздвигающимися боковыми стенами и крышей. Методы: Анализ конструктивных решений основания съемного кузова производился с помощью метода конечных элементов, используя программный пакет SolidWorks Simulation, и согласно техниконормативным документациям. Результаты: Сконструированы четыре варианта основания съемного кузова с различными конструктивными особенностями. Получены эпюры распределения эквивалентных узловых напряжений в конструкции основания съемного кузова. В соответствии с результатами исследования и расчета была выбрана наиболее прочная конструкция основания съемного кузова. Практическая значимость: Описанная базовая конструкция основания будет служить для проектирования и создания съемного кузова крытого типа с раздвигающимися боковыми стенами и крышей.
\end{abstract}

Ключевые слова: Основание съемного кузова, конструкция, метод конечных элементов, напряженно-деформированное состояние, узловое напряжение, усталостное повреждение.

\section{Введение}

В соответствии с программой по разработке и производству грузового подвижного состава нового поколения предусматривается переход от проектирования отдельных специализированных вагонов к семейству вагонов на базе основной конструкции, которое позволяет создавать образцы вагонов с заданным уровнем надежности, заменять традиционные методы конструирования, применять специальные унифицированные конструктивные элементы, повысить технико-логичность конструкции, уровни механизации и автоматизации производства, а также эксплуатационную надежность за счет более полного учета загруженности в эксплуатации соответствующего ускорения грузооборота вагонов $[1,2]$.
Проектируемый съемный кузов крытого типа с раздвигающимися боковыми стенами и крышей не имеет прочные боковые стены и соединяется сверху одной пролётной балкой, прикрепленной с двух сторон к торцевым стенкам кузова [3].

Цель данной работы - выбор оптимальных конструктивных решений основания съемного кузова с анализом напряженно-деформированного состояния металлоконструкции составных несущих элементов основания съемного кузова.

Для провидения статического анализа конечных элементов основания съемного кузова были спроектированы четыре варианта основания съемного кузова (рамы), отличающиеся друг от друга разными конструктивными особенностями (рис. 1). 

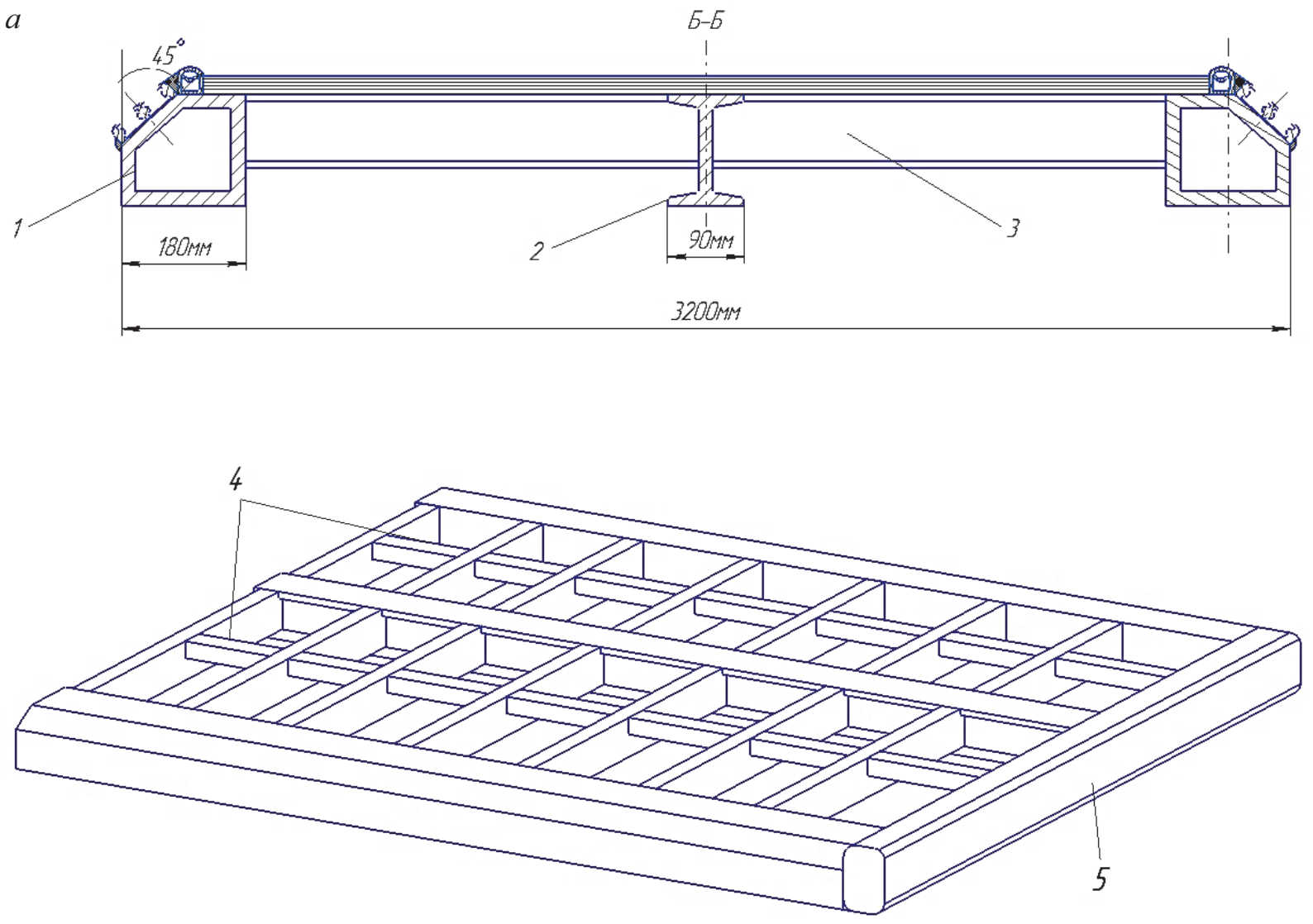

6

$6-5$




2

$5-5$
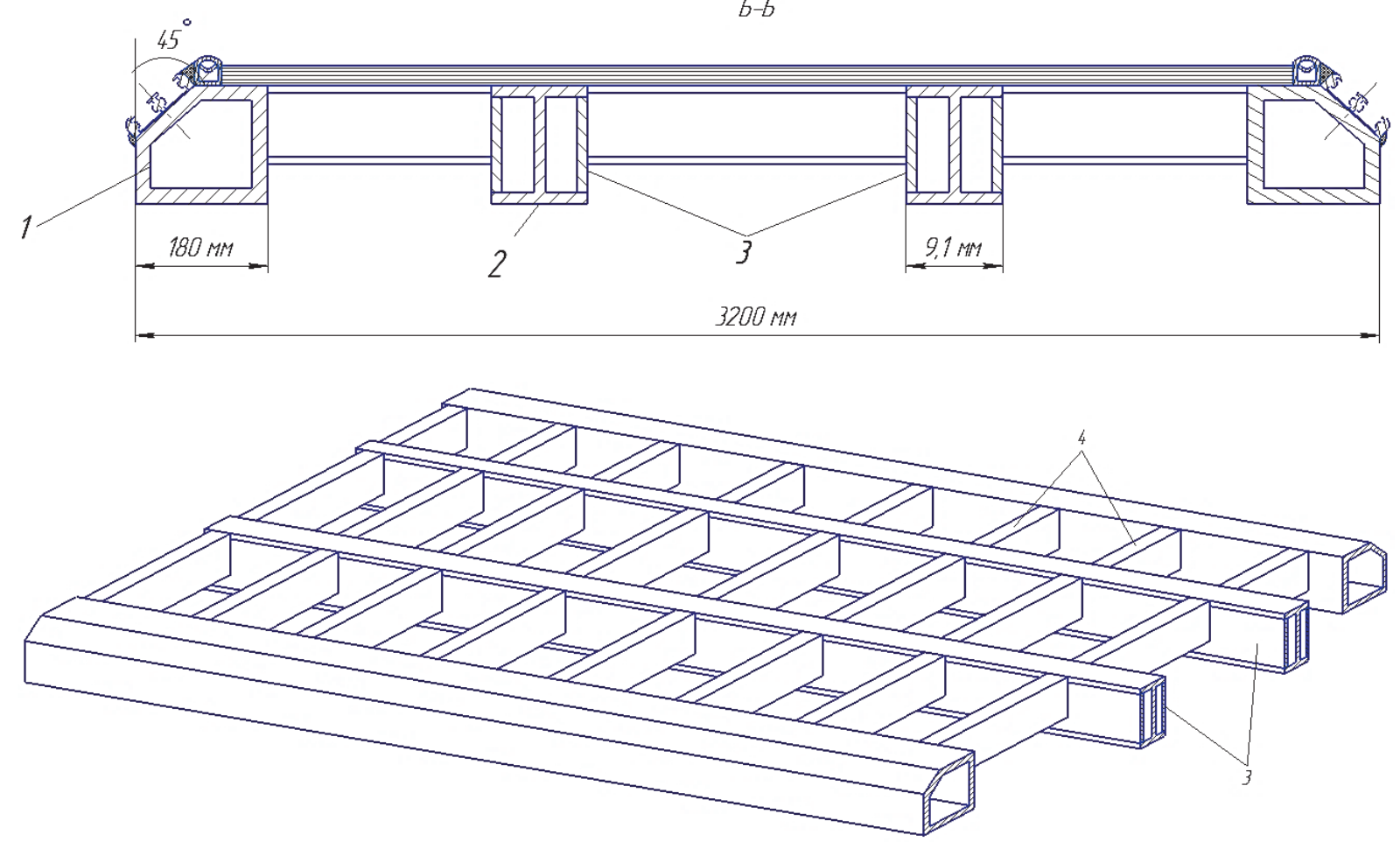

Рис. 1. Конструктивные чертежи четырех вариантов основания съемного кузова: $a-$ первый вариант: 1, 2 - продольные балки, 3 - поперечные балки, 4 - промежуточные балки, 5 - концевые балки; б - второй вариант: 1, 2 - продольные балки, 3 - поперечные балки; 8 третий вариант: 1 - боковые продольные балки, 2 - стальные листы, 3 - стальные вертикальные ребра, 4 - промежуточные профильные балки; 2 - четвертый вариант:

1 - боковые продольные балки, 2 - средние составные продольные балки, 3 - усиливающие стальные листы, 4 - поперечные балки 
Все варианты конструкции основания съемного кузова имеют одинаковые технические параметры: длину - 13800 мм, ширину - 3200 мм и толщину (высоту) основания без напольного настила - 180 мм.

Опишем первый вариант конструкции основания съемного кузова (рис. 1, a), который имеет сварную металлоконструкцию и состоит из основных трех продольных 1,2 , нескольких промежуточных поперечных балок 3 , промежуточных продольных балок 4 и двух концевых балок 5. Масса конструкции основания первого варианта без учета массы напольного настила и роликовых направляющих составляет 2570 кг.

Рассмотрим второй вариант конструкции основания съемного кузова (рис. 1, б), отличающийся от предыдущего тем, что по середине основания 1 проходят две прочные продольные прямоугольные балки 2 размером $180 \times 150 \times 12$ мм, удерживающиеся по бокам вспомогательными поперечными балками швеллерами 3 , которые служат основными несущими элементами основания при всех испытаниях. Масса конструкции основания второго варианта без учета массы напольного настила и роликовых направляющих составляет 3670 кг.

У основания третьего варианта (рис. 1, в) особое конструктивное решение по сравнению с предыдущими и отличается тем, что основание съемного кузова 1 имеет своеобразную металлоконструкцию из стального листового материала 2 , усиленную изнутри стальными вертикальными ребрами 3 толщиной 14 мм и удерживающими по бокам квадратными профилями 4. Масса данной конструкции основания без учета массы напольного настила и роликовых направляющих - более 13000 кг.

Рассмотрим конструкцию основания четвертого варианта (рис. 1, г), сходную с конструкциями первого и второго вариантов основания, который также имеет по середине основания 1 две основные несущие продольные балки 2 из двух двутавров с параллельными гранями полок, усиленных с двух сторон стальными листами 3 , и несколько поперечных балок из швеллеpa 4. Масса данной конструкции основания без учета массы напольного настила и роликовых направляющих - около 3310 кг.

\section{Исследование напряженно- деформированного состояния основания съемного кузова}

Для выбора оптимального варианта конструкции основания съемного кузова были проведены предварительные прогнозные расчеты и исследована выносливость на статическую нагрузку всех вариантов основания съемного кузова, который производился с помощью метода конечных элементов при использовании программного пакета SolidWorks Simulation.

При расчете на статическую нагрузку четырех видов основания съемного кузова при всех режимах прикладывалась одинаковая распределенная нагрузка, равная 200 МПа, согласно стандартам, ГОСТу 33211-2014, ГОСТу Р 53192-2014 и ГОСТу P 53077-2008 [4-6].

Сила тяжести основания съемного кузова учитывалась путем приложения распределенного по ее объему ускорения свободного падения $g=9,81 \mathrm{~m} / \mathrm{c}^{2}$.

В результате расчета были построены эпюры распределения эквивалентных узловых напряжений в конструкции основания съемного кузова. Результаты исследования напряженнодеформированного состояния конструкции всех вариантов основания представлены на рис. 2, $a-2$.

В результате исследования четырех вариантов конструкции основания на прочность были выявлены наиболее напряженные зоны, требующие конструктивные усиления и дополнения. Как видно на рис. 3, $a-2$, при расчете всех вариантов конструкции основания съемного кузова наиболее напряженные зоны одинаковые в местах соединения продольных балок с концевой балкой.

Наиболее максимальную нагрузку принимают узлы соединения балок и сварные швы. Для решения данной проблемы предлагается усилить более напряженные зоны дополнительными 

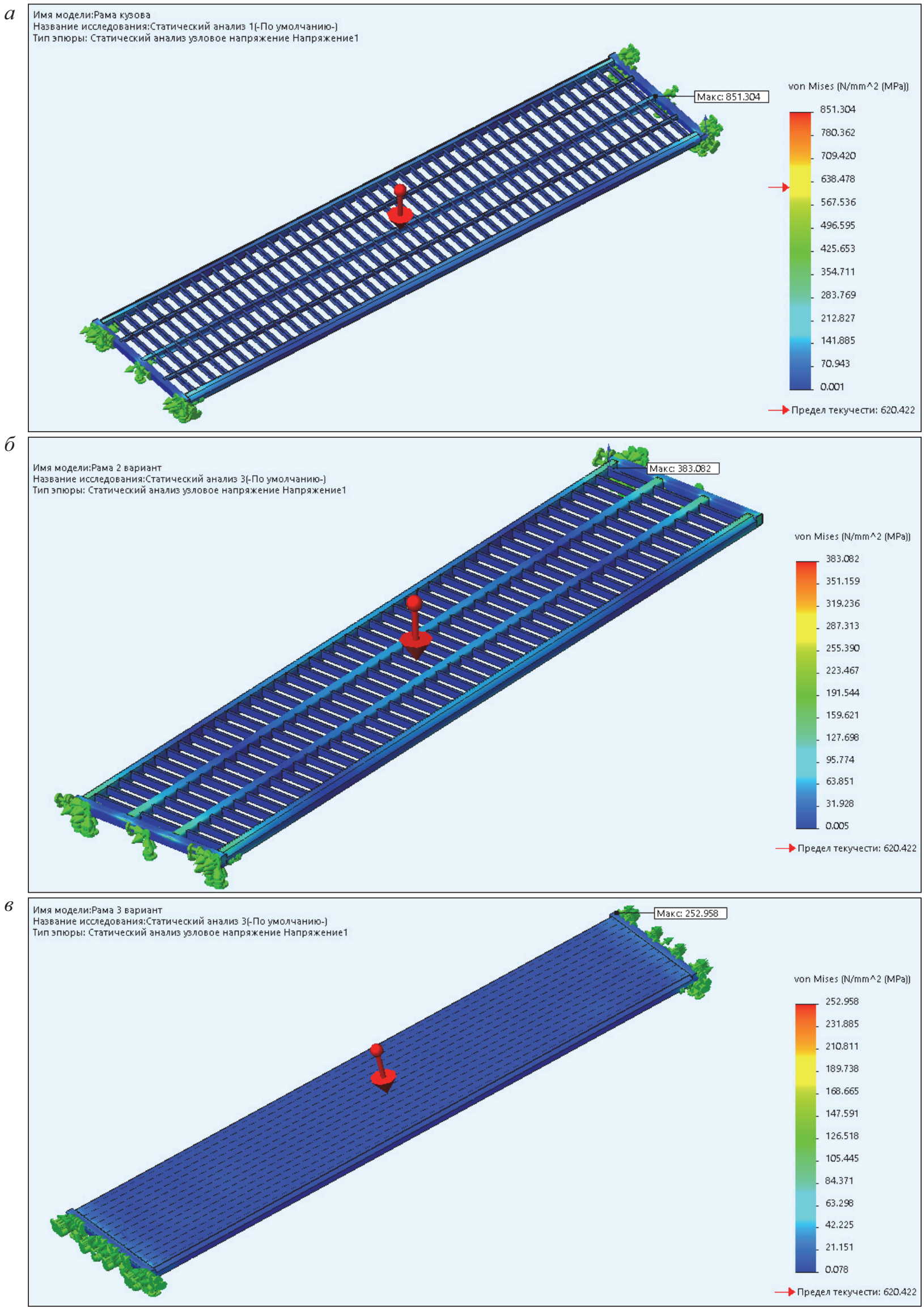

ISSN 1815-588X. Известия ПГУПС 


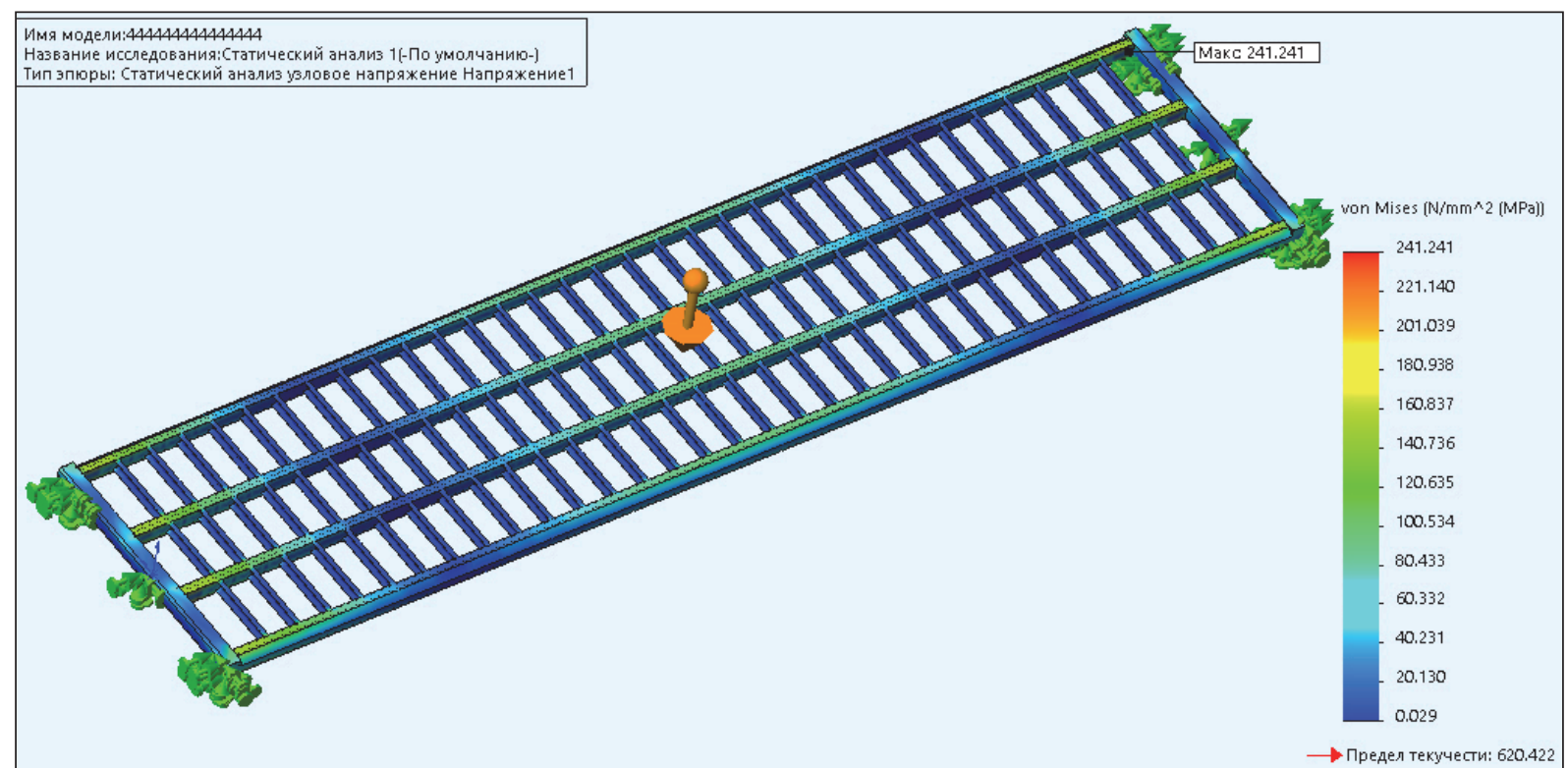

Рис. 2. Распределение эквивалентных узловых напряжений четырех вариантов конструкции основания съемного кузова (МПа)

$a$



B

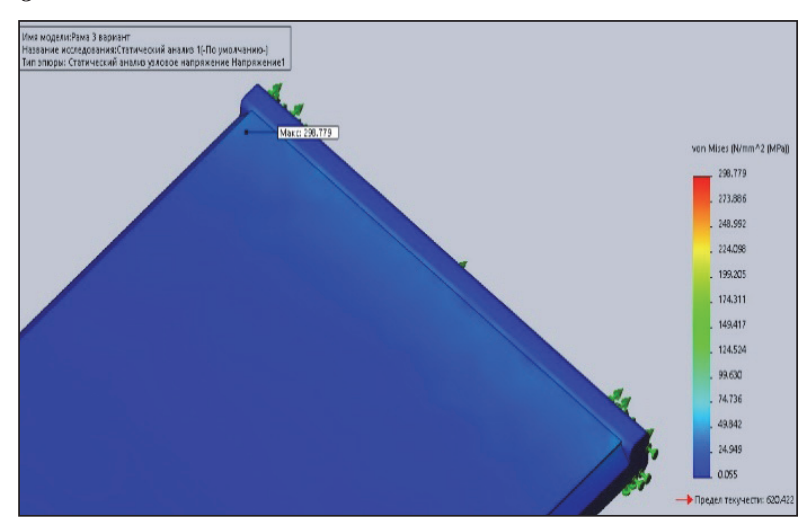

6
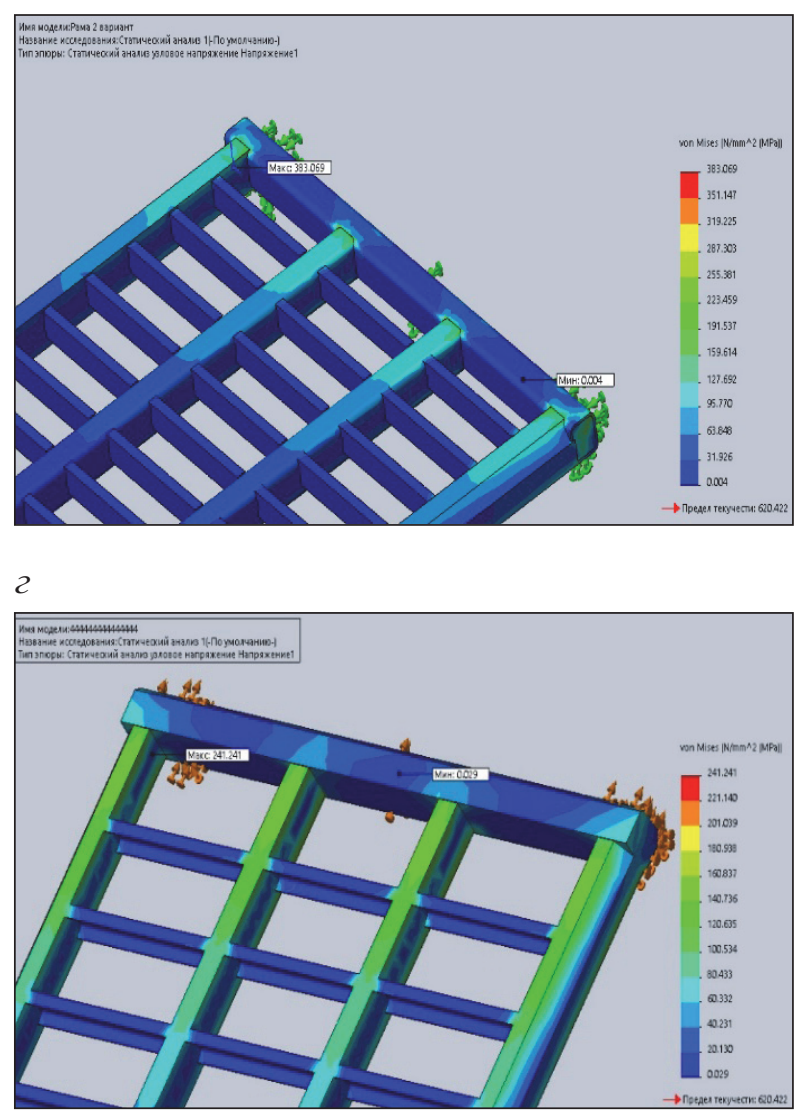

Рис. 3. Наиболее напряженные зоны, выявленные при расчете всех вариантов конструкции основания съемного кузова 
ребрами жесткости или планками. Ребра жесткости, диафрагмы и другие дополнительные усиливающие детали следует устанавливать с учетом напряжений в конструкции, действующих в основном сечении, размещая их в менее напряженных местах [7].

\section{Результаты исследования}

Результаты расчета напряженно-деформированного состояния всех вариантов конструкции основания съемного кузова с узловыми напряжениями приведены в таблице.

Из нее видно, что максимальное эквивалентное напряжение в первом варианте конструкции основания съемного кузова (см. рис. 2, a) при действии силы тяжести $g=9,81 \mathrm{~m} / \mathrm{c}^{2}$ составило 851 МПа. По результатам расчета узлового напряжения и запаса прочности, равным 0,80 , этот вариант основания съемного кузова не удовлетворяет условиям прочности.

Результаты расчета второго варианта конструкции основания съемного кузова (см. рис. 2, б) показывает, что максимальное узловое напряжение составляет 383 МПа с коэффициентом запаса прочности, равным 1,6, который удовлетворяет условиям прочности конструкции.

Результаты расчета третьего варианта конструкции основания съемного кузова (см. рис. 2, , ) максимальное узловое напряжение составляет 253 МПа с коэффициентом запаса прочности, равным 2,1. Такая конструкция основания имеет высокую прочность и большую массу за счет нескольких внутренних стальных вертикальных ребров, которые в целом превышают его придельный вес основания примерно на 10000 кг.

Результаты расчета четвертого варианта конструкции основания съемного кузова (см. рис. 2, 2) имеет максимальное узловое напряжение, равное $241 \mathrm{MПа,} \mathrm{и} \mathrm{более} \mathrm{высокий} \mathrm{коэффициент} \mathrm{запаса}$ прочности 2,6 по сравнению с тремя вариантами основания съемного кузова.

Из полученных результатов можно сделать вывод, что конструкция основания четвертого варианта основания съемного кузова удовлетворяет требованиям прочности вышеперечисленных нормативных документов и поэтому выбрана в качестве базовой для дальнейшего проектирования съемного кузова крытого типа с раздвигающимися боковыми стенами и крышей.

Конечно-элементную модель основания четвертого варианта иллюстрирует рис. 4. Данная модель включает в себя 58208 элементов и 107282 узлов.

На рис. 5 представлена усталостная кривая при циклическом нагружении выбранного четвертого базового варианта основания съемного кузова.

Сравнительный анализ результатов исследования основания съемного кузова по теории Мизеса

\begin{tabular}{|l|c|c|c|c|}
\hline \multirow{2}{*}{ Параметры испытания } & \multicolumn{3}{c|}{ Варианты конструкции основания } \\
\cline { 2 - 5 } & $a$ & 6 & 6 & 200 \\
\hline Приложенная нагрузка, МПа & 200 & 200 & 200 & 620 \\
\hline Придел текучести материала, МПа & 620 & 620 & 620 & 241 \\
\hline Узловое напряжение максимальное, МПа & 851 & 383 & 298 & 2,6 \\
\hline Коэффициент запаса прочности & 0,80 & 1,6 & 2,1 & 3310 \\
\hline Масса основания, кг & 2570 & 3670 & 13000 & 58,552 \\
\hline $\begin{array}{l}\text { Усталостное повреждение } \\
\text { при 10 циклов, максимальное, МПа }\end{array}$ & 1,757661 & 587,181 & 1,409415 & 58208 \\
\hline $\begin{array}{l}\text { Элементы } \\
\text { Узлы }\end{array}$ & $\begin{array}{c}96391 \\
192274\end{array}$ & $\begin{array}{c}93116 \\
185327\end{array}$ & 29583 & 107282 \\
\hline
\end{tabular}




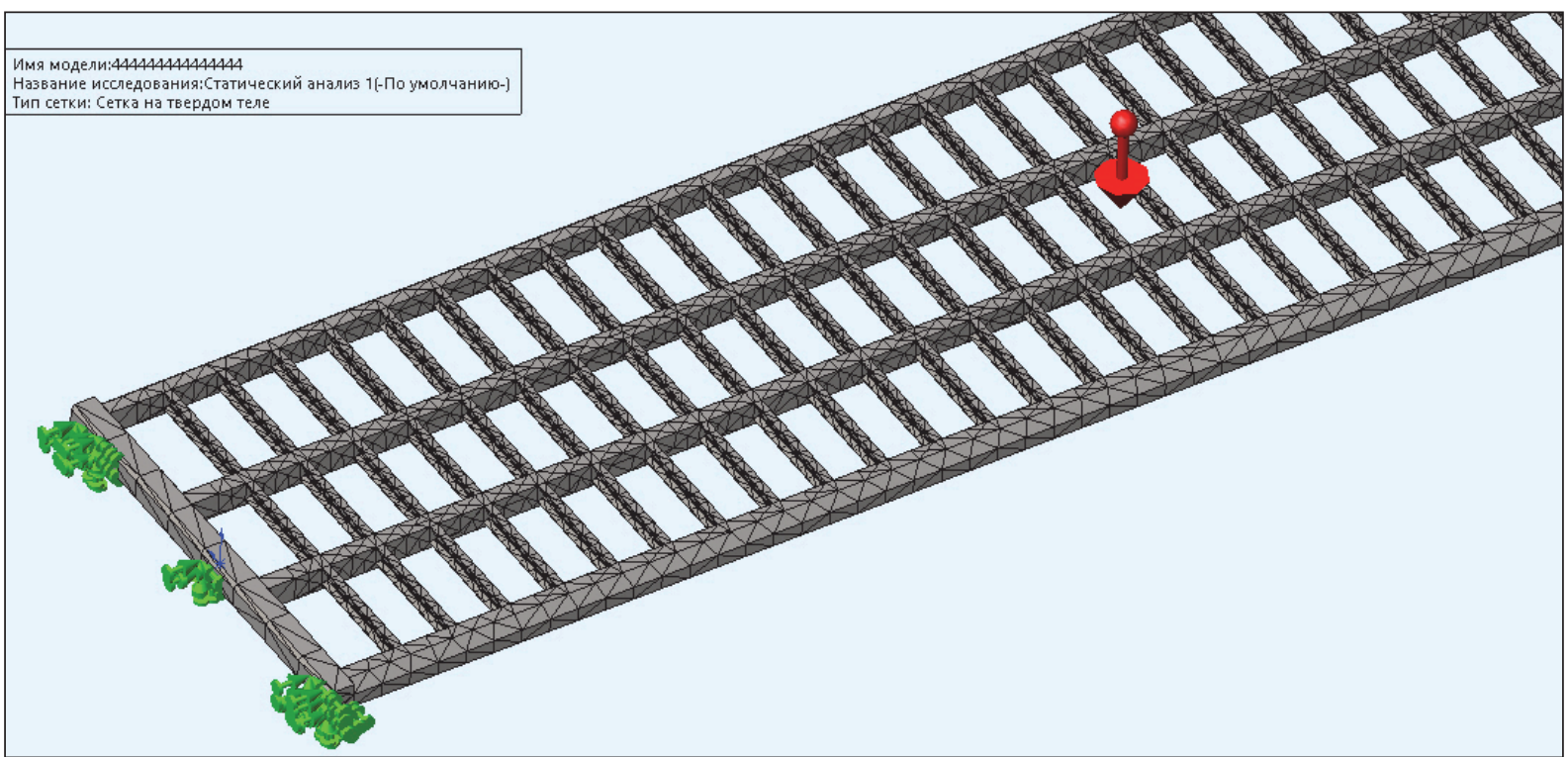

Рис. 4. Конечно-элементная модель основания четвертого варианта

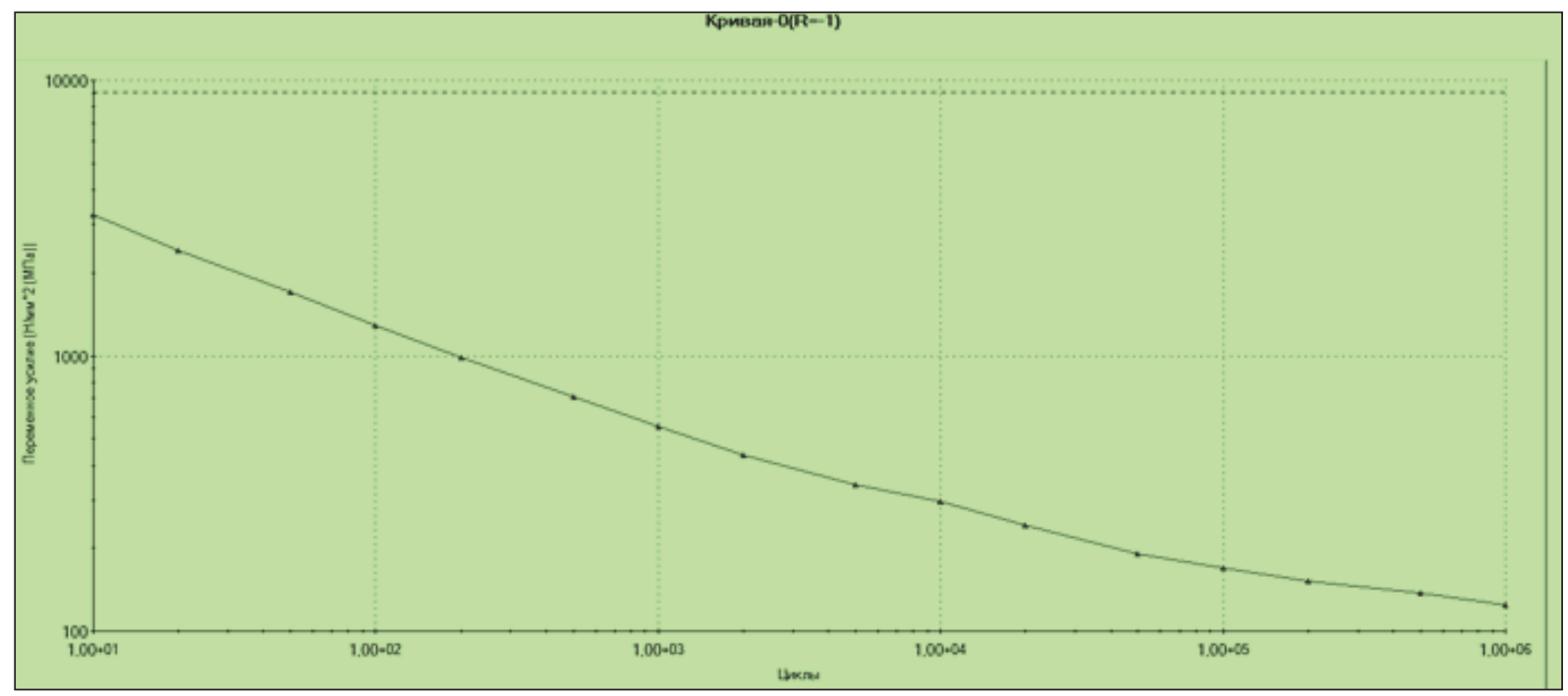

Рис. 5. Состояние выбранного варианта основания при циклическом нагружении

При $10^{6}$ циклической нагрузки выбранная конструкция основания четвертого варианта выдерживает заданную нагрузку без потери устойчивости.

\section{Заключение}

В работе представлены конструктивные чертежи четырех вариантов конструкции основания съемного кузова. Проведен статический анализ нагрузок и напряженно-деформированного состояния металлоконструкции основания съемного кузова. Выявлены наиболее напряженные зоны во всех узлах конструкции и предложены способы усиления напряженных зон конструкции. Согласно результатам моделирования и проведенных исследований, была выбрана базовая конструкция основания четвертого варианта съемного кузова, который удовлетво- 
ряет прочностным требованиям нормативных документов для дальнейшего проектирования съемного кузова крытого типа с раздвигающимися боковыми стенами и крышей.

\section{Библиографический список}

1. Бондаренко К.В. Оценка прочности рамы скоростного вагона-платформы / К.В. Бондаренко // Транспорт Российской Федерации. - 2014. - № 3 (52).C. 49-51.

2. Даукша А.С. Перспективы внедрения вагонов со съемными кузовами увеличенной грузоподъемности / А. С. Даукша, Ю.П. Бороненко // Известия Петербургского университета путей сообщения. - СПб. : ПГУПС, 2017.- Т. 14. - Вып. 3.- С. 437-451.

3. Зайнитдинов О.И. Конструирование съемного кузова с раздвигающимися боковыми стенами и крышей / О. И. Зайнитдинов // Известия Петербургского университета путей сообщения.- СПб. : ПГУПС, 2021.- Т. 18. - Вып. 1.- С. 62-71.

4. ГОСТ 33211-2014. Вагоны грузовые. Требования к прочности и динамическим качествам. - Принят Межгосударственным советом по стандартизации, метрологии и сертификации по переписке № 73-ст. от 27 декабря 2014 г.-М. : Стандартинформ, 2016.- 108 c.
5. ГОСТ Р 53192-2014. Соединения сварные в стальных конструкциях железнодорожного подвижного состава. Требования к проектированию, выполнению и контролю качества - Утв. Приказом Федерального агентства по техническому регулированию и метрологии № 1985-ст. от 12 декабря 2014 г.- М. : Стандартинформ, 2015.- 50 c.

6. ГОСТ Р 53077-2008. Рельсовый транспорт. Правила проектирования и испытаний конструкции рамы тележки. - Утв. Приказом Федерального агентства по техническому регулированию и метрологии № 458-ст. от 18 декабря 2008 г. - М. : Стандартинформ, 2009. $-28 \mathrm{c}$.

7. ГОСТ 33976-2016. Соединения сварные в стальных конструкциях железнодорожного подвижного состава. Требования к проектированию, выполнению и контролю качества. - Утв. Межгосударственным советом по стандартизации, метрологии и сертификации № 92-ст. от 25 октября 2016 г. - М. : Стандартинформ, 2017. $-52 \mathrm{c.}$

Дата поступления: 10.04.2021

Решение о публикации: 15.04.2021

Контактная информация:

БОРОНЕНКО Юрий Павлович - д-р техн. наук, проф.; boron49@уа.ru

ЗАЙНИТДИНОВ Олмос Ирикович - аспирант, zaynitdinovo@mail.ru

\section{Selection and analysis of design solutions for the base of the swap body}

\section{Y.P. Boronenko, O. I. Zaynitdinov}

Emperor Alexander I Petersburg State Transport University, 9, Moskovsky pr., Saint Petersburg, 190031, Russian Federation

For citation: Boronenko Y.P., Zaynitdinov O.I. Selection and analysis of design solutions for the base of the swap body. Proceedings of Petersburg Transport University. Saint Petersburg, Petersburg State Transport University, 2021, vol. 18, iss. 2, pp. 273-282. (In Russian) DOI: 10.20295/1815-588X-2021-2-273-282

\section{Summary}

Objective: Selection of the most optimal and durable base structure for the further design of a covered swap body with sliding side walls and roof. Methods: The analysis of the design solutions of the base of the swap body were carried out using a finite element method with the SolidWorks Simulation software package, and in accordance with technical and regulatory documents. Results: Four variants of the swap body base with different design features were designed. Diagrams of the distribution of equivalent nodal 
stresses in the structure of the demountable body foundations were obtained. From the results of the study and calculation, the most robust design of the base of the swap body was selected. Practical importance: The basic base structure described will serve for the design and construction of a covered swap body with retractable side walls and a roof.

Keywords: Swap body base, structure, finite element method, stress-strain state, nodal stress, fatigue damage.

\section{References}

1. Bondarenko K.V. Otsenka prochnosti ramy skorostnogo vagona-platformy [Evaluation of the frame strength of a high-speed flat car]. Transport Rossiyskoy Federatsii [Transport of the Russian Federation], 2014, no. 3 (52), pp. 49-51. (In Russian)

2. Dauksha A.S. \& Boronenko Y. P. Perspektivy vnedreniya vagonov so s"yemnymi kuzovami uvelichennoy gruzopodyemnosti [Prospects for the introduction of swapbody cars with increased carrying capacity]. Izvestiya Peterburgskogo universiteta putey soobshcheniya [Proceedings of Petersburg Transport University]. Saint Petersburg, Petersburg State Transport University Publ., 2017, vol. 14, iss. 3, pp. 437-451. (In Russian)

3. Zaynitdinov O.I. Konstruirovaniye s"yemnogo kuzova s razdvigayushchimisya bokovymi stenami i kryshey [Swap body construction with sliding side walls and roof]. Izvestiya Peterburgskogo universiteta putey soobshcheniya [Proseedings of Petersburg Transport University]. Saint Petersburg, Petersburg State Transport University Publ., 2021, vol. 18, iss. 1, pp. 62-71. (In Russian)

4. GOST 33211-2014. Vagony gruzovyye. Trebovaniya k prochnosti i dinamicheskim kachestvam. Prinyat Mezhgosudarstvennym sovetom po standartizatsii, metrologii i sertifikatsii po perepiske no. 73-st. ot 27 dekabrya 2014 [GOST 33211-2014. Freight wagons. Requirements for strength and dynamic properties. Adopted by the Interstate Council for Standardization, Metrology and Certification by correspondence N 73-st. of December 27, 2014]. Moscow, Standartinform Publ., 2016, 108 p. (In Russian)

5. GOST R 53192-2014. Soyedineniya svarnyye v stal'nykh konstruktsiyakh zheleznodorozhnogo podvizhnogo sostava. Trebovaniya k proyektirovaniyu, vypolneniyu i kontrolyu kachestva. Utv. Prikazom Federal'nogo agentstva po tekhnicheskomu regulirovaniyu i metrologii no. 1985-st. ot 12 dekabrya 2014 g. [GOST R $53192-$ 2014. Welded joints in steel structures of railway rolling stock. Requirements for design, implementation and quality control. Approved by order of the Federal Agency for Technical Regulation and Metrology N 1985-st. of December 12, 2014]. Moscow, Standartinform Publ., 2015, 50 p. (In Russian)

6. GOST R 53077-2008. Rel'sovyy transport. Pravila proyektirovaniya i ispytaniy konstruktsii ramy telezhki. Utv. Prikazom Federal'nogo agentstva po tekhnicheskomu regulirovaniyu i metrologii no. 458-st. ot 18 dekabrya 2008 g. [GOST R 53077-2008. Rail transport. Rules for the design and testing of the bogie frame structure. Approved order of the Federal Agency for Technical Regulation and Metrology N 458-st. December 18, 2008]. Moscow, Standartinform Publ., 2009, 28 p. (In Russian)

7. GOST 33976-2016. Soyedineniya svarnyye vstal'nykh konstruktsiyakh zheleznodorozhnogo podvizhnogo sostava. Trebovaniya k proyektirovaniyu, vypolneniyu $i$ kontrolyu kachestva. - Utv. Mezhgosudarstvennym sovetom po standartizatsii, metrologii i sertifikatsii no. 92-st. ot 25 oktyabrya 2016 g. [GOST 33976-2016. Welded joints in steel structures of railway rolling stock. Requirements for design, implementation and quality control. Approved Interstate Council for Standardization, Metrology and Certification N 92-st. of October 25, 2016]. Moscow, Standartinform Publ., 2017, 52 p. (In Russian)

Received: April 10, 2021

Accepted: April 15, 2021

\section{Authors' information:}

Yuri P. BORONENKO - D. Sci. in Engineering, Professor; boron49@ya.ru

Olmos I. ZAINITDINOV - Postgraduate Student; zaynitdinovo@mail.ru 


\title{
Разработка методов обеспечения информационной безопасности децентрализованных баз данных
}

\author{
Е. А. Буквина ${ }^{1}$, Е. В. Зверева², Е. В. Фалеева ${ }^{1}$, Р. А. Ешенко ${ }^{1}$ \\ 1 Дальневосточный государственный университет путей сообщения, Российская Федерация, \\ 680021, Хабаровск, ул. Серышева, 47 \\ 2 Петербургский государственный университет путей сообщения Императора Александра I, \\ Российская Федерация, 190031, Санкт-Петербург, Московский пр., 9
}

Для цитирования: Буквина Е.А., Зверева Е.В., Фалеева Е. В., Ешенко Р.А. Разработка методов обеспечения информационной безопасности децентрализованных баз данных // Известия Петербургского университета путей сообщения.- СПб.: ПГУПС, 2021.- Т. 18. - Вып. 2. - С. 283-293.

DOI: 10.20295/1815-588X-2021-2-283-293

\begin{abstract}
Аннотация
Цель: Разработать проект модели баз данных, адаптированную для использования в рамках децентрализованных баз данных. Описать стек протоколов взаимодействия компонентов систем управления базами данных, оперирующих децентрализованными ресурсами. Спроектировать механизмы распределения прав доступа субъектов к объектам доступа. Методы: Применяются: 1) анализ функционирования децентрализованных протоколов; 2) системный анализ структур и алгоритмов обработки данных; 3) анализ принципов работы децентрализованных приложений и требований, предьявляемых к децентрализованным базам данных; 4) прототипирование моделей построения данных; 5) классификация угроз безопасности информации; 6) экспериментальный метод, включающий проведение нагрузочных тестов, анализ и обобщение полученных данных. Результаты: Рассмотрена новая концепция организации данных, позволяющая отделять модели хранения данных от моделей бизнес-процессов предприятия и тем самым быстро подстраивать приложение под требования компании. Представлен ряд механизмов, которые способны обеспечивать работоспособность приложений, функционирующих на основе децентрализованных хранилищ. Описан метод разграничения прав доступа к объектам через ограничение области видимости данных в зависимости от роли, назначенной пользователю. Практическая значимость: Разработки в данной сфере имеют как теоретическую, так и практическую значимость, обусловленную популяризацией принципов так называемой «распределенной экономики» как в сфере государственных и коммерческих структур, так и среди проектировщиков программного обеспечения. Подобные преобразования в проектировании моделей данных, организации как самой разработки, так и внутренней архитектуры приложения позволили бы решить проблему чрезмерной централизации ресурсов и информационных потоков, а также распределить ответственность за целостность и актуальность данных между участниками процесса. Полученные результаты могут применяться для практической реализации децентрализованных хранилищ, а также для проектирования программных модулей, устраняющих уязвимости и обеспечивающих стабильную нейтрализацию угроз информационной безопасности децентрализованных баз данных.
\end{abstract}

Ключевые слова: Децентрализованная база данных, децентрализованное приложение, блокчейн, графо-ориентированная модель построения данных, безопасность информации, ролевой метод управления доступом, права доступа, ревизия поля, консенсус принятия изменений. 


\section{Введение}

За последнее десятилетие наблюдается усиление акцента в развитии информационных технологий на работу с децентрализованными приложениями, в которых обработка входных данных производится в большей степени на стороне клиента, а необходимость в постоянном доступе к централизованному хранилищу данных отпадает.

Этому также способствует в настоящее время всемирная пандемия. Заинтересованность в распределенных технологиях хранения и обработки данных связана с тенденцией смещения вектора угроз, связанных как с отказом в обслуживании, так и с несанкционированным доступом к данным, в направлении распределенной ответственности за их безопасность. Для поддержания информационной безопасности децентрализованной системы следует применять исключительно новые методы взаимодействия между участниками распределенных вычислительных процессов [1].

Из-за того, что современные информационные системы объединяют труд множества участников рабочего процесса, основное внимание необходимо обратить на обеспечение информационной безопасности при формировании совместного доступа к данным.

Экономический эффект от внедрения средств защиты в применяемое пользователями программное обеспечение может быть косвенным, так как сама разработка не выступает в качестве источника дохода. Однако своевременно спроектированная и введенная в эксплуатацию система защиты позволит исключить имеющиеся уязвимости и нейтрализовать возможные угрозы безопасности информации (незаконное использование привилегий, утечка данных, нарушение правил работы с информацией), осуществление которых способно привести как к финансовым убыткам разной степени, так и к потере положительного имиджа организации [2]. Таким образом, стоимость негативных последствий реализации злоумышленником угроз безопасности информации в денежном эквиваленте зависит, условно говоря, от стоимости клиентов, ушедших к конкурентам.

В настоящее время для управления доступом к объектам в эксплуатируемой системе существуют такие основные методы как:

- дискреционный (избирательный) метод контроля доступа;

- обязательный (полномочный) метод контроля доступа (мандатное управление доступом);

- ролевой метод контроля доступа [3-5].

В зависимости от особенностей предметной области приложения и выявленных угроз эти три метода могут комбинироваться для выполнения различных требований, предъявляемых к информационной безопасности системы [6].

\section{Постановка задачи}

Жестко детерминированные механизмы управления правами доступа к данным не позволяют обеспечить быстрой адаптации информационных потоков под нужды сотрудников фирмы.

В этом исследовании рассматривается задача проектирования такой модели управления доступом к данным, которая бы гибко обеспечивала распределение прав доступа между постоянно меняющимися участниками бизнеспроцессов, описываются логическое устройство и техническая реализация базовых механизмов управления доступом к данным в условиях децентрализованной среды. В основу модели хранения данных взяты правила построения децентрализованных баз данных К. Дж. Дейта [7].

\section{Абстрагирование модели хранения данных от модели бизнес-процессов}

В процессе работы была спроектирована модель среды оперативного ведения деятельности предприятия, которая сможет работать при децентрализованной организации данных с исключением единой точки отказа [8]. 
Можно сказать, что в большинстве случаев безопасность информационных систем и баз данных будет обеспечиваться за счет наличия данных в локальном хранилище, согласно правам пользователя, а не распределением прав доступа к данным, как в других системах. Эта возможность достигается посредством уменьшения диапазонов изменяемых данных и распределения механизмов поддержания их непротиворечия между участниками, согласно правам доступа к определенной минимальной ячейке доступа.

Одной из необходимых составляющих, добавленных в модель системы, стала независимость от бизнес-процессов предприятия. Таким образом, была получена требуемая отвлеченность модели хранения данных от реализации модели бизнес-процессов. Для этой цели была использована фрактальная модель создания объектов в рамках табличного отображения данных [9]. Набор базовых сущностей системы представлен в табл. 1.

Минимально возможный уровень доступа к данным доведен до уровня поля объекта, т. е. данные могут быть модифицированы сотрудниками организации в рамках одного объекта в различных полях. Такой механизм позволяет одновременно работать с одними объектами нескольким пользователям, имеющим доступ к разным группам полей. Это означает, что объект может консолидировать в себе информацию из множества источников как без пересечения (если различные группы полей редактируются пользователями с разными ролями), так и с пересечением (когда пользователи изменяют различные группы полей и принадлежат одновременно к нескольким группам (ролям)).

Все объекты повторяют свою структуру, и вся логика их взаимосвязи укладывается в наличие связей одного объекта с другими. Доступ к сущности выполняется с использованием идентификатора объекта и подразумевает получение данных в формате JSON.

\section{Модель доступа к данным}

Доступ к данным обеспечивается комбинацией элементов дискреционного и ролевого методов контроля доступа.

Управление доступом на основе ролей осуществляется путем создания объектов доступа, учетных записей пользователей, ролей и профилей [10].

Каждая роль имеет разные уровни доступа к экземплярам определенных классов на основе настроенных прав доступа и области видимости данных, которые организованы в виде ориентированных графов. Поэтому необходимо предоставить как права на чтение связанных с этим экземпляром классов, так и доступ к самим данным в зоне ответственности роли.

Каждая группа пользователей с одинаковыми правами принимает консенсус в вопросе принятия изменения данных в процессе работы. Группу пользователей, отнесенных к одной роли, будем называть «стратой». Каждому пользователю может быть доступно любое количество страт и возможность осуществлять доступ к данным, согласно привилегиям, определенным для роли.

ТАБЛИЦА 1. Базовые сущности системы

\begin{tabular}{|l|l|}
\hline \multicolumn{1}{|c|}{ Объект } & \multicolumn{1}{|c|}{ Описание } \\
\hline Шаблон & $\begin{array}{l}\text { Представляет собой объект шаблона (класс); содержит перечень полей } \\
\text { (атрибутов класса), идентификационные данные }\end{array}$ \\
\hline Объект & Содержит перечень данных в соответствии с полями шаблона-родителя \\
\hline Поле & Элемент шаблона (атрибут) \\
\hline Запрос & $\begin{array}{l}\text { Массив данных, согласно сформированной цепочке запросов и заданным } \\
\text { критериям }\end{array}$ \\
\hline
\end{tabular}


Пользователи производят редактирование полей объекта в локальном хранилище своей системы как равные участники. В ходе редактирования изменяется ревизия экземпляра поля, и в момент изменения, во избежание коллизий, соответствующая запись блокируется на уровне приложения.

Каждый пользователь может передать право доступа к данным, на которые имеет полный доступ. В момент добавления прав на добавление/изменение данных на уровне класса данных экземпляры этого класса создаются в локальном хранилище пользователя, у которого есть назначенная роль. Таким образом, здесь появляются элементы дискреционной модели распределения прав доступа через самостоятельное назначение пользователями сети прав на часть своих данных (своей зоны ответственности) другим пользователям.

Архивирование данных (для хранения состояния сети организации) реализуется запуском клиента с полными правами в сети на все данные, поэтому локальное клиентское хранилище данных будет содержать все изменения всех экземпляров всех классов [9].

\section{Поддерживающие технологии}

Уровень обмена данными децентрализованного приложения может базироваться на различных моделях сетевого взаимодействия и их комбинациях, а также на разных уровнях модели OSI. Среди моделей сетевого взаимодействия можно выделить следующие: сети доверия, рассылка соседям, широковещание на адрес, широковещательные сети, хеш-таблицы, кэширование, клонирование, блоковые сети. В этом случае используется F2F-сеть между пользователями, обладающими схожими ролями [11].

В настоящее время изучаются два варианта нахождения пользователей «своего круга»: путем распространения информации о новых пользователях своей страты во время передачи прав доступа или с использованием механизмов запроса передачи (оповещения) и погашения волнового эффекта транслирования запросов через своих «друзей» [9].

Обсуждая вопрос безопасности децентрализованных приложений, следует обратить внимание на некоторые поддерживающие технологии.

Идея расслоения данных и принятия консенсуса не всей сетью, а только внутри определенного слоя имеет частичное отношение к использованию блокчейна для фиксации изменений только в той степени, в которой возникает фиксация последней ревизии (изменений) объекта данных, а также происходит обновление изменений в рамках страты [12].

\section{Ревизии поля}

Когда заходит речь об информационной безопасности, необходимо отметить работу механизма, обеспечивающего надежность данных.

При формировании объекта поля в качестве его атрибута (наименование атрибута-copies) в базу данных заносится соответствующая запись, в которой указывается, сколько дополнительных копий объектов типа рассматриваемого поля будет храниться в базе. Значение атрибута copies объекта поля выставляется пользователем в режиме редактирования поля.

При изменении значения поля в объекте запрос с данными посылается на сервер. В ходе этого процесса проверяется необходимость резервирования поля (является ли атрибут copies объекта поля непустым).

Для резервируемого поля, когда появляется надобность хранения истории изменений значения текущего поля, в базе данных формируется новая запись, в которой указаны новое значение поля (value), последняя дата изменения (rev) и редактор поля (editor).

Следующим шагом записи, соответствующие этому полю, сортируются по полю rev.

Затем идет этап проверки: если количество полученных записей превышает значение copies для заданного объекта поля, то первая созданная запись автоматически удаляется из базы дан- 
ных. Если же поле нерезервируемое, то все изменения отражаются в соответствующей полю записи, и резервная копия не создается. Резервные копии, предоставляющие возможность отслеживать изменения значения, ревизии и редактора поля, создаются для критически важных (например, системных) полей.

Следующим этапом планируется ограничить количество ревизий поля для каждого конкретного пользователя, что уменьшает объем базы данных.

Авторство пользователя на каждую копию (поле editor содержит уникальный идентификатор пользователя) при уменьшении количества ревизий позволит избежать ситуации уничтожения всего объема данных одним пользователем.

\section{Фиксация прав доступа}

Права доступа назначаются через включение пользователя в группу роли; в системе образуется связка экземпляра роли с экземпляром пользователя (рисунок).

Продемонстрированная на рисунке модель может осуществляться через любой хост при помощи оператора в том случае, когда последний имеет права полного доступа на шаблон, а также привилегии назначения роли.

Регистрация всех операций с правами доступа происходит в блокчейн-цепочке. При необходимости внесения изменений в такую цепочку пользователь должен обладать соответствующими правами. Причем каждый новый блок должен быть согласован со всеми пользователями страты, так как, именно воспользовавшись записями в этой цепочке, хост принимает или отклоняет запросы других хостов на работу с данными.

При добавлении нового пользователя в страту (назначении заданной роли новому пользователю) формируется запрос на обновление цепочки прав, после чего хост производит проверку всей блокчейн-цепочки на возможность добавления заданных прав другому пользователю. Процесс отправки (обработки) запросов и возмож- ность участия в обмене данными при этом зависит от установленных прав доступа в цепочке прав.

Каждая цепочка прав доступа (ЦПД) выполняет функцию фиксации публичных ключей всех участников обмена данными, хранит информацию о правах доступа и содержит в своем составе наборы последовательно соединенных полей.

При добавлении в одну из страт нового узла формируется запрос на предоставление публичного ключа для него, что делает такой механизм схожим с f2f-сетями, где добавление в сеть возможно посредством приглашения «другом» [11]. Происходит формирование двух ключей - открытого и закрытого. Открытый ключ отправляется узлу, оператор которого добавляет нового пользователя в страту (назначает ему роль).

Далее хост публикует открытый ключ в ЦПД с указанием идентификатора роли, назначенной пользователю. В дальнейшем опубликованный ключ будет использоваться для согласования (открытия) каналов обмена данными всеми узлами.

Согласование канала осуществляется путем отправки зашифрованного открытым ключом сообщения на хост, выдающий себя за хост с обозначенным идентификатором. Хост, получивший запрос на подтверждение, расшифровывает его своим закрытым ключом и отвечает хосту-инициатору, шифруя сообщение открытым ключом последнего [13-15].



Модель профилирования 
Возможность атаки «Maninthemiddle», когда сторонний хост может отправить запрос с идентификатором другого хоста, в таком случае исключается.

\section{Контроль доступа к данным на уровне ролей}

Метод управления доступом к данным реализуется путем назначения списка идентификаторов ролей для каждого атрибута объекта (табл. 2).

Поскольку объекты, шаблоны, поля - все это сущности одного уровня, механизмы доступа ко всем таким сущностям будут идентичны.

Особенностью реализации децентрализованной базы данных является требование к наличию на узле (рабочем месте) всех данных, к которым пользователь может иметь доступ [16]. При изменении данных или добавлении новой роли для пользователя происходит репликация данных на узел. При назначении пользователю новой роли узел запрашивает все данные, доступные для заданной роли. Следовательно, наличие данных в локальном хранилище узла есть результат следующих последовательных процедур:

- получение списка узлов для заданной роли;

- принятие списка изменений с момента участия в последней процедуре консенсуса;

- отправка и получение цепочки запросов в хранилище данных;

- фиксация полученных изменений в локальной версии хранилища данных.
Так как в приведенной модели данных отдельно выделенная запись, идентифицирующая объект, отсутствует (а объект есть набор записей с одним идентификатором), то это дает возможность гибкого управления записями хранилища в выборке.

Ранее было отмечено, что один пользователь может иметь несколько ролей, которые должны быть независимы друг от друга. В таком случае возможен вариант пользовательского доступа к одному и тому же массиву данных через разные роли.

Стоит отметить, что, независимо от потенциально «самостоятельно» установленных прав доступа к данным на узле назначения, решение о запуске синхронизации и передаче массива данных принимает каждый узел, оператором которого является пользователь, входящий в указанную страту. Вследствие этого можно утверждать, что обеспечение информационной безопасности на уровне пользователя осуществляется автоматически посредством лимитирования запросов на репликацию/изменение данных.

Через добавление записей на доступ на уровне записи данных в хранилище реализуются механизмы ролевой модели доступа.

Если приходит запрос на получение данных, то производятся проверка доступа и выдача разрешения. Такой процесс включает ряд этапов: проверку разрешения на доступ к конкретному объекту, к которому происходит обращение; при положительном исходе проверки осуществляется выборка лишь тех атрибутов объекта, к которым назначен доступ.

ТАБЛИЦА 2. Поля в хранилище данных, обеспечивающие реализацию принципов ролевого управления доступом

\begin{tabular}{|l|l|}
\hline \multicolumn{1}{|c|}{ Поле } & \multicolumn{1}{c|}{ Описание } \\
\hline access_read & Идентификаторы объектов роли с разрешением на чтение объекта доступа \\
\hline access_write & Идентификаторы объектов роли с разрешением на изменение объекта доступа \\
\hline access_delete & Идентификаторы объектов роли с разрешением на удаление объекта доступа \\
\hline admin & $\begin{array}{l}\text { Идентификаторы объектов роли с разрешением на управление правами } \\
\text { доступа к объекту }\end{array}$ \\
\hline
\end{tabular}




\section{Управление консенсусом принятия изменений}

Все изменения между территориально разделенными узлами проходят через особый механизм фиксации в цепочке транзакций. Каждое изменение в локальном хранилище обязательно транслируется и жестко фиксируется на всех узлах страты. Изменения применяются к конкретному полю любого объекта и транслируются узлом, отредактировавшим поле, на всех участников страты, доступных в данный момент.

Последовательность операций заключается в следующем:

1) когда происходит блокировка поля в конкретном локальном хранилище, узел передает запрос на блокировку данной записи (информацию которой он изменяет) на все доступные узлы страты;

2) остальные узлы страты фиксируют у себя данное поле как «заблокированное» сторонним узлом, чтобы избежать возникновения конфликтов при трансляции изменений (при этом для каждого поля каждый узел хранит свою цепочку транзакций в блокчейн);

3) после изменения данных узел добавляет в такую цепочку новый блок и отправляет его всем доступным на данный момент узлам страты;

4) узлы получают цепочку, проверяют ее правильность (новый блок является следующим за последним блоком в настоящей цепочке);

5) если проверка узлов проходит успешно, производится операция изменения данных в текущем хранилище. Существуют два решения трансляции изменений. Первое решение заключается в пересылке SQL-запроса, который принимающие хосты должны повторить со своей базой данных. Такой способ является универсальным для любых операций (добавления, изменения, удаления), но с ограничениями на его использование в in-Memory- и NoSQL-хранилищах [17]. Суть второго подхода состоит в передаче наименования операции и конечного результата. Он универсален для абсолютно любых типов баз данных, однако требует дополнительных обработчиков;
6) в случае принятия изменений каждым узлом производится отправка уведомления о принятии блока;

7) узел-инициатор получает ответы блоков и, если общее количество ответов достигло минимум $51 \%$, то в нем фиксируется принятая информация.

\section{Заключение}

При децентрализованном режиме работы, где каждый узел является фактически хранилищем данных, доступных для просмотра/изменения, организация совместного последовательного доступа к данным со стороны системы претерпевает значительные изменения.

Поскольку данные локальны, то они доступны в полной мере пользователю узла. Однако принятие изменений данных стратой возможно лишь при наличии прав на изменение для роли пользователя.

В случае децентрализованной обработки нет единого контролирующего механизма поддержания распределения прав доступа на совместный доступ к данным, а присутствует лишь алгоритм принятия изменений, исходя из наличия записанных прав роли на манипуляцию сущностью в цепочке блоков.

В ходе исследовательской работы были проанализированы основные принципы функционирования децентрализованных баз данных и требования, предъявляемые к ним.

В рамках проектирования был предложен новый подход к организации взаимодействия данных и представления структуры модели хранения.

Описанное решение является расширенной реализацией системы с учетом всех требований для децентрализованных хранилищ данных, выделенных К. Дж. Дейтом.

Помимо этого была разработана и технически реализована модель доступа к данным через хранение идентификаторов доступа в цепочке блоков, а также ограничение видимости данных в рамках групп пользователей. 
Предложенная модель безопасного доступа к данным основывается на персональной ответственности каждого пользователя за предоставляемые им права на доступ к данным другим пользователям. Каждый пользователь децентрализованной базы данных может разрешить доступ на просмотр/изменение/создание данных в рамках привилегий своей роли. Вследствие этого необходимость в администраторе для обеспечения безопасности отпадает, что позволяет переложить ответственность за обеспечение доступа к данным на сами узлы и их операторов.

Результаты проведенных исследований в дальнейшем могут быть использованы в практической реализации децентрализованных баз данных, что позволит выстраивать сложные бизнессистемы без предварительного проектирования схем баз данных, исключив единую точку отказа в работе, повысив безопасность данных и сделав бессмысленными большинство типов атак.

\section{Библиографический список}

1. Буквина Е. А. Роль и место децентрализованных приложений в цифровой экономике / Е.А. Буквина // Глобальная экономика в XXI веке : роль биотехнологий и цифровых технологий : сб. науч. статей по итогам работы пятого круглого стола с международным участием. Москва, 15-16 июля 2020 г.- М. : ООО «Конверт», 2020.- С. 195-196.

2. Буквина Е. А. Экономические аспекты информационной безопасности предприятия / Е. А. Буквина // Глобальная экономика в XXI веке : роль биотехнологий и цифровых технологий : сб. науч. статей по итогам работы пятого круглого стола с международным участием. Москва, 15-16 июля 2020 г. - М. : ООО «Конверт», 2020.- С. 192-194.

3. Модели защиты информационных активов. URL : https://revolution.allbest.ru/radio/00479423_0. html (дата обращения : 10.01.2021 г.).

4. Методы управления доступом в распределенных средах. - URL: http://www.ict.nsc.ru/ws/YM2003/6299/ (дата обращения : 20.01.2021 г.).

5. Обзор и сравнение существующих методов управления доступом. - URL : http://www.ict.nsc.ru/ws/ YM2003/6312 (дата обращения : 20.01.2021 г.).
6. Меры защиты информации в государственных информационных системах. - URL : https://fstec.ru/ component/attachments/download/675 (дата обращения : 10.05.2021 г.).

7. Зеневич А. М. Системы обработки многопользовательских баз данных / А. М. Зеневич. - URL : http:// www.bseu.by/it/tohod/lekcii8_5.htm (дата обращения : 07.02.2021 г.).

8. Буквина Е. A. Buildbox Platform как инструмент для разработки отраслевых IT-решений / Е. А. Буквина, И. В. Ловецкий, М. А. Буквина и др. // Глобальная экономика в XXI веке : роль биотехнологий и цифровых технологий : сб. науч. статей по итогам работы четвертого круглого стола с международным участием. Москва, 15-16 июня 2020 г. - М. : ООО «Конверт», 2020. - C. 29-31.

9. Ловецкий И. В. Децентрализация баз данных как путь к безопасности данных предприятия / И. В. Ловецкий, Д. С. Добровинский, М. А. Попов // Докл. VII Пленума СибРОУМО и материалы XVI конференции «Проблемы информационной безопасности государства, общества и личности». Томск, 6-10 июня 2018 г. - Томск : В.-Спектр, 2018. - С. 65-67.

10. Буквина Е. A. Buildbox Platform. Реализация методов управления доступом / Е. А. Буквина // Приоритетные направления инновационной деятельности в промышленности : сб. науч. статей седьмой международной научной конференции. Казань, 30-31 июля 2020 г. - Казань : ООО «Конверт», 2020. - С. 31-33.

11. Friend-to-friend. - URL : https://dic.academic.ru/ dic.nsf/ruwiki/479045 (дата обращения : 24.03.2021 г.).

12. Raval S. Decentralized applications: Harnessing Bitcoin's Blockchain Technology / S. Raval. - O'Reilly Media, 2016. - 118 p.

13. Анисимов В. В. Криптография : метод. указания / В. В. Анисимов. - Хабаровск : ДВГУПС, 2004. $33 \mathrm{c}$.

14. Рябко Б. Я. Криптографические методы защиты информации : учеб.пособие / Б. Я. Рябко, А. Н. Фионов. - М. : Горячая линия-Телеком, 2005.$229 \mathrm{c}$.

15. Мао В. Современная криптография : теория и практика / В. Мао ; пер. с англ. и ред. Д. А. Клюшина. - М. : Издат. дом «Вильямс», 2005. - 763 с.

16. Яковлев Ю. С. О концепции построения и выбора распределенных баз данных информационно- 
поисковых систем / Ю.С. Яковлев // Математические машины и системы. - 2003. - № 2. - С. 35-53.

17. Sadalage P. J. NoSQL distilled : A brief guide to the Emerging World of Polyglot Persisrence / P. J. Sadalage, M. Fowler.- New York : Addison-Wesley Professional, 2012. $-192 \mathrm{p}$.

Дата поступления: 16.02.2021

Решение о публикации: 23.04.2021

\author{
Контактная информация: \\ БУКВИНА Екатерина Алексеевна - преподава- \\ тель; bukvina.katerina.96@mail.ru \\ ЗВЕРЕВА Елена Валерьевна - канд. экон. наук, \\ доц.; zverelv@mail.ru \\ ФАЛЕЕВА Елена Валерьевна - канд. техн. наук, \\ доц.; elena_ha2004@mail.ru \\ ЕШЕНКО Роман Анатольевич - канд. техн. наук, \\ доц.; era99@yandex.ru
}

\title{
Development of methods for ensuring information security of decentralized databases
}

\author{
E. A. Bukvina ${ }^{1}$, E. V. Zvereva ${ }^{2}$, E. V. Faleeva ${ }^{1}$, R. A. Yeshenko ${ }^{1}$ \\ ${ }^{1}$ Far Eastern State Transport University, 47, Serysheva ul., Khabarovsk, 680021, Russian Federation \\ 2 Emperor Alexander I Petersburg State Transport University, 9, Moskovsky pr., Saint Petersburg, \\ 190031, Russian Federation
}

For citation: Bukvina E.A., Zvereva E. V., Faleeva E.V., Yeshenko R.A. Development of methods for ensuring information security of decentralized databases. Proceedings of Petersburg Transport University. Saint Petersburg, Petersburg State Transport University, 2021, vol. 18, iss. 2, pp. 283-293 (In Russian) DOI: 10.20295/1815-588X-2021-2-283-293

\section{Summary}

Objective: To develop a draft database model adapted for use in decentralized databases. To describe the protocol stack for interaction between the components of database management systems operating with decentralized resources. To design mechanisms for distributing access rights of access subjects to access objects. Methodology: 1) analysis of the functions of decentralized protocols; 2) system analysis of structures and data processing algorithms; 3 ) analysis of the principles of decentralized applications and the requirements for decentralized databases; 4) prototyping data building models; 5) classification of threats to information security; 6) experimental methodology, including stress tests and the analysis and summary of the data obtained. Results: A new concept of data organization was considered, which allowed separating data storage models from business process models, thereby enabling the quick adjustment of the application to the company's requirements. A number of mechanisms are presented that are capable of ensuring the performance of applications operating on the basis of decentralized storages. A method for differentiating access rights to objects by limiting the data scope depending on the role assigned to the user is described. Practical importance: Developments in this area have both theoretical and practical significance due to the popularization of the principles of the so-called "distributed economy" both in the field of government and commerce, and among software designers. Such transformations in the design of data models, the organization of both the development itself, and the internal architecture of the application would solve the problem of excessive centralization of resources and information flows, as well as distribute responsibility for the integrity and relevance of data among the participants in the process. The results obtained can be used for the practical implementation of decentralized storage, as well as for the design of software modules that eliminate vulnerabilities and ensure stable neutralization of threats to information security of decentralized databases. 
Keywords: Decentralized database, decentralized application, blockchain, graph-oriented model of data construction, information security, role-based access control, access rights, field revision, consensus of adoption of changes.

\section{Preferences}

1. Bukvina E.A. Rol' i mesto detsentralizovannykh prilozheniy v tsifrovoy ekonomike [Role and place of decentralized applications in digital economy]. Global 'naya ekonomika $v$ XXI veke: rol' biotekhnologiy i tsifrovykh tekhnologiy. Sbornik nauchnykh statey po itogam raboty pyatogo kruglogo stola s mezhdunarodnym uchastiyem [The Global Economy in the 21st Century: The Role of Biotechnology and Digital Technologies. A Collection of Scientific Articles on the Results of the Fifth Round Table with International Participation]. Moscow, LLC "Convert" Publ., 2020, pp. 195-196. (In Russian)

2. Bukvina E. A. Ekonomicheskiye aspekty informatsionnoy bezopasnosti predpriyatiya [Economic aspects of information security of an enterprise]. Global'naya ekonomika $v$ XXI veke: rol' biotekhnologiy i tsifrovykh tekhnologiy. Sbornik nauchnykh statey po itogam raboty pyatogo kruglogo stola s mezhdunarodnym uchastiyem [The Global Economy in the 21st Century: The Role of Biotechnology and Digital Technologies. A Collection of Scientific Articles on the Results of the Fifth Round Table with International Participation]. Moscow, LLC "Convert" Publ., 2020, pp. 192-194. (In Russian)

3. Modeli zashchity informatsionnykh aktivov [Information asset protection models]. Available at: https://revolution.allbest.ru/radio/00479423_0.html (accessed: January 10, 2021). (In Russian)

4. Metody upravleniya dostupom $v$ raspredelennykh sredakh [Access control techniques in distributed environments]. Available at: http://www.ict.nsc.ru/ws/YM2003/ 6299/(accessed: January 20, 2021) (In Russian)

5. Obzor i sravneniye sushchestvuyushchikh metodov upravleniya dostupom [Review and comparison of existing methods of access control]. Available at: http://www. ict.nsc.ru/ws/YM2003/6312/(accessed: January 20, 2021). (In Russian)

6. Mery zashchity informatsii v gosudarstvennykh informatsionnykh sistemakh [Information protection measures in state information systems]. Available at: https:// fstec.ru/component/attachments/download/675 (accessed: May 10, 2021). (In Russian)
7. Zenevich A. M. Sistemy obrabotki mnogopol'zovatel'skikh baz dannykh [Multi-user database processing systems]. Available at: http://www.bseu.by/it/tohod/ lekcii8_5.htm (accessed: February 07, 2021). (In Russian)

8. Bukvina E. A., Lovetskiy I.V., Bukvina M.A. et al. Buildbox Platform kak instrument dlya razrabotki otraslevykh IT-resheniy [Buildbox Platform as a tool for developing industry IT solutions]. Global'naya ekonomika v XXI veke: rol'biotekhnologiy i tsifrovykh tekhnologiy. Sbornik nauchnykh statey po itogam raboty pyatogo kruglogo stola s mezhdunarodnym uchastiyem [The Global Economy in the 21st Century: The Role of Biotechnology and Digital Technologies. A Collection of Scientific Articles on the Results of the Fifth Round Table with International Participation]. Moscow, LLC "Convert" Publ., 2020, pp. 29-31. (In Russian)

9. Lovetskiy I. V., Dobrovinsky D. S. \& Popov M.A. Detsentralizatsiya baz dannykh kak put' $k$ bezopasnosti dannykh predpriyatiya [Decentralizing databases as a path to enterprise data security]. Doklady VII Plenuma Sibirskogo regional'nogo otdeleniya uchebno-metodicheskogo ob"yedineniya vuzov Rossii i materialy XVI konferentsii "Problemy informatsionnoy bezopasnosti gosudarstva, obshchestva i lichnosti”. Tomsk, 6-10 iyunya 2018 g. [Reports of the VII Plenum of the Siberian regional branch of the educational and methodological association of Russian universities and materials of the XVI conference "Problems of information security of the state, society and the individual". Tomsk, June 6-10, 2018]. Tomsk, V.-Spectr Publ., 2018, pp. 65-67. (In Russian)

10. Bukvina E.A. Buildbox Platform. Realizatsiya metodov upravleniya dostupom [Buildbox Platform. Implementing Access Control Methods]. Prioritetnyye napravleniya innovatsionnoy deyatel'nosti v promyshlennosti. Sbornik nauchnykh statey sed'moy mezhdunarodnoy nauchnoy konferentsii. Kazan', 30-31 iyulya 2020 g. [Priority areas of innovation in industry. Collection of scientific articles of the seventh international scientific conference. Kazan, 30-31 July 2020]. Kazan, LLC “Convert” Publ., 2020, pp. 31-33. (In Russian)

11. Friend-to-friend. Available at: https://dic.academic.ru/dic.nsf/ruwiki/479045 (accessed: March 24, 2021). (In Russian) 
12. Raval S. Decentralized applications: Harnessing Bitcoin's Blockchain Technology. O'Reilly Media Publ., 2016, 118 p.

13. Anisimov V.V. Kriptografiya. Metod. ukazaniya [Cryptography. Method. directions]. Khabarovsk, Far Eastern State Transport University Publ., 2004, 33 p. (In Russian)

14. Ryabko B.Y. \& Fionov A.N. Kriptograficheskiye metody zashchity informatsii. Uchebnoye posobiye [Cryptographic information security methods. A Tutorial]. Moscow, Hotline-Telecom Publ., 2005, 229 p. (In Russian)

15. Mao W. Sovremennaya kriptografia. Teoria i praktika [Modern Cryptography. Theory and Practice]. Moscow, Publishing House "Williams", 2005, 763 p. (In Russian)

16. Yakovlev Y. S. O kontseptsii postroyeniya i vybora raspredelennykh baz dannykh informatsionno-poiskovykh system [On the concept of building and choosing distributed databases of information retrieval systems].
Matematicheskiye mashiny i sistemy [Mathematical machines and systems], 2003, no. 2, pp. 35-53. (In Russian)

17. Sadalage P. J. \& Fowler M. NoSQL Distilled: A brief guide to the Emerging World of Polyglot Persisrence. New York, Addison-Wesley Professional Publ., 2012, $192 \mathrm{p}$.

Received: February 16, 2021

Accepted: April 23, 2021

\section{Authors' information:}

Ekaterina A. BUKVINA - Teacher; bukvina.katerina.96@mail.ru

Elena V. ZVEREVA - PhD in Economics, Associate Professor; zverelv@mail.ru

Elena V. FALEEVA - PhD in Engineering, Associate professor; elena_ha2004@mail.ru

Roman A. YESHENKO - PhD in Engineering, Associate professor; era99@yandex.ru 
УДК 621.876 .1

\section{Распределенная система многопараметрического ежедневного контроля технического состояния рабочего оборудования мобильных подъемников с рабочими платформами мачтового типа}

\section{М. С. Коровина, С. К. Коровин}

Петербургский государственный университет путей сообщения Императора Александра I, Российская Федерация, 190031, Санкт-Петербург, Московский пр., д. 9

Для цитирования: Коровина М. С., Коровин С. К. Распределенная система многопараметрического ежедневного контроля технического состояния рабочего оборудования мобильных подъемников с рабочими платформами мачтового типа // Известия Петербургского университета путей сообщения. - СПб.: ПГУПС, 2021.- Т. 18. - Вып. 2.- С. 294-302.

DOI: $10.20295 / 1815-588 X-2021-2-294-302$

\section{Аннотация}

Цель: Рассмотреть требования к приборам безопасности мобильных подъемников с рабочими платформами и проанализировать особенности ежедневного контроля их технического состояния. Изучить вопрос о необходимости расширения функций встроенных систем безопасности этих подъемников. Показать необходимость углубленного контроля и анализа динамических процессов цикла работы мобильных подъемников с рабочими платформами мачтового типа и дать технические решения его реализации. Методы: Выявление взаимосвязей механических и электромеханических характеристик электроприводов мобильных подъемников с рабочими платформами мачтового типа с выходными параметрами распределенной системы многопараметрического ежедневного контроля на различных режимах с помощью адаптивной нейро-нечеткой системы ANFIS пакета MATLAB. Результаты: На лабораторном стенде получены значения минимальных среднеквадратичных ошибок определения частоты вращения, момента на валу и тока статора асинхронного электродвигателя с короткозамкнутым ротором по данным трехосевых акселерометра LIS331DLH, гироскопа I3G4250D и магнитометра LIS3MDL, а также электретного микрофона_на обучающих и тестовых выборках, с помощью различных методов обучения и функций принадлежности сгенерированных структур адаптивной нейро-нечеткой системы ANFIS. Практическая значимость: Показана возможность расширения функций встроенных систем безопасности мобильных подъемников с рабочими платформами мачтового типа на основе контроля динамических процессов работы в цикле распределенной системой многопараметрического ежедневного контроля, обученной с помощью адаптивной нейро-нечеткой системы ANFIS пакета MATLAB, которая может быть рекомендована к практическому использованию.

Ключевые слова: Распределенная система многопараметрического ежедневного контроля, техническое состояние рабочего оборудования, анализ динамических процессов цикла работы, лабораторный стенд, нечеткое моделирование, адаптивная нейро-нечеткая система ANFIS.

\section{Введение}

В классификации подъемников с рабочими платформами и подъемным оборудованием мачтового типа представлены подъемники одно- мачтовые и многомачтовые, с мачтой фиксированной и изменяемой длины, с вертикальной и наклонной мачтами, со свободностоящей и закрепленной мачтами [1]. Приведенные в [2] требования к устройствам (приборам) безопасности 
мобильных подъемников с рабочими платформами (МПРП) предусматривают оборудование МПРП следующими устройствами безопасности:

- системой, чувствительной к нагрузке (например, ограничителем предельного груза);

- системой, чувствительной к положению подъемного оборудования и ограничивающей превышение допускаемых напряжений;

- системой, чувствительной к опрокидывающему моменту и ограничивающей зону обслуживания;

- устройством ориентации пола рабочей платформы в горизонтальном положении;

- устройством блокировки подъема и поворота подъемного оборудования при неустановленном на опорах подъемнике, кроме винтовых опор, размещаемых вручную;

- устройством блокировки подъема опор при поднятом рабочем оборудовании, кроме винтовых опор, поставленных вручную;

- устройством аварийного опускания рабочей платформы при отказе основных систем привода;

- устройством, предохраняющим выносные опоры от самопроизвольного выдвижения (поворота) при работе подъемника;

- устройством (указателем) угла наклона подъемника;

- системой аварийной остановки привода перемещения при управлении из рабочей платформы и с нижнего пульта, которая должна быть оснащена кнопкой «Стоп»;

- переговорным устройством и/или видеосистемой (для подъемников с высотой подъема рабочей платформы более $22 \mathrm{M}$ );

- анемометром (для подъемников с высотой подъема рабочей платформы более 22 м).

Датчики или выключатели допускается использовать в электрических устройствах безопасности при условии постоянного наблюдения за правильностью их функционирования. Контроль электрических, гидравлических и механических устройств безопасности в [2] предусмотрен на основе проверки конструкции и функциональных испытаний. Функциональные испытания должны подтвердить, что: 1) все движения МПРП могут выполняться плавно при перемещении нагрузки, составляющей $110 \%$ номинальной нагрузки при номинальных скоростях; 2) все устройства безопасности работают исправно; 3) не превышаются максимально разрешенные скорости. Согласно [3], ежедневный контроль технического состояния МПРП состоит из систем визуального и функционального контроля, включающих, но не ограничивающих проверки рабочего и аварийного управления; устройств и приборов безопасности; средств индивидуальной защиты; утечки из пневматической, гидравлической и топливных систем; кабелей и жгутов электропроводки, наличия ослабленных, поврежденных или утерянных компонентов; шин, колес и креплений для колес, рамы, шасси; информационных табличек, указательных и предупреждающих надписей и надписей на органах управления, а также эксплуатационных документов; элементов конструкции, содержащей и выносные опоры; рабочей платформы. Выполнение перечисленных проверок занимает значительное время, требует высокой квалификации обслуживающего персонала. Полные сведения о безопасной эксплуатации МПРП представлены в руководствах по эксплуатации, например [4-6]. Дальнейшее расширение функций встроенных систем безопасности МПРП мачтового типа возможно за счет углубленного контроля и анализа динамических процессов цикла работы МПРП. В конструкциях МПРП мачтового типа обычно используются асинхронные электродвигатели переменного тока, в том числе и с преобразователями частоты. Механические и электромеханические характеристики асинхронного двигателя переменного тока основаны на зависимостях частоты вращения двигателя от полезного момента на валу при постоянных значениях частоты и амплитуды питающего напряжения, а также частоты вращения от тока статора.

\section{Конструкция лабораторного стенда}

Исследования контроля и анализа динамических процессов цикла работы МПРП мачтового 
типа производились на модулях распределенной системы многопараметрического ежедневного контроля (МРСМЕК), установленных на лабораторном стенде «Электрооборудование и автоматика лифта» ЭОиА-Л-СК [7]. Лабораторный стенд состоит из макета лифта с размещенными на нем электроприводами подъема/опускания кабины (асинхронный двигатель с короткозамкнутым ротором АИР63 В4 мощностью 370 Вт), открытия/закрытия дверей кабины лифта (трехфазная синхронная машина переменного тока с постоянными магнитами ECMD91207M мощностью 90 Вт) и стойки управления, позволяющей управлять этими двигателями по заданному закону с помощью частотного и тиристорного преобразователей. В состав стойки управления также входит электромашинный агрегат, объединяющий машину постоянного тока независимого возбуждения ПЛ-72 мощностью 180 Вт, асинхронный двигатель с фазным ротором IMM71B4Y2 мощностью 370 Вт и импульсный датчик скорости E40S6-500-6-L-5. Штатные возможности стенда позволяют определять зависимости частоты вращения машины постоянного тока независимого возбуждения от момента нагрузки и тока якоря при номинальных значениях напряжения якоря, тока возбуждения при отсутствии дополнительного сопротивления в якорной цепи. Исследование машины постоянного тока независимого возбуждения возможно в режиме рекуперативного торможения, когда источником питания служит отдающий энергию в сеть тиристорный преобразователь. С помощью асинхронного электродвигателя с короткозамкнутым ротором могут быть получены зависимости частоты вращения двигателя от полезного момента на валу двигателя при постоянных значениях частоты и амплитуды питающего напряжения, а также частоты вращения от тока статора. В данном случае в качестве нагрузки выступает двигатель постоянного тока, подключенный к тиристорному преобразователю.

Также могут быть получены зависимости частоты вращения от полезного момента на валу при постоянном токе возбуждения и тока статора синхронного электродвигателя в период пуска.
Стенд дает возможность обеспечить скалярное управление в системе преобразователь частоты - асинхронный электродвигатель за счет изменения параметров напряжения и частоты тока статора при заранее установленном законе связи между ними, а также позволяет поддерживать заданную частоту вращения асинхронного электродвигателя частотным преобразователем в замкнутой системе векторного управления за счет управления токами и напряжениями статорных обмоток, согласно заданным значениям скорости и момента. Механические и электромеханические характеристики замкнутой системы векторного управления могут быть получены как в двигательном режиме, так и в генераторном (рекуперативном торможении). Перечисленные зависимости по различным электродвигателям приводят к расширению возможности контроля динамических процессов работы МПРП в цикле, уточнению прогноза развития аварийных ситуаций. Взаимосвязи механических и электромеханических характеристик штатных электроприводов лабораторного стенда с выходными параметрами МРСМЕК исследовались на различных режимах.

\section{Модуль распределенной системы многопараметрического ежедневного контроля}

Каждый МРСМЕК построен на основе платформ Troyka-WiFi Slot и модулях ESP-12 с чипом ESP8266EX [8]. В чипе установлены 32-битный процессоp Xtensa Tensilica L106 с частотой 80 МГц и ультранизким энергопотреблением, радиочастотный трансивер с физическим уровнем WiFi IEEE 802.11 b/g/и блоки памяти SRAM, позволяющие работать со сложными пользовательскими приложениями и цифровой сигнальной обработкой. Платформа WiFi Slot позволяет подключить до четырех Troyka-модулей. Платформа имеет режимы работы клиент, точка доступа, клиент + точка доступа. Платформа включает программный интерфейс I² $/$ TWI, беспроводной интерфейс Wi-Fi $802.11 \mathrm{~b} / \mathrm{g}$ с частотой 
2,4 ГГц, аппаратный интерфейс SPI и два аппаратных интерфейса UART/Serial. Программирование платформы проводилось на языке $\mathrm{C}++$ с использованием интегрированной среды разработки Arduino IDE. На платформе WiFi Slot установлены четыре Troyka-модуля: IMU-сенсор 10-DOF v2 [9], SD картридер [10], часы реального времени RTC [11] и датчик шума (Troykaмодуль) [12]. Питание МРСМЕК производилось от внешнего портативного аккумулятора RC02ABE емкостью $2500 \mathrm{mAh}$ с разъемами USB-microUSB.

Общий вид комплектующих МРСМЕК представлен на рис. 1, а сборка модуля - на рис. 2.

IMU-сенсор 10-DOF v2 содержит четыре микросхемы от STMicroelectronics. Трехосевые ак-

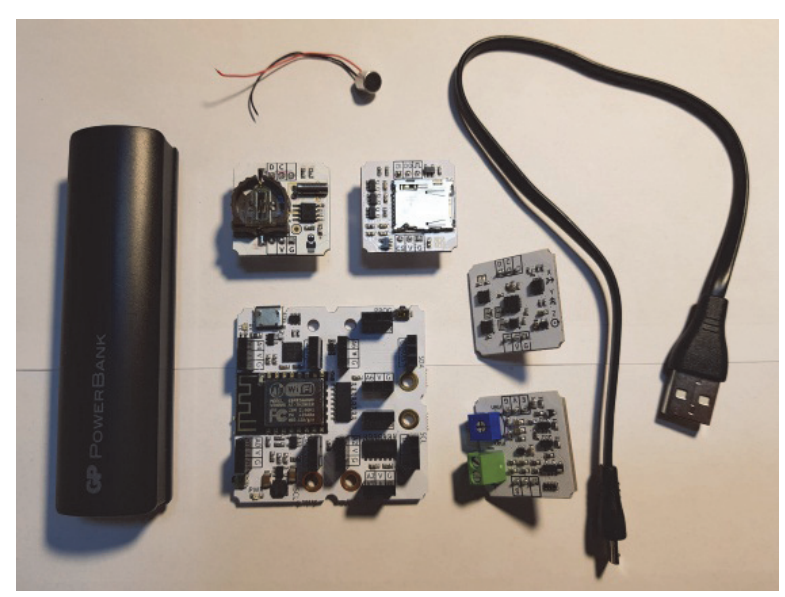

Рис. 1. Общий вид комплектующих МРСМЕК

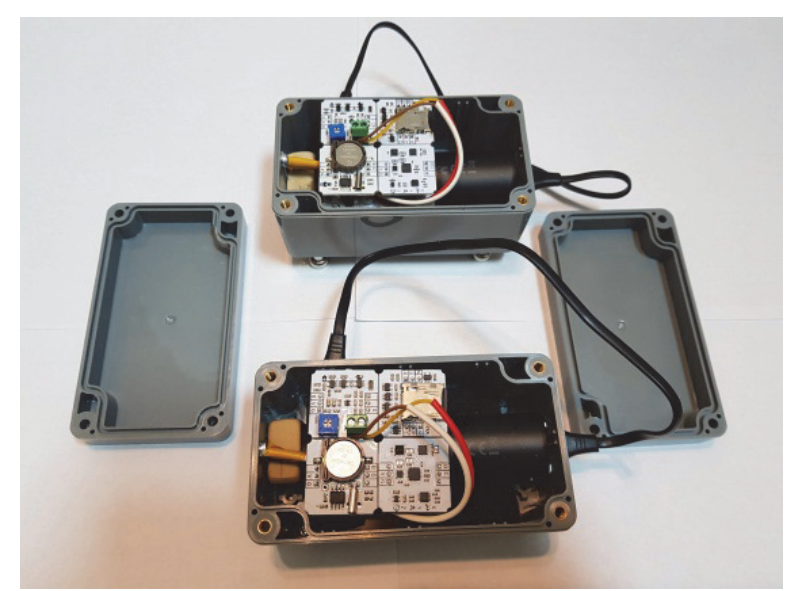

Рис. 2. Сборка МРСМЕК селерометр LIS331DLH, гироскоп I3G4250D и магнитометр LIS3MDL показывают ускорение, скорость вращения и напряженность магнитного поля относительно собственных осей $X, Y$ и $Z$. Барометр LPS25HB измеряет атмосферное давление.

Показания акселерометра, гироскопа и магнитометра использовались в качестве входных данных для фильтров Маджвика, Махони или Калмана для получения на выходе кватерниона, позволяющего представить положение в пространстве IMU-сенсора 10-DOF v2 через углы Эйлера. В фильтре Маджвика реализовано определение ориентации IMU-сенсора 10-DOF v2 в пространстве с использованием данных акселерометра и гироскопа или акселерометра, гироскопа и магнитометра. В первом случае угол рыскания будет указывать на изначальное направление датчика, а во втором - на север. В табл. 1 представлены основные технические характеристики всех четырех чипов IMU-сенсора 10-DOF v2.

SD картридер [10] позволяет получить до 32 Гб энергонезависимой памяти. Он поддерживает карты форматов microSD под файловую систему FAT16 и microSDHC под файловую систему FAT32. C контроллером SD картридер общается по протоколу SPI стандартной библиотеки «SD», входящей в состав Arduino IDE. В библиотеке приведены примеры выполнения основных операций - получения данных о карте, работа с файловой структурой, чтения и записи файлов.

Часы реального времени RTC (Real Time Clock) [11] представлены модулем на базе чипа DS1307 c автономным питанием от батарейки CR1225 на 3 В. При потребляемом чипом DS1307 токе 500 нА батарейка может работать примерно 6 месяцев. Часы реального времени позволяют записывать в энергонезависимую память значения текущей секунды, минуты, часа, дня недели, месяца и года протоколирования данных.

К каждой записи показаний на SD-карту или на удаленный сервер можно добавлять таймкод. Чип DS1307 общается с управляющей электроникой по протоколу I ${ }^{2} \mathrm{C} / \mathrm{TWI}$.

Датчик шума «Troyka-модуль» [12] состоит из электретного микрофона и управляющей 
ТАБЛИЦА 1. Технические характеристики чипов IMU-сенсора 10-DOF v2

\begin{tabular}{|l|c|c|c|c|}
\hline \multicolumn{1}{|c|}{ Модуль } & Чип & $\begin{array}{c}\text { Частота обновления } \\
\text { сигнала, Гц }\end{array}$ & $\begin{array}{c}\text { Максимальная } \\
\text { чувствительность }\end{array}$ & Диапазон измерений \\
\hline Акселерометр & LIS331DLH & $0,5-1000$ & $9,8 \cdot 10^{-3} \mathrm{M} / \mathrm{c}^{2}$ & $\pm 2 / \pm 4 / \pm 8 \mathrm{~g}$ \\
\hline Гироскоп & I3G4250D & $100-800$ & $8,7 \cdot 10^{-3} \% \mathrm{c}$ & $\pm 250 / \pm 500 / \pm 2000 \% \mathrm{c}^{2}$ \\
\hline Магнитометр & LIS3MDL & $0,625-80$ & $1,46 \cdot 10^{-4} \Gamma \mathrm{c}$ & $\pm 4 / \pm 8 / \pm 12 / \pm 16 \Gamma \mathrm{c}$ \\
\hline Барометр & LPS25HB & $1-25$ & $2,4 \cdot 10^{-4}$ мбар & $260-1260$ мбар \\
\hline
\end{tabular}

электроники. Последняя усиливает сигнал микрофона, устраняет отрицательную полуволну сигнала и сглаживает его. Сигнал, поступающий с микрофона, является звуковой волной колебаний относительно нуля. Измерение максимальных значений амплитуды этой волны не дает четкой информации об уровне громкости, что заставляет проводить измерения максимально часто и подвергать их математической обработке. Электронная обвязка датчика шума вычисляет площадь под графиком звуковой волны, что позволяет определить изменение общего звукового фона в виде аналогового сигнала в диапазоне от 0 до напряжения питания. Выходное напряжение пропорционально средней шумности за последние несколько сотен миллисекунд. Для регулировки чувствительности на датчике шума установлен регулятор. Данные микрофона доступны и напрямую. В ходе проведения экспериментов с управляющей электроникой применялись три типа электретных микрофонов: НМО0603А, НМО0603В и ЕСМ-10С. Их основные технические характеристики представлены в табл. 2.

\section{Экспериментальные исследования}

В экспериментах использовались пять МРСМЕК, установленных на кабине лифта, противовесе, металлоконструкции корпуса, асинхронном двигателе привода кабины лифта, трехфазной синхронной машине переменного тока с постоянными магнитами привода открытия дверей кабины. Еще две МРСМЕК размещены на машине постоянного тока независимого возбуждения и асинхронном двигателе с фазным ротором, входящих в состав отладочного электромашинного агрегата. Общий вид лабораторного стенда с МРСМЕК представлен на рис. 3.

В ходе проводимых экспериментов программно изменялись скорость движения кабины, времена разгона и торможения кабины при движении вверх и вниз. На всех семи МРСМЕК измерения проводились с использованием:

- часов реального времени при записи на SDкартридер линейных ускорений;

- угловых скоростей, напряженности магнитного поля, звукового фона;

ТАБЛИЦА 2. Технические характеристики электретных микрофонов

\begin{tabular}{|l|c|c|c|c|c|c|}
\hline Микрофон & $\begin{array}{c}\text { Диаметр, } \\
\text { мм }\end{array}$ & $\begin{array}{c}\text { Напряжение, } \\
\text { В }\end{array}$ & $\begin{array}{c}\text { Ток, } \\
\text { мА }\end{array}$ & $\begin{array}{c}\text { Чувствительность, } \\
\text { дБ }\end{array}$ & $\begin{array}{c}\text { Частота, } \\
\text { Гц }\end{array}$ & $\begin{array}{c}\text { Отношение } \\
\text { сигнал/шум, } \\
\text { дБ }\end{array}$ \\
\hline HМО0603А & 6,0 & 3,0 & 0,5 & $-60 \pm 3$ & $30-16000$ & 58 \\
\hline НМО0603В & 6,0 & 3,0 & 0,5 & $-65 \pm 4$ & $30-16000$ & 58 \\
\hline ЕСМ-10С & 6,0 & 4,5 & 0,5 & $-64 \pm 3$ & $50-13000$ & 40 \\
\hline
\end{tabular}


ТАБЛИЦА 3. Минимальные среднеквадратичные ошибки определения параметров асинхронного электродвигателя с короткозамкнутым ротором на обучающих и тестовых выборках

\begin{tabular}{|l|c|c|}
\hline \multicolumn{1}{|c|}{ Параметр контроля } & Обучающая выборка & Тестовая выборка \\
\hline Частота вращения & 0,2945 & 3,4576 \\
\hline Момент на валу & 0,2736 & 3,1239 \\
\hline Ток статора & 0,2877 & 2,9323 \\
\hline
\end{tabular}
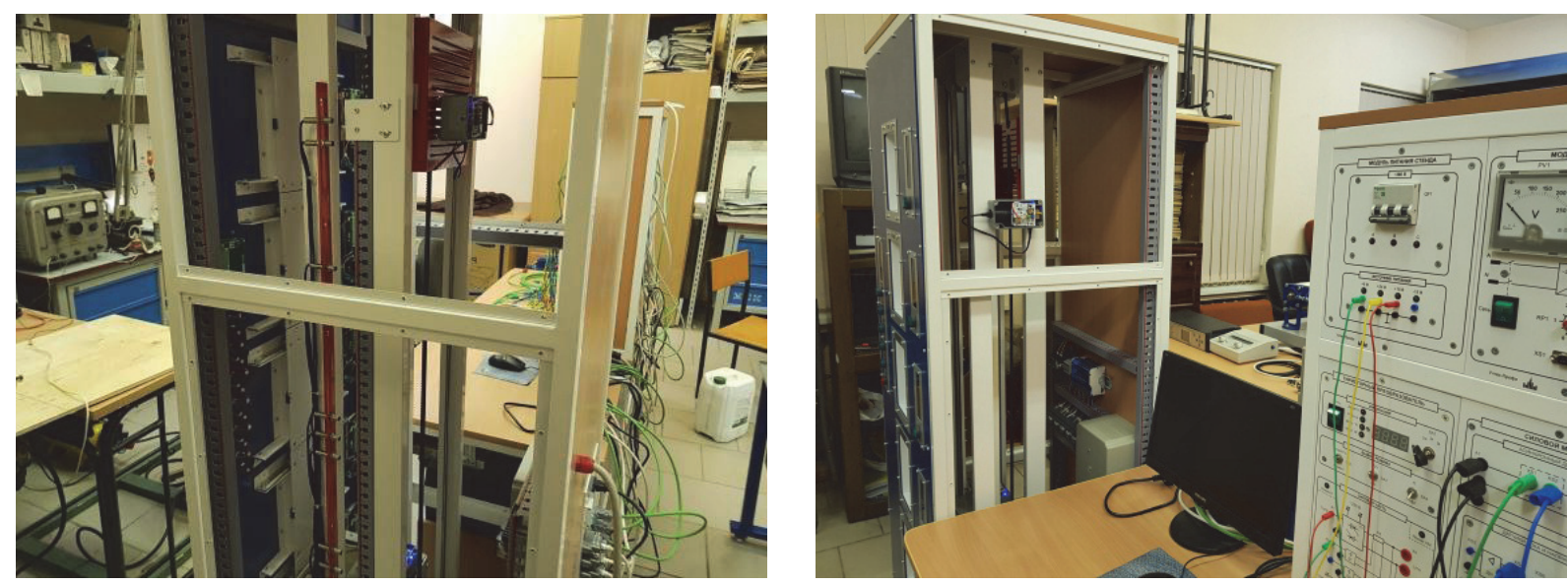

Рис. 3. Общий вид лабораторного стенда с установленными МРСМЕК

- времени одновременно с частотой вращения, полезным моментом на валу;

- тока статора асинхронного электродвигателя с короткозамкнутым ротором.

Также осуществлялась запись частоты вращения, момента нагрузки, тока якоря. Запись производилась при подключении тиристорного преобразователя в качестве нагрузки двигателя постоянного тока независимого возбуждения.

Выявление взаимосвязей механических и электромеханических характеристик штатных электроприводов лабораторного стенда с выходными параметрами МРСМЕК на различных режимах производилось в адаптивной нейронечеткой системе ANFIS пакета MATLAB [13], объединяющей достоинства нейронных сетей и систем нечеткого вывода и позволяющей после обучения минимизировать отклонения между результатами нечеткого моделирования и экспериментальными данными.

\section{Заключение}

Значения минимальных среднеквадратичных ошибок определения параметров асинхронного электродвигателя с короткозамкнутым ротором на обучающих и тестовых выборках, с помощью различных методов обучения и функций принадлежности сгенерированных структур адаптивной нейро-нечеткой системы ANFIS представлены в табл. 3.

В ходе проведенных на лабораторном стенде экспериментов получены значения минимальных среднеквадратичных ошибок определения частоты вращения, момента на валу и тока статора асинхронного электродвигателя с короткозамкнутым ротором по данным трехосевых акселерометра LIS331DLH, гироскопа I3G4250D, магнитометра LIS3MDL, а также электретных микрофонов НМО0603А, НМО0603В и ЕСМ-10С. Эти данные были получены на обучающих и те- 
стовых выборках, с помощью различных методов обучения и функций принадлежности сгенерированных структур адаптивной нейро-нечеткой системы ANFIS. Показана возможность расширения функций встроенных систем безопасности мобильных подъемников с рабочими платформами мачтового типа на основе контроля динамических процессов работы в цикле распределенной системой многопараметрического ежедневного контроля, обученной с помощью адаптивной нейро-нечеткой системы ANFIS пакета MATLAB. Распределенная система многопараметрического ежедневного контроля технического состояния мобильных подъемников с рабочими платформами мачтового типа может быть рекомендована к практическому применению.

\section{Библиографический список}

1. ГОСТ 33649-2015. Подъемники с рабочими платформами. Классификация. - URL : http://docs. cntd.ru/document/1200135779 (дата обращения : 10.01. 2021 г.).

2. ГОСТ 34443-2018. Мобильные подъемники с рабочими платформами. Расчеты конструкции, требования безопасности, методы испытаний. - URL : http://docs.cntd.ru/document/1200160957 (дата обращения : 10.01.2021 г.).

3. ГОСТ Р 53984-2010. Мобильные подъемники с рабочими платформами. Требования безопасности и контроль технического состояния при эксплуатации.URL : http://docs.cntd.ru/document/gost-r-53984-2010 (дата обращения : 07.01.2021 г.).

4. Мачтовая подъемная рабочая платформа, модель IZA-30-100 : руководство по эксплуатации и обслуживанию.- Изм. 6 января 2012 г.- URL : https:// arendalulek.ru/sites/default/files/iza-30-100.pdf (дата обращения : 08.01.2021 г.)

5. Мачтовый подъемник с электроподъемом GTWY100 : инструкция.- URL : https://spb.gortorgsnab.ru/ upload/iblock/65e/3bb231cd_ce29_11e8_8120_0cc47a d8da8b_1dc0f13a_0a8f_11ea_8141_0cc47ad8da8b.pdf (дата обращения : 08.01.2021 г.).

6. Подъемники мачтовые телескопические, модель GTWY. - URL : https:/gruz7.ru/wp-content/uploads/ 2019/07/podemniki-machtovye-telesko-picheskie-gtwy. pdf (дата обращения : 08.01.2021 г.).

7. Бычков А.Е. и др. Техническое описание лабораторного стенда «Электрооборудование и автоматика лифта» / А. Е. Бычков и др. - Челябинск : ЛабСис, 2020. $-28 \mathrm{c}$.

8. Troyka-WiFi Slot, Wi-Fi платформа на основе модуля ESP12 с чипом ESP8266EX. - URL : https://www. chipdip.ru/product/troyka-wifi-slot (дата обращения : 10.01.2021 г.)

9. IMU-сенсор 10-DOF v2 : инструкция, схемы и примеры использования. - URL : http://wiki.amperka. ru/products: troyka-imu-10-dof-v2 (дата обращения : 10.01.2021 г.).

10. SD картридер (Troyka-модуль). - URL : https:// amperka.ru/product/troyka-sd (дата обращения : 10.01.2021 г.).

11. Часы реального времени (Troyka-модуль).URL : https://amperka.ru/product/troyka-rtc (дата обращения : 10.01.2021 г.).

12. Датчик шума (Troyka-модуль).- URL : http:// amperka.ru/product/troyka-sound-loudness-sensor (дата обращения : 10.01.2021 г.).

13. Штовба С.Д. Проектирование нечетких систем средствами MATLAB / С. Д. Штовба. - М. : Горячая линия-Телеком, 2007.-288 с.

Дата поступления: 25.02.2021

Решение о публикации:15.03.2021

\section{Контактная информация:}

КОРОВИНА Мария Сергеевна - ассистент; pgups2013@yandex.ru КОРОВИН Сергей Константинович - канд. техн. наук, доц.; big-bernar@yandex.ru 


\section{The distributed system of multipoint daily monitoring of the technical condition of the working equipment of mobile lifts with mast-type work platforms}

\section{S. Korovina, S. K. Korovin}

Emperor Alexander I Petersburg State Transport University, 9, Moskovsky pr., Saint Petersburg, 190031, Russian Federation

For citation: Korovina M. S., Korovin S. K. The distributed system of multipoint daily monitoring of the technical condition of the working equipment of mobile lifts with mast-type work platforms. Proceedings of Petersburg Transport University. Saint Petersburg, Petersburg State Transport University, 2021, vol. 18, iss. 2, pp. 294-302. (In Russian) DOI: 10.20295/1815-588X-2021-2-294-302

\section{Summary}

Objective: To consider the requirements for safety devices of mobile lifts with working platforms and analyze the specifics of daily monitoring of their technical condition. To consider the need to expand the functionality of the built-in safety systems of these lifts. To demonstrate the need for in-depth control and analysis of the work cycle dynamic processes of mobile lifts with mast-type work platforms and provide technical solutions for their implementation. Methods: The relationship of mechanical and electromechanical characteristics of electric drives of mobile lifts with mast-type work platforms with the output parameters of a distributed system of multipoint daily monitoring in various modes has been revealed using the Adaptive Neuro-Fuzzy Inference System (ANFIS) of the MATLAB package. Results: On the laboratory bench, the values of the minimum root-mean-square errors in determining the speed, torque on the shaft, and the stator current of an asynchronous electric motor with a squirrel-cage rotor were obtained according to the data of the three-axis accelerometer LIS331DLH, gyroscope I3G4250D, and magnetometer LIS3MDL, as well as an electret microphone on training and test samples, various training methods and membership functions of the generated structures of ANFIS, the Adaptive Neuro-Fuzzy Inference System. Practical importance: The possibility of expanding the functionality of built-in safety systems of mobile lifts with masttype work platforms is shown based on the control of the work cycle dynamic processes by a distributed system of multipoint daily monitoring trained using the ANFIS of the MATLAB package, which can be recommended for practical use.

Keywords: Distributed system of multipoint daily monitoring, technical condition of the working equipment, analysis of the work cycle dynamic processes, laboratory bench, fuzzy modeling, Adaptive Neuro-Fuzzy Inference System.

\section{References}

1. GOST 33649-2015. Pod"yemniki s rabochimi platformami. Klassifikatsiya [Elevating work platforms. Classification]. Available at: http://docs. cntd.ru/document/1200135779 (accessed: January 10, 2021). (In Russian)

2. GOST 34443-2018. Mobil'nyye pod"yomniki s rabochimi platformami. Raschety konstruktsii, trebovaniya bezopasnosti, metody ispytaniy [Mobile lifts with working platforms. Construction calculations, safety requirements, test methods]. Available at: http:// docs.cntd.ru/document/1200160957 (accessed: January 10, 2021). (In Russian)

3. GOST R 53984-2010. Mobil'nyye pod"yomniki s rabochimi platformami. Trebovaniya bezopasnosti $i$ kontrol'tekhnicheskogo sostoyaniya pri ekspluatatsii [Mobile elevating work platforms. Safety principles and inspection of technical operational state]. Available at: http://docs.cntd.ru/document/gost-r-539842010 (accessed: January 07, 2021). (In Russian)

4. Machtovaya pod"yemnaya rabochaya platforma, model'IZA-30-100. Rukovodstvo po ekspluatatsii i obsluzhivaniyu [Mast-type lift work platform, 
model IZA-30-100. Operation and Maintenance Manual]. Rev. on January 06, 2012. Available at: https:// arendalulek.ru/sites/default/files/iza-30-100.pdf (accessed: January 08, 2021). (In Russian)

5. Machtovyy pod"yemnik s elektropod"yemom GTWY-100. Instruktsiya [Mast lift with electric lifting mechanism GTWY-100. Manual]. Available at: https:// spb.gortorgsnab.ru/upload/iblock/65e/3bb231cd_ce2 9_11e8_8120_0cc47ad8da8b_1dc0f13a_0a8f_11ea_8 141_0cc47ad8da8b.pdf (accessed: January 08, 2021). (In Russian)

6. Pod"yemniki machtovyye teleskopicheskiye, model' GTWY [Telescopic mast lifts, model GTWY]. Available at: https://gruz7.ru/wp-content/uploads/ 2019/07/podemniki-machtovye-teleskopicheskiegtwy.pdf (accessed: January 08, 2021). (In Russian)

7. Bychkov A.E. et al. Tekhnicheskoye opisaniye laboratornogo stenda "Elektrooborudovaniye i avtomatika lifta" [Technical description of the laboratory stand "Electrical equipment and automation of the elevator"]. Chelyabinsk, LabSys Publ., 2020, 28 p. (In Russian)

8. Troyka-WiFi Slot, Wi-Fi platforma na osnove modulya ESP12 s chipom ESP8266EX [Troyka-WiFi Slot, Wi-Fi platform based on ESP12 module with ESP8266EX chip]. Available at: https://www.chipdip.ru/product/troyka-wifi-slot (accessed: January 10, 2021). (In Russian)
9. IMU-sensor 10-DOF v2. Instruktsiya, skhemy $i$ primery ispol'zovaniya [IMU-sensor 10-DOF v2. Manual, diagrams, and examples of use]. Available at: http://wiki.amperka.ru/products: troyka-imu-10dof-v2 (accessed: January 10, 2021). (In Russian)

10. SD card reader (Troyka module). Available at: https://amperka.ru/product/troyka-sd (accessed: January 10, 2021). (In Russian)

11. Chasy real'nogo vremeni (Troyka-modul') [Realtime clock (Troyka module)]. Available at: https://amperka.ru/product/troyka-rtc (accessed: January 10, 2021). (In Russian)

12. Datchik shuma (Troyka-modul') [Noise sensor (Troyka module)]. Available at: http://amperka. ru/product/troyka-sound-loudness-sensor (accessed: January 10, 2021). (In Russian)

13. Shtovba S. D. Proyektirovaniye nechetkikh sistem sredstvami MATLAB [Designing fuzzy systems using MATLAB]. Moscow, Goryachaya liniyaTelekom Publ., 2007, 288 p. (In Russian)

Received: February 25, 2021

Accepted: March 15, 2021

\section{Author's information:}

Maria S. KOROVINA - Assistant; pgups2013@yandex.ru

Sergey K. KOROVIN - PhD in Engineering, Associate Professor; big-bernar@yandex.ru 
УДК 69.059.327

\title{
О расчете размывающих скоростей при проектировании фильтрующих сооружений в связных грунтах
}

\section{В. И. Штыков ${ }^{1}$, А. Б. Пономарев ${ }^{1}$, Ю. Г. Янко ${ }^{2}$}

${ }^{1}$ Петербургский государственный университет путей сообщения Императора Александра I, Российская Федерация, 190031, Санкт-Петербург, Московский пр., 9

2 Агрофизический научно-исследовательский институт, Российская Федерация, 195220, Санкт-Петербург, Гражданский пр., 14

Для цитирования: Штыков В. И., Пономарев А. Б., Янко Ю.Г. О расчете размывающих скоростей при проектировании фильтрующих сооружений в связных грунтах // Известия Петербургского университета путей сообщения.- СПб.: ПГУПС, 2021.- Т. 18.- Вып. 2.- С. 303-312.

DOI: $10.20295 / 1815-588 X-2021-2-303-312$

\begin{abstract}
Аннотация
Цель: Разработка методики расчета размывающих скоростей на контакте фильтрующих сооружений со связными грунтами. Методы: Ранее во ВНИИГ им. Б. Е. Веденеева были установлены гидродинамический и прочностной критерии контактной суффозии применительно к гидротехническим сооружениям. Однако отсутствовали расчетные зависимости для определения критического числа Рейнольдса и соответственно критической скорости для крупнозернистых материалов. Путем специальной обработки экспериментальных данных по фильтрации в различных по крупности заполнителях бесполостных дрен удалось многочисленные кривые свести в одну, благодаря чему стало возможным выделить границы переходного режима и получить формулу для критического числа Рейнольдса. Это позволило вычислить критическую скорость. В итоге была получена формула для расчета размывающей скорости. Результаты: Расчетные зависимости позволили по исходным данным крупнозернистого материала, из которого выполнены фильтрующие сооружения, и характеристикам грунтов, в которых они построены, определить критическую скорость для материала заполнителя и размывающую скорость на границе контакта фильтрующего сооружения с грунтом. Практическая значимость: Представленная методика расчета дала возможность установить: 1) возможны ли проявления размывов фильтрационным потоком на контакте фильтрующего сооружения с грунтом; 2) разработать мероприятия по исключению размывов. По границе контакта фильтрующего сооружения с грунтом можно проложить геотекстильный материал или в качестве заполнителя фильтрующего сооружения использовать более мелкий материал, действительные скорости движения фильтрационного потока в котором будут меньше размывающих. При этом величины размывающей скорости на контакте с более мелким материалом увеличиваются.
\end{abstract}

Ключевые слова: Размывающие скорости, фильтрация, связные грунты, фильтрующие насыпи, фильтрующие прорези, бесполостные дрены.

\section{Введение}

Связные грунты-самые распространенные на территории России. Эти грунты являются проблемными при их осушении, а также при строительстве на них различных сооружений. При осу- шении связных грунтов перспективно применение бесполостного дренажа $[1,2]$, в частности в районах с глубоким промерзанием, так как такой дренаж не боится воздействия отрицательных температур [3]. Фильтрующие сооружения (фильтрующие насыпи, фильтрующие прорези) 
используются при строительстве железной дороги в районах с вечной мерзлотой [4]. Во всех фильтрующих сооружениях крупнозернистый заполнитель контактирует с окружающим грунтом. В этом случае возникает вопрос: всегда ли в связных грунтах необходимо защищать заполнитель с боков геотекстильным материалом?

Поток, движущийся в заполнителе бесполостных дрен, фильтрующих насыпей и дренирующих прорезей, при определенных гидродинамических условиях может вызывать фильтрационные разрушения на контакте с примыкающими к ним грунтами, имеющие характер размыва. Они возникают при определенных скоростях фильтрации в заполнителе этих сооружений. Изучение физической сущности этой разновидности суффозии с предварительным разделением задачи на гидравлическую и прочностную применительно к конструкциям гидротехнических сооружений проводилось В.Н. Жиленковым и Н. И. Шевченко [5].

Полученные данные подтвердили, что контактный размыв, в том числе и глинистых грунтов, не происходит при ламинарном режиме течения фильтрационного потока, потому отклонение от линейного закона фильтрации было принято за гидродинамический критерий контактной суффозии.

Вода в крупнозернистом заполнителе движется по искривленным фильтрационным ходам, огибающим частицы заполнителя. Б. С. Петухов [6], исследуя движение воды в криволинейных трубах, отмечает, что при этом возрастает роль инерционных сил и последние выполняют роль турбулизаторов, изменяющих распределение скоростей по поперечному сечению труб и соответственно сопротивление движению воды в них.

Это же имеет место и в фильтрационных ходах. Обобщение работ, посвященных определению критического числа Рейнольдса $\left(\mathrm{Re}_{\text {кр }}\right)$ было проведено В.Д. Дмитриевым [7]. Полученные им результаты показали, что $\mathrm{Re}_{\text {кр }}$ зависит от пористости материала загрузки, его крупности, степени неоднородности и формы частиц, но формулы для определения $\mathrm{Re}_{\text {кр }}$ получено не было.
Одна из причин заключалась в том, что в случае фильтрации диапазон чисел Рейнольдса, соответствующий переходному режиму, как показали наши исследования $[8,9]$, очень велик и отклонение от ламинарного режима в начале идет очень медленно. Путем специальной обработки многочисленные экспериментальные данные для разных по крупности материалов удалось обобщить одной кривой и стало возможным более четко установить границы переходного режима и одновременно получить для определения критического числа Рейнольдса [9] расчетную формулу

$$
\operatorname{Re}_{\text {кр }}=8,6 \cdot n \sqrt{\frac{d_{17}}{d_{u}}},
$$

в которой $n-$ пористость; $d_{17}-$ диаметр частиц заполнителя, меньше которого в его составе содержится $17 \%$ частиц по массе, см; $d_{u}$ - расчетное значение диаметра фильтрационного хода, $\mathrm{cm}$,

$$
d_{u}=0,57 \sqrt[6]{\eta} \frac{n}{1-n} \cdot \frac{d_{17}}{\psi}
$$

где $\eta=\frac{d_{60}}{d_{10}}-$ коэффициент неоднородности заполнителя; $\psi$ - коэффициент, учитывающий форму частиц, который при турбулентной фильтрации может быть определен по табл. $1[8] ; d_{10}$ и $d_{60}$ - диаметры частиц заполнителя, меньше которых в его составе содержится соответственно 10 и $60 \%$ частиц по массе, см.

ТАБЛИЦА 1. Значения коэффициента $\psi$

\begin{tabular}{|l|c|}
\hline \multicolumn{1}{|c|}{ Материал } & $\psi$ \\
\hline Керамзит & 1,16 \\
\hline Галька & 1,23 \\
\hline Гранитный щебень & 1,67 \\
\hline Известняковый щебень & 1,73 \\
\hline
\end{tabular}

В.Н. Жиленковым и Н.И. Шевченко в качестве характеристики размываемости глинистого грунта введен индекс размываемости $\chi$, 
равный отношению критической скорости линейной фильтрации в данном заполнителе $V_{\text {кр }}$ к фактической размывающей скорости $V_{\text {рз }}[10]$ :

$$
\chi=\frac{V_{\mathrm{кр}}}{V_{\mathrm{p} 3}} .
$$

Таким образом, контактный размыв определяется индексом размываемости и критической скоростью фильтрации в зоне контакта. Выразим из формулы критическую скорость:

$$
V_{\text {кр }}=8,6 \cdot n \cdot v \sqrt{\frac{d_{17}}{d_{u}^{3}}},
$$

где $v$ - коэффициент кинематической вязкости воды, $\mathrm{cm}^{2} / \mathrm{c}$.

\section{Методика исследования}

Подставив полученное выше значение $V_{\text {кр }}$ в зависимость (2), выводим формулу для расчета размывающих скоростей в заполнителях в виде

$$
V_{\mathrm{p} 3}=\frac{8,6 \cdot n \cdot \mathrm{v}}{\chi} \sqrt{\frac{d_{17}}{d_{u}^{3}}} .
$$

Из нее следует, что с уменьшением индекса размываемости (с увеличением поверхностной связности окружающего заполнитель фильтрующего сооружения грунта) и диаметра фильтрационных ходов величина размывающей скорости при прочих равных условиях увеличивается.

Индекс размываемости $\chi$ характеризует суффозионную устойчивость грунта, которая зависит от сил сцепления его частиц. Результаты исследований различных глинистых грунтов показали, что между сцеплением глинистых частиц и коэффициентом пористости существует связь, на основании которой получено выражение индекса размываемости глинистого грунта [10]:

$$
\chi=2 \cdot 10^{-4} \cdot \exp \left(6,67 \cdot \frac{W_{\mathrm{H}}}{W_{\mathrm{T}}}\right),
$$

в котором $W_{\text {н }}$ влажность грунта по массе при его полном насыщении, доли единицы; $W_{\text {т }}$ влажность грунта по массе на границе текучести, доли единицы.

Зависимость была подтверждена данными 53 испытаний разных глинистых грунтов на контактный размыв фильтрационным потоком [10].

Подставив значение индекса размываемости, определенное по (4), в зависимость (3), будем иметь расчетную формулу для определения размывающих скоростей на контакте заполнителей фильтрующих сооружений с примыкающим к ним грунтом в следующем виде:

$$
\begin{gathered}
V_{\mathrm{p} 3}=4,3 \cdot 10^{4} \times \\
\times \exp \left(-6,67 \cdot \frac{W_{\mathrm{H}}}{W_{\mathrm{T}}}\right) n \cdot v \sqrt{\frac{d_{17}}{d_{u}^{3}}} .
\end{gathered}
$$

Таким образом, контактный размыв грунта, окружающего заполнитель фильтрующего сооружения фильтрационным потоком, не произойдет при условии, что $V<V_{\text {pз }}$ для данного грунта, где $V$ - скорость фильтрации в заполнителе в рассматриваемом сечении фильтрующего сооружения на контакте с окружающим его грунтом. Полученные зависимости могут быть использованы для определения размывающих скоростей на контакте крупнозернистых, хорошо фильтрующих материалов с примыкающим к ним грунтом для любых фильтрующих сооружений.

Для проверки зависимости на опытных участках, расположенных в Выборгском и Ломоносовском районах Ленинградской области, были проведены раскопки бесполостных дрен и отобраны образцы заполнителей и грунта ненарушенной структуры в зоне контакта с дренажем. Показатели гранулометрического состава заполнителей бесполостных дрен, их пористость $n$ и коэффициент формы частиц $\psi$ приведены в табл. 2. Влажность грунта по массе при его полном насыщении $W_{\text {н }}$ определялась опытным путем на образцах с нарушенной структурой по методике, изложенной в методических указаниях [11], влажность грунта по массе на границе 
текучести $W_{\text {т }}$ - стандартным ручным методом. При расчете размывающих скоростей по формуле коэффициент кинематической вязкости $v=$ $=0,0131 \mathrm{~cm}^{2} /$ c. Из табл. 2 следует, что грунты на уровне заложения бесполостных дрен на опытных участках представлены супесями, суглинками и глинами. Индекс размываемости грунтов $\chi$ на опытных участках, вычисленный по зависимости, свидетельствует о том, что наименьшую поверхностную связность имеют грунты на участке «Ударник», наибольшую - на участке «Новоселье- $1 »$.

Данные, приведенные в табл. 2, свидетельствуют о том, что наиболее неблагоприятные гидродинамические условия при движении потока в бесполостном дренаже наблюдаются на участке «Ударник», где контактный размыв возможен уже при незначительных скоростях фильтрации. При увеличении связности окружающего дрену грунта (уменьшение $\chi$ ) размывающие скорости увеличиваются. Анализ данных, полученных на участке «Дальнее поле», подтверждает, что величины размывающих скоростей в дренах со щебенчатым заполнителем меньше, хотя и тот, и другой дренаж заложены в однотипных грунтовых условиях.
На значения размывающих скоростей большое влияние оказывает крупность частиц заполнителя. Так, если бы на указанных участках в качестве заполнителя дрен была использована мраморная крошка, то размывающие скорости по отношению к существующим увеличились бы в 3-14 раз.

Таким образом, подбирая гранулометрический состав заполнителя бесполостных дрен так, чтобы соблюдалось условие $V<V_{\text {р3 }}$, можно исключить отрицательное воздействие контактного размыва на работоспособность дренажа путем обоснованного определения размывающих скоростей, учитывающих суффозионную устойчивость грунтов.

\section{Практическая значимость}

Рассмотрим два примера применительно к железнодорожному полотну.

Пример 1. С целью эффективного осушения земляного полотна вдоль рельсовых нитей проложена бесполостная дрена треугольного поперечного сечения [12]. Заполнителем дрены служит гранитный щебень, характеризующий-

ТАБЛИЦА 2. Расчетные значения размывающих скоростей грунтов на объектах Ленинградской области

\begin{tabular}{|c|c|c|c|c|c|c|c|c|c|}
\hline \multirow{2}{*}{$\begin{array}{c}\text { Наиме- } \\
\text { нование } \\
\text { опытного } \\
\text { участка }\end{array}$} & \multirow[t]{2}{*}{$\begin{array}{c}\text { Заполни- } \\
\text { тель } \\
\text { дрен }\end{array}$} & \multicolumn{3}{|c|}{$\begin{array}{c}\text { Показатели } \\
\text { гранулометрического } \\
\text { состава заполнителей } \\
\text { бесполостных дрен }\end{array}$} & \multirow[t]{2}{*}{$\begin{array}{c}\text { Вид } \\
\text { грунтов }\end{array}$} & \multirow[t]{2}{*}{$W_{\text {н }}$} & \multirow[t]{2}{*}{$W_{\mathrm{T}}$} & \multirow[t]{2}{*}{$\chi$} & \multirow[t]{2}{*}{ 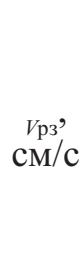 } \\
\hline & & $\begin{array}{l}d_{17} \\
\mathrm{cM}\end{array}$ & $\eta$ & $n$ & & & & & \\
\hline Ударник & Гравий & 3,3 & 1,77 & 0,44 & Супесь & 0,216 & 0,259 & 0,052 & 2,3 \\
\hline Новоселье-1 & $\begin{array}{l}\text { Известняко- } \\
\text { вый щебень }\end{array}$ & 2,8 & 1,77 & 0,50 & \begin{tabular}{|l|} 
Глина \\
средняя
\end{tabular} & 0,171 & 0,280 & 0,012 & 9,5 \\
\hline \multirow[t]{4}{*}{$\begin{array}{l}\text { Дальнее } \\
\text { поле }\end{array}$} & Керамзит & 1,26 & 1,36 & 0,44 & $\begin{array}{l}\text { Суглинок } \\
\text { тяжелый }\end{array}$ & 0,160 & 0,224 & 0,023 & 8,9 \\
\hline & $\begin{array}{l}\text { Гранитный } \\
\text { щебень }\end{array}$ & 2,2 & 3,5 & 0,48 & $\begin{array}{l}\text { Суглинок } \\
\text { тяжелый }\end{array}$ & 0,160 & 0,224 & 0,023 & 5,8 \\
\hline & $\begin{array}{l}\text { Мраморная } \\
\text { крошка }\end{array}$ & 0,33 & 2,38 & 0,46 & Супесь & 0,216 & 0,259 & 0,052 & 20,5 \\
\hline & $\begin{array}{l}\text { Мраморная } \\
\text { крошка }\end{array}$ & 0,33 & 2,38 & 0,46 & \begin{tabular}{|l|} 
Глина \\
средняя
\end{tabular} & 0,171 & 0,280 & 0,012 & 88,8 \\
\hline
\end{tabular}


ся следующими данными: $d_{17}=1,2$ см; $\eta=1,9$; $n=0,48 ; \psi=1,68 ; v=0,0131 \mathrm{~cm}^{2} / \mathrm{c} ;$ коэффициент откоса $m=1,0$; удельная приточность к дрене $q=0,00005 \mathrm{~m}^{2} / \mathrm{c}$.

Земляное полотно представлено супесью, у которой $W_{\text {н }}=0,216$ и $W_{\text {т }}=0,259$.

Определим для левой части бесполостной дрены длину участка, примыкающего к коллектору, на котором скорость фильтрации в бесполостной дрене будет превышать величину размывающей скорости $V_{\text {рз }}$, потому потребуется защита откосов геотекстильным материалом.

\section{Ход расчета.}

1. Вычисляем расчетный диаметр фильтрационного хода в заполнителе бесполостной дрены:

$$
\begin{aligned}
& d_{u}=0,57 \sqrt[6]{\eta} \frac{n}{1-n} \cdot \frac{d_{17}}{\psi}= \\
& =0,57 \sqrt[6]{1,6} \frac{0,48}{1-0,48} \cdot \frac{1,2}{1,68}=0,42 \mathrm{~cm} .
\end{aligned}
$$

2. Определяем скорость фильтрации $v_{\text {кр }}$, которая соответствует ламинарному режиму движения воды в данном заполнителе:

$$
\begin{gathered}
V_{\text {кр }}=8,6 \cdot n \cdot v \sqrt{\frac{d_{17}}{d_{u}^{3}}}= \\
=8,6 \cdot 0,48 \cdot 0,0131 \sqrt{\frac{1,2}{0,42^{3}}}=0,22 \mathrm{~cm} / \mathrm{c} .
\end{gathered}
$$

3. Находим величину размывающей скорости. Учитывая, что для данной супеси имеем уже вычисленное значение $\chi$, воспользуемся данными табл. 2. В этом случае $V_{\text {рз }}$ можно рассчитать по такой зависимости:

$$
V_{\mathrm{p} 3}=\frac{V_{\mathrm{\kappa p}}}{\chi}=\frac{0,22}{0,052}=4,2 \mathrm{~cm} / \mathrm{c} .
$$

4. Установим длину устьевого участка, в пределах которого скорость движения воды в бесполостной дрене будет удовлетворять условию $V \geq V_{\text {рз }}$. Для этого надо знать в сечении, где $V=$ $=V_{\mathrm{p} 3}$, глубину фильтрационного потока и рас- ход воды, т. е. воспользоваться формулами для гидравлического расчета бесполостной дрены треугольного поперечного сечения, изложенными в [12]. Допустим, что в результате гидравлического расчета получили, что глубина $h$ в интересующем нас сечении равна 0,1 м. Тогда

$$
\begin{gathered}
V=V_{\mathrm{Kр}}=\frac{(24-l) \cdot q}{\omega}= \\
=\frac{(24-l) \cdot 0,5 \cdot 10^{-4}}{1 \cdot 0,1^{2}}=4,2 \cdot 10^{-2} \mathrm{M} / \mathrm{c}
\end{gathered}
$$

где $\omega=m h^{2}$ - площадь живого сечения, имеющего форму треугольника.

Откуда $l=8,8 \mathrm{м}$.

Таким образом, на участке длиной 8,8 м (отсчитывается от коллектора) скорость движения воды в заполнителе бесполостной дрены будет равна или превышать размывающую скорость и откосы потребуется защищать геотекстильным материалом. В правой части дрены величина $l$ будет уже другой, и расчет для нее выполняется в той же последовательности.

Пример 2. Рассмотрим расчетную схему, размещенную в приложении 8 ВСН 61-89 [13], показанную на рисунке.

Данные нормы были актуализированы в текущем, т. е. в 2020 г., и, следовательно, в настоящее время являются действующими. В п. 1 приложения 8 [13] говорится о том, что укрепление откосов обсыпками из дренирующих и крупнообломочных грунтов применяют для предотвращения эрозионных повреждений откосов и образования сплывов. Расчет же откосов производится только на устойчивость. Обусловлено это, вероятно, тем, что в годы составления ВСН методика расчета размывающих скоростей на контакте обсыпок с грунтом поверхности откосов еще только начинала разрабатываться. Теперь же представляется возможность сделать поверочный расчет, чтобы установить: действительно ли при этом исключается и эрозия, в том числе фильтрационным потоком, в обсыпке. Воспользуемся исходными данными, взятыми из примера 1. Дополнительно только примем, что коэффициент 


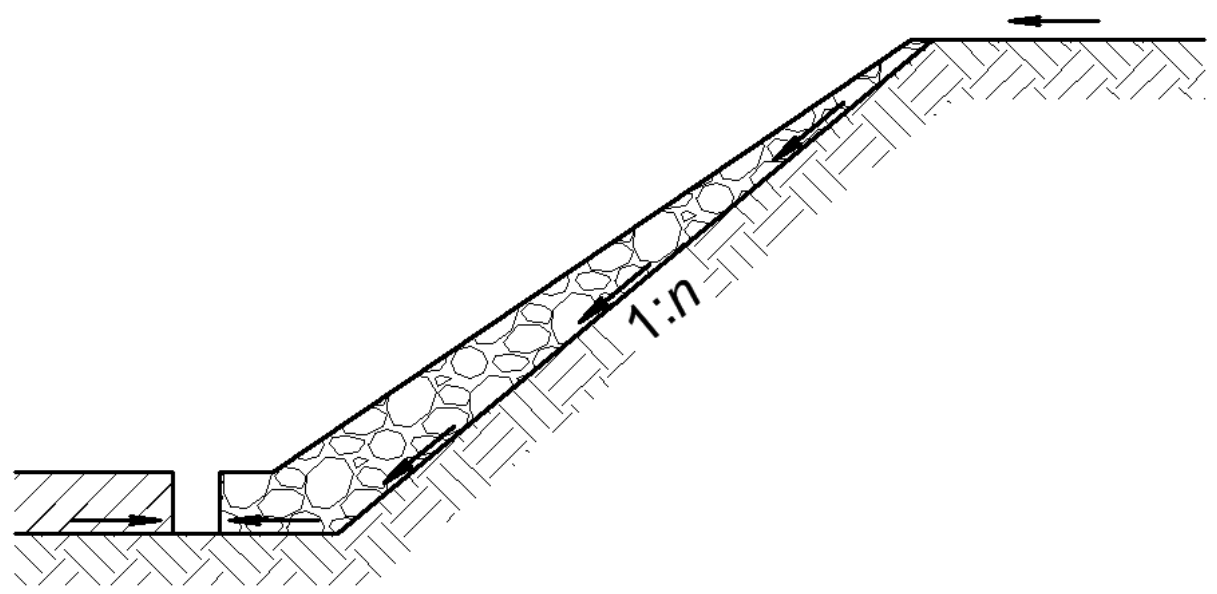

Схема присыпки на откосах для предотвращения эрозионных повреждений поверхности откосов и сплывов

откоса $m=1,5$. Обсыпка выполнена гранитным щебнем фракции 5-20 мм.

Ход расчета.

1. Вычисляем расчетный диаметр фильтрационного хода обсыпки:

$$
d_{u}=0,57 \sqrt[6]{\eta} \frac{n}{1-n} \cdot \frac{d_{17}}{\psi}=0,42 \mathrm{~cm}
$$

2. Чтобы определить режим фильтрации потока в обсыпке по откосу, найдем критическое число Рейнольдса по формуле (1):

$$
\operatorname{Re}_{\mathrm{кр}}=8,6 \cdot n \sqrt{\frac{d_{17}}{d_{u}}}=8,6 \cdot 0,48 \sqrt{\frac{1,2}{0,42}}=7 .
$$

3. В связи с большой величиной уклона $i=$ $=0,667$ предполагаем, что движение воды в обсыпке будет происходить периодически тонким слоем в процессе снеготаяния или выпадения значительных осадков при равномерном движении и переходном турбулентном режиме. Вычислим коэффициент фильтрации обсыпки при турбулентном режиме. Примем, что коэффициент Шези $C_{0}$ для обсыпки равен 80:

$$
\begin{gathered}
K_{T}=\frac{n \cdot C_{0}}{\pi^{1,5}} \sqrt{2 \cdot d_{u}}=\frac{0,48 \cdot 80}{3,14^{1,5}} \sqrt{2 \cdot 0,42}= \\
=6,3 \mathrm{~cm} / \mathrm{c} .
\end{gathered}
$$

4. Для определения скорости фильтрации в обсыпке при турбулентном режиме воспользуемся формулой А.А. Краснопольского

$$
V=K_{T} \sqrt{i}=6,3 \sqrt{0,667}=5,1 \mathrm{~cm} / \mathrm{c} .
$$

5. Рассчитаем число Рейнольдса, соответствующее полученной скорости фильтрации, и сравним его с $\mathrm{Re}_{\text {кр }}=7$ :

$$
\operatorname{Re}=\frac{V \cdot d_{u}}{v}=\frac{5,1 \cdot 0,72}{0,0131}=163
$$

Так как $\mathrm{Re}$ существенно больше $\mathrm{Re}_{\text {кр }}=7$, то в обсыпке действительно имеет место переходный или турбулентный режим движения фильтрационного потока.

6. По формуле (3) вычисляем размывающую скорость для грунта, из которого выполнено земляное полотно. В примере 1 мы ее уже нашли и получили равной $4,2 \mathrm{~cm} / \mathrm{c}$. Так как $V_{\text {рз }}=4,2 \mathrm{~cm} / \mathrm{c}<$ $<V=5,1 \mathrm{~cm} / \mathrm{c}$, то обсыпка из данного относительно крупного материала не способна предотвратить размывы, поэтому следует использовать более мелкий материал, коэффициент фильтрации которого меньше.

Воспользуемся для устройства обсыпки мраморной крошкой, показатели гранулометрического состава которой представлены в табл. 2: $d_{17}=0,33 \mathrm{~cm} ; \eta=2,38 ; n=0,46 ; \psi=2$. Исходные 
данные по грунту земляного полотна остаются прежними. Повторяем расчет.

\section{Ход расчета.}

1. Вычисляем расчетный диаметр фильтрационного хода обсыпки:

$$
\begin{gathered}
d_{u}=0,57 \sqrt[6]{\eta} \frac{n}{1-n} \cdot \frac{d_{17}}{\psi}= \\
=0,57 \sqrt[6]{2,38} \frac{0,46}{1-0,46} \cdot \frac{0,33}{2,0}=0,09 \mathrm{~cm}
\end{gathered}
$$

2. Имеем, что

$$
\operatorname{Re}_{\mathrm{\kappa p}}=8,6 \cdot n \sqrt{\frac{d_{17}}{d_{u}}}=8,6 \cdot 0,46 \sqrt{\frac{0,33}{0,09}}=7,6
$$

3. Рассчитаем коэффициент фильтрации при ламинарном режиме:

$$
K_{\text {л }}=\frac{n \cdot g \cdot d_{u}^{2}}{8 \cdot \pi^{2} \cdot v}=\frac{0,46 \cdot 980 \cdot 0,09^{2}}{8 \cdot 9,86 \cdot 0,0131}=3,5 \mathrm{~cm} / \mathrm{c} .
$$

4. По формуле Дарси для ламинарного режима находим скорость фильтрации в обсыпке:

$$
V=K \cdot i=3,5 \cdot 0,667=2,3 \mathrm{~cm} / \mathrm{c} .
$$

5. Определяем число Рейнольдса Re.

Так как $\operatorname{Re}>\operatorname{Re}_{\text {кр }}$, то в обсыпке будет иметь место либо переходный, либо турбулентный режим. Известно, что потери напора (энергии) при переходном и турбулентном режимах больше, чем при ламинарном. Следовательно, скорости будут меньше. Сравним полученное значение $V$ с $V_{\text {рз }}$ и сделаем окончательный вывод. В табл. 2 для заполнителя из мраморной крошки на контакте с супесью размывающая скорость равна 21,9 см/с. Так как $V=3,5 \mathrm{~cm} / \mathrm{c}$ меньше $V_{\text {рз }}=$ $=21,9 \mathrm{~cm} / \mathrm{c}$, размывы земляного полотна при использовании для обсыпки откосов более мелкого материала (мраморной крошки) происходить не будут. Далее в соответствии с приложением ВСН 61-89 необходимо произвести расчет откосов на устойчивость.

\section{Заключение}

1. Исследованиями ВНИИГ им. Б. Е. Веденеева были установлены гидродинамический и прочностной критерии контактной суффозии при фильтрации в крупнозернистых материалах на границе их соприкосновения со связными грунтами. Взаимосвязь между этими критериями выражалась через критическую скорость $V_{\text {кр}}$, которая соответствовала ламинарному режиму движения воды в крупнозернистом материале. Проведенное обобщение результатов исследований, посвященных определению критического числа Рейнольдса $\mathrm{Re}_{\mathrm{kp}}$, вследствие большого диапазона изменения этих чисел, не позволила получить расчетную формулу для $\operatorname{Re}_{\text {кр }}$ и соответственно $V_{\text {кр }}$.

2. Проведенные многочисленные экспериментальные исследования по фильтрации в крупнозернистых заполнителях бесполостных дрен и их специальная обработка позволили все полученные результаты обобщить в виде одной кривой, благодаря чему были получены формулы для $\operatorname{Re}_{\text {кр }}$ и $V_{\text {кр }}$ при движении воды в крупнозернистых материалах.

3. Получена формула для определения размывающей скорости на границе фильтрационного потока со связным грунтом, учитывающая как характеристики заполнителя фильтрующих сооружений, так и примыкающего к ним грунта.

4. Разработана методика расчета размывающих скоростей на контакте фильтрующих сооружений со связными грунтами. Рассмотрены примеры применения этой методики, позволяющей установить и обосновать, необходимы или нет, и конкретно какие мероприятия, исключающие возможность возникновения контактной суффозии в грунтах, окружающих фильтрующие сооружения.

\section{Библиографический список}

1. Штыков В.И. Гидравлический расчет бесполостного пластового дренажа при грунтовом напорном питании / В. И. Штыков, А. В. Козлова // Изв. ВНИИГ им. Б.Е. Веденеева.-2007.- Т. 247. - С. 84-91. 
2. Блажко Л.С. Бесполостной дренаж : опыт и перспективы / Л. С. Блажко, В. И. Штыков, Е. В. Черняев // Железнодорожный транспорт.-2013. - № 18. C. $47-49$.

3. Kalyzhnyi I. L. Influence of soil freezing on density / I.L. Kalyzhnyi, S.A. Lavrov, V.I. Shtykov // Russian Meteorology and Hydrology.- 2001. - N 3. - P. 69-77.

4. Жинкин Г.Н. Особенности строительства железных дорог в районах распространения вечной мерзлоты и болот : учеб. пособие / Г.Н. Жинкин, И.А. Грачев. - М. : Изд-во «Лань», 2000.- 420 с.- URL : https://e.lanbook.com/book/59028 (дата обращения : 19.08.2020 г.).

5. Жиленков В.Н. Гидродинамические условия контактного размыва глинистых грунтов фильтрационным потоком / В. Н. Жиленков, Н.И. Шевченко // Изв. ВНИИГ им. Б. Е. Веденеева.-1980.- Т. 144. C. 11-19.

6. Петухов Б.С. Теплообмен и сопротивление при ламинарном течении жидкости в трубах / Б. С. Петухов. - М. : Энергия, 1967.-411 с.

7. Дмитриев В.Д. Определение предельных чисел Рейнольдса для различных режимов движения жидкостей и газов при фильтрации / В. Д. Дмитриев // Водоснабжение и санитарная техника. - 1969.- № 4.C. $9-12$.

8. Штыков В.И. Применимость модели криволинейных фильтрационных ходов к определению фильтрационных свойств зернистых материалов / В.И. Штыков // Изв. ВНИИГ им. Б.Е. Веденеева.-1988.- Т. 209. C. $75-79$.

9. Штыков В.И. Исследование фильтрационных свойств зернистых материалов, исходя из модели криволинейных фильтрационных ходов / В.И. Штыков // Сб. науч. статей Междунар. конференции «Современные проблемы теории фильтрации» (1-3 июня 1998 г.).- Ровно, 1998. - С. 170-173.

10. Жиленков В.Н. О сопротивляемости глинистых грунтов контактному размыву фильтрационным потоком / В.Н. Жиленков, Н. И. Шевченко // Изв. ВНИИГ им. Б.Е. Веденеева.-1981.- Т. 146. - С. 55-67.

11. Методические указания по проведению гидрогеологомелиоративных наблюдений в Нечерноземной зоне РСФСР. - Л. : Изд-во СевНИИГиМ, 1983.$115 \mathrm{c}$.

12. Штыков В.И. Гидравлический расчет бесполостных дрен треугольного поперечного сечения при переходном режиме / В. И. Штыков, А. Б. Пономарев // Известия Петербургского университета путей сообщения. - СПб. : ПГУПС, 2019.- Т. 16. - Вып. 3.C. 523-532. https://doi.org/10.20295/1815-588X-2019$3-523-532$

13. ВСН 61-89. Изыскания, проектирование и строительство железных дорог в районах вечной мерзлоты. - М. : Минтрансстрой СССР, 1990.207 c.

Дата поступления: 25.01.2021

Решение о публикации: 25.02.2021

\section{Контактная информация:}

ШТЫКОВ Валерий Иванович - чл.-корр. РАН, д-р техн. наук, проф.; shtykov41@mail.ru

ПОНОМАРЕВ Андрей Борисович - канд. техн. наук, доц.; pol1nom@yandex.ru

ЯНКО Юрий Григорьевич - канд. техн. наук, зав. лабораторией; janko@agrophys.ru

\section{Discussing the calculation of erosion rates in the design of filtering structures in cohesive soils}

\section{V.I.Shtykov' ${ }^{1}$ A. B. Ponomarev ${ }^{1}$, Yu. G. Yanko ${ }^{2}$}

${ }^{1}$ Emperor Alexander I Petersburg State Transport University, 9, Moskovsky pr., Saint Petersburg, 190031, Russian Federation

${ }^{2}$ Agrophysical Research Institute, 14, Grazhdanskiy pr., Saint Petersburg, 195220, Russian Federation

For citation: Shtykov V.I., Ponomarev A. B., Yanko Yu. G. Discussing the calculation of erosion rates in the design of filtering structures in cohesive soils. Proceedings of Petersburg Transport University. Saint Petersburg, Petersburg State Transport University, 2021, vol. 18, iss. 2, pp. 303-312. (In Russian) DOI: $10.20295 / 1815-588 X-2021-2-303-312$ 


\section{Summary}

Objective: To develop a method for calculating erosion rates in the place of contact of filtering structures with cohesive soils. Methods: Previously at the VNIIG n. a. B.E. Vedeneev, hydrodynamic and strength criteria of contact suffusion were established concerning hydraulic structures. However, there were no calculated dependencies for determining the critical Reynolds number and, accordingly, the critical velocity for coarse-grained materials. Through special processing of experimental data on filtration in non-cavity drain fillers of various grades, it was possible to integrate numerous curves into a single one, making it possible to isolate the transient regime boundaries and obtain a formula for the critical Reynolds number. This made it possible to calculate the critical rate. As a result, a formula was obtained for calculating the erosion rate. Results: The calculated dependencies made it possible to determine the critical rate for the filler material and the erosion rate at the contact boundary between the filtering structure and the soil, based on the initial data of the coarse-grained material from which the filtering structures are made, and the characteristics of the soils in which they are built. Practical importance: The proposed calculation method made it possible to: 1) establish whether the manifestations of erosion by the filtration flow are possible in the place of contact of the filtering structure with the soil; 2) develop measures to eliminate erosion. Geotextile material can be laid along the border of the contact of the filtering structure with the soil, or a finer material can be used as a filler in the filtering structure, the actual filtration flow rates in which will be less than the erosional rates. In this case, the erosion rates in the place of contact with the finer material will increase.

Keywords: Erosion rates, filtration, cohesive soils, filtering embankments, filtering slots, non-cavity drains.

\section{References}

1. Shtykov V. I. \& Kozlova A. V. Gidravlicheskiy raschet bespolostnogo plastovogo drenazha pri gruntovom napornom pitanii [Hydraulic calculation of non-cavity reservoir drainage with soil pressure supply]. Proceedings of the VNIIG n.a.B.E. Vedeneev, 2007, vol. 247, pp. 84-91. (In Russian)

2. Blazhko L. S., Shtykov V.I. \& Chernyaev E. V. Bespolostnoy drenazh: opyt i perspektivy [Non-cavity drainage: Experience and prospects]. Zheleznodorozhnyy transport [Railroad Transport], 2013, no. 18, pp. 47-49. (In Russian)

3. Kalyzhnyi I. L., Lavrov S.A. \& Shtykov V.I. Influence of soil freezing on density. Russian Meteorology and Hydrology, 2001, no. 3, pp. 69-77. (In Russian)

4. Zhinkin G. N. \& Grachev I.A. Osobennosti stroitel'stva zheleznykh dorog $v$ rayonakh rasprostraneniya vechnoy merzloty i bolot. Uchebnoye posobiye [Specific features of railway construction in areas of permafrost and marshes. Training manual]. Moscow, Lan' Publishing House, 2000, 420 p. Available at: https://e.lanbook.com/ book/59028 (accessed: August 19, 2020). (In Russian)
5. Zhilenkov V.N. \& Shevchenko N.I. Gidrodinamicheskiye usloviya kontaktnogo razmyva glinistykh gruntov fil'tratsionnym potokom [Hydrodynamic conditions of contact erosion of clay soils by filtration flow]. Proceedings of the VNIIG n.a.B. E. Vedeneev, 1980, vol. 144, pp. 11-19. (In Russian)

6. Petukhov B. S. Teploobmen i soprotivleniye pri laminarnom techenii zhidkosti $v$ trubakh [Heat transfer and resistance in laminar flow of liquid in pipes]. Moscow, Energiya Publ., 1967, 411 p. (In Russian)

7. Dmitriev V.D. Opredeleniye predel'nykh chisel Reynol'dsa dlya razlichnykh rezhimov dvizheniya zhidkostey i gazov pri fil'tratsii [Determination of the limiting Reynolds numbers for various motion modes of liquids and gases during filtration]. Vodosnabzheniye i sanitarnaya tekhnika [Water Supply and Sanitary Technique], 1969, no. 4, pp. 9-12. (In Russian)

8. Shtykov V.I. Primenimost' modeli krivolineynykh fil'tratsionnykh khodov k opredeleniyu fil'tratsionnykh svoystv zernistykh materialov [Applicability of the model of curvilinear filtration passages to the determination of filtration properties of granular materials]. Proceedings of the VNIIG n. a. B. E. Vedeneev, 1988, vol. 209, pp. 75-79. (In Russian) 
9. Shtykov V.I. Issledovaniye fil'tratsionnykh svoystv zernistykh materialov, iskhodya iz modeli krivolineynykh fil'tratsionnykh khodov. Sb. nauch. statey Mezhdunar. konferentsii "Sovremennyye problemy teorii fil tratsii" [Study of filtration properties of granular materials based on the model of curvilinear filtration passages. Collected scientific articles of International conference "Modern problems of filtration theory”'] (June 01-03, 1998). Rovno, 1998, pp. 170-173. (In Russian)

10. Zhilenkov V.N. \& Shevchenko N. I. O soprotivlyayemosti glinistykh gruntov kontaktnomu razmyvu fil'tratsionnym potokom [Discussing the resistance of clay soils to contact erosion by filtration flow]. Proceedings of the VNIIG n.a.B.E. Vedeneev, 1981, vol. 146, p. 55-67. (In Russian)

11. Metodicheskiye ukazaniya po provedeniyu gidrogeologomeliorativnykh nablyudeniy $v$ Nechernozemnoy zone RSFSR [Guidelines for conducting hydrogeological and reclamation observations in the Nonchernozem Belt of the RSFSR]. Leningrad, SevNIIGiM [Northern Scientific Research Institute of Hydraulic Engineering and Melioration] Publ., 1983, 115 p. (In Russian)

12. Shtykov V.I. \& Ponomarev A. B. Gidravlicheskiy raschet bespolostnykh dren treugol'nogo poperechnogo secheniya pri perekhodnom rezhime [Hydraulic calcula- tion of non-cavity drains of a triangular cross-section in a transient mode]. Proceedings of Petersburg Transport University. Saint Petersburg, PGUPS [Petersburg State Transport University] Publ., 2019, vol. 16, iss. 3, pp. 523-532. (In Russian)

https://doi.org/10.20295/1815-588X-2019-3-523-532

13. VSN 61-89. Izyskaniya, proyektirovaniye i stroitel'stvo zheleznykh dorog $v$ rayonakh vechnoy merzloty [Industry-Specific Code of Construction Practice 61-89. Research, design and construction of railways in permafrost regions]. Moscow, USSR Mintransstroy [Ministry of Transport and Construction] Publ., 1990, 207 p. (In Russian)

Received: January 25, 2021

Accepted: February 25, 2021

\section{Author's information:}

Valery I. SHTYKOV - Corresponding Member of the Russian Academy of Sciences, Dr. Sci. in Engineering, Professor; shtykov41@mail.ru, Andrey B. PONOMAREV - PhD in Engineering, Associate Professor; pol1nom@yandex.ru Yury G. YANKO - PhD in Engineering, Head of Laboratory; yanko@agrophys.ru 